\title{
THE INTRAOVARIAN CELLULAR ORIGINS OF GDF9 AND BMP15 IN THE MOUSE AND ASPECTS OF THEIR BIOLOGICAL PROPERTIES
}

\section{Brigitta Mester}

A thesis submitted to the Victoria University of Wellington in fulfilment of the requirements for the degree of Doctor of Philosophy 


\section{Table of Contents}

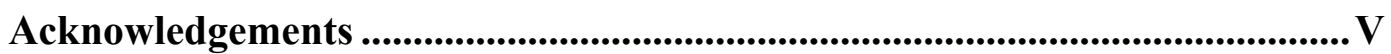

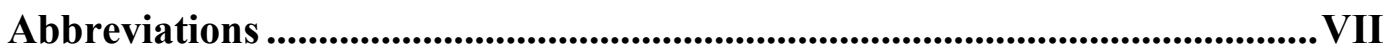

List of Figures and Tables........................................................................... IX

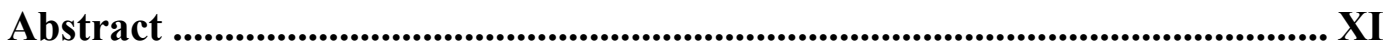

Chapter 1: Introduction .................................................................................1

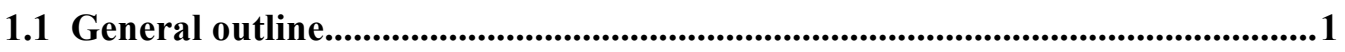

1.2 Overview of the female reproductive system ...................................................2

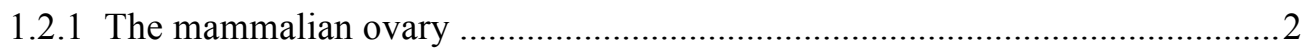

1.2.1.1 The cellular composition of the mammalian ovary ................................................

1.2.2 Follicular development in mammals.........................................................

1.2.3 Gonadotrophin regulation of ovarian follicular development.........................8

1.2.4 The role of steroids in regulating ovarian follicular development...................11

1.2.5 Bidirectional oocyte-somatic cell communication........................................ 15

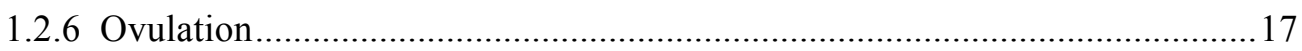

1.2.6.1 Artificially-induced ovulation....................................................................... 19

1.3 Overview of the TGF- $\beta$ Protein Superfamily......................................................20

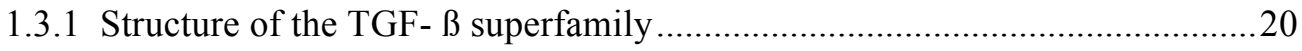

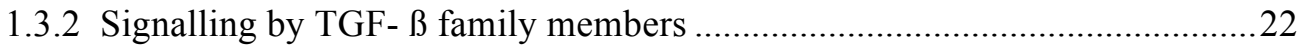

1.3.3 Roles of the proregion and proprotein in regulating activity ........................23

1.3.4 TGF- $\beta$ superfamily proteins in mammalian reproduction .............................25

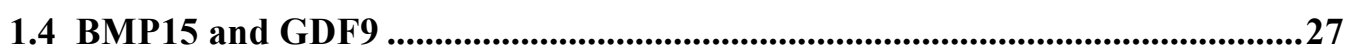

1.4.1 The roles of BMP15 and GDF9 in mammalian reproduction.......................28

1.4.2 Expression patterns of BMP15 and GDF9 and their receptors .......................30

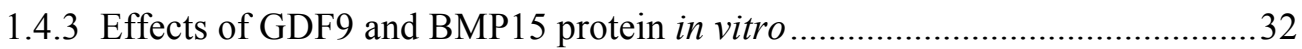

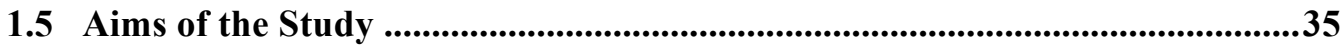

Chapter 2: Materials and methods ........................................................36

2.1 Animals, treatments and tissue collection ................................................................36

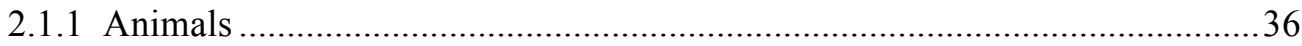

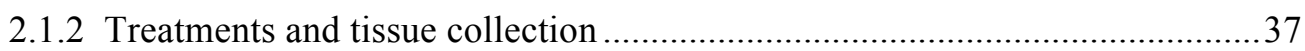

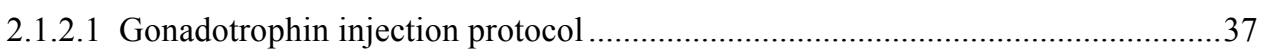

2.1.2.2 Ovarian collections for in situ hybridisation (ISH) .......................................... 39

2.1.2.3 Ovarian collection and dissection for Western blotting .......................................39

2.1.2.4 Ovarian collection and dissection for qPCR analysis ........................................41 
2.1.2.5 Collection of rat granulosa cells for methyl- ${ }^{3} \mathrm{H}$-thymidine bioassay.

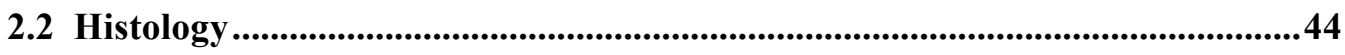

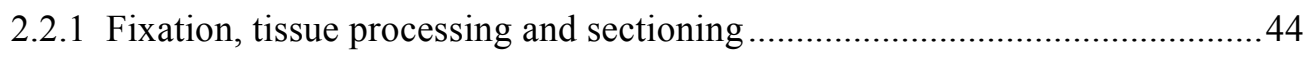

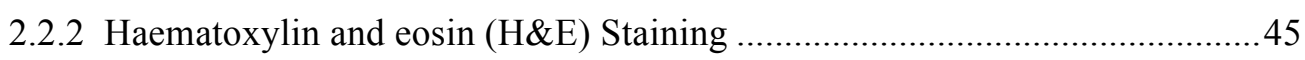

2.3 In Situ Hybridisation (ISH) ..................................................................................45

2.3.1 Mouse Bmp15 and Gdf9 DNA template preparation ....................................46

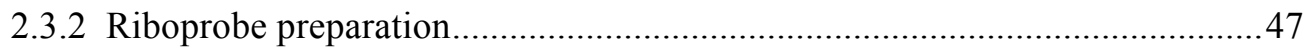

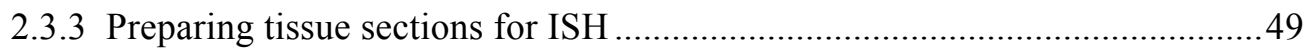

2.3.4 ISH and post hybridisation treatment.......................................................50

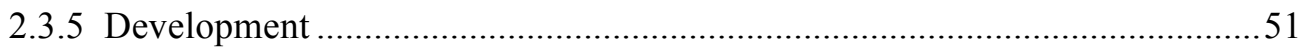

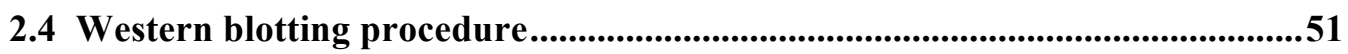

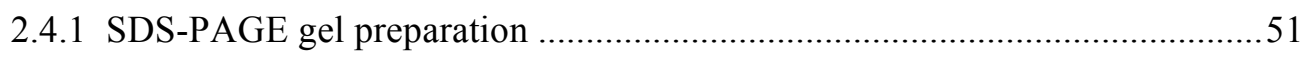

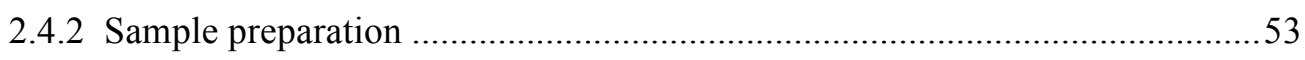

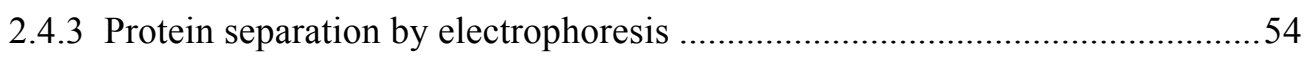

2.4.4 Protein transfer to nitrocellulose membrane ..................................................54

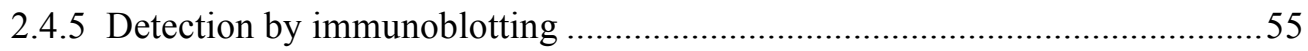

2.4.6 Visualisation with Enhanced Chemiluminescence ………………................56

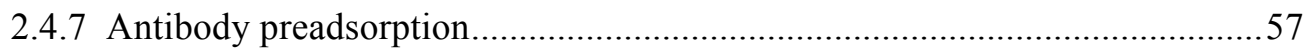

2.4.8 Bicinchononic (BCA) Protein Quantification assay .......................................58

2.5 Quantitative PCR (qPCR) .......................................................................................58

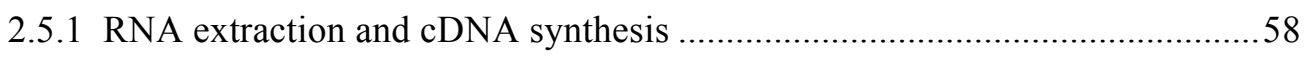

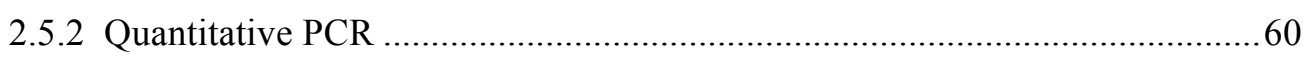

2.5.2.1 Primer and TaqMan Probe optimisation ............................................................6

2.5.2.2 Multiplex qPCR reaction efficiencies ...............................................................62

2.5.2.3 Quantification of gene expression by multiplex qPCR.......................................63

2.6 Generating non-cleavable forms of mouse BMP15 and GDF9 proproteins ...64

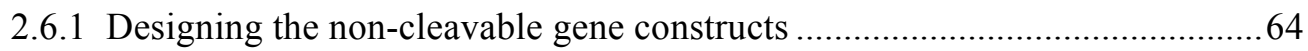

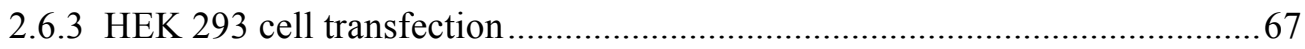

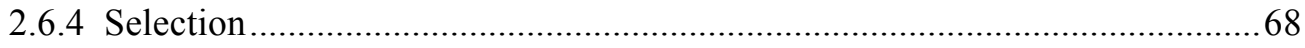

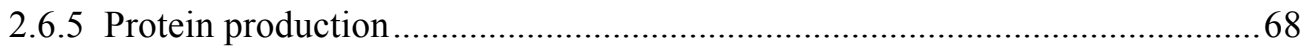

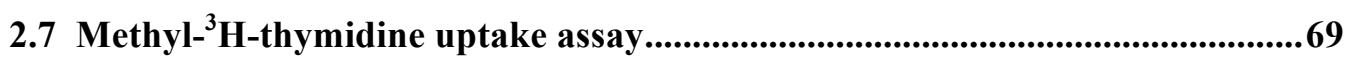

Chapter 3: BMP15 and GDF9 expression in the mouse ovary ......................72

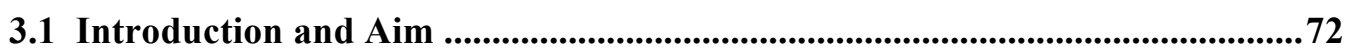

3.2 Method Optimisation ...........................................................................................

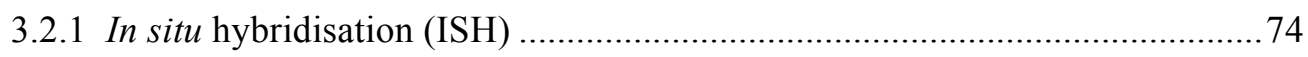

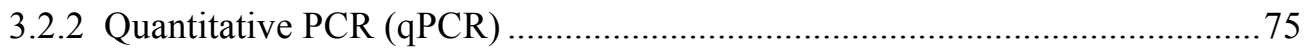

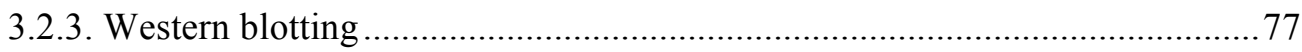




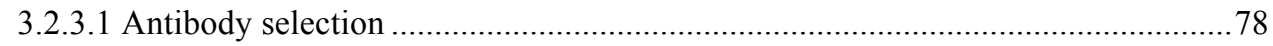

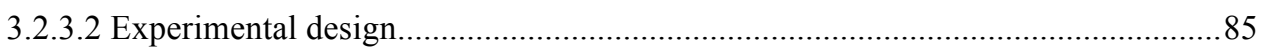

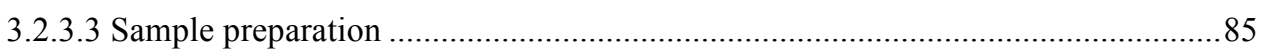

3.3 Results and conclusions................................................................................................86

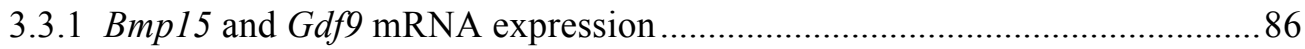

3.3.2 BMP15 and GDF9 protein localisation............................................... 92

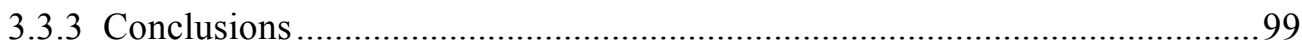

Chapter 4: Biological activity of the non-cleaved precursor proteins of mouse BMP15 and GDF9..........................................................................................106

4.1 Introduction ...............................................................................................106

4.2 Method Optimisation .................................................................................... 108

4.2.1 Designing and generating non-cleavable mouse Bmp15 and Gdf9 gene constructs

4.2.2 Detection and quantification of the non-cleavable mouse BMP15 and GDF9 protein forms

4.2.3 Methyl- ${ }^{3} \mathrm{H}$-thymidine uptake assay optimisation.

4.3 Results................................................................................................................ 113

4.3.1 Generation of non-cleavable mouse promature BMP15 and GDF9 ...........113

4.3.2 Biological activity of the non-cleavable mouse BMP15 promature protein.118

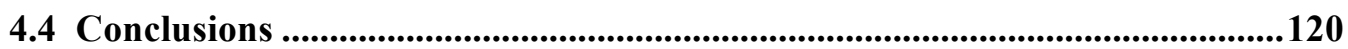

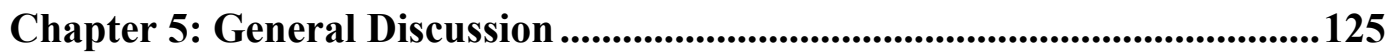

5.1 The sole source of $B m p 15$ and $G d f 9$ is the oocyte in the mouse ovary ...........125 5.2 BMP15 and GDF9 protein is localised primarily to cumulus/granulosa cells in the mouse ovary following the preovulatory LH surge....................................127

5.3 The uncleaved promature form of mouse BMP15 is biologically active .......134

5.4 Future Directions..........................................................................................136

Appendix I. Reagents and Solutions ................................................................. 140

Appendix II. Original images for Figure 3I ....................................................149

Appendix III. In situ hybridisation images..................................................150

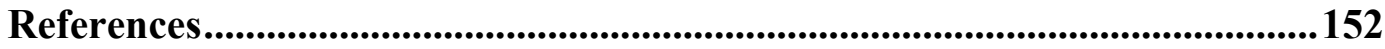




\section{Acknowledgements}

First of all I would like to thank my supervisors Professor Ken McNatty, Dr Joy McIntosh and Dr Jenny Juengel for their guidance and support. I learnt a lot from them and they have helped me grow both as a person and as a scientist. I will forever be grateful for the opportunity they have given me.

I would also like to thank Dr Janet Pitman, Adrian Bibby, Norma Hudson, Derek Heath and Associate Professor Doug Eckery for sharing their expertise, patiently training and supervising me through various parts of this $\mathrm{PhD}$ work. Their support and encouragement meant a lot.

I would like to acknowledge Peter Johnston from AgResearch Ltd for his invaluable help with statistical analysis.

To my fellow PhD students at the Reproduction Group: Dr Joy Lin, Dr Jozsef Ekart, Shalen Kumar, Catherine Davis, Kelly Campen and Peter Li, I would also like to say heartfelt thanks for all the help and support. I am glad we could share this journey and I am grateful for your friendship.

I would also like to mention my managers, friends and colleagues at the Malaghan Institute of Medical Research, for giving me a part time job, providing animals for my projects and sharing their expertise. I would especially like to thank Professor Graham LeGros, Professor Franca Ronchese, Associate Professor Ian Hermans, Kylie Price and Evelyn Bauer for their support and Marie Armstrong and Dr Lindsay Ancelet for their help with editing this thesis.

Last, but not least, I am grateful for my family and friends, both in Hungary and in New Zealand, whose love and support have helped me reach my goal. 
I would like to acknowledge the Royal Society of New Zealand Marsden Grant (08-VUW-010) for funding this PhD project. 


\section{Abbreviations}

ActRII

ActRIIB

ALK

$\mathrm{AMH}$

AMHKO

AMHRII

AR

BMP15

BMPRI

BMPRII

cAMP

$\mathrm{CC}$

c-kit

CL

$\mathrm{CM}$

cSmad

$\mathrm{COC}$

$\mathrm{COX} 2$

DO

DMEM

ECM

$\mathrm{ER} \alpha$

ER $\beta$

FGF

FGF-8

FSH

FSH-R

$\mathrm{FSH} \beta$

GC

GDF9

GnRH

GV

GVBD

HAS2

hCG

ISH

KL

$\mathrm{KO}$

LH

LH-R

Lhcgr

M199

Mab

MAPK

MIQE
Activin receptor type II

Activin receptor type II B

Activin receptor-like kinase

Anti-Mullerian hormone

Anti-Mullerian hormone knockout (deficient)

Anti-Mullerian hormone receptor type II

Androgen receptor

Bone morphogenetic protein 15

Bone morphogenetic protein receptor type I

Bone morphogenetic protein receptor type II

Cyclic Adenosine Monophosphate

Cumulus cells

Kit ligand receptor

Corpus luteum/corpora lutea

Conditioned media

Common Smad

Cumulus-oocyte complex

Cyclooxygenase 2

Denuded oocyte

Dulbecco's Modified Eagle Medium

Extracellular matrix

Oestrogen receptor $\alpha$

Oestrogen receptor $\beta$

Fibroblast growth factor

Fibroblast growth factor 8

Follicle stimulating hormone

Follicle stimulating hormone receptor

Follicle stimulating hormone $\beta$ subunit

Granulosa cells

Growth differentiation factor 9

Gonadotrophin releasing hormone

Germinal vesicle

Germinal vesicle breakdown

Hyaluronan synthase 2

Human chorionic gonadotrophin

In situ hybridisation

Kit Ligand (Stem Cell Factor)

Knockout

Luteinising hormone

Luteinising hormone receptor

Gene encoding Luteinising Hormone Receptor

Medium 199

Monoclonal antibody

Mitogen-activated protein kinase

Minimum Information for Publication of Quantitative 
mRNA

PAGE

PGC

PMSG

POF

PR-A

PR-B

qPCR

RPL19

rSmad

SDS

SLC38a3

Smad

StAR

TGF- $\beta$

TGF- $\beta 1$

TGF- 32

TGF-B3

TGFßRII

uPA

wt
Real-Time PCR Experiments

messenger RNA

Polyacrylamide gel electrophoresis

Primitive germ cell

Pregnant mare serum gonadotrophin

Premature ovarian failure

Progesterone receptor A

Progesterone receptor B

Quantitative PCR

Ribosomal protein L19

Receptor type Smad

Sodium dodecyl sulphate

Sodium-coupled neutral amino acid transporter 3

Similar to mothers against decapentaplegic protein

Steroidogenic acute regulator protein

Transforming growth factor $B$

Transforming growth factor $\beta 1$

Transforming growth factor $B 2$

Transforming growth factor $\beta 3$

Transforming growth factor $\beta$ type II receptor

Urokinase plasminogen activator

Wild-type 


\section{List of Figures and Tables}

Figures

Page Number

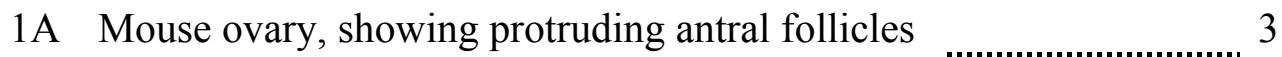

1B Cross section of 3 week old prepubertal mouse ovary 4

1C Cross-section through an antral follicle 6

1D The Pedersen and Peters (1968) classification of follicles in the mouse ovary 7

1E Steroid biosynthesis in the ovary 12

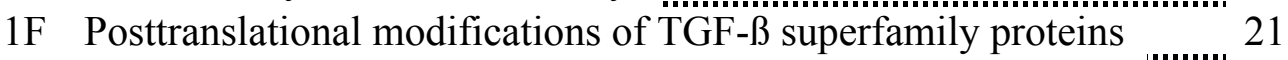

$1 \mathrm{G}$ TGF- $\beta$ signalling through the Smad pathway in mice $\ldots . . . . . . . .23$

2A Timeline of mouse treatments 38

2B Mouse ovarian follicle classification chart based on the Petersen and Peters (1968) classification system 38

2C pGEM-Teasy plasmid vector map

2D Plasmid cloning vector pUC57

3A Wild-type mouse BMP15 and GDF9 amino acid sequences and the tested Western blot primary antibody target regions $\ldots . . . \ldots \ldots \ldots . . . .80$

3B Characterisation of mab37a $\quad 81$

3C Characterisation of mab47b

3D Characterisation of BMP15 mature region antibodies $\mathrm{H}-83$ and $\begin{array}{ll}\text { A-20 } & 83\end{array}$

3E Characterisation of BMP15 proregion antisera 8f ................. 84

3F In situ hybridisation images $\quad 88$

3G Images of intact mouse COC and DO samples collected for qPCR $\quad 89$

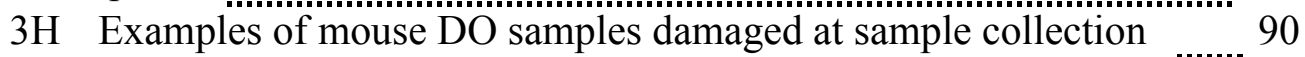

3I Mean relative Bmp15 and Gdf9 mRNA expression levels in DO samples

3J BMP15 protein localisation in saline (control), PMSG and PMSG+hCG treated mouse ovarian follicular samples 94

3K GDF9 protein expression in saline, $\mathrm{PMSG}$ and $\mathrm{PMSG}+\mathrm{hCG}$ treated mouse ovarian follicular samples

3L Mouse BMP15 protein localisation in ovarian follicular samples before and after the preovulatory LH surge $\ldots 6$

3M Mouse GDF9 protein expression in ovarian follicular samples before and after the preovulatory LH surge ................................... 98

4A Comparison of wild-type and non-cleavable mouse BMP15 conditioned media as detected on 13.5\% SDS PAGE gel 110

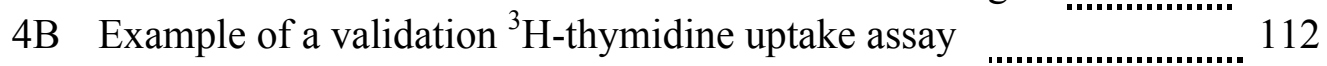


4C Comparison of non-cleavable mouse GDF9 protein and wild-type mouse GDF9 protein conditioned media

4D Mouse BMP15 protein forms in non-cleavable and wild type mouse BMP15 protein conditioned media, detected on $10 \%$ SDS PAGE gel

4E Quantification of protein forms in non-cleavable mouse BMP15 protein conditioned media using 7.5\% SDS PAGE gel

4F Overexposed Western immunoblot of wt and non-cleavable mouse BMP15 conditioned media

4G Parallelism between standard curves of the non-cleavable and wild-type mouse BMP15 promature proteins

4H Methyl- ${ }^{3} \mathrm{H}$-thymidine uptake by rat granulosa cells

4I Potential alternative furin cleavage site generated in the altered mouse GDF9 amino acid sequence

5A BMP15 and GDF9 protein expression in the mouse follicle before the LH surge

5B BMP15 and GDF9 protein expression in the mouse follicle after the LH surge

\section{Tables}

1A Identified mutations of BMP15, GDF9 and their receptors, affecting fertility in sheep and humans

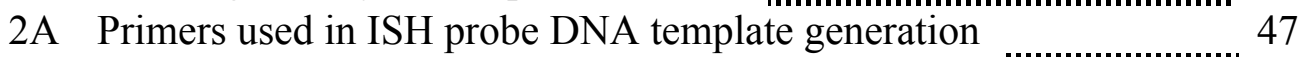

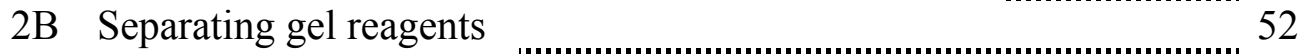

2C Stacking gel reagents

2D Primary and secondary antibodies used in Western blot experiments and target protein sizes

2E Primers, Taqman probes and final concentrations for use in multiplex qPCR reactions

2F $\mathrm{mBmp} 15$ and $\mathrm{m} G d f 9$ sequences, with mutated cleavage sites

2G Primers used to amplify full-length $\mathrm{mBmp} 15$ and $\mathrm{m} G d f 9$ from transfected 293 HEK cell lysates

3A In situ hybridisation summary

3B Ratio of Bmp 15:Gdf9 mRNA levels between treatment groups

3C Summary table of BMP15 protein localisation and mRNA expression in mouse follicular cells

3D Summary table of GDF9 protein localisation and mRNA

expression in mouse follicular cells 


\begin{abstract}
Bone morphogenetic protein 15 (BMP15) and growth differentiation factor 9 (GDF9) are both members of the TGF- $\beta$ protein superfamily and are known to be essential for normal follicular development in mammals. Several studies have highlighted the species-specific effects of BMP15 and GDF9, which could be attributed, at least in part to the differences in the follicular expression patterns and to different forms of the secreted proteins. In the mouse, GDF9 is required for follicular development, whereas BMP15 appears to be only required near ovulation with contradictory reports as to the timing of BMP15 expression. However, mouse BMP15 and GDF9 are known to have the capability of acting together synergistically. The aims of this thesis were to characterise in the mouse ovary, the expression patterns (localisation and levels) of Bmp15 and Gdf9 mRNA throughout follicular development, and to determine the peri-ovulatory expression of the corresponding proteins.
\end{abstract}

In situ hybridisation and quantitative PCR analyses of ovarian samples and follicular cells collected from control and superovulated mice confirmed that $G d f 9$ and Bmpl5 mRNA are expressed exclusively in oocytes from primary and early secondary stage follicles respectively. qPCR analysis of denuded oocytes (DO) revealed a tight correlation, and therefore co-regulation, between the expression levels of Bmp15 and Gdf9 irrespective of follicular developmental stage, with steady expression until the preovulatory LH surge when down-regulation of Bmp15 and Gdf9 occurred. Throughout the follicular developmental stages examined, Gdf9 was expressed in greater abundance relative to Bmp15, with a Bmp15:Gdf9 mRNA ratio of 1:4.12.

Western blot analyses of DO, intact cumulus-oocyte complex (COC), and somatic follicular cell samples, collected both before and after the preovulatory LH surge, showed that prior to the LH surge, BMP15 was present in the DO lysates as unprocessed precursor, and processed proregion and mature proteins, as well as mature protein dimer and large, potentially multimeric complexes. From the forms 
of GDF9 able to be identified, it seemed likely that the GDF9 protein expression pattern is similar to that of BMP15 in the mouse follicles.

Following the preovulatory LH surge, once the oocyte underwent germinal vesicle breakdown (GVBD), the only protein form detected in DO was the unprocessed BMP15 precursor, indicating that processing of BMP15, and potentially GDF9 stops prior to ovulation. In the expanded cumulus cells of GVBD COC and granulosa cell lysates, however, all BMP15 protein forms were detected. This suggests that posttranslational processing of BMP15 and GDF9 could be taking place both inside and outside of the oocyte.

The present study confirmed that in vivo, the mouse oocyte secretes the uncleaved promature form of BMP15 as well as the cleaved proregion and mature proteins in large complexes, but the biological activities of these different forms are unknown. The biological activity of the BMP15 precursor protein was investigated, to determine if the precursor form regulates the bioactivity of the growth factor or has a separate bioactivity. By transfecting 293 HEK cells with a Bmp15 gene construct where the RXXR proprotein convertase cleavage site was modified to QXXQ, production of non-cleavable mouse BMP15 promature protein conditioned media was achieved. The biological activity of the BMP15 precursor protein was then tested in a ${ }^{3} \mathrm{H}$-thymidine incorporation assay in rat granulosa cells. Mitogenic effects were compared with wild-type mouse BMP15 conditioned media, both as individual treatments and in combination with ovine GDF9. These data confirmed that the BMP15 precursor is biologically active, and while the wild-type mouse BMP15 was able to enhance rat granulosa cell proliferation only when combined with ovine GDF9, the non-cleavable mouse BMP15 promature protein was weakly mitogenic without GDF9.

In conclusion, oocyte-derived Bmp15 and $G d f 9$ mRNA expression is co-regulated throughout follicular development in mice, with Gdf9 being more abundant than Bmp15, which might be an important factor in determining high ovulation quota. The expression of the target genes is down-regulated as the oocyte reaches developmental competence following the preovulatory LH surge. Protein expression data provided evidence that in vivo the immature mouse oocyte is 
capable of secreting all BMP15 protein forms previously detected in vitro. After the preovulatory LH surge, all visible protein forms are associated with the somatic follicular cells, in particular with the expanded cumulus mass. Of particular interest is the presence of the large protein complexes in the cumulus cell lysates, which suggests a storage and activation process involving ECM proteins, similar to the mechanism reported for other TGF- $B$ superfamily members, such as TGF-ß1 and myostatin.

The finding that the BMP15 precursor protein is biologically active with a different activity to that of the processed mature protein form suggests that the full-length precursor protein may regulate or provide at least a portion of the biological activity of BMP15 in mice. 


\section{Chapter 1: Introduction}

\subsection{General outline}

The scope of this chapter includes an overview of the female reproductive system in mammals starting from the development of the ovaries and the formation of follicles during embryonic and early neonatal life and thereafter to follicular growth and subsequently ovulation from the onset of puberty. In addition, the endocrine, morphological and physiological aspects of these processes are discussed. Since the experimental work presented in this thesis is focussed on follicular growth in mice, the introduction will primarily review what is currently known about the reproductive system of this species.

At the start of this thesis, it was already known that the oocyte itself plays a crucial role in regulating its own development within the growing follicle and in determining the number of follicles that will ovulate in each cycle. It was also understood that two TGF- $\beta$ superfamily members, bone morphogenetic protein 15 (BMP15) and growth differentiation factor 9 (GDF9) play an important role in the communication between the oocyte and the surrounding somatic follicular cells during follicular development (Dong, Albertini et al. 1996; Galloway, McNatty et al. 2000; Shimasaki, Moore et al. 2004; Juengel and McNatty 2005; Gilchrist, Lane et al. 2008). 


\subsection{Overview of the female reproductive system}

1.2.1 The mammalian ovary

The mammalian ovary forms in early embryonic life, when the primitive germ cells (PGCs) and somatic cells migrate to the genital ridge, which is the site of the undifferentiated gonad. This early differentiating gonad consists of a surface epithelium, enclosing mesenchymal cells and mitotically-active PGC (Peters and McNatty 1980). The migration of the PGCs occurs around 8.5-11.5 days of embryonic life in the mouse (Chiquoine 1954; Spiegelman and Bennett 1973; Clark and Eddy 1975; Ginsburg, Snow et al. 1990; Edson, Nagaraja et al. 2009). After gonadal sex differentiation, the PGCs differentiate into oogonia and form attachments to adjacent somatic cells (i.e. pre-granulosa cells) (Mork, Maatouk et al. 2012). At day 12.5 of embryonic life, the oogonia associated with pre-granulosa cells enter into meiosis and are thereafter referred to as oocytes. In mice, follicular formation begins around 18.5 days (reviewed in Edson, Nagaraja et al. 2009). Individual oocytes and associated granulosa cells separate from their adjacent oocyte-granulosa cell entities by a basement membrane to form a primordial follicle. At this time, the follicular-enclosed oocytes have been arrested at meiosis I (MI) (Mork, Maatouk et al. 2012). In mice, the process of follicular formation normally occurs from shortly before birth until around day 3 of neonatal life depending on the strain. In humans, primordial follicle formation begins around day 140 of fetal life (Baker 1963; Rabinovici and Jaffe 1990). The initiation of follicular growth occurs shortly after ovarian follicles are formed (Sawyer, Smith et al. 2002), so that the first follicles that start to grow are among the first that are formed (Sawyer, Smith et al. 2002; Mork, Maatouk et al. 2012). Once a follicle starts to grow, it continues to grow without rest until it ovulates or becomes atretic and dies (Peters, Byskov et al. 1975; Fair 2003). 
1.2.1.1 The cellular composition of the mammalian ovary

In neonatal life, the ovary is surrounded by the surface epithelium, consisting of a single layer of cells with a distinct basal membrane. The next structure under the surface epithelium is the ovarian cortex. The outer layer of the cortex is denser and more fibrous then the inner layer, which contains the follicles and interstitial tissue. The growing follicles are often observed near the surface of the ovary, with large preovulatory follicles visible as protruding structures immediately under the surface epithelium (see Figures 1A and 1B). Below the cortical layer lies the ovarian medulla, containing the blood supply which branches out into an extensive network of capillaries that project into the cortex and cluster around growing follicles (Reynolds 1973). The medullary region also contains a predominant lymphatic system (Peters and McNatty 1980).

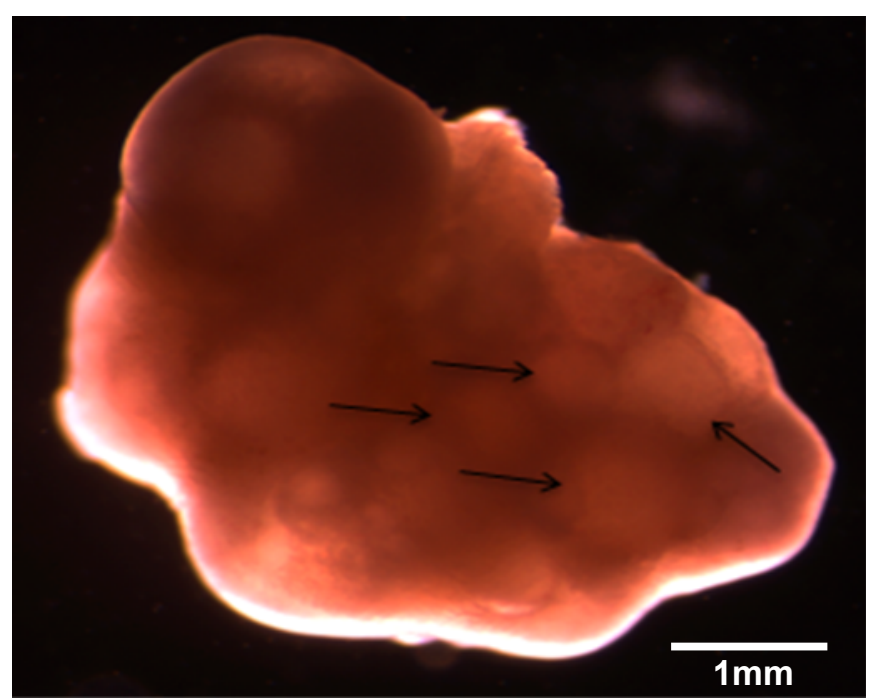

Figure 1A: Mouse ovary, showing protruding antral follicles (arrows) 


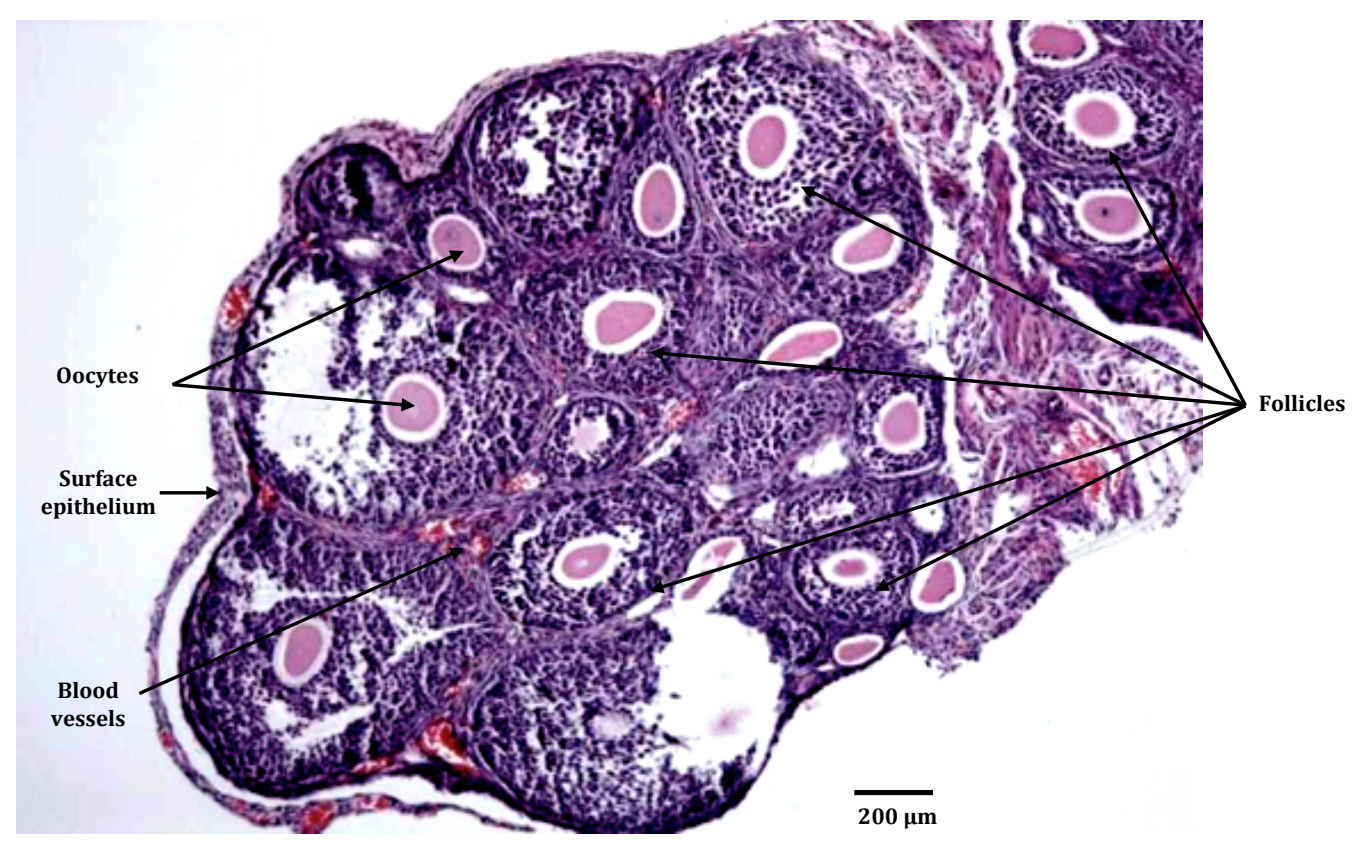

Figure 1B: Cross section of 3 week old prepubertal mouse ovary, showing follicles at various stages of development

\subsubsection{Follicular development in mammals}

Recruitment of follicles from the primordial pool is a continuous process throughout life. Follicles leave the primordial pool sequentially and enter the primary (growth committed) stage. This sequential departure from the primordial pool is uninterrupted by reproductive or hormonal status (Peters, Byskov et al. 1975; Rabinovici and Jaffe 1990; Sawyer, Smith et al. 2002). This process only ceases in some species with age when the pool of primordial follicles is depleted, as in some primates including humans (Richardson, Senikas et al. 1987).

The mechanisms involved in initiating growth from the primordial pool are largely unknown. Studies in mice carrying mutations in loci encoding the growth factor kit ligand $(\mathrm{KL})$ or its tyrosine kinase receptor, c-kit, point to these factors being involved in the activation of primordial follicles, as well as in the later stages of follicular growth (Hutt, McLaughlin et al. 2006).

As mentioned earlier, primordial follicles consist of an oocyte, surrounded by a layer of squamous granulosa cells, encapsulated by a fully formed basal membrane. Morphologically, the transition from primordial to primary follicles can be identified by a change in the shape of the granulosa cells from a squamous 
to cuboidal appearance. The secretion of a glycoprotein layer, the zona pellucida, separating the oocyte and the granulosa cells also happens at this transitional stage (Odor 1960; Zamboni 1974; Wassarman and Josefowicz 1978; Sinowatz, Amselgruber et al. 1995; Senbon, Hirao et al. 2003).

When the oocyte is surrounded by more than one concentric layer of granulosa cells, the theca cell layer outside the basal membrane of the follicle becomes distinguishable. At this stage of growth, the follicle is commonly referred to as a secondary follicle. Thereafter, with increasing granulosa cell proliferation, follicles develop a fluid-filled antrum. The composition of follicular fluid in this antral cavity changes during follicular maturation. This viscous fluid is composed of serum-derived products including proteins, hormones and numerous other metabolites (McNatty and Baird 1978) together with secreted materials from cells within the follicle. The follicular fluid maintains different microenvironments within each follicle (Peters and McNatty 1980). The formation of the antrum results in the granulosa cells differentiating into two different phenotypes, namely the cumulus cells (the granulosa cells immediately adjacent to the oocyte) and mural granulosa cells (the cells lining the follicular wall encased by the basement membrane) (Eppig 2001; Senbon, Hirao et al. 2003; Juengel and McNatty 2005). As the follicles grow, theca cells on the outer side of a basal membrane form two layers (theca interna and theca externa) (see Figure 1C). Unlike the granulosa and cumulus cells, the theca cells, and predominantly the theca interna, are in direct contact with the ovarian blood supply (Reynolds 1973; Peters and McNatty 1980).

Follicles with a fully-formed antrum are called antral or tertiary follicles. These follicles continue to increase in size due to proliferating granulosa and cumulus cells and an increase in follicular fluid accumulation until a diameter is reached corresponding to the preovulatory stage for that species. At this time, and in response to the preovulatory LH surge, the oocyte resumes meiosis shortly before ovulation. However, in all species including humans, over $99 \%$ of follicles that enter the growth-committed stage will degenerate before maturation to the preovulatory stage. Most appear to undergo atresia during the early stages of antral development since relatively low numbers degenerate before antrum formation (Byskov 1978). 
In mice, the oocyte increases in size from about $12 \mu \mathrm{m}$ in the non-growing follicle to $70 \mu \mathrm{m}$ by antrum formation (Peters and McNatty 1980). The oocyte remains in meiotic arrest throughout these phases of follicular development in response to inhibitory signals from the follicular somatic cells (Schultz, Montgomery et al. 1983; Eppig, Ward-Bailey et al. 1985; Bornslaeger, Mattei et al. 1986), due to communication between the oocyte and the cumulus cells mainly via gap junctions. During the preovulatory surge and rise in intrafollicular LH, the gapjunctional connections between the cumulus cells and oocyte break down leading to the resumption of meiosis (Dekel, Lawrence et al. 1981). During this time, the oocyte resumes meiosis to complete metaphase I, thereby achieving developmental competence prior to extrusion of the second polar body and preparation for fertilisation following ovulation (reviewed in Russell and Robker 2007).

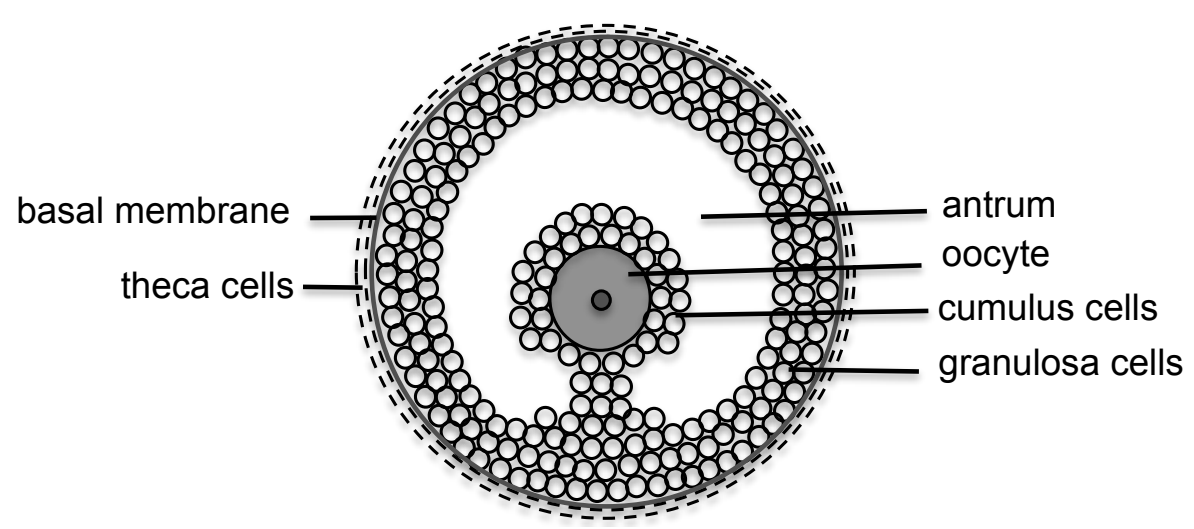

Figure 1C: Cross-section through an antral follicle

The antral follicle is encapsulated in the basal membrane, and surrounded by the fully formed theca layer, consisting of the steroidogenically active theca interna and the non-steroidogenic theca externa. The somatic cells lining the inside of the follicular wall are called granulosa cells, while those surrounding the oocyte are the cumulus cells. Both the granulosa and the cumulus cells rapidly proliferate during the growth phase of follicular development

Several classification systems for follicles have been proposed, based on the morphology through the largest cross-section of the follicle and the oocyte nucleolus, noting the shape and number of somatic cells and the presence or 
absence of the follicular fluid-filled antrum. These follicular classification systems in various species have been summarised elsewhere (Pedersen and Peters 1968; Lundy, Smith et al. 1999).

In mice, the classification system used for different follicular types in this thesis is as described by Pedersen and Peters 1968 (see Figure 1D). Type 1 and type 2 follicles are small, non-growing primordial follicles. Type $3 a-3 b$ follicles are the primordial to primary follicle transformation stages. Type $3 b-5 a$ follicles refer to the secondary or preantral stages. Type $5 b-8$ follicles refer to the tertiary or antral stages of growth. Type 8 follicles are those that proceed to become the ovulatory follicles.

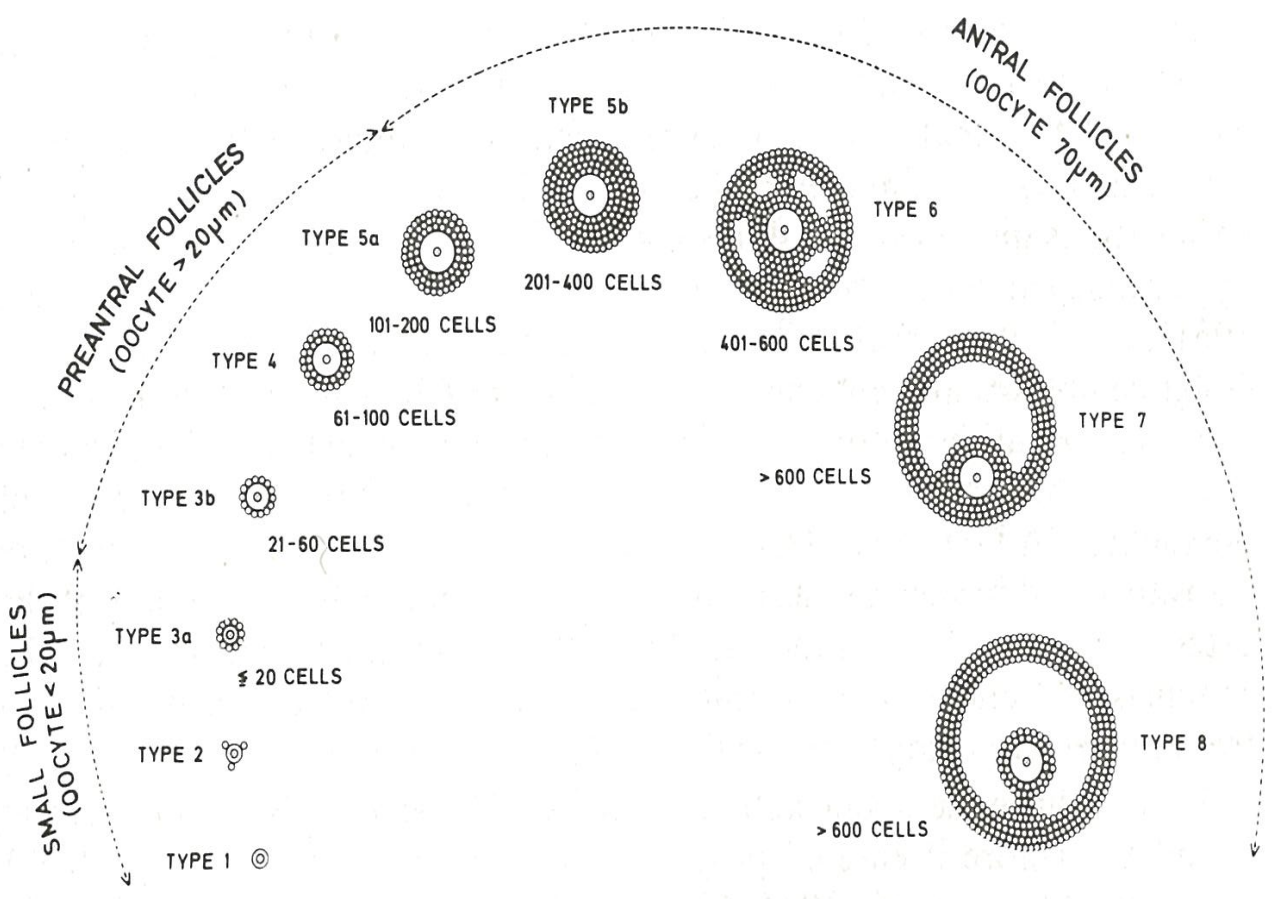

(From Peters and McNatty, 1978, with permission from Professor Ken McNatty)

Figure 1D: The Pedersen and Peters (1968) classification of follicles in the mouse ovary 
The primary and early secondary stages of follicular growth are independent of gonadotrophins (reviewed in Edson, Nagaraja et al. 2009), suggesting that the early stages of follicular development are regulated by locally produced (i.e. paracrine) growth factors. Follicles develop a responsiveness to gonadotrophins at the preantral stage and their continued growth becomes increasingly dependent on gonadotrophins during the antral stages (reviewed in Scaramuzzi, Baird et al. 2011). Deficiencies in gonadotrophin [folliclestimulating hormone (FSH) and/or luteinising hormone, (LH)] (Kumar, Wang et al. 1997; Dierich, Sairam et al. 1998; Abel, Wootton et al. 2000) or gonadotrophin releasing hormone $(\mathrm{GnRH})(\mathrm{Cattanach}$, Iddon et al. 1977) lead to impaired antral follicular development. In hypophysectomised sheep, follicular growth is arrested during antral development, and follicles are unable to develop to the preovulatory stage (McNatty, Heath et al. 1990).

\subsubsection{Gonadotrophin regulation of ovarian follicular development}

A main regulator of mammalian fertility and ovarian follicular growth is the hypothalamus-pituitary-ovarian system. The anterior pituitary gland secretes LH and FSH into the bloodstream under the influence of GnRH, produced by the hypothalamus (Carmel, Araki et al. 1976; Peters and McNatty 1980). The pattern of release of gonadotrophins is regulated by the ovarian hormones; oestrogens, progestins and inhibin through feedback loops (Knobil 1974; Yen, Lasley et al. 1975; Nakai, Plant et al. 1978; Plant, Nakai et al. 1978; Peters and McNatty 1980).

Concentrations of FSH vary across the oestrous cycle characterised by periodic and low amplitude fluctuations in serum. FSH, together with higher amplitude episodic fluctuations in serum LH concentrations, stimulate the growth of enlarging antral follicles and eventually the emergence of the large preovulatory follicle(s). The healthy, large antral follicles in the ovary are the primary source of the rising concentrations of oestradiol- $17 \beta$ in venous blood. These rising levels of oestradiol feed back to regulate the release of both FSH and LH from the pituitary gland (Baird, Swanston et al. 1981; Backstrom, McNeilly et al. 1982; Scaramuzzi, Adams et al. 1993; McGee and Hsueh 2000). Initially, oestradiol inhibits the 
release of FSH but increases the frequency of episodic LH secretion (Yen, Lasley et al. 1975; Moenter, Caraty et al. 1991). In mice, this leads to insufficient trophic support of the smaller growing follicles at late secondary to early antral follicle phase of development, causing many to become atretic (Peters and McNatty 1980). In general, it seems that the developing follicle is most likely to become atretic during the transitional period from preantral to early-mid antral stages of growth (Hirshfield 1991; McGee and Hsueh 2000). In hypophysectomised animals, follicles do not develop beyond this stage. The granulosa cells become apoptotic, the follicles undergo atresia and die (Nahum, Beyth et al. 1996). Both FSH and LH are necessary survival factors for antral follicles during the final phases of development. With the emergence of dominant follicles capable of being supported by $\mathrm{LH}$ but not $\mathrm{FSH}$, oestradiol levels reach a critical threshold, leading to the stimulation of preovulatory surges of both FSH and LH secretion (Docke and Dorner 1965; Moenter, Caraty et al. 1990). The large preovulatory surge of LH, together with $\mathrm{FSH}$, triggers a chain of events leading to the rupture of the preovulatory follicle(s) and the release of the mature oocyte(s) into the oviduct, ready for fertilisation (Scaramuzzi, Adams et al. 1993; Messinis, Messini et al. 2010). The granulosa cells in the ovulated follicle undergo luteinisation and form the major component of the corpus luteum (CL; reviewed in Hirshfield 1991; Knobil 1994). These luteinising cells become the main ovarian source of progesterone. After ovulation, progesterone plays an important role with respect to implantation of the zygote and in supporting pregnancy (Graham and Clarke 1997). The highly vascularised CL is normally visible as a protruding body on the surface of the ovary. If pregnancy does not occur, then the CL structure slowly degrades over the next few cycles, while during pregnancy it remains active, providing progesterone to maintain the pregnancy (reviewed in Peters and McNatty 1980).

FSH acts specifically on granulosa and cumulus cells within the follicle. Granulosa and cumulus cells acquire FSH receptors (FSH-R), thus the ability to respond to FSH stimulation, during the early secondary (preantral) stage of follicular development (Presl, Pospisil et al. 1974; Nimrod, Erickson et al. 1976; Kumar, Wang et al. 1997). FSH receptor (FSH-R) knockout mice are infertile due to granulosa cell proliferation being blocked at the antral stage, causing arrested follicular development (Burns, Yan et al. 2001). The absence of FSH-R expression 
by follicular cells during early follicular growth and the ability of follicles to develop to the secondary stage in mice, and to the early antral stage in humans, with minimal or no FSH in the bloodstream, also highlights the fact that FSH is not essential in early follicular development (Halpin, Jones et al. 1986; Hillier 1994; Aittomaki, Lucena et al. 1995; Fauser and Van Heusden 1997; Dierich, Sairam et al. 1998; McGee and Hsueh 2000). However, in hypophysectomised rats, antral follicles developed at a slower rate and in smaller numbers than in the untreated prepubertal or mature animals (Hirshfield 1985). This supports the notion that FSH, while not essential for early follicular development, may play a regulatory role.

LH acts directly on theca cells during preantral and antral follicle development and also on granulosa cells of the presumptive preovulatory follicles during the final stages of maturation. LH-R are first detected on the theca cells during the early secondary follicular stage whereas they are not expressed in granulosa cells until the late antral and preovulatory stages (Webb and England 1982; Peng, Hsueh et al. 1991; McGee and Hsueh 2000; Russell and Robker 2007). In FSH $\beta$ knockout (KO; FSH-deficient) mice, growth beyond the late preantral stage is impaired, granulosa cells don't accumulate LH-R mRNA and do not differentiate in response to the preovulatory LH surge. Theca cell function however is unimpaired (Burns, Yan et al. 2001). Nevertheless, ovulation in these mice could be achieved by exogenous administration of FSH and LH, showing that the ability of granulosa cells to respond to pituitary stimulation remained intact (Kumar, Wang et al. 1997).

In vitro studies show that administration of $\mathrm{FSH}$, but not $\mathrm{LH}$ alone, protects granulosa cells from apoptosis (Chun, Eisenhauer et al. 1996). FSH action promotes granulosa cell survival and proliferation through activation of intracellular signalling pathways, such as PI3K/Akt pathway (Gonzalez-Robayna, Falender et al. 2000; Zeleznik, Saxena et al. 2003), recruitment of adaptor proteins, such as 14-3-3 (involved in the regulation of FSH induced cAMP accumulation) (Cohen, Nechamen et al. 2004), and up-regulating the expression of certain genes, such as the ones encoding LH-R and vascular endothelial growth factor (Richards 1994; Alam, Maizels et al. 2004). LH is necessary to stimulate androgen production by theca cells. Androgens are converted to oestrogens by granulosa 
cells, under the influence of FSH-induced aromatase action (Hsueh, Adashi et al. 1984; Richards 1994; McGee and Hsueh 2000).

1.2.4 The role of steroids in regulating ovarian follicular development

The ovarian tissues, capable of producing the main ovarian steroid hormones progestins, androgens and oestrogens, are the follicle, corpus luteum (CL) and the stroma (tissue separating the follicles within the ovary) (McNatty, Makris et al. 1979; Peters and McNatty 1980). Steroid production by ovarian tissues happens sequentially, with each steroid, in turn, acting as a precursor for the next in the steroid biosynthetic pathway (see Figure 1E). Each of the ovarian cell types has a different ability to produce specific steroids. The primary steroids produced by a healthy developing follicle are oestrogens, produced by granulosa cells in a twostep process known as the 'two-cell, two-gonadotrophin model'. This model shows strict compartmentalisation in ovarian steroid production: in response to $\mathrm{LH}$, theca cells produce large amounts of androgens, which are converted to oestrogens by granulosa cells, under the influence of FSH (review: Drummond 2006).

Oestradiol-17 $\beta$ plays an important role in follicular development, by being involved in a number of intrafollicular events. Oestradiol-17 $\beta$, together with FSH, is responsible for mediating proliferation of granulosa cells throughout follicular growth (Rao, Midgley et al. 1978) by activating cyclinD2 expression. CyclinD2 protein is involved in the regulation of mitosis and in cyclinD2 deficient mice, granulosa cell proliferation is impaired. Despite the gonadotrophin signalling pathways remaining intact, follicles of cyclinD2 deficient mice are unable to ovulate in response to the preovulatory LH surge. Instead they form luteinised structures without releasing the oocyte (Sicinski, Donaher et al. 1996).

Oestrogens exert their effects through binding to oestrogen receptors (ER $\alpha$ and ERß) expressed by the target cells (Drummond, Britt et al. 2002). The relative roles of ER $\alpha$ and ERß in ovarian follicular development have been studied using KO mouse models. In ER $\alpha \mathrm{KO}$ mice, follicles developed to the large antral stage unimpaired, but the animals were infertile due to the inability to ovulate (Lubahn, Moyer et al. 1993; Elvin and Matzuk 1998). 


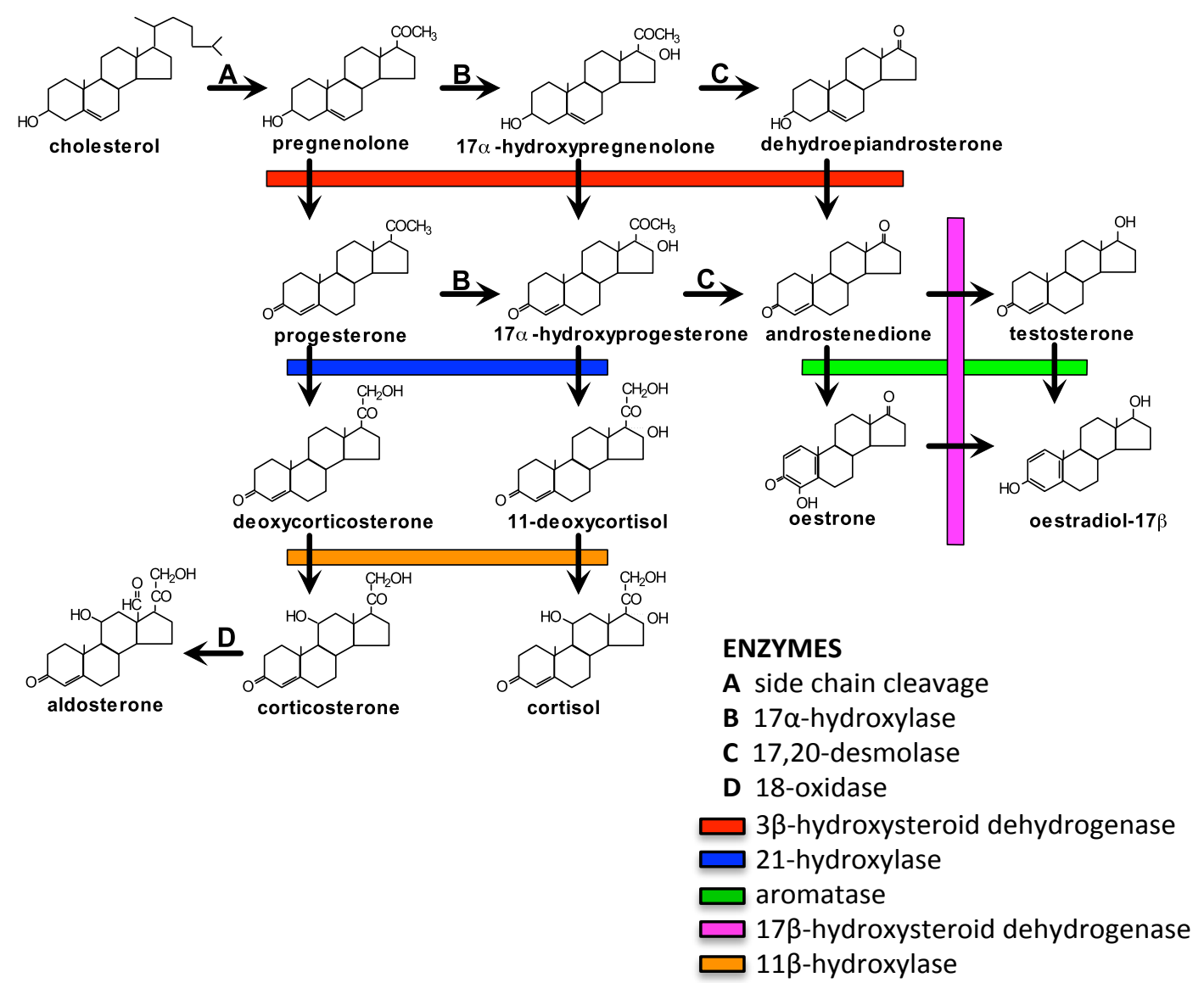

(With permission from the author of the thesis Dr G Shuttleworth)

Figure 1E: Steroid biosynthesis in the ovary (modified from Shuttleworth 2000)

Simplified illustration of steroid synthesis by somatic follicular cells, showing the basic structure of steroids and their precursor molecules, as well as the enzymes responsible for each step in the pathway.

ERß KO mice have smaller ovaries than the wild-type, follicular growth is impaired and the ovaries have larger numbers of primordial follicles with fewer in the growth phases. The incidence of atresia amongst the growing follicle population is also increased, possibly caused by up-regulated androgen receptor expression. The ovulatory process appears to be impaired as well, evidenced by lower number of corpora lutea and smaller litter size (Krege, Hodgin et al. 1998). In vitro, granulosa cells harvested from follicles of ERß knockout mice produce less oestrogen and have lower aromatase activity than that of the wild type (Emmen, Couse et al. 2005). The FSH-oestradiol synergy seems to be mediated through ERß, expressed by granulosa cells and oocytes of growing follicles 
(Cardenas, Burke et al. 2001; Jansen, West et al. 2001; Juengel, Heath et al. 2006). ERß expression is down-regulated in preovulatory follicles, following the preovulatory LH surge (Byers, Kuiper et al. 1997). Taken together, these findings suggest a role for ERß in gonadotrophin-mediated granulosa cell differentiation (Krege, Hodgin et al. 1998; Cheng, Weihua et al. 2002; Emmen, Couse et al. 2005). The structure of ovaries of double ER KO mice shows signs of significant morphological changes with extensive intraovarian epithelial tubules and large somatic cells reminiscent of luteal or Sertoli-like cells. If oocytes are present at all, they show signs of degeneration (Couse, Hewitt et al. 1999; Dupont, Krust et al. 2000). Studies on mice lacking the ability to produce oestrogen, through inactivation of the aromatase gene, also provide insights to the role of oestrogens in ovarian function. Aromatase $\mathrm{KO}$ mice had a similar phenotype to those of the oestrogen receptor knockout mice. Follicular development was arrested at the antral stage and mice were unable to ovulate. The number of primordial follicles had decreased and antral follicles were more likely to become atretic or to undergo premature luteinisation. As the mice grew older, the number of tubular-like structures increased, together with an increased incidence of cysts. The effects of oestrogen deficiency were partially eliminated by oestrogen treatment (Fisher, Graves et al. 1998; Britt, Drummond et al. 2000; Hillier 2000; Britt, Drummond et al. 2001; Findlay, Britt et al. 2001; Britt, Saunders et al. 2004; Britt, Stanton et al. 2004). The aforementioned mouse models highlight the importance of oestradiol and its receptors in normal follicular development in mammals.

Androgens are also key ovarian steroids produced by the theca and, in some species, the stroma (interstitial glands). One of the main roles of androgens in the regulation of fertility is as a precursor for oestrogen synthesis by $\mathrm{P} 450$ aromatase (CYP19A1) in granulosa cells (Dorrington, Moon et al. 1975; Drummond 2006). Under the influence of $\mathrm{LH}$, the theca cells produce androgens, namely androstenedione and testosterone. Many cell-types in the ovary are receptive to androgens. Androgen receptors (AR) are expressed in granulosa cells, stromal cells, thecal cells and in some species (rat, pig, mouse) the oocyte (Schreiber and Ross 1976; Horie, Takakura et al. 1992; Hirai, Hirata et al. 1994; Tetsuka, Whitelaw et al. 1995; Szoltys and Slomczynska 2000). Mice lacking AR remain fertile, but have a reduced ovulation rate and smaller litter size (Lyon and Glenister 
1980; Hu, Wang et al. 2004). Under in vitro conditions, androgens enhanced follicular growth by promoting granulosa cell proliferation (Wang, Andoh et al. 2001). Androgens have also been shown to promote FSH-induced granulosa cell differentiation (Hillier, Knazek et al. 1977; Nimrod 1977; Hillier and De Zwart 1981) and have effects on oocyte maturation (Gill, Jamnongjit et al. 2004; Drummond 2006 (review). In contrast however, it has been reported that androgens may promote granulosa cell apoptosis during antral follicular growth in rats (Billig, Furuta et al. 1993), but not primates (Weil, Vendola et al. 1998). In humans, excess production of androgens, thought to be caused by abnormal regulation of steroid biosynthesis in the theca (and stromal) cells, is often a common feature in the polycystic ovarian syndrome (PCOS) (Gilling-Smith, Willis et al. 1994; Abbott, Dumesic et al. 2002; Jonard and Dewailly 2004).

The main progestin, namely progesterone, is produced by granulosa cells of the ovulating follicle following the preovulatory LH surge, and by the corpus luteum. Progesterone acts through two different isoforms of progesterone receptors in regulating granulosa cell function and ovulation. These isoforms result from the generation of two splice variants of a single gene. PR-A has the ability to repress the activity of PR-B in target cells, with the balance between the two receptor expressions determining the progesterone responsiveness of the target cell (Kastner, Krust et al. 1990; Tung, Mohamed et al. 1993; Vegeto, Shahbaz et al. 1993; Conneely, Mulac-Jericevic et al. 2002; Conneely, Mulac-Jericevic et al. 2003). Premature increases in granulosa cell progesterone synthesis during the earlier stages of follicular growth preceding the preovulatory stages are indicative of atretic processes (Fukuda, Katayama et al. 1980). Under in vitro conditions, progesterone treatment enhanced FSH responsiveness but also the inhibition of oestradiol synthesis, mitosis and apoptosis in granulosa cells (Schreiber, Nakamura et al. 1980; Schreiber, Nakamura et al. 1981; Fortune and Vincent 1983; Peluso and Pappalardo 1994; Luciano and Peluso 1995; Peluso, Luciano et al. 1995; Peluso 2003). In vivo, progesterone treatment of newborn rats caused inhibition of the primordial to primary follicle transition (Kezele and Skinner 2003). Importantly, progesterone has an essential role during the final stages of ovarian follicular development. PR expression is localised to granulosa cells of large antral follicles following the preovulatory LH surge. If the LH surge is blocked, PR 
mRNA expression does not occur, proving that $\mathrm{LH}$ is necessary for inducing progesterone responsiveness of granulosa cells (Hild-Petito, Stouffer et al. 1988; Iwai, Yasuda et al. 1991; Iwai, Fujii et al. 1991; Park and Mayo 1991; Natraj and Richards 1993). In PR knockout mice, follicular growth remains unimpaired, but follicles are unable to ovulate, and undergo luteinisation without releasing the oocyte, pointing to progesterone having an essential role in the ovulation process (Lydon, DeMayo et al. 1995; Robker, Russell et al. 2000).

\subsubsection{Bidirectional oocyte-somatic cell communication}

The oocyte is thought to promote its own development through metabolic cooperation with cumulus cells (Eppig, Pendola et al. 2005). Cumulus cells play an essential role in oocyte maturation by providing nutrients for the oocyte such as amino acids, and substrates such as pyruvate for energy production (Sugiura and Eppig 2005), through gap junctions. In mice lacking connexin 37, (i.e. the main gap junction protein in oocytes), more than $90 \%$ of oocytes do not attain developmental competence (Simon, Goodenough et al. 1997). Mouse oocytes were shown to up-regulate glycolysis in cumulus cells, by producing growth factors, such as bone morphogenetic protein 15 (BMP15) and fibroblast growth factor 8 (FGF8) (Sugiura, Su et al. 2007). Glycolysis in cumulus cells harvested from oocyte-cumulus complexes (COC) of BMP15 KO mice was reduced. In wild-type mouse cumulus cells, recombinant BMP15 treatment alone was unable to increase glycolysis. However, BMP15 was effective in increasing glycolysis when administered in combination with FGF (Sugiura, Su et al. 2007). Mouse oocytes also promote the expression of Slc38a3, a gene encoding an amino acid transporter protein in cumulus cells. SLC38a3 has an affinity to transport L-glutamine, Lhistidine and L-alanine, all three of which are ineffectively taken up by the oocyte directly and are reliant upon cumulus cells for their supply via gap-junctions. By increasing the ability of cumulus cells for uptake and transport of these amino acids, the oocyte thereby supports its own development (Eppig, Pendola et al. 2005). Apart from glycolysis and amino acid transport, the oocyte was also shown to control cholesterol synthesis by cumulus cells in mice. The oocyte itself

produces negligible amount of cholesterol. In the oocytectomised (i.e. the ooplasm 
is surgically removed from the COC) mouse COC model, as well as in cumulus cells of BMP15 KO and Bmp15-/- Gdf9+/- double mutant mice, the expression of genes encoding enzymes required for cholesterol synthesis were down-regulated, providing further evidence for the importance of oocyte-derived factors in regulating cooperation between the oocyte and the surrounding somatic cells ( $\mathrm{Su}$, Sugiura et al. 2008).

The gene encoding luteinising hormone receptor, Lhcgr and the gene encoding kit ligand (KL), Kitl, are both expressed by granulosa cells and regulated in cumulus cells by oocyte-secreted factors (Otsuka and Shimasaki 2002; Eppig 2005). The granulosa cell-derived KL, and its oocyte-expressed receptor c-kit play an important role in oocyte-granulosa cell communication. The cooperation between KL and c-kit was shown to up-regulate the oocyte-derived growth factors, growth differentiation factor 9 (GDF9) and FGF-8 and down-regulate BMP15, thus influencing oestradiol production and proliferation by granulosa cells (Miyoshi, Otsuka et al. 2012). Once granulosa cells start expressing luteinising hormone receptor (LH-R) at late antral stage of follicular development, they are able to respond to $\mathrm{LH}$ and differentiate into progesterone-producing luteal cells following the preovulatory LH surge. The down-regulation of Lhcgr and Kitl expression in cumulus cells is necessary to maintain cumulus phenotype during follicular development (Eppig 2005).

Evidence shows that the oocyte regulates cumulus cell function through the synthesis and secretion of paracrine factors, such as GDF9 (Elvin, Clark et al. 1999; Dragovic, Ritter et al. 2005) and BMP15 (Yan, Wang et al. 2001; Yoshino, McMahon et al. 2006), both of which have been identified as important factors maintaining the cumulus cell phenotype in mice. Growth factors such as BMP15 and GDF9 and their roles in ovarian follicular development will be discussed in detail in paragraph 1.3 .

As discussed previously, the oocyte orchestrates its own development and regulates follicular growth through locally produced growth factors. Moreover, even during the gonadotrophin-dependent stage, the oocyte has the ability to suppress progesterone production by granulosa cells (Vanderhyden and Tonary 1995), thus preventing premature luteinisation of the follicle (el-Fouly, Cook et al. 1970; Nekola and Nalbandov 1971; Buccione, Vanderhyden et al. 1990; Salustri, Ulisse et al. 1990; Salustri, Yanagishita et al. 1990; Vanderhyden, Caron et al. 
1990). The oocyte retains this regulatory capability even after ovulation, but the cumulus cells lose the ability to respond to the suppression signal in large preovulatory follicles (Vanderhyden and Macdonald 1998).

Bidirectional communication between the oocyte and the surrounding follicular cells ensures optimal follicular development and the ovulation of a developmentally competent mature oocyte at the end of each cycle, ready for fertilisation.

\subsubsection{Ovulation}

The ovulatory process is controlled by both paracrine and endocrine factors. The gonadotrophin surge induces morphological changes within the preovulatory follicle leading to follicular rupture. These morphological changes include breakdown of the follicular basement membrane, disrupted angiogenesis and vascular haemorrhage, infiltration of the follicular antrum by thecal cells as well as transformation of granulosa cells into luteal cells (reviewed in Russell and Robker 2007). After the expulsion of the oocyte with its associated mucified cumulus cell complex during ovulation, the luteinised granulosa cells together, in varying degrees, with theca cells form the corpus luteum (Peters and McNatty 1980; Eppig 2001).

The preovulatory gonadotrophin surge initiates major changes within the cumulus oocyte complex. The cumulus cells undergo expansion due, in part, to the increased production of hyaluronic acid, a glycosaminoglycan that holds the separated cells and oocyte in a mucified, jelly-like matrix (Eppig 1979a; Eppig 1979b; Salustri, Yanagishita et al. 1989; Vanderhyden, Caron et al. 1990; Chen, Russell et al. 1993; Eppig, Wigglesworth et al. 1993; Singh, Zhang et al. 1993; Elvin, Yan et al. 1999; Matzuk 2000; Di Pasquale, Beck-Peccoz et al. 2004; Gilchrist, Ritter et al. 2004; Dragovic, Ritter et al. 2005). In vitro, LH alone does not induce cumulus expansion, indicating that the effect of the preovulatory LH surge on the cumulus mass is indirect (Eppig 1979a; Eppig 1979b). Cumulus expansion, one of the key events before ovulation, is regulated by the oocyte (Eppig 2001; Dragovic, Ritter et al. 2005). An oocyte-derived factor that enables 
cumulus expansion was shown to be produced by developmentally competent oocytes from mice (Vanderhyden, Caron et al. 1990; Eppig, Wigglesworth et al. 1993), pigs (Singh, Zhang et al. 1993) and cows (Gilchrist, Ritter et al. 2004). In vitro, recombinant mouse GDF9, was shown to up-regulate hyaluronan synthase 2 (HAS2), cyclooxygenase $2(\mathrm{COX}-2)$ and the steroidogenic acute regulator protein (StAR) mRNA expression, whilst LH-R and urokinase plasminogen activator (uPA) were down-regulated. The up-regulation of HAS2 and down-regulation of uPA are necessary for hyaluronic acid production during cumulus expansion, thus GDF9 was implicated as one of the important paracrine factors regulating cumulus expansion (Elvin, Clark et al. 1999; Matzuk 2000). Neutralisation of oocytederived GDF9 using specific antibodies did not fully block cumulus expansion (Dragovic, Ritter et al. 2005), suggesting that other factors, potentially another TGF- $\beta$ superfamily member such as BMP15, may play a role in the regulation of this important preovulatory event. It is also likely that the regulation of cumulus expansion is species specific (Elvin, Yan et al. 1999; Di Pasquale, Beck-Peccoz et al. 2004).

Cumulus cells supply the oocyte with high levels of cyclic AMP (cAMP) through gap junctions during follicular growth, keeping the oocyte in meiotic arrest. After the preovulatory LH surge, the gap junctions maintaining the bidirectional communication between the oocyte and the surrounding somatic cells stop functioning, causing a decrease in cAMP levels in the oocyte (Dekel, Lawrence et al. 1981), which leads to germinal vesicle (nucleolus) breakdown (GVBD), followed by the completion of metaphase I to achieve developmental competence (Schultz, Montgomery et al. 1983; Eppig, Ward-Bailey et al. 1985; Bornslaeger, Mattei et al. 1986; Webb, Marshall et al. 2002). Termination of gap junction communication leads to physical separation of oocyte and cumulus cells after cumulus expansion (Larsen, Chen et al. 1996), down-regulation of connexins, which are the building blocks of gap junctions (Granot and Dekel 1994; Kalma, Granot et al. 2004; Sela-Abramovich, Chorev et al. 2005) and phosphorylation of gap junction proteins (reviewed in Russell and Robker 2007). 


\subsubsection{Artificially-induced ovulation}

Experiments characterising follicles in sheep, bovine and human ovaries provided evidence that, at any given time, the microenvironment within each follicle is unique, supporting the hypothesis that follicular growth in mammals is a hierarchical process (McNatty 1978; McNatty, Gibb et al. 1981; McNatty, Heath et al. 1984; McNatty, Heath et al. 2010). Moreover, at any moment in time, the individual follicles demonstrate different levels of responsiveness to gonadotrophins (McNatty, Heath et al. 1990; McNatty, Heath et al. 1999). During natural cycles (i.e. when no exogenous hormones are administered to stimulate growth of the follicles), there are always follicles in the ovary with granulosa cells responsive to $\mathrm{LH}$ and having the potential to become preovulatory follicles if provided with the appropriate gonadotrophic stimuli (Webb and England 1982; Webb, Baxter et al. 1992).

During fertility treatment, the growth of large numbers of LH-responsive follicles followed by ovulation induction is achieved by using exogenous gonadotrophins. This superovulation treatment is aimed at increasing the numbers of LHresponsive follicles in experimental animals and in humans undergoing IVF with the objective of increasing the number of oocytes available for fertilization. The effectiveness of the treatment however is highly variable, does not lead to synchronisation of preovulatory follicular maturation and does not necessarily lead to increased ovulation, yield of fertilizable oocytes or pregnancy rates (Hafez, Sugie et al. 1963; Hahn 1992; Patrizio and Sakkas 2009).

A number of studies have demonstrated that the size of the follicle is not indicative of its ability to respond to LH (Souza, Campbell et al. 1996; McNatty, Heath et al. 2010). Moreover, successful ovulation and fertilisation requires not only LH-responsive granulosa cells in the follicle, but also the presence of a healthy, mature cumulus-oocyte complex (Moor, Dai et al. 1998; Sugiura and Eppig 2005; Gilchrist, Lane et al. 2008).

Exogenous gonadotrophin treatment leads to the maturation of the somatic cells within the follicle, but does not necessarily ensure the maturation of the oocyte- 
cumulus complex or the synchronisation of the microenvironment of each follicle. Even though greater numbers of follicles becomes responsive to $\mathrm{LH}$ following superovulation treatment, the oocyte-cumulus complexes may each remain at different developmental stages within these follicles: this may explain the discrepancies between ovulation rates and pregnancy outcomes. The superovulation treatments do not appear to override the hierarchical nature of follicular development (McNatty, Heath et al. 2010). Even though the event of ovulation is dependent on gonadotrophins, other follicle-derived factors must play a part in the ovulation process, as well as in the process of follicular growth and oocyte maturation.

\subsection{Overview of the TGF- $\beta$ Protein Superfamily}

The proteins of interest in this study, BMP15 and GDF9, are members of the TGF- $\beta$ protein superfamily. Therefore it is important to understand general concepts of TGF- $\beta$ superfamily functions, such as structure, receptors and signalling. Furthermore, given that multiple members of this family have regulatory roles in mammalian fertility, a brief overview of the actions of other TGF- $\beta$ superfamily members with well-established roles in fertility is provided in this section.

\subsubsection{Structure of the TGF- $\beta$ superfamily}

The TGF- $\beta$ superfamily consists of over 40 structurally related proteins (reviewed in Juengel and McNatty 2005). Depending on the extent of sequence homology, the family members can be classified into subgroups (McPherron and Lee 1993), including the TGF- $\beta, B M P / G D F$ and activin/inhibin subgroups.

TGF- $\beta$ superfamily proteins are expressed as a preproprotein, consisting of a signal peptide, and a proregion and mature protein. After the removal of the Nterminal signal peptide, the proprotein undergoes dimerisation, followed by enzymatic cleavage (Figure 1F) (Massague 1990; McPherron and Lee 1993; 
Chang, Brown et al. 2002; reviewed in Juengel and McNatty 2005). After cleavage, the proregion remains in non-covalent interaction with the mature protein for several of the TGF- $\beta$ family members (Wilson, di Clemente et al. 1993; Bottinger, Factor et al. 1996; Wolfman, McPherron et al. 2003; Jiang, Liang et al. 2004; Le Good, Joubin et al. 2005; McIntosh, Lun et al. 2008).

The cleavage site that separates the proregion and the mature region is a basic RXXR amino acid motif, enzymatically recognised by members of the proprotein convertase family, including furin protease (Thomas 2002; Taylor, Van De Ven et al. 2003; Rockwell and Thorner 2004; Juengel and McNatty 2005).

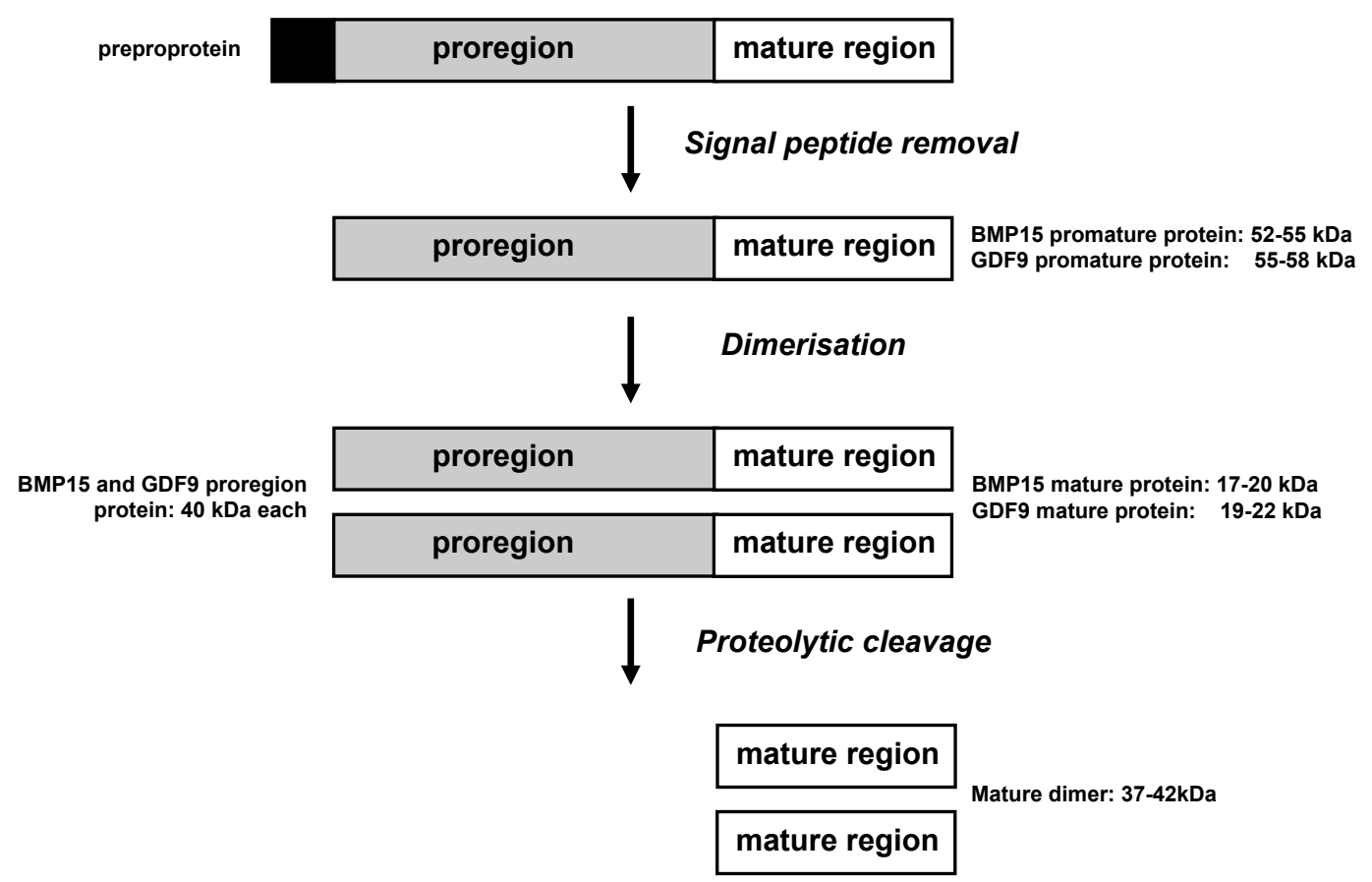

Figure 1F: Posttranslational modifications of TGF- $\beta$ superfamily proteins, indicating the molecular weights of the different mouse BMP15 and GDF9 protein forms as examples

TGF- $\beta$ superfamily proteins are structurally similar, consisting of conserved cysteine molecules, forming a cysteine knot and allowing dimerisation by forming disulphide bonds (see reviews by Kingsley 1994; Drummond 2005; Knight and Glister 2006). For most TGF- $\beta$ family proteins, the active form of the 
protein appears to be the disulphide-linked mature protein homodimer. In some cases, such as for the inhibins and certain TGF-ßs, mature protein heterodimers have also been reported. Heterodimers appear to have different biological properties than homodimers (McPherron and Lee 1993).

\subsubsection{Signalling by TGF- $\beta$ family members}

TGF- $\beta$ family members appear to exert their effects through binding to membrane-bound serine-threonine kinase receptor complexes and activating intracellular signalling molecules. Many TGF- $\Omega$ family members bind first to a type II receptor (ActRII, ActRIIB, BMPRII, TGFßRII, AMHRII) which then enables binding to a type I receptor (ALK1-7). However, it has also been reported that some BMP proteins might bind the type I receptor first, followed by the mobilization of a type II receptor to form a receptor-ligand oligomeric complex (ten Dijke and Hill 2004; Drummond 2005). After formation of the receptor-ligand complex, phosphorylation of the type I receptor activates intracellular signalling Smad molecules. The phosphorylation of the type I receptor is followed by the ligand-specific activation of a receptor type Smad molecule (rSmad). The activated rSmad forms a complex with Smad4, also known as common Smad (cSmad). The rSmad-cSmad complex is capable of regulating gene transcription upon translocation to the nucleus (reviews by Miyazawa, Shinozaki et al. 2002; ten Dijke, Korchynskyi et al. 2003; de Caestecker 2004; Shimasaki, Moore et al. 2004; ten Dijke and Hill 2004; Juengel and McNatty 2005). Inhibitory Smads (Smad6 and Smad7) can prevent the phosphorylation of the type I BMP receptor, blocking the recruitment of rSmads and the activation of the Smad signalling pathway, outlined in Figure $1 G$. Studies have shown that TGF- $\beta$ superfamily proteins can also signal through alternative pathways, such as MAPK (mitogen-activated protein kinase) pathway (Derynck and Zhang 2003; Reader, Heath et al. 2011). 


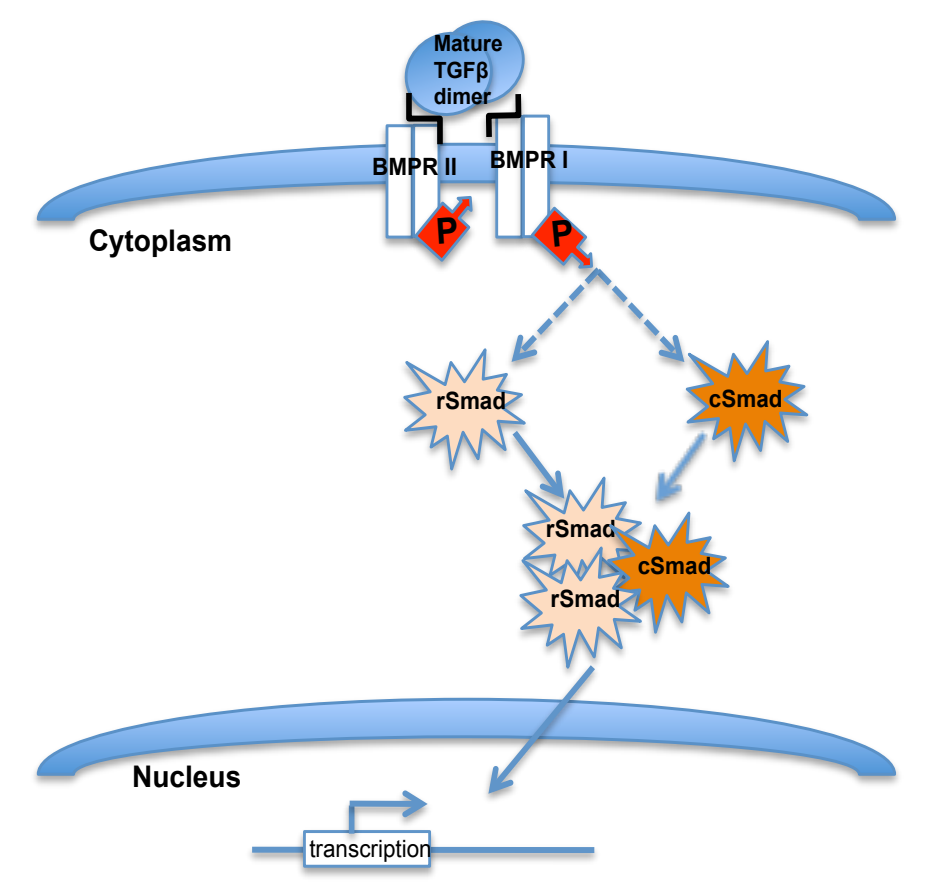

The TGF $\beta$ dimer forms a ligand-receptor complex with BMPRII and BMPRI. The phosphorylation of BMPRI activates the receptor-type Smad molecules. At least two receptor-type Smad molecules and a common Smad molecule form a complex, which upon translocation to the nucleus influences gene transcription.

Figure 1G: TGF- $ß$ signalling through the Smad pathway in mice

1.3.3 Roles of the proregion and proprotein in regulating activity

Until recently, the proregion was thought only to play a part in the folding of the precursor protein, and the dimerisation process, before enzymatic cleavage releases the biologically active mature dimer (reviews: Shimasaki, Moore et al. 2004; Juengel and McNatty 2005). However, in some species, such as mice (McIntosh, Lun et al. 2008), sheep (McNatty, Lawrence et al. 2006) and humans (Saito, Yano et al. 2008), BMP15 and GDF9 are also secreted in vitro as uncleaved promature and proregion proteins, but the biological activities of these forms are unknown. There is increasing evidence to support the importance of the proregion (prodomain) of TGF- $\beta$ superfamily proteins in regulating the activity of the growth factors. The non-covalent interaction between the cleaved proregion and the mature dimer in some TGF- $\beta$ superfamily members is thought to keep the growth factor inactive, while in others the interaction is necessary to store the 
protein in the extracellular matrix (ECM) (Annes, Chen et al. 2004; Ramirez and Sakai 2010). Shi et al, (2011) describes a structure for TGF- $\$ 1$ protein, where two TGF-ß1 monomers create a complex with a single ECM linked binding protein, which prevents disulphide bridge formation between the TGF- $\beta$ molecules, keeping them inactive. Integrin molecules, recognising a binding site in the proregion of TGF- $\beta 1$, release and activate the growth factors by applying tactile force (Shi, Zhu et al. 2011). Following posttranslational modification, continued interaction between the pro- and mature regions of TGF-ß1 (McMahon, Dignam et al. 1996) or GDF8 (Thies, Chen et al. 2001) was shown to be inhibitory to the bioactivities of these proteins, but had no effect on BMP9 bioactivity (Brown, Zhao et al. 2005).

In humans, mutations of the gene encoding the prodomain of BMP15 are associated with hypergonadotrophic ovarian failure (Di Pasquale, Beck-Peccoz et al. 2004; Di Pasquale, Rossetti et al. 2006; Dixit, Rao et al. 2006), while mutations affecting the GDF9 proregion led to dizygotic twinning (Palmer, Zhao et al. 2006). In mice, the non-covalently associated pro- and mature regions of the TGF- $\beta 1$, TGF- $\beta 2$ and TGF- 33 proteins have been shown to have an inhibitory effect on the mitogenic activity of the mature protein forms both in vitro and in vivo (Bottinger, Factor et al. 1996). Immunoneutralisation of the proregions of mouse BMP15 and GDF9 led to inhibition of the synergistic mitogenetic effect of these growth factors in granulosa cell cultures (McIntosh, Lun et al. 2008). Immunisation against these protein forms resulted in different ovulation rates and reduced litter sizes in mice (McIntosh, Lawrence et al. 2012), emphasising the importance of the proregions of BMP15 and GDF9.

In zebrafish embryos, TGF- $\beta$ proteins belonging to the nodal family were shown to have different bioactivity and stability when associated with the proregion protein (Le Good, Joubin et al. 2005).

There is little information available about the biological activity of the precursor (proprotein) forms of TGF- $ß$ superfamily proteins. The uncleaved precursor form of the Nodal protein was shown to enhance nodal expression during mouse embryonic development, by up-regulating Bmp4 expression. The Nodal precursor protein also maintains proprotein convertase enzyme (furin and PACE4) activity 
in the mouse embryo, thus promoting its own processing (Ben-Haim, Lu et al. 2006). Another TGF- $ß$ superfamily protein, anti-Mullerian hormone, reportedly requires intact proregion-mature interaction for enhanced bioactivity (Wilson, di Clemente et al. 1993).

\subsubsection{TGF- $\beta$ superfamily proteins in mammalian reproduction}

TGF- $\beta 1$, TGF- $\beta 2$ and TGF- $\beta 3$ belong to the TGF- $\beta$ subgroup and were shown to be expressed by theca and granulosa cells, and the oocyte (Skinner, Keski-Oja et al. 1987; Chegini and Flanders 1992; Teerds and Dorrington 1992; Schmid, Cox et al. 1994; Nilsson, Doraiswamy et al. 2003; Bristol and Woodruff 2004). The effect of these proteins on granulosa cell function is species specific. Overall they seem to have a stimulatory effect on granulosa cell proliferation (Dorrington, Chuma et al. 1988; Roy 1993; Saragueta, Lanuza et al. 2002), progesterone production (Dodson and Schomberg 1987; Hutchinson, Findlay et al. 1987; Knecht, Feng et al. 1987) and FSH-induced oestradiol production (Adashi, Resnick et al. 1989; Zachow, Weitsman et al. 1999) in rodents, but have no effect or even inhibitory effect on ovine (Fabre, Pierre et al. 2003; Juengel, Bibby et al. 2004), bovine (Skinner, Keski-Oja et al. 1987; Gilchrist, Morrissey et al. 2003), porcine (May, Frost et al. 1988; Mondschein, Canning et al. 1988; Gangrade and May 1990; Kubota, Kamada et al. 1994) and human (McAllister, Byrd et al. 1994) granulosa cells.

Activin, inhibin and follistatin are produced by the granulosa cells of the growing follicles as well as by the pituitary, and are necessary for the regulation of the hypothalamus-pituitary-ovarian system during follicular development. Activin increases the responsiveness of the pituitary gland to the hypothalamic hormone, GnRH, thus enhancing FSH production by the pituitary gland (Bilezikjian, Blount et al. 2006). The effect of activin is regulated by inhibin and follistatin (Knight 1996; Fraser, Groome et al. 1999; Welt, Sidis et al. 2002; Bilezikjian, Blount et al. 2006). Inhibin, produced by the growing follicle, acts as an activin antagonist, providing negative feedback to the pituitary gland and suppressing FSH production (Welt, Sidis et al. 2002; Bilezikjian, Blount et al. 
2006). Follistatin, which binds activin, also has the ability to inhibit activin binding to its type 2 BMP receptor, ActRII/B (Teerds and Dorrington 1992; Sidis, Schneyer et al. 2001; Welt, Sidis et al. 2002).

Activin has been shown to stimulate proliferation (Miro and Hillier 1996) and FSHR expression (Hutchinson, Findlay et al. 1987; Xiao, Robertson et al. 1992; Nakamura, Minegishi et al. 1993) of rat granulosa cells in vitro and oestradiol production by bovine granulosa cells (Hutchinson, Findlay et al. 1987). In vivo, inhibin and follistatin are likely to act as activin antagonists in the follicle to modulate the growth-promoting effects of activin. For example, small growing follicles have high activin expression, whereas in antral and preovulatory follicles, higher expression levels of inhibin and follistatin are evident (Knight and Glister 2001). In short, activin, inhibin and follistatin together act to co-ordinate the differentiation of granulosa cells from FSH-responsive towards LH-responsive during follicular development.

Anti-Mullerian hormone (AMH) is produced by granulosa cells throughout follicular growth to preovulatory development, although the expression levels are much lower during the later stages of growth as well as in atretic follicles (Gruijters, Visser et al. 2003). AMH has been implicated in the recruitment of follicles from the primordial pool to the growth-committed follicular population, since ovaries in AMH knockout mice (AMHKO) presented with lower number of primordial and larger numbers of growing follicles when compared to wild type (Durlinger, Kramer et al. 1999). Studies of AMHKO mice (Durlinger, Kramer et al. 1999) and AMH treated preantral mouse follicle cultures confirmed that AMH also has an inhibitory effect on FSH-induced proliferation (Durlinger, Gruijters et al. 2001) as well as aromatase and LHR expression by granulosa cells (di Clemente, Wilson et al. 1994).

The roles of other TGF- $\beta$ family members remains to be elucidated (see Gilchrist, Lane et al. 2008 for review). 


\subsection{BMP15 and GDF9}

BMP15 and GDF9 belong to a unique subset of the TGF- $\beta$ superfamily, which has only six of the seven conserved cysteines that are characteristic of other TGF- 3 family members (McPherron and Lee 1993; Laitinen, Vuojolainen et al. 1998). It was proposed that these proteins might exist as monomers or noncovalently bound homodimers and/or heterodimers (McPherron and Lee 1993; Shimasaki, Moore et al. 2004). Indeed, recent studies in mice (Liao, Moore et al. 2003; McIntosh, Lun et al. 2008) showed that BMP15 and GDF9 can form heterodimers in vitro. The mature region of mouse GDF9 was shown to interact, either directly or indirectly, with the proregion of mouse BMP15, forming heteromeric complexes. Multimers containing both mouse BMP15 and GDF9 proand mature region proteins were also observed (McIntosh, Lun et al. 2008).

Phosphorylation has been shown to be essential for the bioactivity of BMP15 and GDF9, as well as other TGF- $\beta$ protein family members (McMahon, Sharma et al. 2008). Both proteins appear to have only one phosphorylation site, $\mathrm{Ser}^{6}$, in the mature region (Tibaldi, Arrigoni et al. 2010). No phosphorylation site has been identified in the proregion of either protein. Golgi apparatus casein kinase has been identified as the enzyme responsible for the phosphorylation of both BMP15 and GDF9 (Tibaldi, Arrigoni et al. 2010).

Following post-translational modifications, the biologically active form of GDF9 was shown to bind to BMPRII (Vitt, Mazerbourg et al. 2002) and ALK5 (Mazerbourg, Klein et al. 2004; Kaivo-Oja, Mottershead et al. 2005) and to signal via Smad 2 and 3 (Kaivo-Oja, Bondestam et al. 2003; Roh, Bondestam et al. 2003), while BMP15 binds to BMPRII and ALK6 to signal via Smad 1, 5, and 8 (Moore, Otsuka et al. 2003; reviews by Shimasaki, Moore et al. 2004; Juengel and McNatty 2005). In vitro studies however provided evidence that, in some species, BMP15 and GDF9 can also act, directly or indirectly, through pathways other than those involving Smad signalling, such as the mitogen-activated protein kinase (MAPK), c-Jun N-terminal kinase (JNK), or nuclear factor- $\kappa \mathrm{B}$ (NFKB) pathways (Moore, Otsuka et al. 2003; Reader, Heath et al. 2011; Mottershead, Ritter et al. 2012). 


\subsubsection{The roles of BMP15 and GDF9 in mammalian reproduction}

In most species studied, BMP15 and GDF9 are produced by the oocyte of the growing follicle. These key oocyte-secreted factors play crucial roles in regulating the growth and maturation of follicles and ovulation quota (the number of follicles ovulating at each cycle) (Eppig 2001; McNatty, Juengel et al. 2003; McNatty, Hudson et al. 2007).

Development of primary and secondary follicles is independent of gonadotrophins, suggesting that the process is regulated by locally produced paracrine factors. Inactivation of GDF9, either through targeted disruptions of the gene in mice or through naturally occurring mutations in sheep and humans, provides strong evidence that GDF9 is a key factor regulating growth of small follicles. In GDF9 null mice, follicular development stops at the primary stage causing infertility in these animals (Dong, Albertini et al. 1996; Elvin, Yan et al. 2000). GDF9 homozygous mutant ewes (Hanrahan, Gregan et al. 2004; Nicol, Bishop et al. 2009; Silva, Castro et al. 2011) (Table 1A) or ewes immunised against GDF9 (Juengel, Hudson et al. 2002) are also infertile due to arrested development at the primary follicle stage whereas ewes heterozygous for the mutation have increased ovulation rates (McNatty, Juengel et al. 2003; Hanrahan, Gregan et al. 2004; Nicol, Bishop et al. 2009; Silva, Castro et al. 2011). Similarly, mutations in GDF9 in humans (Table 1A) have been linked to premature ovarian failure (Dixit, Rao et al. 2005; Laissue, Christin-Maitre et al. 2006; Zhao, Qin et al. 2007). The role of BMP15 in regulating the development of primary and secondary follicles is species-dependent. BMP15 null mice undergo normal follicular development, but have a reduced fertilization rate and decreased litter size (Yan, Wang et al. 2001). However, an inactivating mutation of the BMP15 gene in sheep leads to increased ovulation rate and fertility in heterozygous animals, but infertility in homozygous carriers (Galloway, McNatty et al. 2000). The homozygous mutant BMP15 phenotype is very similar to ewes with homozygous mutations in GDF9. Similarly, a dominant negative mutation in human BMP15 lead to primary ovarian failure (Dixit, Rao et al. 2006) (Table 1A). 
Table 1A: Identified mutations of BMP15, GDF9 and their receptors, affecting fertility in sheep and humans

\begin{tabular}{|c|c|c|c|c|}
\hline $\begin{array}{l}\text { Mutation } \\
\text { Site }\end{array}$ & $\begin{array}{l}\text { Protein } \\
\text { affected }\end{array}$ & $\begin{array}{c}\text { Species } \\
\text { (Sheep } \\
\text { lines) } \\
\end{array}$ & Phenotype & Reference \\
\hline $\mathrm{FecX}^{\mathrm{H}}$ & BMP15 & $\begin{array}{c}\text { Sheep } \\
\text { (Inverdale) } \\
\text { Sheep } \\
\text { (Hanna) }\end{array}$ & $\begin{array}{l}\text { Homozygotes: sterile } \\
\text { due to follicular } \\
\text { development blocked at } \\
\text { primary stage } \\
\text { Heterozygotes: increased } \\
\text { ovulation rate }\end{array}$ & $\begin{array}{l}\text { (Galloway, McNatty et al. } \\
2000) \\
\text { (Galloway, McNatty et al. } \\
2000)\end{array}$ \\
\hline $\begin{array}{l}\mathrm{FecG}^{\mathrm{H}} \\
\mathrm{FecX}^{\mathrm{G}}\end{array}$ & $\begin{array}{l}\text { GDF9 } \\
\text { BMP15 }\end{array}$ & $\begin{array}{c}\text { Sheep } \\
\text { (Belclare, } \\
\text { Cambridge) }\end{array}$ & & $\begin{array}{c}\text { (Hanrahan, Gregan et al. } \\
\text { 2004) }\end{array}$ \\
\hline $\mathrm{FecX}^{\mathrm{L}}$ & BMP15 & $\begin{array}{c}\text { Sheep } \\
\text { (Lacaune) }\end{array}$ & Homozygotes: sterile & $\begin{array}{l}\text { (Bodin, Di Pasquale et al. } \\
\text { 2007) }\end{array}$ \\
\hline $\mathrm{FecX}^{\mathrm{R}}$ & BMP15 & $\begin{array}{c}\text { Sheep } \\
\text { (Rasa, } \\
\text { Aragonesa) } \\
\text { Sheep } \\
\text { (Thoka) }\end{array}$ & $\begin{array}{l}\text { Heterozygotes: increased } \\
\text { fertility }\end{array}$ & $\begin{array}{l}\text { (Martinez-Royo, Dervishi } \\
\text { et al. 2009; Monteagudo, } \\
\text { Ponz et al. 2009) } \\
\text { (Nicol, Bishop et al. 2009) }\end{array}$ \\
\hline $\mathrm{FecG}^{\mathrm{E}}$ & GDF9 & $\begin{array}{c}\text { Sheep } \\
\text { (Santa Ines) }\end{array}$ & $\begin{array}{l}\text { Homozygotes have } \\
\text { increased ovulation rate }\end{array}$ & (Silva, Castro et al. 2011) \\
\hline $\mathrm{FecX}^{\mathrm{B}}$ & ALK6 & $\begin{array}{c}\text { Sheep } \\
\text { (Booroola) }\end{array}$ & $\begin{array}{l}\text { Homozygotes: } \\
\text { superfertile } \\
\text { Heterozygotes: increased } \\
\text { fertility }\end{array}$ & $\begin{array}{l}\text { (Mulsant, Lecerf et al. } \\
\text { 2001; Souza, MacDougall } \\
\text { et al. 2001; Wilson, Wu et } \\
\text { al. 2001) }\end{array}$ \\
\hline Y235C & BMP15 & Human & $\begin{array}{l}\text { Impaired granulosa cell } \\
\text { proliferation in vitro }\end{array}$ & $\begin{array}{c}\text { (Di Pasquale, Beck-Peccoz } \\
\text { et al. 2004) }\end{array}$ \\
\hline $\begin{array}{c}\text { K67E } \\
\text { V216M }\end{array}$ & $\begin{array}{l}\text { GDF9 } \\
\text { GDF9 }\end{array}$ & \multirow[b]{4}{*}{ Human } & \multirow[b]{4}{*}{$\begin{array}{l}\text { Potential role in } \\
\text { premature ovarian failure } \\
\text { (POF) }\end{array}$} & (Dixit, Rao et al. 2005) \\
\hline T238A & GDF9 & & & (Zhao, Qin et al. 2007) \\
\hline $\begin{array}{l}\text { S186Y } \\
\text { L148P }\end{array}$ & $\begin{array}{l}\text { GDF9 } \\
\text { BMP15 }\end{array}$ & & & $\begin{array}{c}\text { (Laissue, Christin-Maitre } \\
\text { et al. 2006) }\end{array}$ \\
\hline $\begin{array}{c}\text { R61W } \\
\text { R61E } \\
\text { R76C } \\
\text { R76H } \\
\text { A180T } \\
\text { A180F } \\
\text { N196K } \\
\text { R206H } \\
\text { E211X } \\
\text { W221R } \\
\text { I243G } \\
\end{array}$ & $\begin{array}{l}\text { BMP15 } \\
\text { BMP15 } \\
\text { BMP15 } \\
\text { BMP15 } \\
\text { BMP15 } \\
\text { BMP15 } \\
\text { BMP15 } \\
\text { BMP15 } \\
\text { BMP15 } \\
\text { BMP15 } \\
\text { BMP15 }\end{array}$ & & & (Dixit, Rao et al. 2006) \\
\hline $\begin{array}{l}\text { P103S } \\
\text { T121L } \\
\text { P374L } \\
\text { R454C }\end{array}$ & $\begin{array}{l}\text { GDF9 } \\
\text { GDF9 } \\
\text { GDF9 } \\
\text { GDF9 } \\
\end{array}$ & Human & $\begin{array}{l}\text { Potential role in } \\
\text { dizygotic twinning }\end{array}$ & (Palmer, Zhao et al. 2006) \\
\hline
\end{tabular}

Several studies of women with premature ovarian failure (POF) have identified BMP15 and GDF9 as possible factors in causing this condition. A higher 
incidence of BMP15 and GDF9 mutations have been identified in women with POF, compared to control populations. Some of these mutations have also been found in mothers of dizygotic twins, but not in controls (Di Pasquale, BeckPeccoz et al. 2004; Dixit, Rao et al. 2005; Dixit, Rao et al. 2006; Zhao, Qin et al. 2007; Zhao, Painter et al. 2008; Rossetti, Di Pasquale et al. 2009). Most of these mutations occur in the proregion of the protein, causing impaired mature protein production and potentially disrupting normal biological functions.

It has been hypothesised that women carrying certain mutations experience an enhanced fertility with potential for dizygotic twinning early in their reproductive life, which mostly goes undetected due to the trend in the western world of women having children later in life. This early enhanced fertility period can cause POF due to the earlier exhaustion of the primordial follicular pool (Inagaki and Shimasaki 2010). However, studies in ewes that carry either homozygous or heterozygous BMP15 or GDF9 mutations showed that the number of follicles growing in the ovaries of mutant ewes at any given time is no different from normal ewes (Smith, O et al. 1997).

One possible reason given for higher ovulation rates in women with certain mutations in BMP15 or GDF9 genes is that the follicles gain an earlier responsiveness to gonadotrophins, especially $\mathrm{FSH}$, than in women without these mutations. A study carried out on the effects of BMP15 on the FSH receptor expression in rat granulosa cells seems to support this hypothesis (Otsuka, Yamamoto et al. 2001; Inagaki and Shimasaki), but is contradicted by a study that shows no change in the FSH responsiveness of follicles of BMP15 mutant ewes at any stage of follicular development. In this study more follicles showed responsiveness to $\mathrm{LH}$ at an earlier stage of follicular growth, which could account for the higher ovulation rate in ewes carrying the mutation (McNatty, Heath et al. 2009).

\subsubsection{Expression patterns of BMP15 and GDF9 and their receptors}

In mice, Bmp15 mRNA expression is detected exclusively in the oocyte from primary stage follicles and the expression is maintained until after ovulation (Dube, Wang et al. 1998). However, there is some data suggesting that BMP15 
protein expression in mouse oocytes may not happen until just before ovulation (Yoshino, McMahon et al. 2006), while another report shows mouse BMP15 protein expressed in oocytes at all follicular developmental stages, and in the follicular fluid and the cumulus mass following the preovulatory LH surge (Gueripel, Brun et al. 2006). Gdf9 $m R N A$ expression is first observed also in primary follicles (Dube, Wang et al. 1998) and has been shown to be expressed until after ovulation and up to 1.5 days after fertilisation (McGrath, Esquela et al. 1995).

GDF9 mRNA and protein in sheep is expressed by the oocyte throughout follicular development from the primordial stage of growth (Bodensteiner, Clay et al. 1999; Juengel, Bodensteiner et al. 2004) and BMP15 is present from the primary stage (Galloway, McNatty et al. 2000; McNatty, Lawrence et al. 2006).

In humans, both $B M P 15$ and GDF9 mRNA and protein are first observed in primary follicles (Dube, Wang et al. 1998; Aaltonen, Laitinen et al. 1999).

It has been reported that, in some species, BMP15 and/or GDF9 expression occurs not only in the oocyte, but in other follicular cell types as well. GDF9 mRNA was detected in pig somatic follicular cells (Prochazka, Nemcova et al. 2004) and in primate granulosa cells adjoining the oocytes (Sidis, Fujiwara et al. 1998; Duffy 2003). However, there are other reports suggesting the GDF9 and BMP15 expression is exclusive to the oocyte (Crawford and McNatty 2012).

In some species, GDF9 and BMP15 mRNA are expressed in tissues other than the ovary, such as the pituitary and the testis, which means that the actions of these proteins might not be ovary specific in all mammals (Fitzpatrick, Sindoni et al. 1998; Aaltonen, Laitinen et al. 1999; Galloway, McNatty et al. 2000; Eckery, Whale et al. 2002; Otsuka and Shimasaki 2002).

The receptors for GDF9 were shown to be BMPRII and ALK5 (Vitt, Mazerbourg et al. 2002; Mazerbourg, Klein et al. 2004; Mottershead, Pulkki et al. 2008), while BMP15 preferentially binds to BMPRII and ALK6 (Moore, Otsuka et al. 2003). $B M P R I I$ is expressed in rat granulosa cells from primary stage follicles onwards, with no BMPRII mRNA expression in oocytes or theca cells (Erickson and Shimasaki 2003). In sheep however, oocytes and granulosa cells from primordial to antral and theca cells from preantral to antral follicular stages expressed 
BMPRII (Wilson, Wu et al. 2001). The type I BMP receptor ALK6 is expressed in oocytes and granulosa cells from the primordial to antral stages in both rats and sheep, as well as in theca cells from preantral follicles onwards (Wilson, Wu et al. 2001; Souza, Campbell et al. 2002; Erickson and Shimasaki 2003). ALK5 mRNA and protein are expressed in oocytes of mouse, sheep and human at all developmental stages (Juneja, Chegini et al. 1996; Roy and Kole 1998; Qu, Godin et al. 2000; Juengel, Bibby et al. 2004). ALK5 expression was also observed in mouse granulosa cells from primordial to preantral stages of growth (Juneja, Chegini et al. 1996), in human granulosa cell from primary to preantral stages and theca cells of small antral follicles (Roy and Kole 1998; Qu, Godin et al. 2000). In sheep, granulosa and theca cells of preantral and antral follicles showed ALK5 expression (Juengel, Bibby et al. 2004).

The expression patterns of BMP15, GDF9 and their receptors suggests that these growth factors ascertain their effects in a species-specific manner, affecting different somatic follicular cell types at different developmental stages during follicular growth in mammals.

\subsubsection{Effects of GDF9 and BMP15 protein in vitro}

In vivo, BMP15 and GDF9 have proven mitogenic effects on somatic follicular cells, promoting follicular growth during the gonadotrophin independent stage (Hayashi, McGee et al. 1999; Otsuka, Yao et al. 2000; Vitt, Hayashi et al. 2000; Hreinsson, Scott et al. 2002; Nilsson and Skinner 2002; McNatty, Juengel et al. 2005a; McNatty, Juengel et al. 2005b).

In vitro, ovine granulosa cell proliferation rate was not affected by treatment with GDF9 alone, but BMP15 alone stimulated a modest increase (McNatty, Lawrence et al. 2006). Proliferation of rat granulosa cells increased when treated with BMP15 and GDF9 together in vitro, and this mitogenic effect was reduced by treatment with an immunoneutralising BMP15 antibody (McIntosh, Lun et al. 2008). Rat granulosa cells treated with mouse but not ovine GDF9 showed increased proliferation rate (McNatty, Juengel et al. 2005b), suggesting that the actions of these growth factors are species specific. 
The treatment of mouse oocyte-cumulus cell co-cultures with an antibody to neutralise the effects GDF9, halved the proliferation rate of cumulus cells (Gilchrist, Ritter et al. 2004), and inhibited gonadotrophin-induced expansion of the cumulus mass (Dragovic, Ritter et al. 2005), highlighting the importance of GDF9 in regulating cumulus cell functions. Co-culturing mouse cumulus cells with oocytes from GDF9 or BMP15 KO mice supports the role of GDF9, but not BMP15 in cumulus expansion (Gui and Joyce 2005), although treating cumulus cell cultures with GDF9 alone failed to induce cumulus expansion (Dragovic, Ritter et al. 2005). Likewise, immunoneutralising with GDF9 but not BMP15 antibodies inhibited the proliferating effects of rat oocytes on rat granulosa cells (Lin, Pitman-Crawford et al. 2012). Immunoneutralising BMP15 in mouse oocyte-cumulus cultures, however, reduced cumulus expansion (Yoshino, McMahon et al. 2006), therefore it is likely that both growth factors play a role in regulating cumulus function in mice. BMP15 treatment prevented apoptosis of cultured bovine cumulus cells, but GDF9 had no anti-apoptotic effect (Hussein, Froiland et al. 2005).

Theca cells collected from bovine follicles at the early stages of follicular development showed increased proliferation in response to GDF9 treatment but decreased LH-R expression and steroidogenic activity, suggesting that GDF9 or a related TGF- $\beta$ factor prevents gonadotrophin-induced differentiation of the theca layer at early stages of follicle growth (Spicer, Aad et al. 2008). An increase in thecal cell proliferation following GDF9 treatment has also been observed in human theca cell cultures (Yamamoto, Christenson et al. 2002).

Both GDF9 and BMP15 appear to block gonadotrophin-induced progesterone production by granulosa cells, thus preventing premature luteinisation (Otsuka, Yao et al. 2000; Vitt, Hayashi et al. 2000; Yamamoto, Christenson et al. 2002; McNatty, Juengel et al. 2005b). The anti-luteinisation effect of BMP15 and GDF9 could potentially be attributed to their role in regulating the gonadotrophinresponsiveness of somatic follicular cells through mitigating the expression of FSH-R and LH-R. GDF9 suppresses LH-R mRNA and BMP15 was shown to suppress FSH-R mRNA expression by granulosa cells (Elvin, Clark et al. 1999; Vitt, Hayashi et al. 2000; Otsuka, Yamamoto et al. 2001). 
In both human theca and granulosa cells, recombinant GDF9 treatment reduced steroidogenic acute regulatory protein (StAR) mRNA and protein expression, P450 aromatase (CYP19A1) and P450 side chain cleavage (CYP11A1) expression. All three proteins are involved in the ovarian steroid biosynthesis pathway, suggesting that GDF9 regulates steroid hormone synthesis in somatic follicular cells (Yamamoto, Christenson et al. 2002).

The addition of recombinant GDF9 to cultured ovarian follicles from mice (Hayashi, McGee et al. 1999) and humans (Hreinsson, Scott et al. 2002) induced follicular growth in vitro. BMP15 treatment of mice follicle cultures however supported follicular growth only in the first $24 \mathrm{~h}$, after which it induced apoptosis in granulosa cells, unless GDF9 treatment was also administered (Fenwick, Mora et al. 2013). Supplementing IVM oocyte culture media with GDF9 (Yeo, Gilchrist et al. 2008) or BMP15 (Hussein, Thompson et al. 2006) led to improved embryo development in mice. A study analysing the GDF9 and BMP15 content of human follicular fluid from IVF patients also found positive correlation between GDF9 level, oocyte nuclear maturation and subsequent embryo quality (Gode, Gulekli et al. 2011), adding to the evidence supporting GDF9 and BMP15 as potentially valuable IVM culture media supplements to improve fertility outcomes.

A potential role of BMP15 and GDF9 has been demonstrated during embryonic development as well. For example, BMP15 was shown to be necessary for the specification of dorso-anterior structures of Xenopus embryos. Without the inhibitory effect of BMP15 on the Smad1/5/8 and the Wnt pathways, the embryos developed secondary ectopic heads (Di Pasquale and Brivanlou 2009).

In several species, combining BMP15 and GDF9 has more effect than administering either growth factor alone, suggesting that these proteins cooperate to promote follicular somatic cell proliferation and regulate gonadotrophin induced differentiation ( $\mathrm{Su}, \mathrm{Wu}$ et al. 2004; McNatty, Juengel et al. 2005a; McNatty, Juengel et al. 2005b; Edwards, Reader et al. 2008; McIntosh, Lun et al. 2008; Mottershead, Ritter et al. 2012; Peng, Li et al. 2013). 


\subsection{Aims of the Study}

As highlighted in the literature review, there are conflicting reports as to the timing and expression of both Bmpl5 and Gdf9 mRNA and protein in mice, especially in relation to the preovulatory LH surge (McGrath, Esquela et al. 1995; Dong, Albertini et al. 1996; Dube, Wang et al. 1998; Laitinen, Vuojolainen et al. 1998; Gueripel, Brun et al. 2006; Yoshino, McMahon et al. 2006). The first aim of this thesis was to investigate and confirm that Bmpl5 and Gdf9 mRNA are expressed only in the mouse oocyte, both before and after hCG-induced oocyte maturation. A second aim was to quantify the level of expression of Bmpl5 and Gdf9 mRNA in relation to cumulus expansion and nuclear maturation of the oocyte with particular emphasis on determining if the co-ordinated expression of Bmp15 and Gdf9 mRNA observed in growing antral follicles (Crawford and McNatty 2012) is maintained during the final stages of maturation prior to ovulation. Thirdly, by mapping the protein expression pattern of BMP15 and GDF9 in the mouse ovary, this project aimed to determine the secreted forms of the target proteins and gain further understanding of the posttranslational processing of BMP15 and GDF9 at different stages of follicular development.

In addition to the effects of the mature proteins, recent studies have also highlighted a potential role for other forms of BMP15 and GDF9 protein. Therefore, to better understand the potential role of the proregion of the protein, the final aim of this thesis was to test the mitogenic effect of a non-cleavable promature (precursor) form of mouse BMP15 generated by mutating the cleavage site between the proregion and mature domains to inhibit enzymatic cleavage.

The hypothesis tested was that BMP15 and GDF9 are produced exclusively by the oocyte during follicular development in mice and that the BMP15:GDF9 ratio influences follicular development in a species specific manner. Moreover, cumulus and granulosa cells are the major targets for the secreted forms of BMP15 and GDF9 proteins. 


\section{Chapter 2: Materials and methods}

Detailed instructions on preparing stock solutions and reagents described in this chapter can be found in Appendix I.

\subsection{Animals, treatments and tissue collection}

\subsubsection{Animals}

All experiments were performed with the approval of the Animal Ethics Committee of Victoria University of Wellington (2008/R2) in accordance with the New Zealand Animal Welfare Act 1999.

The animal models for this study were chosen on the basis of ovulation rate and predominance in the literature with respect to their reproductive physiology. The animals selected were mice (C57BL/6 wild type strain) and rats (Sprague-Dawley) and both were species with a high ovulation rate phenotype. The mice were purchased from the Malaghan Institute of Medical Research (Wellington, NZ) and the rats were obtained from the Psychology Department, Victoria University of Wellington, NZ. Mice were used in all experiments, except for the methyl- ${ }^{3} \mathrm{H}$-thymidine uptake assays when rat granulosa cells were used. The animals were housed in a purpose built animal facility at Victoria University of Wellington, NZ, and had access to food and water ad libidum. 
2.1.2 Treatments and tissue collection

\subsubsection{Gonadotrophin injection protocol}

For all studies using mice, three week old prepubertal female mice were separated into three experimental groups for gonadotrophin priming and appropriate controls (Figure 2A). These treatments represented the developmental changes that the follicles undergo during the follicular phase of development and in response to preovulatory gonadotrophin surges.

Group 1 received intraperitoneal (IP) saline $(100 \mu \mathrm{l})$ injections twice, $48 \mathrm{~h}$ apart as a control group.

Group 2 was injected IP with 5 IU Pregnant mare serum gonadotrophin (PMSG, Folligon, Intervet, Upper Hutt, NZ). A second injection of saline $(100 \mu \mathrm{l})$ was given $48 \mathrm{~h}$ later. PMSG, containing follicle stimulating hormone (FSH)-like activity, promotes preantral and antral follicular growth. It was anticipated that this treatment would result in the development of more Type 8 ovarian follicles (Pedersen and Peters 1968) (Figure 2B). This was expected to be in contrast to controls, where fewer large follicles would be present. The ovarian phenotype in this PMSG-treatment group represented the follicular developmental stage before the preovulatory luteinising hormone (LH) surge.

Group 3 received a traditional superovulation treatment applied to mice (Gates 1956; Luo, Zuniga et al. 2011) consisting of a 5 IU PMSG injection followed by $5 \mathrm{IU}$ hCG (Chorulon ${ }^{\circledR}$, Intervet, Upper Hutt, NZ) injected 48 h later. The ovarian phenotype in this group represented the follicular developmental stage immediately after the preovulatory LH surge. Human chorionic gonadotrophin (hCG), used as a surrogate of LH, was likely to ensure the presence of large preovulatory follicles in the ovaries, with an expanded cumulus cell mass and oocytes undergoing germinal vesicle breakdown (GVBD): these represent a chain of events necessary to achieve ovulation and subsequent fertilisation (Eppig 1979a; Salustri, Yanagishita et al. 1989; Chen, Russell et al. 1993; Handel and Eppig 1998).

Mice from all three treatment groups were sacrificed $9 \mathrm{~h}$ after the second injection using asphyxiation by $\mathrm{CO}_{2}$ inhalation, followed by cervical dislocation. The 
ovaries were harvested and prepared as described below, depending on the experimental protocol.

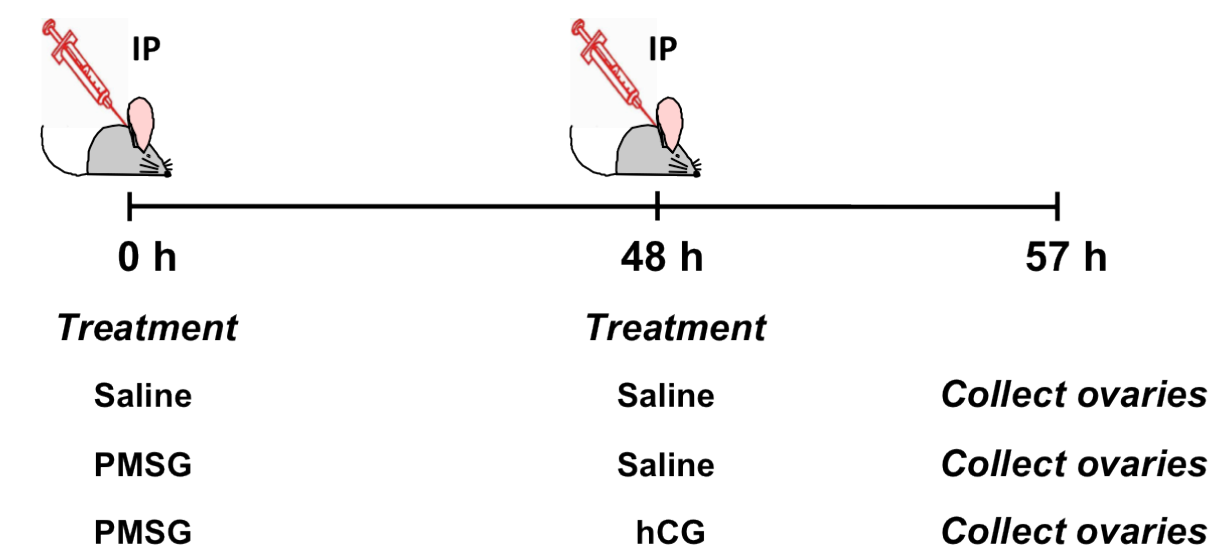

Figure 2A: Timeline of mouse treatments

Follicular Type

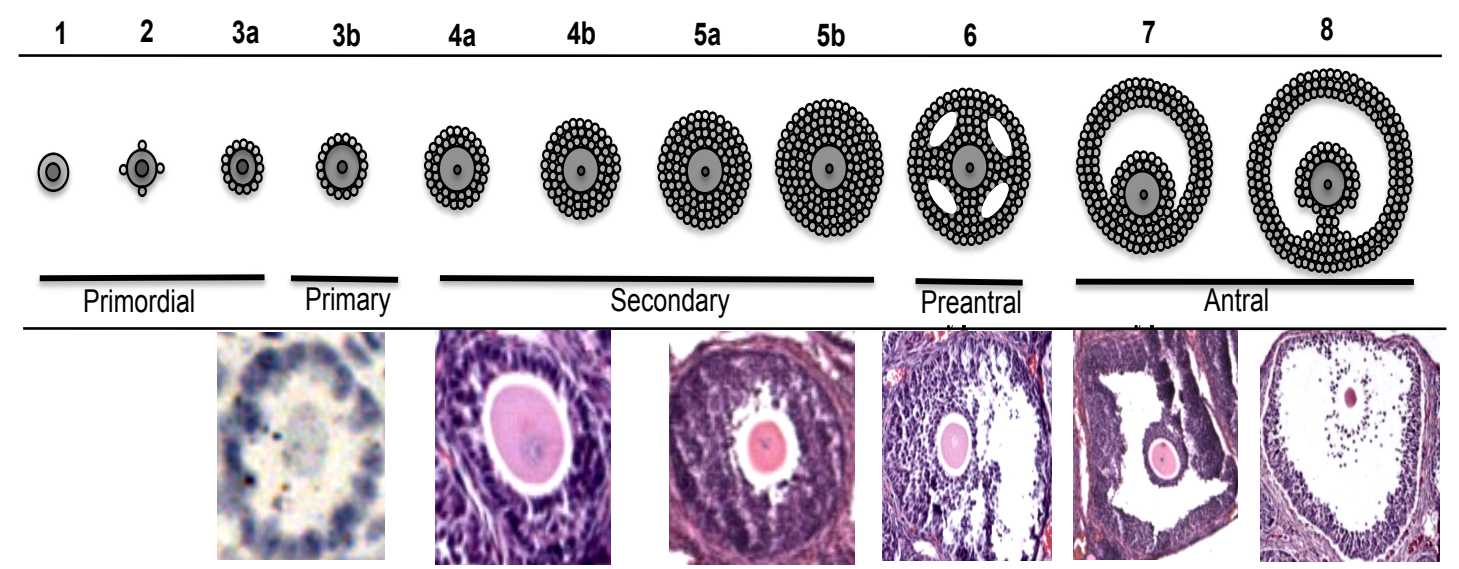

Figure 2B: Mouse ovarian follicle classification chart based on the Petersen and Peters (1968) classification system 
All animals $(n=36 ; 12$ animals per treatment group over three separate experiments) were euthanised $9 \mathrm{~h}$ after the $\mathrm{hCG} /$ saline injection. The ovaries were dissected free of excess tissue, washed in cold PBS and collected into individual $20 \mathrm{ml}$ glass vials containing freshly made 4\% (w/v) paraformaldehyde fixative. Each vial containing an ovary was labelled with the experimental number and animal ID. One ovary from each animal was processed for ISH ( $\mathrm{n}=36$ ovaries) and the other ovary ( $n=36$ ovaries) for confocal immunohistochemistry.

\subsubsection{Ovarian collection and dissection for Western blotting}

For the Western blot sample collection, another three treatment groups of mice were set up, as described in section 2.1.2.1. It was established in a pilot study that the maximum amount of time between harvesting of ovaries and freezing the samples should not be more than $2 \mathrm{~h}$, to ensure the quality/viability of the collected ovarian cells. The ovaries collected for ISH hybridisation were fixed immediately after euthanasia, so sample degradation was not an issue.

To be able to adhere to the timeline for these studies, the superovulation treatment plan was modified slightly. One animal from each of the 3 treatment groups were injected every 2 hours. The first injection was administered at $10 \mathrm{pm}$ on day 1 to one Group 1 (control), one Group 2 (PMSG only) and one Group 3 (PMSG+hCG) animal. The second animal from each treatment group received the first injection 2 hours after this at $1 \mathrm{am}$. The third animal per group was injected at 3 am and the fourth animal at $5 \mathrm{am}$. The second injection followed $48 \mathrm{~h}$ later, where animals received their second treatment in the same order. All animals were euthanised $9 \mathrm{~h}$ after the second treatment, i.e. $57 \mathrm{~h}$ after the treatments commenced.

The ovaries from each animal were washed and collected into PBS in labelled 1.7 $\mathrm{ml}$ eppendorf tubes and transferred to the tissue culture laboratory on ice. On arrival they were dissected free of excess tissue under a dissecting microscope (Leica MZ95) and placed in clean 35x10 mm Petri dishes, containing PBS with 
$0.1 \%$ bovine serum albumin (BSA, ICPbio, Cat. No. ABRE-010). BSA was added to the PBS to prevent cells sticking to the plastic tube, thus leading to loss of sample. The ovaries were dissected individually, but the resulting samples were pooled for each individual animal and labelled accordingly.

Each ovary was cut in half horizontally to facilitate the visualisation of follicles. All visible follicles were punctured with a $20 \mathrm{G}$ needle attached to a $3 \mathrm{ml}$ syringe. A new needle was fitted for each ovary to minimise cross contamination and to ensure optimal sharpness of the needle to prevent tissue maceration. The somatic follicular cells and the oocyte were released from the follicles by gentle scraping with the needle and forceps. The depleted ovaries were discarded and the cumulus-enclosed oocytes were identified and separated from the somatic cells using a pulled glass pipette, attached to a mouthpiece through a $0.22 \mu \mathrm{m}$ filter. Cumulus-oocyte complexes (COC) were then separated into denuded oocyte (DO) and cumulus cell (CC) fractions by gentle pipetting. Granulosa cells (GC) and CC were then pooled to give the somatic cell fraction. COC from large preovulatory follicles with expanded cumulus mass were incubated in hyaluronidase (HYASETM-10X, Vitrolife, Goteborg, Sweden) solution (10 IU in PBS), for up to 2 min to dissociate the CC from the DO. The cells were washed once to remove the hyaluronidase before either being added to the somatic cell pool, or frozen down separately as a CC sample, depending on the planned experiment. The DO were rinsed and added to the DO sample pool.

The somatic cells (i.e. the mixture of GC and CC) were transferred into $15 \mathrm{ml}$ Falcon tubes, centrifuged at $453 \mathrm{~g}$ for $5 \mathrm{~min}$ at $4^{\circ} \mathrm{C}$, washed once in fresh PBS $+0.1 \%$ BSA, pelleted again and then snap frozen on dry ice. The DO were counted, moved into sterile $1.7 \mathrm{ml}$ eppendorf tubes and gently centrifuged at $200 \mathrm{~g}$ for $5 \mathrm{~min}$ at $4^{\circ} \mathrm{C}$. The supernatant was discarded and the DO were snap frozen on dry ice. The dissections resulted in 2 groups of samples: i) follicular somatic cells (pooled granulosa and cumulus cells) and a pool of denuded oocytes from each animal; and ii) an individual pool of $\mathrm{CC}$ and a DO from the same COC. All samples were stored at $-80^{\circ} \mathrm{C}$ until analysis. 


\subsubsection{Ovarian collection and dissection for qPCR analysis}

The superovulation injection timetable was further modified for the qPCR sample collection experiments to allow for longer time intervals between individual animal treatments and dissections. The longer time allowance needed to accommodate the extended sample collection times was found to be necessary to ensure the purity of the samples collected for qPCR analyses. Group 1 and 2 animals could be injected at the same time, but only one animal per group per day. Group 3 animals had to be treated and dissected individually, because of even longer sample collection time requirements, due to some of the oocytes having undergone germinal vesicle breakdown (GVBD) and cumulus mass expansion.

The ovaries ( $\mathrm{n}=6$ from each treatment group) were collected, transported and prepared for dissection the same way as for the Western blot sample collection. The qPCR sample collection protocol described here was that described previously (Crawford and McNatty 2012). Follicles were punctured under a dissecting microscope (Leica MZ95) using a 20G needle. Intact, healthy-looking COC were pipetted one by one into individual wells of a 96 well plate, containing $100 \mu \mathrm{PBS} / 0.01 \% \mathrm{BSA}$. The COC were washed twice by moving them through two wells of the same 96 well plate, containing $100 \mu \mathrm{l}$ fresh PBS/0.01\% BSA. After washing, COC were placed in wells containing $10 \mu \mathrm{PBS} / 0.01 \% \mathrm{BSA}$ and photographed individually, using a DFK 41AF02 camera on a Leica DMI 4000B inverted fluorescent microscope, to assess the health of the COC.

The oocytes were denuded of cumulus cells in the same well by pipetting them up and down gently, using a 2-10 $\mu$ l Gilson pipette. The DO were put through two more wash wells, then pipetted into a new well and photographed again in $10 \mu 1$ $\mathrm{PBS} / 0.01 \%$ BSA to ensure that the oocyte remained undamaged during the denuding and wash steps. To avoid cross contamination between samples, a new sterile $10 \mu 1$ pipette tip was used for each transfer. The 96 well plate was sealed and snap frozen on dry ice, then stored at $-80^{\circ} \mathrm{C}$ until RNA extraction. 
Some oocytes from large, preovulatory follicles collected from animals in Group 3 (PMSG + hCG treated) had undergone germinal vesicle breakdown (GVBD) with expanded cumulus cell mass where others were GV oocytes with non-expanded cumulus mass. The COC containing GVBD oocytes were subjected to a brief enzymatic digestion step before the $\mathrm{CC}$ could be removed. Expanded $\mathrm{COC}$ were washed in PBS/0.01\% BSA, then placed into wells of a 96 well plate containing $10 \mu \mathrm{PBS} / 0.01 \%$ BSA and photographed. Hyaluronidase solution $(100 \mu \mathrm{l}$, HYASETM-10X, Vitrolife, Goteborg, Sweden) was added to the COC to aid the removal of the outer layer of $\mathrm{CC}$. COC were incubated for up to $2 \mathrm{~min}$ in the solution, during which the outer cumulus layer was removed by gentle pipetting. The oocyte, surrounded by the corona radiata, was moved through two wash wells and then photographed before the oocyte was completely denuded in $10 \mu \mathrm{l}$ PBS/0.01\% BSA. After a further two wash steps, the DO was placed in a fresh well with $10 \mu \mathrm{PBS} / 0.01 \% \mathrm{BSA}$ and photographed.

The used hyaluronidase solution, containing the cells from the outer cumulus layer, was transferred to sterile $0.65 \mathrm{ml}$ eppendorf tubes. The cells were centrifuged at $150 \mathrm{~g}$ and the pellet was resuspended in fresh PBS + BSA to remove the hyaluronidase. All samples were placed on dry ice to freeze down instantly. Thereafter the samples were stored at $-80^{\circ} \mathrm{C}$ until RNA extraction.

\subsubsection{Collection of rat granulosa cells for methyl- ${ }^{3} \mathrm{H}$-thymidine bioassay}

Granulosa cells (GC) and COC required for the methyl- ${ }^{3} \mathrm{H}$-thymidine uptake assays were collected from 3 week-old (prepubertal) Sprague-Dawley rats. Animals ( $n=1$ per experiment) were euthanised by asphyxiation, followed by cervical dislocation. Ovaries were removed and transported to the laboratory in PBS at room temperature. On arrival at the laboratory, the eppendorf tube containing the ovaries was incubated in a $37^{\circ} \mathrm{C}$ waterbath until dissection $(<1$ hour).

The dissection medium, M199 (Sigma-Aldrich, Cat. No. M4530) supplemented with $100 \mathrm{IU}$ Penicillin and $100 \mu \mathrm{g}$ streptomycin (Pen Strep, Gibco by Life Technologies, Cat. No. 15070-063) per $\mathrm{ml}$ and 15 mM HEPES (Sigma-Aldrich, 
Cat. No. H4034-100G), and cell culture medium (M199 with 1\% PenStrep and no HEPES buffer) were also kept at $37^{\circ} \mathrm{C}$ to ensure the viability of the collected GC.

Ovaries ( $\mathrm{n}=2$ per experiment) were washed in the dissection medium and dissected free of excess tissue under a dissection microscope (Leica MZ95). They were then placed in a new 35x10 mm petri dish (Biofil ${ }^{\circledR}$, Cat. No. TCD000035) with the dissection medium, cut in half horizontally and all visible follicles were punctured with a $20 \mathrm{G}$ needle attached to a $3 \mathrm{ml}$ syringe. GC and COC were released from the follicles by gentle scraping with the needle and forceps. The depleted ovaries were discarded and all visible COC were transferred into a new petri dish with fresh, warm dissection media, using a hand-pulled glass pipette, attached to a mouthpiece through a $0.22 \mu \mathrm{m}$ filter. The COC were placed in the incubator until the GC were processed.

All GC were pooled into a $15 \mathrm{ml}$ Falcon tube and pelleted by centrifugation, using an Eppendorf 5810R centrifuge at $150 \mathrm{~g}$ for $5 \mathrm{~min}$ at room temperature. The cells were washed once with culture medium, and resuspended in $1 \mathrm{ml}$ of fresh media. An aliquot of $50 \mu \mathrm{l}$ cell suspension was removed for cell counting and viability assessments, using a haemocytometer and Trypan blue exclusion. Cell concentration was established using the following formula:

$\mathrm{N}=\mathrm{X} * 25 / \mathrm{Y} * 10^{4} * \mathrm{~V}$

Where $\mathrm{N}=$ total cell number

$\mathrm{X}=$ number of cells counted under the haemocytometer

$\mathrm{Y}=$ number of squares counted on the haemocytometer

$\mathrm{V}=$ total volume of cell suspension (in this case $1 \mathrm{ml}$ )

Non-viable cells turn blue when adding Trypan blue to the suspension ( $5 \mu 10.4 \%$ dye to $50 \mu$ l cell suspension), due to a compromised cell membrane being permeable to the dye. Live and dead (blue) cells were counted separately to calculate the viability percentage, to assess cell quality and the success of the dissection method. The cell suspension was diluted to a concentration of 1000 
cells/ $\mu 1$ and plated at 20,000 cells per well in 96 well plates (NUNC, Cat. No. 167008).

The COC were mechanically denuded en mass in the petri dish by manual pipetting repeatedly using a 50-200 $\mu \mathrm{l}$ Gilson pipette. The DO were used as one of the positive controls, by adding $32 \mathrm{DO}$ to the GC culture wells. DO are known to stimulate methyl- ${ }^{3} \mathrm{H}$-thymidine uptake by GC (Lin, Pitman-Crawford et al. 2012), thus providing positive proliferation measurements for the assay.

\subsection{Histology}

\subsubsection{Fixation, tissue processing and sectioning}

Mouse ovaries collected for ISH and confocal microscopy were placed individually into fresh $4 \%$ paraformaldehyde fixative as described in section 2.1.2.2, and processed in batches of 24 ovaries per experiment, 8 ovaries per treatment group. The individually labelled vials were kept at $4{ }^{\circ} \mathrm{C}$ for $24 \mathrm{~h}$ on a rotator (Stuart SB2 Rotator, Barloworld Scientific Limited, Stone, Staffordshire, UK). After $24 \mathrm{~h}$ in fixative, the paraformaldehyde was replaced with $70 \%$ ethanol in all vials and vials were rotated for $24 \mathrm{~h}$ at $4{ }^{\circ} \mathrm{C}$ before replacing with fresh $70 \%$ ethanol for storage until processing.

For processing, each ovary was placed into individual embedding cassettes (ProSciTech Pty Ltd, Cat. No. CASHD-05) and processed using the Leica TP1020 automated tissue processor on Routine program consisting of $2 \mathrm{~h}$ in $70 \%$ ethanol, $1.3 \mathrm{~h}$ in $80 \%$ ethanol, $2 \mathrm{x} 1 \mathrm{~h}$ in $95 \%$ ethanol, followed by $1.3 \mathrm{~h}$ in absolute ethanol and another $2 \times 1.15 \mathrm{~h}$ in absolute ethanol. Cassettes were placed in absolute ethanol/xylol for $1.3 \mathrm{~h}$, and xylol for $2 \mathrm{x} 1 \mathrm{~h}$. The program finished with $1.3 \mathrm{~h}$ in wax, then another $2 \mathrm{~h}$ in wax under vacuum. The processing was followed by paraffin embedding, using the Leica EG1160 embedder, and sectioning using a Leica RM2235 microtome. Each ovary was fully cut into $5 \mu \mathrm{m}$ serial sections, 
placing 2 sections onto each slide. The slides were stored at $4{ }^{\circ} \mathrm{C}$ for either ISH or confocal microscopy.

\subsubsection{Haematoxylin and eosin (H\&E) Staining}

Haematoxylin and eosin staining was carried out on every $10^{\text {th }}$ slide of each ovary as a quality control for the tissue processing and sectioning, and to help identify suitable slides to use in ISH experiments (Fischer, Jacobson et al. 2008; Gill 2010).

The slides chosen for H\&E staining were placed into staining racks and washed in xylol for $5 \mathrm{~min}$ to remove the paraffin from the sections. This was followed by two $5 \mathrm{~min} 100 \%$ and one $5 \mathrm{~min} 70 \%$ ethanol wash, and $5 \mathrm{~min}$ under running tap water to rehydrate the sections.

The staining rack was transferred to a staining dish containing Gills haematoxylin stain (Sigma-Aldrich, Cat. No. GHS332-1L) for $5 \mathrm{~min}$, followed by a quick wash in running tap water, 10 dips in acid alcohol reagent (see Appendix I.) and then 10 min in running tap water. The slides were then placed in eosin stain (SigmaAldrich, Cat. No. HT110132-1L) for $2 \mathrm{~min}$, followed by ten quick dips in water, 10 dips in $70 \%$ ethanol, a quick pass through $100 \%$ ethanol and $2 \mathrm{~min}$ in fresh $100 \%$ ethanol to dehydrate the sections again. The process was finished with two 5 min washes in xylol. After cover-slipping and sealing the sections with clear nail polish, they were viewed and photographed on a Leica DM6000B microscope, equipped with a Leica DFC490 camera.

\subsection{In Situ Hybridisation (ISH)}

The ISH method described here was modified from a protocol described previously (Tisdall, Hudson et al. 1994). 
The DNA templates used to create riboprobes for the mouse Bmp15 mature region and mouse Gdf9 mature region for the ISH experiments were full length mouse Bmp15 (accession number: AF082348.1) and mouse Gdf9 (accession number: NH_008110.2) DNA samples, amplified from mouse ovarian cDNA, supplied by Adrian Bibby (VUW, Reproduction Group). The templates were diluted 1:10 with nuclease free water (UltraPure, Invitrogen, Cat. No. 10977015). PCR amplification was performed using primers described in Table 2A.

Initially samples were heated to $95^{\circ} \mathrm{C}$ for $2 \mathrm{~min}$. This was followed by 35 cycles of denaturation $\left(95^{\circ} \mathrm{C}, 20 \mathrm{~s}\right)$, annealing $\left(60^{\circ} \mathrm{C}, 15 \mathrm{~s}\right)$ and elongation $\left(72^{\circ} \mathrm{C}, 50 \mathrm{~s}\right)$, then an additional elongation step at the end of 35 cycles $\left(72^{\circ} \mathrm{C}, 7 \mathrm{~min}\right)$. Mouse Bmp15 and Gdf9 mature region size products were identified by electrophoresis of the PCR products on $1.5 \%$ agarose gel, using SYBR Green dye for detection.

The correct size products encoding the mouse Bmp15 mature region and mouse Gdf9 mature region (374 and 404 bp respectively) were excised from the gel under a UV lamp and purified using the QIAQuick Gel Extraction kit (QIAGEN, Cat. No. 28704), according to the manufacturer's instructions. The gel extracted DNA was ligated into pGEM-Teasy plasmid vector (Promega, Cat. No.A1360) by mixing $5 \mu \mathrm{l}$ of $2 \mathrm{x}$ Ligase 10x buffer, 50 ng pGEM-Teasy plasmid vector, $3 \mu 1$ gel extracted DNA and $1 \mu 1$ T4 DNA Ligase, followed by $2 \mathrm{~h}$ incubation at room temperature. The ligation mix was used to transform TOP10 DH5 $\alpha$ competent cells (Life Technologies, C4040-10) to amplify the available inserted DNA. DH5 $\alpha$ cells were transformed with the DNA ligation mix for $30 \mathrm{~min}$ on ice, 2 min at $37^{\circ} \mathrm{C}$, followed by 2 min on ice. The transformed cells were left to recover in LB broth for 1 hour, then spread on ampicillin-LB agar plates $(50 \mu \mathrm{g} / \mathrm{ml})$, pre-soaked with $200 \mu 1$ of $2 \% \mathrm{X}-\mathrm{Gal}$ in N, N dimethylformamide. The colonies containing the inserts were chosen using blue-white screening. White colonies containing the insert were picked and grown overnight in LB broth, then purified using QIAPrep Spin Miniprep kit (QIAGEN, Cat. No. 29106), as per the manufacturer's instructions. The resulting products were verified by automated sequence analysis 
(Waikato DNA Sequencing Facility, University of Waikato, Hamilton, New Zealand).

Table 2A: Primers used in ISH probe DNA template generation

\begin{tabular}{|c|c|l|c|c|}
\hline Target gene & Primer name & $\begin{array}{c}\text { Oligonucleotide } \\
\text { sequence }\end{array}$ & $\begin{array}{c}\text { Nucleotide } \\
\text { positions }\end{array}$ & $\begin{array}{c}\text { Predicted } \\
\text { Annealing } \\
\text { temperature } \\
\text { ( }\end{array}$ \\
\hline $\begin{array}{c}\text { Mouse } \text { Bmp15 } \\
\text { Forward primer }\end{array}$ & mBMP15 mat & $\begin{array}{l}\text { CAAGCATGCA } \\
\text { GCATTGAATCT }\end{array}$ & $1045-1065$ & 58.8 \\
\hline $\begin{array}{c}\text { Mouse Bmp15 } \\
\text { Reverse primer }\end{array}$ & $3^{\prime}$ Xbal o15 mat & $\begin{array}{l}\text { GCTCTAGATTA } \\
\text { TCTACATGTAC } \\
\text { AGGACTG }\end{array}$ & $1402-1428$ & 59.4 \\
\hline $\begin{array}{c}\text { Mouse Gdf9 } \\
\text { Forward primer }\end{array}$ & mGDF9 mat & $\begin{array}{l}\text { GCAGAAAGCC } \\
\text { ATCCGCTC }\end{array}$ & $1041-1058$ & 58.7 \\
\hline $\begin{array}{c}\text { Mouse Gdf9 } \\
\text { Reverse primer }\end{array}$ & $\begin{array}{c}\text { 3'EcoRI m9 } \\
\text { mat }\end{array}$ & $\begin{array}{l}\text { GGAATTCCTAA } \\
\text { CGACAGGTGC } \\
\text { ACCTCGTAG }\end{array}$ & $1424-1451$ & 64 \\
\hline
\end{tabular}

mat $=$ mature sequence

\subsubsection{Riboprobe preparation}

The pGEM-Teasy plasmid vector contains RNA polymerase promoters T7 and SP6, adjacent to multiple restriction enzyme cut sites (see Figure 2C). The miniprep-purified plasmid containing the inserted foreign DNA was linearised by digestion at $37{ }^{\circ} \mathrm{C}$ for $2 \mathrm{~h}$, followed by $5 \mathrm{~min}$ at $65^{\circ} \mathrm{C}$ with restriction enzymes SalI or NcoI for the mouse Bmp15 mature region sample and SalI or SphI for the mouse $G d f 9$ mature region sample. All linearised DNA samples were separated by electrophoresis on a 1.5\% agarose gel with SYBR Green dye added for detection. The correct size bands were cut out under a UV lamp, followed by gel extraction (QIAquick ${ }^{\circledR}$ Gel Extraction kit, QIAGEN, Cat. No. 28704), before an aliquot of each sample was sent away for sequencing. Sequencing results confirmed that the Bmp15 mature insert was cloned into the pGEM-Teasy plasmid vector in reverse orientation, while the Gdf9 mature insert was in the forward orientation. This resulted in the Bmp15 sense probe being generated by linearising with digestion by NcoI and the use of a SP6 promoter, while linearisation with SalI and a T7 
promoter generated an anti-sense probe using the Riboprobe combination system (Promega, PMP1460). The Gdf9 sense probe was generated by linearisation with SalI digestion enzyme and transcription from the T7 promoter, whilst the antisense probe was linearised with SphI and the SP6 promoter used to transcribe the DNA in RNA in the same system. The sense probes were used as negative controls to detect the extent of non-specific binding, whilst the antisense probes would bind specifically to the target messenger RNA on the tissue sections. The amount of DNA used to create each probe was 9-11 $\mu \mathrm{g}$.

The digestion enzyme SphI, used to linearise the Gdf9 antisense probe, is known to create 3'overhangs, which would inhibit the probe from being generated by preventing the reverse transcriptase from transcribing the RNA probe. For this reason the $G d f 9$ antisense probe had to be prepared using the Klenow procedure, whereas the rest of the probes were prepared using the standard procedure. For both procedures, the Promega Riboprobe in vitro Transcription Systems kit (Cat. No. P1460) was used.

For probes prepared using the standard procedure, $4 \mu 1$ xxTranscription Buffer, 2 $\mu \mathrm{l} 0.1 \mathrm{M}$ DTT, $1 \mu \mathrm{l}$ RNasin, $1 \mu \mathrm{l}$ of each of $10 \mathrm{mM}$ rATP, rCTP, rGTP and $0.8 \mu \mathrm{l}$ rUTP (1:100) were mixed with $3.3 \mu 1$ template linearised DNA, followed by $5 \mu 1$ of $\left[{ }^{33} \mathrm{P}\right]$-UTP (Perkin Elmer, Cat. No. NEG607H250UC) and $2 \mu 1$ of either SP6 or T7 RNA polymerase (Promega).

The Klenow procedure, used to prepare Gdf9 antisense probe, included a 15 min pre-incubation step at $22^{\circ} \mathrm{C}$ with the $5 \mathrm{xTranscription}$ Buffer, $0.1 \mathrm{M}$ DTT, RNasin, $1 \mu 1$ Klenow enzyme (Promega, M220A) and the template linearised DNA, before adding the rATP, rCTP, rGTP, rUTP, the $\left[{ }^{33} \mathrm{P}\right]-\mathrm{UTP}$, and the RNA polymerase. From here on, all probes were treated the same way. After $1 \mathrm{~h}$ incubation at $37^{\circ} \mathrm{C}$, $1 \mu 1$ of RQ1 Dnase was added, followed by a further 15 min incubation at $37^{\circ} \mathrm{C}$, after which $4 \mu 110 \mathrm{mg} / \mathrm{ml}$ tRNA, $12 \mu 17.5 \mathrm{M}$ ammonium acetate (pH7.0) and 80 $\mu 1$ ice cold $100 \%$ ethanol were mixed into the probes. At this point, the probes were either placed on dry ice for $1 \mathrm{~h}$, or left at $-20^{\circ} \mathrm{C}$ overnight.

Following this, the probes were centrifuged at $10000 \mathrm{~g}$ for $20 \mathrm{~min}$ at $4^{\circ} \mathrm{C}$ and the resulting pellet was resuspended in $30 \mu \mathrm{LEPC}$ treated water. The probes then 
received $15 \mu \mathrm{l}$ of $7.5 \mathrm{M}$ ammonium acetate and $90 \mu \mathrm{l}$ ice cold $100 \%$ ethanol and placed on dry ice for $1 \mathrm{~h}$. All samples were pelleted by centrifugation, dried and resuspended in $30 \mu 1$ autoclaved DEPC treated water.

Each probe $(1 \mu 1)$ was mixed with $200 \mu 1$ scintillation fluid (Beta Scint, Perkin Elmer, Cat. No. SC/9200.21) to determine the CPM (counts per minute), using a Wallac 1409 Liquid Scintillation Counter.

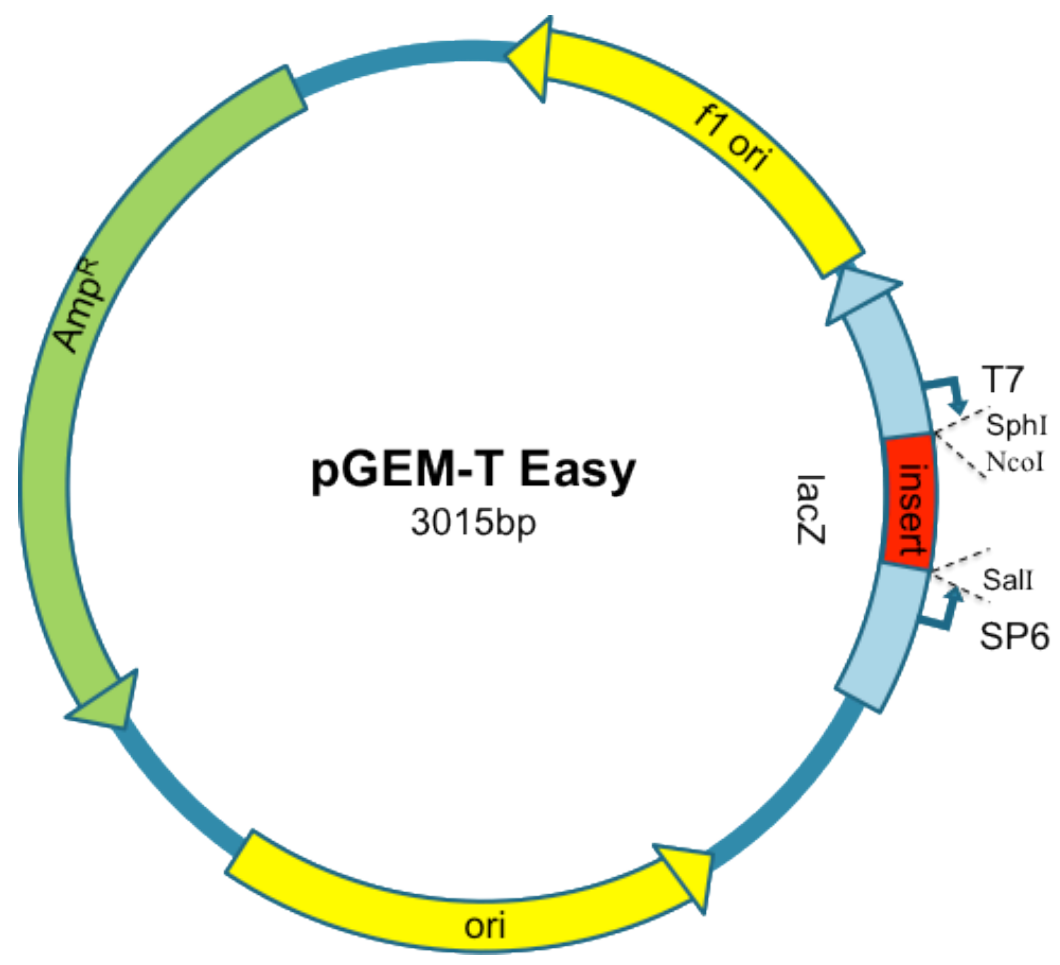

Figure 2C: pGEM-Teasy plasmid vector map, showing restriction enzyme cut sites and RNA polymerase promoters utilised in generating ISH riboprobes

\subsubsection{Preparing tissue sections for ISH}

The sections used for ISH were chosen from the paraffin embedded and sectioned $(5 \mu \mathrm{m})$ mouse ovaries collected and processed as described in section 2.1.2.2. Care was taken to choose sections where all ovarian cell types were represented in a wide range of follicle sizes. 
The slides underwent deparaffinisation using xylol, rehydration in a series of ethanol $(100 \%, 95 \%$ and $70 \%)$ washes, followed by DEPC-water treatment. After rehydration, a pretreatment was carried out to remove all positive protein charges that could affect probe binding. The pretreatment included a $20 \mathrm{~min} 0.2$ $\mathrm{M} \mathrm{HCl}$ wash, two 30 min washes in $2 x S S C$ buffer, and Proteinase $\mathrm{K}$ digestion for $5 \mathrm{~min}$ at $37^{\circ} \mathrm{C}$.

The pretreatment was followed by acetylation to reduce non-specific binding of the probes. This was achieved by pipetting $250 \mu 1$ of acetic anhydride onto the sections and incubating the slides for $5 \mathrm{~min}$ in $0.1 \mathrm{M}$ triethanolamine. This process was repeated once more, and the slides were then washed in $2 \mathrm{xSSC}$ buffer for $5 \mathrm{~min}$.

Following acetylation, the sections were dehydrated in a series of 5 min ethanol washes, starting with $70 \%$ ethanol, followed by $95 \%$ and two $100 \%$ ethanol washes. The slides were then air dried before ISH.

\subsubsection{ISH and post hybridisation treatment}

The probes were diluted with hybridisation mix to give $45000 \mathrm{cpm} / \mu 1$.

Diluting the probes to the required volume was calculated by the formula:

$\mathrm{X}=\underline{45000 \times \mathrm{V}}$

where $\mathrm{X}=$ total volume of probe

$\mathrm{V}=$ Volume required (number of small sections $\mathrm{x} 40 \mu \mathrm{l}+$ number of large sections $\mathrm{x} 70 \mu \mathrm{l})$

$\mathrm{M}=$ measured $\mathrm{cpm} / \mu \mathrm{l}$ probe

Either 40 or $70 \mu \mathrm{l}$ of diluted probes $\left(45000 \mathrm{cpm} / \mu \mathrm{m}^{2}\right)$ were added to each section, depending on the size of the coverslip needed to cover the section. The pretreated 
$5 \mu \mathrm{m}$ tissue sections were incubated overnight at $55^{\circ} \mathrm{C}$ with the ${ }^{33} \mathrm{P}$-labelled antisense/sense riboprobes in a humidified chamber, to prevent evaporation.

Following incubation, the slides were washed $2 \times 15 \mathrm{~min}$ in $5 \times \mathrm{XSC} / \mathrm{DEPC}$ solution at $50^{\circ} \mathrm{C}$ during which the coverslips were removed. This was followed by a 30 min wash in $2 \mathrm{xSSC} / 50 \%$ formamide/DEPC at $65^{\circ} \mathrm{C}$ and $4 \mathrm{x} 5 \mathrm{~min}$ washes in $2 \mathrm{x}$ $\mathrm{SSC} / \mathrm{DEPC}$ at $37^{\circ} \mathrm{C}$. Non-hybridised RNA was removed by RNaseA digestion at $37^{\circ} \mathrm{C}$ for $30 \mathrm{~min}$, and a series of washes $\left(2 \times \mathrm{SSC} / 50 \%\right.$ formamide at $65^{\circ} \mathrm{C}$ for 30 $\min , 2 \times \mathrm{SSC} / \mathrm{MQ}$ water at $37^{\circ} \mathrm{C}$ for $15 \mathrm{~min}$ and $0.2 \times \mathrm{SSC} / \mathrm{MQ}$ water at $37^{\circ} \mathrm{C}$ for $15 \mathrm{~min})$. Sections were then dehydrated, air dried and coated with autoradiographic silver emulsion (LM-1 emulsion; GE biosciences) in the darkroom. The emulsion coated slides were dried overnight and then incubated at $4^{\circ} \mathrm{C}$ for 1 week.

\subsubsection{Development}

After the week-long exposure, the slides were developed in the dark room for $3.5 \mathrm{~min}$ in Ilford developer solution (Ilford Ltd). Development was stopped by $1 \mathrm{~min}$ incubation in $1 \%$ acetic acid and slides were fixed after 10 min incubation in Ilfofix II (Ilford Ltd) and washed for $1 \mathrm{~h}$ under running tap water.

The sections were stained with Gills haematoxylin and exposed for 1 min to Scott's tap water (see Appendix I.) before being dehydrated as described previously in section 2.3.3. Subsequently, the sections were coverslipped, viewed and photographed using both light and dark field illumination on a Leica DM6000B microscope, equipped with a Leica DFC490 camera.

\subsection{Western blotting procedure}

\subsubsection{SDS-PAGE gel preparation}

The polyacrylamide gels were prepared in various concentrations, depending on the size of the protein(s) of interest to be detected. The exact reagent amounts for 2 separating and 4 stacking gels are listed in Tables $2 \mathrm{~B}$ and 2C. Gels were 
prepared using the Mini-Protean Tetra Cell apparatus (Bio-Rad Laboratories (New Zealand) Pty Ltd, Albany, Auckland, NZ, Cat. No. 165-8000).

The separating gel ingredients were combined and gently layered in glass casts secured on stands. They were left to polymerase for 2-4 h, with water layered on top to prevent the gel from drying out. After polymerisation was complete, the water was removed from the top of the gel and a stacking gel was layered on top. A gel comb (10 or 15 well depending on the sample volume to be loaded onto the gel) was inserted into the stacking gel layer. Once the stacking gel was polymerised, the SDS-PAGE gels were removed from the stand and either stored wrapped in wet paper towels in a zip lock bag at $4^{\circ} \mathrm{C}$, or used straight away.

Table 2B: Separating gel reagents (see Appendix I. for recipes of stock solutions and suppliers of reagents)

\begin{tabular}{|c|c|c|c|}
\hline Reagents & $\begin{array}{c}\mathbf{7 . 5 \%} \\
\text { Separating gel }\end{array}$ & $\begin{array}{c}\mathbf{1 0 \%} \\
\text { Separating gel }\end{array}$ & $\begin{array}{c}\mathbf{1 3 . 5 \%} \\
\text { Separating gel }\end{array}$ \\
\hline Distilled water & $4.88 \mathrm{ml}$ & $4 \mathrm{ml}$ & $2.88 \mathrm{ml}$ \\
\hline $0.5 \mathrm{M}$ Tris-HCl $\mathrm{pH} 6.8$ & $2.5 \mathrm{ml}$ & $2.5 \mathrm{ml}$ & $2.5 \mathrm{ml}$ \\
\hline Bis-acrylamide $(30 \%)$ & $2.5 \mathrm{ml}$ & $3.35 \mathrm{ml}$ & $4.5 \mathrm{ml}$ \\
\hline $10 \%(\mathrm{w} / \mathrm{v})$ SDS & $100 \mu \mathrm{l}$ & $100 \mu \mathrm{l}$ & $100 \mu \mathrm{l}$ \\
\hline $\begin{array}{c}10 \%(\mathrm{w} / \mathrm{v}) \text { ammonium } \\
\text { persulphate }\end{array}$ & $50 \mu \mathrm{l}$ & $50 \mu \mathrm{l}$ & $50 \mu \mathrm{l}$ \\
\hline TEMED & $5 \mu \mathrm{l}$ & $5 \mu \mathrm{l}$ & $5 \mu \mathrm{l}$ \\
\hline
\end{tabular}

Table 2C: Stacking gel reagents (see Appendix I. for recipes of stock solutions and suppliers of reagents)

\begin{tabular}{|c|c|}
\hline Reagents & $\begin{array}{c}\mathbf{4 \%} \\
\text { Stacking gel }\end{array}$ \\
\hline Distilled water & $3.0 \mathrm{ml}$ \\
\hline $0.5 \mathrm{M}$ Tris-HCl $\mathrm{pH} 6.8$ & $1.25 \mathrm{ml}$ \\
\hline Bis-acrylamide $(30 \%)$ & $0.65 \mathrm{ml}$ \\
\hline $10 \%(\mathrm{w} / \mathrm{v})$ SDS & $50 \mu \mathrm{l}$ \\
\hline $\begin{array}{c}10 \%(\mathrm{w} / \mathrm{v}) \text { ammonium } \\
\text { persulphate }\end{array}$ & $25 \mu \mathrm{l}$ \\
\hline TEMED & $5 \mu \mathrm{l}$ \\
\hline
\end{tabular}




\subsubsection{Sample preparation}

The amount of sample able to be loaded onto the gel depended on the well size. The 10 well gels held up to $25 \mu 1$ sample per well, the 15 well gels held up to $15 \mu 1$ sample per well. In experiments where HEK 293 cell-derived media samples were tested, the sample amount was kept constant between all wells within each Western blot. Equal amounts of samples were mixed with 5x loading dye (see Appendix I) and incubated at $95^{\circ} \mathrm{C}$ for $5 \mathrm{~min}$ before being loaded onto the gel. All Western blot assays were run under reducing conditions, with the loading dye containing $1.08 \% \mathrm{w} / \mathrm{v}$ DTT.

When testing cell lysates, it was important to be able to load the entire sample from the individual animals or from groups of animals within a treatment group into individual wells. The ovarian somatic cell $(\mathrm{GC} / \mathrm{CC})$ or oocyte pellets collected in various experiments were stored frozen at $-80^{\circ} \mathrm{C}$ in eppendorf tubes. On the day of the analysis, samples were quickly thawed and $15 \mu 1$ RIPA lysis buffer (see Appendix I.) was added. The samples were mixed by vortexing, briefly spun down and snap-frozen on dry ice. The freeze/thawing was repeated 3 times in quick succession to aid sample lysis. Sample aliquots $(5 \mu 1)$ were then removed from all $\mathrm{GC} / \mathrm{CC}$ cell lysates for $\mathrm{BCA}$ protein quantification assay (see paragraph 2.4.8) to measure the exact amount of protein loaded per well. This information was used only to ensure that samples with similar protein content were analysed on the same gel, not for standardisation of loaded sample amounts. The sample portion not used for BCA assay $(10 \mu \mathrm{l})$ received the $5 \mathrm{x}$ loading dye, was mixed and incubated at $95^{\circ} \mathrm{C}$ for $5 \mathrm{~min}$, then loaded onto the gel. The oocyte lysate samples were prepared the same way as the $\mathrm{GC} / \mathrm{CC}$ samples, but without protein quantification due to very limited sample amounts. Instead, the number of oocytes loaded per well was recorded at collection and was kept as similar as possible between the wells. 
2.4.3 Protein separation by electrophoresis

The prepared samples and the molecular ladder (BioRad, Cat. No. 1610305) were loaded onto the SDS-PAGE gels, secured in a Mini-Protean Tetra Cell running cassette. The cassette was filled with SDS-PAGE running buffer (see Appendix I.) according to the manufacturer's instructions, and gel electrophoresis carried out at $150 \mathrm{~V}$ for $1-1.5 \mathrm{~h}$, depending on the size of the proteins separated out on the gels.

2.4.4 Protein transfer to nitrocellulose membrane

After the different-sized protein bands in the samples were separated out on the gel by electrophoresis, the protein bands were transferred to nitrocellulose membranes (Amersham Biosciences, Hybond ${ }^{\mathrm{TM}} \_$C Extra, Cat. No. RPN303E).

For preparation of the protein transfer cassette, a tray filled with transfer buffer (see Appendix I) was used to prevent the gel and the nitrocellulose membrane from drying out. The black (negative charge) side of the transfer cassette was placed onto the bottom of the tray and a scotch pad and a piece of blotting paper was layered onto it. Care was taken that no air bubbles remained trapped between the layers.

At the completion of the electrophoresis step, the gel was removed from the running cassette. The top glass plate (cover) was removed and the stacking gel was scraped off the top of the separating gel. The separating gel was carefully removed from the bottom glass plate and placed on top of the transfer blotting paper.

A piece of nitrocellulose membrane pre-wetted in transfer buffer was placed on top of the gel and once again air bubbles were pressed out gently from between the layers using a roller. Another piece of blotting paper was placed on top of the membrane, followed by a scotch pad. Air bubbles were removed, and the transfer cassette was locked tightly with the white (positive charge) side of the transfer cassette, creating a 'sandwich'. The 'transfer sandwich' was placed in a transfer 
stand with an ice pack and magnetic stirbar, and filled with transfer buffer. The protein transfer was carried out at $4^{\circ} \mathrm{C}$ for $1 \mathrm{~h}$ at $100 \mathrm{~V}$.

To prove the transfer had been successful, the nitrocellulose membrane was stained with Ponceau S stain (see Appendix I.) for $1 \mathrm{~min}$, and then rinsed briefly with distilled water until only the protein bands and the molecular ladder was visible. The molecular ladder bands were marked with pencil, along with the positions of the wells on the membrane. The stain was then fully washed out of the membrane by repeatedly rinsing with distilled water.

\subsubsection{Detection by immunoblotting}

The nitrocellulose membrane was placed in a plastic $100 \times 100 \mathrm{~mm}$ square Petri dish (ThermoFisher Scientific, LabServe Cat. No. LBS60020) containing 5\% milk powder blotto solution (5\% blotto, see Appendix I) and incubated for $1 \mathrm{~h}$ at room temperature on a mixing platform (Labnet ORBIT LS, Total Lab Systems Ltd, Cat. No. S 2030-L S-230V) set at $60 \mathrm{rpm}$, to prevent non-specific binding of the antibody.

After $1 \mathrm{~h}$, the blocking solution was replaced with the primary antibody, diluted to $1 \mu \mathrm{g} / \mathrm{ml}$ in $12 \mathrm{ml}$ of $5 \%$ blotto, and the membrane was incubated overnight at room temperature with continuous agitation.

The following day, the membrane was washed $3 \times 10 \mathrm{~min}$ in a low salt Tris wash buffer (see Appendix I) and then the secondary antibody solution was diluted 1:3000 with $5 \%$ blotto and added to the membranes. Following a $2 \mathrm{~h}$ incubation at room temperature with the secondary antibody, the membranes were washed $3 x$ 10 min in low salt Tris wash buffer and developed. The primary and secondary antibody combinations used to detect different forms of mouse BMP15 and GDF9 proteins are listed in Table 2D. 
Table 2D: Primary and secondary antibodies used in Western blot experiments and target protein sizes

\begin{tabular}{|c|c|c|}
\hline $\begin{array}{l}\text { Target protein } \\
\text { (size) }\end{array}$ & Primary antibody & Secondary antibody \\
\hline $\begin{array}{c}\text { mBMP15 mature } \\
\text { region } \\
(17-20 \mathrm{kDa})\end{array}$ & $\begin{array}{c}\text { A20 - anti-human BMP15 mature goat } \\
\text { polyclonal IgG } \\
\text { [Santa Cruz, Cat. No. sc-18337] }\end{array}$ & $\begin{array}{c}\text { Rabbit anti-goat IgG-HRP } \\
\text { [Santa Cruz, Cat. No. sc-2768] }\end{array}$ \\
\hline $\begin{array}{c}\text { mBMP15 } \\
\text { proregion } \\
(40 \mathrm{kDa}) \\
\end{array}$ & $\begin{array}{l}\text { 8f - anti-mouse BMP15 proregion } \\
\text { mouse polyclonal ab } \\
\text { [in house,(McIntosh, Lun et al. 2008)] }\end{array}$ & $\begin{array}{c}\text { Rabbit anti-mouse-HRP } \\
\text { [Abacus, Cat. No. 315-035-045] }\end{array}$ \\
\hline $\begin{array}{c}\text { mBMP15 } \\
\text { promature } \\
(55-60 \mathrm{kDa}) \\
\end{array}$ & $\begin{array}{c}8 \mathrm{f}-\text { anti-mouse BMP15 proregion } \\
\text { mouse polyclonal ab } \\
\text { [in house] }\end{array}$ & $\begin{array}{c}\text { Rabbit anti-mouse-HRP } \\
\text { [Abacus] }\end{array}$ \\
\hline $\begin{array}{l}\text { mGDF9 mature } \\
\text { region } \\
(19-22 \mathrm{kDa})\end{array}$ & $\begin{array}{c}\text { 47b - anti-sheep/mouse GDF9 mature } \\
\text { mouse monoclonal ab [provided by Dr } \\
\text { Nigel Groome, Oxford Brookes } \\
\text { University, Oxford, U.K.] }\end{array}$ & $\begin{array}{c}\text { Rabbit anti-mouse-HRP } \\
\text { [Abacus] }\end{array}$ \\
\hline $\begin{array}{c}\text { mGDF9 proregion } \\
\text { (40 kDa) }\end{array}$ & $\begin{array}{l}\text { 4e - anti mouse GDF9 proregion mouse } \\
\text { polyclonal ab } \\
\text { [in house,(McIntosh, Lun et al. 2008)] }\end{array}$ & $\begin{array}{c}\text { Rabbit anti-mouse-HRP } \\
\text { [Abacus] }\end{array}$ \\
\hline $\begin{array}{l}\text { mGDF9 promature } \\
(55-60 \mathrm{kDa})\end{array}$ & $\begin{array}{c}4 \mathrm{e}-\text { anti-mouse GDF9 proregion mouse } \\
\text { polyclonal ab } \\
\text { [in house }]\end{array}$ & $\begin{array}{c}\text { Rabbit anti-mouse-HRP } \\
\text { [Abacus] }\end{array}$ \\
\hline
\end{tabular}

\subsubsection{Visualisation with Enhanced Chemiluminescence}

The immunoblot membrane was transported to the dark room in the low salt Tris wash buffer. Enhanced chemiluminesence (ECL) solutions were prepared fresh (see Appendix I) and mixed immediately before pipetting onto the membrane. After $1 \mathrm{~min}$ incubation with the ECL solution, the membrane was wrapped in clear plastic film, secured onto a developing cassette with masking tape and X-ray film (Kodak) was placed on top of it. A series of exposures using different pieces of film were carried out during each development, ranging from $10 \mathrm{~s}$ to $10 \mathrm{~min}$. The X-ray films were developed for $3 \mathrm{~min}$ in Kodak GBX developer and replenisher (Cat. No. 403 7180), followed by $1 \mathrm{~min}$ in water, $3 \mathrm{~min}$ in Kodak GBX fixer and replenisher (Cat. No. 403 7214) and then another 1 min wash in water. The dried film was aligned onto the membrane to mark the positions of the ladder bands and the wells. 
Membranes were stored in sealed plastic boxes containing PBS with $0.05 \%(\mathrm{w} / \mathrm{v})$ sodium-azide at $4^{\circ} \mathrm{C}$, until being used for preadsorption experiments to measure specificity of the protein bands.

\subsubsection{Antibody preadsorption}

To validate the results of Western blot experiments, immunoblotted antibodies were stripped from the membranes after development and the immunoblotting detection repeated using a preadsorbed primary antibody solution.

For stripping, the membrane was first placed into pre-warmed $62.5 \mathrm{mM}$ Tris- $\mathrm{HCl}$ /2\% SDS stripping buffer, containing 0.7\% ß-mercaptoethanol (see Appendix I.) and incubated at $50^{\circ} \mathrm{C}$ for $30 \mathrm{~min}$. Following incubation, the membrane was rinsed three times with large amounts of PBS to remove all traces of the stripping buffer. The membrane was then placed in a clean plastic dish and washed $3 \times 10$ min in the low salt Tris wash buffer.

The preadsorbed primary antibody solution was prepared the day before by incubating the same amount of antibody as used in the original Western blot with 10 times as much blocking peptide or protein in $1 \mathrm{ml}$ PBS rotating at $4^{\circ} \mathrm{C}$. Following the wash steps, the membrane was blocked for $1 \mathrm{~h}$ at room temperature with 5\% blotto solution. The preadsorbed primary antibody was centrifuged for 10 $\mathrm{m}$ at $13000 \mathrm{~g}$, the cleared supernatant diluted to $12 \mathrm{ml}$ with $5 \%$ blotto, poured onto the membrane and left to incubate overnight at room temperature with continuous agitation. The following day, membrane washing, incubation with the secondary antibody and the ECL development was carried out as in the original Western blot assay, described in sections 2.4.5 and 2.4.6. Protein bands were regarded as specific if they were detected in the original Western blot experiment but were not present on the X-ray film following incubation with the preadsorbed primary antibody. 
The Pierce BCA Protein Assay Kit (Thermo Fisher Scientific, Cat. No. 23227) was used as per the manufacturer's protocol, to quantify the amount of protein loaded onto the SDS-PAGE gels when analysing somatic follicular cell $(\mathrm{GC} / \mathrm{CC})$ lysates.

This assay utilizes the reduction of $\mathrm{Cu}^{2+}$ to $\mathrm{Cu}^{+}$by proteins in an alkaline solution, then detecting $\mathrm{Cu}^{+}$by bicinchononic acid (BCA) in a colorimetric reaction at 562 nm. The colour change was measured by a VICTOR ${ }^{3}$ PerkinElmer 1420 Multilabel Counter. The unknown protein concentrations were estimated from a standard curve, created by plotting the net absorbance of BSA protein standards, prepared from stock solutions contained in the kit.

\subsection{Quantitative PCR (qPCR)}

\subsubsection{RNA extraction and cDNA synthesis}

Cumulus cell (CC) and denuded oocyte (DO) samples were collected for qPCR analyses as described in section 2.1.2.4. The samples were stored frozen at $-80^{\circ} \mathrm{C}$ in 96 well plates and $0.65 \mathrm{ml}$ eppendorf tubes. RNA extraction was carried out on individual DO and on the corresponding CC using the ArrayPure ${ }^{\mathrm{TM}}$ Nanoscale RNA purification kit (EPICENTRE Biotechnologies, MPS04050, Wisconsin, USA). The procedure involved mixing the samples with $30 \mu 1$ nanoscale lysis buffer containing $1 \mu \mathrm{l}$ Proteinase K. After mixing thoroughly by pipetting or vortexing, the samples stored in 96 well plates were transferred into sterile eppendorf tubes and all samples were incubated for $15 \mathrm{~min}$ at $65^{\circ} \mathrm{C}$, followed by $5 \mathrm{~min}$ on ice. After the incubation period, all samples received $18 \mu \mathrm{l}$ of $5 \mathrm{M}$ ammonium acetate solution (MPC Protein Precipitation Reagent, ArrayPure kit). The samples were mixed and centrifuged at $12,000 \mathrm{~g}$ for $7 \mathrm{~min}$ at $4^{\circ} \mathrm{C}$. The supernatants were transferred into sterile eppendorf tubes and pellets were discarded. Total RNA was precipitated from the supernatant by mixing in 50 $\mu 1$ of isopropanol (Global Science, Cat. No. APPA39281000PE) and 
centrifugation at $12,000 \mathrm{~g}$ for $5 \mathrm{~min}$ at $4^{\circ} \mathrm{C}$. The supernatants were discarded and the RNA pellets were air dried for 5 min before resuspended in DNase solution $(0.5 \mu \mathrm{l}$ RNase free DNase I in $20 \mu \mathrm{l}$ of $1 \times$ DNase buffer per sample, ArrayPure kit), used to remove DNA contamination. The samples were incubated with the DNase solution at $37^{\circ} \mathrm{C}$ for $30 \mathrm{~min}$. Following the incubation, $20 \mu \mathrm{l}$ of $2 \mathrm{x}$ nanoscale lysis solution (ArrayPure kit) was added to the samples and mixed by vortexing. Any remaining protein contaminant was removed by the addition of 20 $\mu 1$ of MPC Protein Precipitation Reagent. The samples were vortexed vigorously, and cooled down for $5 \mathrm{~min}$ on ice before centrifuging for $5 \mathrm{~min}$ at $12,000 \mathrm{~g}$ at $4^{\circ} \mathrm{C}$. The supernatants were then transferred to sterile eppendorf tubes and total RNA was precipitated with $50 \mu \mathrm{l}$ of isopropanol and centrifugation for $5 \mathrm{~min}$ at $12,000 \mathrm{~g}$ at $4^{\circ} \mathrm{C}$. The supernatants were discarded and the RNA pellets were washed once with $50 \mu \mathrm{l}$ of $70 \%$ ethanol diluted from $100 \%$ analytical grade ethanol (SigmaAldrich, Cat. No. 24106) with DEPC (Sigma-Aldrich, Cat. No. 40718) treated water. The samples were once more centrifuged for $3 \mathrm{~min}$ at $12,000 \mathrm{~g}$ at $4^{\circ} \mathrm{C}$, and then the ethanol was aspirated from the pellets. The RNA pellets were air dried for $5 \mathrm{~min}$ and resuspended in $10 \mu \mathrm{l}$ of ultra-pure water. Incubation at $55^{\circ} \mathrm{C}$ for $2 \mathrm{~min}$ helped to dissolve the RNA. The samples were either used for cDNA synthesis immediately or stored at $-80^{\circ} \mathrm{C}$.

Synthesis of cDNA was carried out using the Superscript ${ }^{\circledR}$ VILO $^{\text {TM }}$ cDNA synthesis kit (Cat. No. 11754-050, Invitrogen, CA, USA). Each tube of $10 \mu 1$ RNA sample, to be reverse-transcribed to cDNA, was mixed with $4 \mu 1$ of VILO ${ }^{\mathrm{TM}}$ reaction mix, $2 \mu 1$ of 10x Superscript ${ }^{\circledR}$ Enzyme Mix and $4 \mu 1$ of ultra-pure water. After mixing the samples thoroughly, the cDNA synthesis was carried out using a Rotor-Gene $^{\mathrm{TM}} 6000$ Rotary Analyser (Corbett Research Ltd). The program used incubated the samples at $25^{\circ} \mathrm{C}$ for $10 \mathrm{~min}$, followed by $1 \mathrm{~h}$ at $42^{\circ} \mathrm{C}$ and $5 \mathrm{~min}$ at $85^{\circ} \mathrm{C}$. In each cDNA synthesis run, one No-RT PCR control sample was included: this sample did not receive the 10x Superscript ${ }^{\circledR}$ Enzyme Mix and was included in the qPCR to monitor potential genomic DNA contamination in the samples. All cDNA samples were stored at $-20^{\circ} \mathrm{C}$ until qPCR analyses. 


\subsubsection{Quantitative PCR}

\subsubsection{Primer and TaqMan Probe optimisation}

The methods used to optimise conditions for quantitative PCR analysis were described by Crawford and McNatty 2012. The primers and TaqMan probes, listed in Table 2E, were designed using the 'Beacon Designer' computer software package (Premier Biosoft International, Palo Alto, CA, USA) and were based on sequences obtained from NCBI (National Center for Biotechnology Information).

A range of cDNA template and primer concentrations were tested in singleplex (measuring mRNA expression of a single gene) reactions, using the $\mathrm{SYBR}^{\circledR}$ Green system (Agilent Technologies, USA, Cat. No. 600548). SYBR ${ }^{\circledR}$ Green I is a DNA binding dye, emitting strong green $(\sim 520 \mathrm{~nm})$ fluorescence when bound to double-stranded (ds), rather than single-stranded DNA. During the annealing step of the qPCR reaction when dsDNA is synthesised with the aid of the primers, SYBR $^{\circledR}$ Green I fluorescence intensity increases in a linear fashion as the PCR product is amplified over a number of cycles. The cycle number where the fluorescence intensity becomes significant above the background is the cycle threshold $\left(\mathrm{C}_{\mathrm{T}}\right)$. The $\mathrm{C}_{\mathrm{T}}$ value depends on the initial concentration of the target DNA in the sample and is inversely proportional to the log concentration of the original template. This means that the higher the original template concentration the lower the $\mathrm{C}_{\mathrm{T}}$ value. The $\mathrm{C}_{\mathrm{T}}$ values are measured in the exponential part of the PCR amplification curve, before the limited reagent amounts could influence the efficiency of the amplification (Brilliant SYBR $^{\circledR}$ Green qPCR, Instruction Manual, Agilent Technologies).

The optimal template concentration was deemed to be $1.56 \mu \mathrm{l}$ cDNA per reaction, since this resulted in $C_{T}$ values within the measurable range (15-26). The optimal primer concentrations are listed in Table 2E. 
Briefly, cDNA template and forward and reverse primers were pipetted into 0.2 $\mathrm{ml}$ microtubes as a singleplex reaction for each gene. They were mixed with $26 \mu 1$ of 2x Brilliant $^{\circledR}$ Green qPCR Master Mix (Agilent Technologies, Cat. No. 600548). Ultra-pure water was used to bring the final volume to $52 \mu 1$. After mixing the samples thoroughly, they were split into two $25 \mu 1$ aliquots and transferred into capped $0.1 \mathrm{ml}$ strip-tubes (Corbett Research, Mortlake, NSW, Australia). The Rotor-Gene ${ }^{\mathrm{TM}} 6000$ Rotary Analyser (Corbett Research Ltd) was used to amplify the DNA using a program set to heat samples to $95^{\circ} \mathrm{C}$ for $10 \mathrm{~min}$, followed by 40 cycles of $15 \mathrm{~s}$ at $95^{\circ} \mathrm{C}$ and $60 \mathrm{~s}$ at $58^{\circ} \mathrm{C}$. Results were analysed using the Corbett Rotor-Gene 6000 Series Software 1.7.

Multiplex PCR reactions, capable of measuring mRNA expression levels of multiple genes at the same time, utilised TaqMan probes labelled with spectrally distant fluorescent molecules (fluorophores) and quenchers. During the annealing step, when the probe attaches to the target, the DNA polymerase separates the quencher from the fluorophore. This results in the fluorophore emitting a fluorescence signal, which is monitored in real time in a linear fashion. The resulting $\mathrm{C}_{\mathrm{T}}$ value can be used to calculate the original concentration of the target gene in the sample. Using fluorophores with spectrally distant emission peaks allows the detection of multiple genes in a single reaction (Brilliant Multiplex qPCR Master Mix, Instruction Manual, Agilent Technologies). The reagents used in the TaqMan multiplex reactions were supplied as part of the Brilliant Multiplex qPCR Master kit (Stratagene, La Jolla, CA, USA).

The primers and Taqman probes for mouse Bmp15 (accession number: AF082348.1), mouse Gdf9 (accession number: NH_008110.2) and the reference gene mouse Rpl19 (accession number: BC092539.1) were purchased from Invitrogen and Sigma-Proligo respectively (Invitrogen ${ }^{\mathrm{TM}} \mathrm{NZ}$ Ltd., Auckland 1006, New Zealand; Proligo-France SAS 1, Paris, France and Proligo-Singapore Pte Ltd, Helios, Singapore). Rpl19, encoding ribosomal protein 19, was shown to be a suitable reference gene in quantifying ovarian gene expression (Crawford and McNatty 2012). 
Table 2E: Primers, Taqman probes and final concentrations for use in multiplex qPCR reactions

\begin{tabular}{|c|l|c|}
\hline Gene & Primers (forward and reverse) and Taqman probes (P, 5'-3') & $\begin{array}{c}\text { Conc. } \\
\text { (nM) }\end{array}$ \\
\hline mBmp15 & Fwd: GTACAGACCCTGGACTTTCCTC (577-598) & 200 \\
(proregion & Rev: GGTAATTAACTAGATGAAGTTGATGGC (650-676) (607-640) & 300 \\
577-676) & P: (HEX)AACCAGGTAGCATACGAACTAATCAGAGCCACTG(BHQ1) & 50 \\
\hline mGdf9 & Fwd: ATCGGTCTTGCTATACACTCTGAA (585-608) & 300 \\
(proregion & Rev: GTGAATGAGTACGGTGCTCTTG (692-713) & 200 \\
585-713) & P: (6FAM)TCTGCCTCTTCCTCCTCCACTGTGACCT(BHQ1) (613-640) & 50 \\
\hline mRpl19 & Fwd: CAGGAAGCTGATCAAGGATGGG (141-162) & 200 \\
$(141-281)$ & Rev: CGAGCATTGGCAGTACCCTTC (261-281) & 200 \\
& P: (Cy5)CATCCGCAAGCCTGTGACTGTCCATTCC(BHQ3) (168-195) & 50 \\
\hline
\end{tabular}

HEX, 6FAM and Cy5 are fluorophores and BHQ1 and BHQ3 are quenchers. Numbers in brackets refer to the nucleotide positions.

\subsubsection{Multiplex qPCR reaction efficiencies}

Before the samples were analysed in the multiplex qPCR, it was of importance to determine the PCR reaction efficiency for each gene.

Serial dilutions of mouse COC-derived cDNA samples were prepared with ultrapure water, ranging from undiluted to $1: 128$ and these were tested first in singleplex, then duplex and finally in triplex reactions.

Briefly, the reaction mixes were prepared in $0.2 \mathrm{ml}$ microtubes by mixing the primers and TaqMan probes in the optimal concentrations, followed by the addition of $26 \mu \mathrm{l}$ of $2 \mathrm{x}$ Brilliant $^{\circledR}$ Multiplex qPCR Master Mix (Agilent Technologies), $3.12 \mu \mathrm{l}(2 \mathrm{x} 1.56 \mu \mathrm{l})$ of cDNA and ultra-pure water to bring the final sample volume $52 \mu 1$. After thorough mixing, the samples were split into two $25 \mu \mathrm{l}$ duplicates in $0.1 \mathrm{ml}$ strip-tubes (Corbett Research) and capped. The PCR amplification was carried out using the Rotor-Gene ${ }^{\mathrm{TM}} 6000$ Rotary Analyser (Corbett Research Ltd) running the program described in paragraph 2.5.2.1.

The amplification efficiencies were calculated by determining the line of best fit (slope \pm 0.1 ) for each gene, when $\mathrm{C}_{\mathrm{T}}$ values were plotted against the $\log$ concentration of total input RNA. The amplification efficiencies in the triplex reaction were $93 \%, 91 \%$ and $95 \%$ for the $\mathrm{mGdf9}, \mathrm{mBmp} 15$ and $\mathrm{mRpl} 19$ genes respectively. 
2.5.2.3 Quantification of gene expression by multiplex qPCR

All denuded oocyte (DO) and cumulus cell (CC) samples collected for qPCR analyses were tested for the expression levels of $\mathrm{mBmp15}, \mathrm{mGdf} 9$ and the housekeeping gene $\mathrm{m} R$ pl19.

The reaction mixes were prepared in $0.2 \mathrm{ml}$ microtubes, by mixing the 3 sets of primers and the probes at the optimal concentration with $26 \mu \mathrm{l}$ of $2 \mathrm{x}$ Brilliant $^{\circledR}$ Multiplex qPCR Master Mix (Agilent Technologies), $3.12 \mu 1$ of cDNA template and ultra-pure water to make a final sample volume of $52 \mu 1$. The reaction mixes were split into two $25 \mu \mathrm{l}$ aliquots in $0.1 \mathrm{ml}$ strip-tubes (Corbett Research). The PCR amplification was carried out using the Rotor-Gene ${ }^{\mathrm{TM}} 6000$ Rotary Analyser using the same program settings described in paragraph 2.1.2.1.

Each sample was analysed twice in separate qPCR runs and the $\mathrm{C}_{\mathrm{T}}$ value for each sample was calculated as the mean of the two technical repeats.

In each qPCR run, the No-RT PCR controls were included to show the effectiveness of the DNase treatment during RNA extraction. Calibrator controls were also used at the beginning and end of each run. These samples were aliquots of the same cDNA sample used throughout the entire experiment, with known $\mathrm{C}_{\mathrm{T}}$ values, to show the reproducibility and the stability of the multiplex qPCR runs.

The $\mathrm{C}_{\mathrm{T}}$ values of the target genes $\mathrm{mBmp} 15$ and $\mathrm{m} G d f 9$ were normalised to the $\mathrm{C}_{\mathrm{T}}$ values of the reference gene $\mathrm{m} R$ pl19. The $\mathrm{C}_{\mathrm{T}}$ values for the reference gene $\mathrm{m}$ Rpl19 were also used to determine whether the sample had enough RNA for the quantification of gene expression levels. Samples with an $\mathrm{m}^{2} p l 19 \mathrm{C}_{\mathrm{T}}$ value $>30$ were excluded from further analysis. Moreover, in cases where photographic evidence showed damage to the oocyte during sample collection, both the isolated $\mathrm{CC}$ and associated oocytes were excluded from analyses.

Expression levels of the target genes were calculated using a method described by Livak et al, 2001 (Livak and Schmittgen 2001), namely the 2(-Delta Delta C(T)) method. This method calculates relative changes in the target gene expression during qPCR analysis. The $\mathrm{C}_{\mathrm{T}}$ values of the target genes were normalised to the $\mathrm{C}_{\mathrm{T}}$ value of the reference gene, resulting in $\Delta \mathrm{C}_{\mathrm{T}}$ values for each sample. $\Delta \Delta \mathrm{C}_{\mathrm{T}}$ were calculated by normalising $\Delta \mathrm{C}_{\mathrm{T}}$ values to the mean $\Delta \mathrm{C}_{\mathrm{T}}$ value measured in 
samples collected from control animals (Group 1 - see section 2.1.2.1. for treatment details). These values were converted to linear values for statistical analysis, using the formula $2^{-\left(\Delta \Delta \mathrm{C}_{\mathrm{T}}\right)}$. Standard errors of mean (SEM) were calculated by formula $2^{-(\text {mean } \Delta \Delta \mathrm{CT} \pm \mathrm{StDev})}$, where $\mathrm{StDev}$ stands for standard deviation.

The ratio of mRNA expression levels of the two target genes $\mathrm{mBmp} 15$ and $\mathrm{mGdf} 9$ were established using the formula $\left.2^{-(\mathrm{m} G d f 9 \mathrm{C}} \mathrm{T}_{\mathrm{T}}-\mathrm{mBmp} 5 \mathrm{C}_{\mathrm{T}}\right)$. The line of best fit was generated from the plot of linear regression of the $C_{T}$ values of the two target genes, to calculate the correlation coefficients $\left(\mathrm{R}^{2}\right)$. The closer the $\mathrm{R}^{2}$ value is to 1 , the stronger the correlation between the two genes.

\subsection{Generating non-cleavable forms of mouse BMP15 and GDF9 proproteins}

Human embryonic kidney (HEK) cells (originally gifted by Professor Olli Ritvos, Helsinki, Finland) were stably transfected with plasmid constructs containing full-length sequences of mouse Bmpl5 and Gdf9 mutated at the proregion-mature region cleavage site with the aim of expression of non-cleavable precursor forms of mouse BMP15 and mouse GDF9 proteins.

2.6.1 Designing the non-cleavable gene constructs

The non-cleavable forms of the target proteins were designed with mutated putative furin cleavage sites, in order to prevent the enzyme from recognising and releasing the mature protein from the full-length precursor promature protein. The mBMP15 protein cleavage site, RSVR and the mGDF9 cleavage site, RRRR were both modified to QXXQ, where X was kept to the original amino acid in the wild-type sequence. A protein and base substitution table was used to design the mutated $m B m p 15$ and $m G d f 9$ cleavage site sequences (see Table $2 \mathrm{~F}$ ). The guanine to adenine base substitution in the coding sequences of both gene cleavage sites was chosen because of its perceived minimal impact on protein structure. In both cases the base substitution caused peptide change from arginine to glutamine, thus keeping the same charge and polarity. 
Table 2F: $\mathrm{mBmp} 15$ and $\mathrm{m} G d f 9$ sequences, with mutated cleavage sites highlighted in bold, and base substitutions highlighted in red

\begin{tabular}{|c|c|}
\hline $\begin{array}{l}\text { mBmp15 } \\
\text { (1209 bp) } \\
\text { sequence: }\end{array}$ & $\begin{array}{l}\text { GAGCTCCCGCTCGAGCTTTGCAAGATGGCCCTTCTCACAATTCTTAGAAT } \\
\text { TCTTTTGTGGGGAGTGGTGCTTTTTATGGAACAGAGGGTCCAAATGGCA } \\
\text { AAGCCAGGGTGGCCCTCCACCGCCCTCCTTGCTGACGACCCTACATTGC } \\
\text { CCTCAATTTTGGATCTGGCCAAAGAAGCCCCGGCAAGGAGATGAAGCA } \\
\text { ATGGCCCCAAGGCTATCCCCTGAGGTACATGCTCAAGTTATACCATCGT } \\
\text { TCGGCTGACCCGCATGGCCATCCAAGGGAGAACCGCACGATTGGAGCG } \\
\text { AAAATGGTGAGGCTGGTAAAGCCGTCGGCCAACACAGTAAGGCCTCCC } \\
\text { AGAGGTTCCTGGCATGTACAGACCCTGGACTTTCCTCTAGCATCAAACC } \\
\text { AGGTAGCATACGAACTAATCAGAGCCACTGTGGTTACCGCCATCAACT } \\
\text { TCATCTAGTTAATTACCATCTCTCCTGCCATGTGGAAACTTGGTTCCTA } \\
\text { AATGCCGGACCAAGCACTTACCTTCTTCTAAATCGGGTTCCTCAAAGCCT } \\
\text { TCTCCCATGTCTAAAGCCTGGACAGAGATAGATATTACACATTGTATTC } \\
\text { AGCAGAAGCTCTGGAATCGCAAGGGACGGAGTGTTCTTCGCCTCCGCTT } \\
\text { CATGTGTCAGCAGCAAAAAGGCAATGAGACTCGTGAGTCCGGTGGCAT } \\
\text { GGCATGACATCCTTGGATGTTGCCTTCTTGCTACTCTATTTCAATGACAC } \\
\text { CGATGACAGAGTCAGGGTAAACTTCTTGCAAGAGGCCAAGAGGAGTT } \\
\text { AACTGATAGGGAATCTTCTTTTCTCATGCAGAGTGTCCAGCAAGCATGC } \\
\text { AGCATTGAATCTGATGCCTCTTGTCCTTCTCAGGAACATGATGGGTCTGT } \\
\text { AAATAACCAGTGTTCCCTCCATCCTTACAAGGTCAGCTTCCACCAACTA } \\
\text { GGCTGGGATCACTGGATCATTGCTCCTCGTCTCTATACCCCAAATTACTG } \\
\text { TAAAGGAATCTGTACTCGGGTATTACCCTATGGTCTCAATTCACCCAACC } \\
\text { ATGCCATCATTCAGAGCCTTGTCAATGACTAGTGAATCACAGTGTACC } \\
\text { TCAGCCTTCCTGTGTCCTTATAATTTCTTCCTATGAGCATCCTCCTGAT } \\
\text { TGAGACCAACGGGAGTATCTTGTACAAGGAGTATGAGGGTATGATTGCC } \\
\text { CAGTCCTGTACATGTAGATAATCTAGA }\end{array}$ \\
\hline $\begin{array}{l}\mathrm{m} G d f 9 \\
(1350 \mathrm{bp}) \\
\text { sequence: }\end{array}$ & $\begin{array}{l}\text { CCGCTCGAGTCCCAAGTCATGGCACTTCCCAGCAACTTCCTGTTGGGGG } \\
\text { TTTGCTGCTTTGCCTGGCTGTGTTTCTTAGTAGCCTTAGCTCTCAGGCTT } \\
\text { CTACTGAAGAATCCCAGAGTGGAGCCAGTGAAAATTGGATCTGAGG } \\
\text { CAGACCCCTGTCCTTGCTGCTGCTGTAGATGGGACTGACAGGTCTGG } \\
\text { CCTCTTGCCCCCCCTCTTAAGGTTCTATCTGATAGGCGAGGTGAGACCC } \\
\text { CTAAGCTGCAGCCTGACTCCAGAGCACTCTACTACATGAAAAAGCTCTA } \\
\text { TAAGACGTATGCTACCAAAGAGGGGTCCCAAACCCAGCAGAAGTCA } \\
\text { CCTCTACAATACCGTCCGGCTCTTCAGTCCCTGTGCCCAGCAAGAGCAG } \\
\text { GCACCCAGCAACCAGGTGACAGGACCGCTGCCGATGGTGGACCTGCTGT } \\
\text { TTAACCTGGACCGGGTGACTGCCATGGAACACTTGCTCAAATCGGTCTT } \\
\text { GCTATACACTCTGAACAACTCTGCCTCTTCCTCCTCCACTGTGACCTGTA } \\
\text { TGTGTGACCTTGGGTAAAGGAGGCCATGTCTTCTGGCAGGGCACCCCC } \\
\text { AAGAGCACCGTACTCATTCACCCTGAAGAAACACAGATGGATTGAGATT } \\
\text { GATGTGACCTCCCTCCTTCAGCCCCTAGTGACCTCCAGCGAGAGGAGCA } \\
\text { TTCACCTGTCTGTCAATTTACATGCACAAAAGACCAGGTGCCAGAGGA } \\
\text { CGGAGTGTTTAGCATGCCTCTCTCAGTGCCTCCTTCCCTCATCTTGTATCT } \\
\text { CAACGACACAAGCACCCAGGCCTACCACTCTTGGCAGTCTCTTCAGTCC } \\
\text { ACCTGGAGGCCTTTACAGCATCCCGGCCAGGCCGGTGGGCTGCCCGTC } \\
\text { CCGTGAAAGAGGAAGCTATTGAGGTGGAAAGATCTCCCCAGCGCCGTC } \\
\text { AAGGGCAGAAAGCCATCCGCTCCGAAGCGAAGGGGCCACTTCTTACAG } \\
\text { CATCCTTCAACCTCAGCGAATACTTCAAACAGTTTCTTTCCCCCAAAAC } \\
\text { GAGTGTGAACTCCATGACTTCAGACTGAGTTTAGTCAGCTCAAATGGG } \\
\text { ACAACTGGATCGTGGCCCGGACAGGTACAACCCTAGGTACTGTAAAGG } \\
\text { GGACTGTCCTAGGGCGGTCAGGCATCGGTACGGCTCTCCTGTGCACACC } \\
\text { ATGGTCCAGAATATAATCTATGAGAAGCTGGACCCTTCAGTGCCAAGGC } \\
\text { CTTCGTGTGGCCGGGCAAGTACAGCCCCTGAGTGTGTGACCATTGA } \\
\text { ACCCGACGGCTCCATCGCTTACAAAGAGTACGAAGACATGATAGCTACG } \\
\text { AGGTGCACCTGTCGTTAGTCTAGA }\end{array}$ \\
\hline
\end{tabular}


The gene constructs were designed to be flanked by artificial cut sites. The $\mathrm{mBmp} 15$ construct had been cloned into pUC57 vector between the SacI and XbaI cut sites. The mGdf9 sequence was cloned into pUC57 in the more commonly used EcoRV site (see Figure 2D). The gene constructs were purchased from GenScript USA Inc. (Piscataway, NJ, USA).

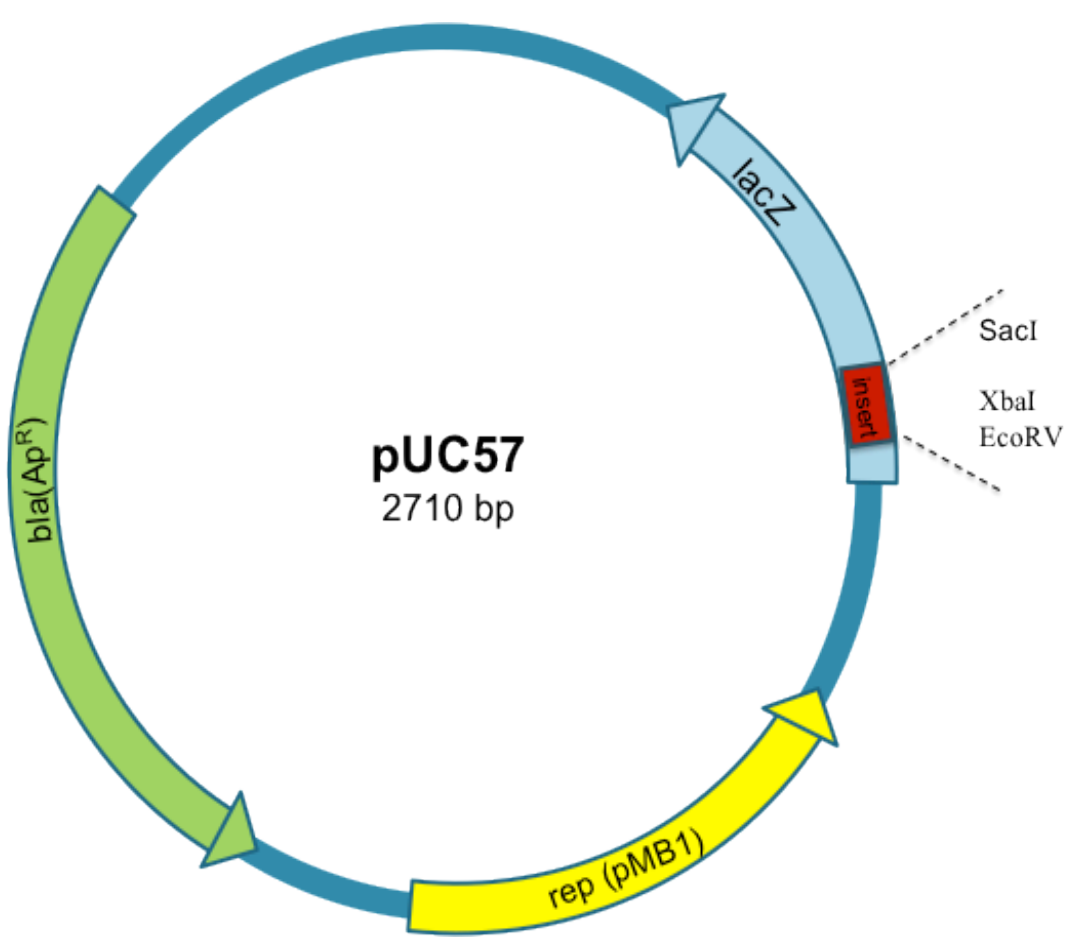

Figure 2D: Plasmid cloning vector pUC57 with utilised restriction enzyme cut sites

Restriction enzyme digests were set up (see sections 2.3.1 and 2.3.2 for protocols) using $0.5-1 \mu \mathrm{g}$ of each purified DNA sample to cut the DNA inserts from the pUC57 vector.

The restriction enzymes used to digest both the mBmp15 and mGdf9 miniprep DNA samples were XhoI and XbaI, because both inserts have XhoI and XbaI cut sites at the $5^{\prime}$ and $3^{\prime}$ ends respectively. The digests were carried out at $37^{\circ} \mathrm{C}$ for 2 $\mathrm{h}$ and then the reaction was stopped by incubation at $65^{\circ} \mathrm{C}$ for $5 \mathrm{~min}$. The DNA 
digests were mixed with SYBRE Green dye and run on a $1 \%$ agarose gel at $100 \mathrm{~V}$ for $1 \mathrm{~h}$.

The correct size bands were excised under a UV lamp, followed by gel extraction using QIAquick $^{\circledR}$ Gel Extraction kit (QIAGEN, Cat. No. 28704). An aliquot of pEFIRES cloning vector was linearised by digestion using the same two restriction enzymes described above, $\mathrm{XbaI}$ and $\mathrm{XhoI}$. A ligation mix was prepared for each gene by mixing $5 \mu \mathrm{l}$ of $2 \mathrm{x}$ ligase buffer (10X), $1 \mu \mathrm{l}$ of linearised pEFIRES plasmid vector, $3 \mu 1$ of linearised DNA insert and $1 \mu 1$ of T4 DNA ligase. The ligation mix was incubated for $2 \mathrm{~h}$ at room temperature and then used to transfect the DH5 $\alpha$ cells in order to amplify the pEFIRES plasmids containing the target DNA inserts. The transformation, colony selection, miniprep purification and linearization of the DNA inserts were carried out as before.

\subsubsection{HEK 293 cell transfection}

The HEK 293 cell line was chosen for this experiment because of its known ability to produce biologically active, correctly folded proteins, as opposed to E. coli. HEK 293 cells were transfected with the non-cleavable mBmp15 and mGdf9 gene constructs, using Fugene 6 transfection reagent (Roche, Cat. No. 04 709705 001), as described previously (McNatty, Juengel et al. 2005b). To prepare 293 HEK cells for transfection, the cells were cultured in 6-well tissue culture plates (BD Falcon ${ }^{\mathrm{TM}}$, Cat. No. 353934) to $60-80 \%$ confluence in Dulbecco modified Eagle medium (DMEM, Invitrogen), supplemented with 10\% fetal calf serum (Invitrogen), 2mM L-glutamine (Glutamax, Invitrogen) and 100 unit/ml penicillin, $100 \mathrm{mg} / \mathrm{ml}$ streptomycin. Pre-warmed Fugene 6 reagent $(4 \mu \mathrm{l})$ was mixed with $2 \mu \mathrm{g}$ DNA construct in pEFIRES plasmid vector and $100 \mu \mathrm{l}$ serum free medium (DMEM/L-glutamine). The transfection mix was incubated for 15 min at room temperature, to allow lipid complexes to form, then added to the cells in a drop wise manner. The plates were mixed gently and placed in a $37 \mathrm{C}^{\circ}$ tissue culture incubator under $5 \% \mathrm{CO}_{2}, 95 \%$ humidity for 24 hours. 


\subsubsection{Selection}

After $24 \mathrm{~h}$ incubation, successfully transfected 293 HEK cells were selected by their resistance to puromycin (Invitrogen). The spent/conditioned culture media was replaced with fresh media containing $1 \mu \mathrm{g} / \mathrm{ml}$ of puromycin. Every 3-4 days the cells were trypsinised from the plates by removing the spent media and dead cells, washing the cell layers with PBS, followed by incubation with $1 \mathrm{ml}$ of trypsin for 3 minutes at $37^{\circ} \mathrm{C}$. After the incubation, fresh culture medium (without Puromycin) was added to the wells to neutralise the trypsin. The cells were pooled into a $15 \mathrm{ml}$ Falcon tube and pelleted by centrifugation at $150 \mathrm{~g}$ for $5 \mathrm{~min}$ at room temperature. After one further wash with warm cell culture medium, the cells were re-plated in fresh 293 cell culture medium, containing increased amounts of puromycin, up to $100 \mu \mathrm{g} / \mathrm{ml}$.

\subsubsection{Protein production}

When the HEK 293 cells were growing steadily in culture media containing $100 \mu \mathrm{g} / \mathrm{ml}$ puromycin, ten $75 \mathrm{~cm}^{2}$ cell culture flasks (BD Falcon ${ }^{\mathrm{TM}}$, Cat. No. 353136) were seeded at 1:5 dilution with the transfected 293 cells for each gene to prepare the cells for exogenous protein production. At $90 \%$ confluence, the culture medium was replaced with protein production medium, prepared with DMEM:Hams F12 at 1:1 ratio (both from Invitrogen), 0.01\% BSA (Sigma), 2 mM L-glutamine (Glutamax, Invitrogen), 100 unit/ml penicillin, 100 $\mathrm{mg} / \mathrm{ml}$ streptomycin and $100 \mu \mathrm{g} / \mathrm{ml}$ heparin (Sigma). The 293 HEK cell layer was washed once with PBS, then $15 \mathrm{ml}$ of protein production media was added to each tissue culture flask. The 293 cells were incubated with the protein production medium at $37 \mathrm{C}^{\circ}$, under $5 \% \mathrm{CO}_{2}$ and $95 \%$ humidity for 3.5 days.

The conditioned media containing the proteins of interest was harvested after 3.5 days and stored frozen at $-80^{\circ} \mathrm{C}$ until used in methyl- ${ }^{3} \mathrm{H}$-thymidine uptake assays. The HEK 293 cells were also harvested and frozen in RIPA lysis buffer (see Appendix I) for subsequent analysis by Western blotting to confirm that the cells produced the non-cleavable forms of mBMP15 and mGDF9. In addition, an 
aliquot from each of the transfected HEK 293 cell preparations were subjected to RNA extraction and cDNA synthesis, using the ArrayPure ${ }^{\mathrm{TM}}$ Nano-scale RNA purification kit (EPICENTRE Biotechnologies, MPS04050, Wisconsin, USA) and the Superscript ${ }^{\circledR}$ VILO $^{\text {TM }}$ cDNA synthesis kit (Cat. No. 11754-050, Invitrogen, CA, USA) as described in section 2.4.1. Full length mouse Bmp15 and Gdf9 were amplified using primers described in Table 2G. Following gel extraction and miniprep purification, the DNA samples were sent to the Waikato DNA sequencing facility to confirm that the HEK 293 cells contained the modified, non-cleavable mouse BMP15 and GDF9 coding sequences. Aliquots of noncleavable mBMP15 and mGDF9 conditioned media were used to quantify the non-cleavable protein content by Western blotting and densitometry.

Table 2G: Primers used to amplify full-length $\mathrm{mBmp} 15$ and $\mathrm{m} G d f 9$ from transfected 293 HEK cell lysates

\begin{tabular}{|c|l|c|}
\hline Gene & \multicolumn{1}{|c|}{ Primers } & $\begin{array}{c}\text { Nucleotide } \\
\text { Position }\end{array}$ \\
\hline mBmp15 & Fwd: CCGCTCGAGCTTTGCAAGATGGCCCTTCTC & $225-255$ \\
& Rev: GCTCTAGATTATCTACATGTACAGGACTG & $1402-1428$ \\
\hline mGdf9 & Fwd: CCGCTCGAGTCCCAAGTCATGGCACTTC & $106-130$ \\
& Rev: GGAATTCCTAACGACAGGTGCACCTCGTAG & $1424-1451$ \\
\hline
\end{tabular}

\subsection{Methyl- ${ }^{3}$ H-thymidine uptake assay}

The rat granulosa cells (GC) and denuded oocytes (DO) were collected and prepared as described in section 2.1.2.5.

Care was taken to keep the $\mathrm{GC}$ and $\mathrm{DO}$ as close as possible to $37^{\circ} \mathrm{C}$ during the culture set up, since this was shown to be essential for maintaining cell viability. The growth factor combinations tested in a series of methyl- ${ }^{3} \mathrm{H}$-thymidine uptake assays ( $\mathrm{n}=5$ assays on $\mathrm{n}=5$ individual pools of cells) were combinations of wildtype and non-cleavable mouse BMP15 and ovine GDF9. The method for generating the non-cleavable form of BMP15 is described in section 2.6. 
Master mixes containing the treatments and GC suspension at 1000 cells/ $\mu 1$ were prepared and aliquoted into 96 well plates with 5 wells/treatment (NUNC, Cat. No. 167008). The final cell concentration was 20,000 cells/well in a total volume of $55 \mu 1$. The growth factor treatments were kept at $8 \%$ of the total volume per well to avoid the HEK 293 cell culture media effecting GC proliferation, as described elsewhere (Edwards, Reader et al. 2008; McIntosh, Lun et al. 2008). Where the treatment volume did not amount to $8 \%$ of the total volume per well, 'empty' HEK 293 cell culture media (harvested from cells transfected with pEFIRES plasmid vector only) was used to standardise the treatment volume to $8 \%$.

The negative control for each assay was 20,000 rat GC, treated with $8 \%$ 'empty' HEK 293 cell culture media. Three sets of positive controls were used. The addition of $32 \mathrm{DO}$ to GC cultures is known to dramatically increase granulosa cell culture proliferation (Lin, Pitman-Crawford et al. 2012), as well as the combination of wild-type mouse BMP15 and ovine GDF9 conditioned media (6ng/ml and $60 \mathrm{ng} / \mathrm{ml}$ respectively), shown to increase rat GC proliferation 3-7 fold (McNatty, Juengel et al. 2005b; McIntosh, Lun et al. 2008). The third positive control, namely recombinant human (rh) activin A treatment at $100 \mathrm{ng} / \mathrm{ml}$ (R\&D Systems, Cat. No. 338-AC-010), has also been shown to produce 2-7 fold increase in rat GC proliferation (Miro and Hillier 1996); this latter effect is comparable to the synergistic effects of the mouse BMP15 and ovine GDF9 combined treatment as measured by ${ }^{3} \mathrm{H}$-thymidine uptake.

The plate with all controls and test treatments was incubated for $16-18 \mathrm{~h}$ at $37^{\circ} \mathrm{C}$, 95\% humidity under $5 \% \mathrm{CO}_{2}$. Following the incubation period each well was treated with $10 \mu \mathrm{l}$ of methyl- ${ }^{3} \mathrm{H}$-thymidine (Perkin Elmer, cat. No. NET355001MC, 1mCi) diluted 1:24 with the cell culture media. The plate was carefully mixed by tapping on the sides and placed back in the incubator for $6 \mathrm{~h}$. At the end of the $6 \mathrm{~h}$ incubation, the cells from each plate were harvested onto a $90 \times 120$ mm glass fibre mat (Perkin Elmer, printed Filtemat A, Cat. No. 1450421), using a cell harvester (TOMTEC, mod. No. MACH 3-FM series). The filter mat was dried and heat sealed (Wallac heat sealer, mod. No. 1295-012) in a plastic sleeve (Perkin Elmer sample bag, Cat. No. 1450-432) with $5 \mathrm{ml}$ of scintillation fluid (Beta Scint, Perkin Elmer, Cat. No. SC/9200.21). The ${ }^{3} \mathrm{H}-$ 
thymidine uptake was measured using a beta counter (Perkin Elmer, 1450-SLC MicroBetaTriLux) and reported as cpm (count per minute) per well, accumulated over a 2 min interval. 


\section{Chapter 3: BMP15 and GDF9 expression in the mouse ovary}

\subsection{Introduction and Aim}

As outlined in Chapter 1, BMP15 and GDF9 are important regulators of follicular development in mammals (McGrath, Esquela et al. 1995; Dong, Albertini et al. 1996; Dube, Wang et al. 1998; Laitinen, Vuojolainen et al. 1998; Aaltonen, Laitinen et al. 1999; Elvin, Clark et al. 1999; Galloway, McNatty et al. 2000; Eppig, Wigglesworth et al. 2002; Juengel and McNatty 2005). These proteins are known to act synergistically (Yan, Wang et al. 2001; Liao, Moore et al. 2003; Su, Wu et al. 2004; McNatty, Juengel et al. 2005a; McNatty, Juengel et al. 2005b; McIntosh, Lun et al. 2008; Reader, Heath et al. 2011; Mottershead, Ritter et al. 2012) and in a species-specific manner (Moore, Erickson et al. 2004; McNatty, Juengel et al. 2005a; McNatty, Juengel et al. 2005b; Reader, Heath et al. 2011; Lin, Pitman-Crawford et al. 2012) to affect a number of intrafollicular events throughout follicular development.

The species specificity of BMP15 and GDF9 has been partially attributed to the differences of their expression patterns in different mammalian species. In some species, such as the sheep, cow (Bodensteiner, Clay et al. 1999; Crawford and McNatty 2012), pig, deer (Crawford and McNatty 2012), hamster (Wang and Roy 2004), possum (Eckery, Whale et al. 2002) and human (Aaltonen, Laitinen et al. 1999), these proteins are reportedly produced only by the oocyte in the developing follicle. However, BMP15 and GDF9 expression has also been detected in somatic follicular cells in goats (Silva, van den Hurk et al. 2005) and cows (Hosoe, Kaneyama et al. 2011), whilst BMP15 alone was shown to be expressed by porcine somatic follicular cells (Paradis, Novak et al. 2009) and GDF9 was detected in somatic follicular cells of some primates (Duffy 2003). 
In the mouse, there are also conflicting reports in the literature regarding the localisation and levels of expression for both BMP15 and GDF9 mRNA and protein, most noticeably around the time of the preovulatory LH surge. A number of studies show Bmp15 and Gdf9 mRNA expression exclusively in the mouse oocyte (McGrath, Esquela et al. 1995; Dong, Albertini et al. 1996; Dube, Wang et al. 1998; Laitinen, Vuojolainen et al. 1998; Crawford and McNatty 2012), but there is no consensus as to the timing of protein production and localisation of the different protein forms.

The biologically active mature BMP15 protein was detected throughout follicular development in the mouse oocyte, as well as in the follicular fluid and the expanded cumulus mass in the preovulatory follicle (Gueripel, Brun et al. 2006). This was contradicted by reports that mouse BMP15 protein production was only up-regulated to a detectable level just before ovulation (Yoshino, McMahon et al. 2006). The non-cleaved promature precursor proteins and the proregions of mouse BMP15 and GDF9 have not yet been characterised in the mouse ovary. However, there is evidence for the proregion to play an important role in follicular development. Immunisation against the BMP15 proregion resulted in decreased ovulation rate while immunisation against the GDF9 proregion resulted in an increase in ovulation rate (McIntosh, Lawrence et al. 2012). However, both immunisations led to a smaller litter size in mice and therefore lowered fertility (McIntosh, Lawrence et al. 2012).

The aims of the experiments in this chapter were to:

i) determine if Bmpl5 and Gdf9 mRNA and protein are produced exclusively by the oocyte in mice

ii) investigate if BMP15 and GDF9 mRNA expression and protein production levels change during follicular development

iii) map (characterise) the localisation patterns of different BMP15 and GDF9 protein forms in the mouse follicle. 


\subsection{Method Optimisation}

The application of several different techniques were utilised to characterise the expression patterns of Bmp15 and Gdf9 mRNA (in situ hybridisation, qPCR) as well as the protein forms (Western blotting) in the mouse follicle. All protocols for these techniques are described in detail in Chapter 2, whilst the aim here is to describe the optimisation and troubleshooting of the above-mentioned methods.

\subsubsection{In situ hybridisation (ISH)}

ISH allowed the localisation of expression of genes responsible for the production of BMP15 and GDF9 proteins, using radio-labelled riboprobes to pinpoint the cellular location, thus answering the question of whether granulosa cells and/or cumulus cells are capable of producing these proteins or whether they are produced exclusively by the oocyte.

By using prepubertal mice primed with PMSG, PMSG + hCG or saline as a control, expression patterns were analysed in follicles at different stages of development: during the early (control) and late (PMSG only) follicular phases and after the preovulatory LH surge (PMSG + hCG).

The ISH method employed was modified from a previously published method (Tisdall, Hudson et al. 1994). The ${ }^{33} \mathrm{P}$ labelled riboprobes were designed to recognise the mature region of Bmpl5 and Gdf9 on $5 \mu \mathrm{m}$ pre-treated, paraffin embedded mouse ovarian sections. The original protocol called for overnight hybridisation of the tissue sections with $45000 \mathrm{cpm}$ radio-labelled probes per $\mu \mathrm{m}^{2}$ section, followed by 3 weeks of incubation of the slides in the darkroom after coating with autoradiographic silver emulsion. When using the original protocol, following development and haematoxylin staining, an overflow of silver grains, as visualised by both light field and dark field microscopy, was observed in the oocytes for both Bmp15 and Gdf9 in all follicles of all three treatment groups. The overflow signal made it impossible to determine whether the somatic follicular cells directly adjacent to the oocyte had specific riboprobe binding or if the signal was from over exposure. The somatic follicular cells further away from the oocyte 
and the rest of the ovarian tissue showed no signal above the background, neither did the sections hybridised with sense probes to serve as negative controls.

To reduce signal strength, two modifications were trialled successfully. In one set of experiments, the slides were hybridised with reduced-strength Bmp 15 and Gdf9 riboprobes. These were prepared by changing the ratio of $\left[{ }^{33} \mathrm{P}\right]$-UTP compared to 'cold' UTP in the riboprobes, but when this was not enough to sufficiently reduce the probe strength, the probes used in the overnight hybridisation step were diluted to $30,000 \mathrm{cpm} / \mu \mathrm{m}^{2}$, rather than the $45,000 \mathrm{cpm} / \mu \mathrm{m}^{2}$ described in the original protocol. The hybridisation step was followed by the usual 3 weeks of incubation and development.

In another experiment series, the tissue sections were hybridised with normal strength $\left(45,000 \mathrm{cpm} / \mu^{2}\right)$ riboprobes overnight, but the silver emulsion coated slides were incubated for only 1 week before developing.

Both measures yielded the expected results in reducing the signal strength in the oocytes, making it possible to determine if any cell type other than the oocyte showed radioactive Bmp15 or Gdf9 riboprobe binding in the mouse ovary.

In further ISH experiments $(n=3)$, the modified protocol requiring normal strength probe and only 1 week incubation time was used.

\subsubsection{Quantitative PCR (qPCR)}

It was considered that the sensitivity of the ISH method might not be sufficient to measure Bmp15 and Gdf9 expression below a certain threshold, thus leading to false negative results in cases where mRNA expression levels might be too low to distinguish from the background. Quantitative PCR (qPCR) - or realtime polymerase chain reaction - is a technique used to amplify and simultaneously quantify the expression level of a targeted DNA molecule. It enables both detection and quantification of a specific sequence in a DNA sample with high sensitivity. The use of the Superscript ${ }^{\circledR}$ VILO ${ }^{\text {TM }}$ cDNA synthesis kit (Invitrogen, CA, USA) to transcribe the extracted mRNA to cDNA, ensured that the mRNA to cDNA ratio was 1:1 and enabled the quantification of the initial target mRNA content in the samples. Multiplex qPCR analysis was used to quantify both target genes and a reference gene in the same sample, minimizing 
the sample mRNA required, thus enabling the detection and quantification of multiple genes in a single oocyte. The highly sensitive qPCR technique was suitable as a confirmation method for the gene expression data obtained using ISH. It was also used to quantify the expression levels of mouse Bmp15 and Gdf9 mRNA at different stages of ovarian follicular development, determining whether the expression levels of the target genes change during follicular growth.

The multiplex qPCR template, primer and probe optimization is explained in detail in Chapter 2, sections 2.5.2.1 and 2.5.2.2. The importance of using the purest possible sample preparation for qPCR analysis was highlighted during the sample collection method optimization. Somatic follicular cell and denuded oocyte (DO) samples were collected from the same three treatment groups of prepubertal mice as used in ISH and described in Chapter 2, section 2.1.2. A number of sample collection methods were trialled to ensure that following RNA extraction and cDNA synthesis, the concentration of the target genes was at a sufficient level to be measured by $\mathrm{qPCR}$ and at the same time to avoid cross contamination between cumulus cells and oocytes.

The use of the ArrayPure ${ }^{\mathrm{TM}}$ Nano-scale RNA purification kit from EPICENTRE Biotechnologies for RNA extraction ensured that a suitable amount of RNA was extracted from individual DO recovered from a range of small antral to large preovulatory follicles, or cumulus cells extracted from a single cumulus-oocyte complex (COC). The inclusion of mouse ribosomal protein L19 (Rpl19) in the multiplex qPCR reaction as reference gene ensured that samples with undetectable levels of mRNA were not included in any subsequent statistical analyses. MIQE guidelines recommend the use of a minimum of two reference genes in qPCR studies. However, it allows the use of only one reference gene if the expression level of the gene in question is proven to be stable under the experimental conditions (Bustin, Benes et al. 2009). Since the average Rpl19 $\mathrm{C}_{\mathrm{T}}$ values remained constant between the three treatment groups (mean $\mathrm{C}_{\mathrm{T}}$ values were 26.5, 27 and 25.6 in Control, PMSG and PMSG + hCG treatment groups respectively), Rpl19 proved to be an ideal reference gene in the present experimental series. It is also difficult to find ovarian reference genes that are not affected by treatments such as the superovulation treatment used in this study, which is another reason a single reference gene was used. Moreover, Rpl19 mRNA expression levels were 
also shown to correlate to cell number as well as total mRNA concentration in the samples (Ekart, McNatty et al. 2013).

The biggest challenge in this study was avoiding cross contamination between the oocyte and the corresponding cumulus cells during sample collection. It was not possible to collect pure mural granulosa cell (GC) populations as damage to any oocyte during collection of the $\mathrm{COC}$ resulted in oocyte contamination of the sample. Therefore, the primary focus was on collection of individual COC from all 3 treatment groups for qPCR analysis, following the method described by Crawford and McNatty (2012). The COC were separated into DO and cumulus cell (CC) fractions and analysed as individual samples. Photographic evidence was taken at each step of the sample collection process and used to determine false positive or false negative results caused by damage to the oocyte in the denuding process. It was observed that even the slightest damage to the oocyte resulted in false positive mRNA expression results in the corresponding cumulus cell samples, therefore photographs of the oocytes were carefully examined and any visible damage resulted in the $\mathrm{qPCR}$ data being excluded from further analysis for both the DO and corresponding CC sample. Being able to link the Bmp15 and Gdf9 gene expression in some CC samples to proven damage to the oocyte at sample collection highlighted the importance of the purity of samples when using highly sensitive detection methods such as qPCR.

\subsubsection{Western blotting}

Western blot analysis was used to assist in localising the presence of BMP15 and GDF9 protein within the mouse ovary during follicular development and also to visualise the different forms, such as the full-length precursor promature proteins, the proregions and the cleaved mature forms of BMP15 and GDF9. The same three treatment groups of mice as used for ISH and qPCR were established for sample collection to enable a protein comparison with the mRNA expression data obtained through ISH and qPCR. For sample collection details see Chapter 2, section 2.1.2.3. 
To detect BMP15 and GDF9 in mouse follicular cell samples, a number of commercially available or in-house antibodies (Figure 3A) were tested for specificity and sensitivity.

\subsubsection{Antibody selection}

Two in-house antibodies for GDF9 were tested, namely mab37A and mab47b (produced under contract to AgResearch by Prof Nigel Groome, Oxford Brookes University, UK). Both monoclonal antibodies were designed to recognise the mature forms of ovine GDF9. Mab37a was generated against E. coli expressed mature ovine GDF9 (Reproduction Laboratory, AgResearch Ltd, Wallaceville Animal Research Centre, Upper Hutt, NZ) and was shown to be successful in recognising mouse mature GDF9 protein in 293 HEK cell expressed GDF9 conditioned media (McIntosh, Lun et al. 2008). Mab47b was generated against the mature GDF9 protein sequence SEYFKQFLFPQNEC, fully conserved between mouse and sheep. It has also been shown to immunoneutralise 293 HEK cell derived mouse GDF9 (McIntosh, Lun et al. 2008). Insufficient quantities of antisera validated previously for the proregion and promature form of mouse GDF9 (McIntosh, Lun et al. 2008) were available for this study. Therefore, another polyclonal mouse antisera 4e, produced against the same mouse GDF9 peptide (PVDGTDRSGLLPPLFKVL) and at the same time as the antisera previously validated (McIntosh, Lun et al. 2008) (Reproduction Laboratory, Victoria University of Wellington, Wellington NZ), was trialled for its ability to recognise the proregion and the non-cleaved promature form of mouse GDF9.

The two commercially available BMP15 antibodies tested in this study for their ability to recognise the mature form of the mouse BMP15 protein were sc-28911 (H-83) and sc-18337 (A-20) from Santa Cruz Biotechnology, Inc., Dallas, Texas, USA.

$\mathrm{H}-83$ is a rabbit polyclonal $\mathrm{IgG}$, raised against the human BMP15 sequence QADGISAEVTASSSKHSGPENNQCSLHPFQISFRQLGWDHWIIAPPFYTPN YCKGTCLRVLRDGLNSPNHAIIQNLINQLVDQ, near the C-terminus of the protein. According to the manufacturer, it is able to recognize mouse, rat, and 
human mature BMP15 protein. A blocking peptide for this antibody was not supplied by the manufacturer.

A-20 is a goat polyclonal $\mathrm{IgG}$, raised against an undisclosed internal region of human BMP15, but was used to recognize mouse mature BMP15 protein by Dr Robert Gilchrist's laboratory at the Research Centre for Reproductive Health, University of Adelaide, Australia (Mester et al 2013, submitted manuscript). A-20 is supplied with a blocking peptide (Santa Cruz, Cat. No. sc-18337P) by the manufacturer. To visualize the proregion form of mouse BMP15, a polyclonal mouse antisera $8 \mathrm{f}$ was used. This antibody was raised against the mouse BMP15 proregion sequence ADDPTLPSILDLAKEAPG at the same time as another antisera was generated against the same sequence in a different mouse, as used and described by McIntosh, et al (2008).

In pilot experiments for the present study, mab37a was successful in recognising 293 HEK cell-expressed mouse GDF9 mature protein in conditioned media, therefore this media was used in the Western blot assays as a positive control (Figure 3B). The antibody also identified a protein band corresponding in size to the uncleaved promature form of mouse GDF9 $(60 \mathrm{kDa})$ when DO lysates from the control, PMSG or PMSG + hCG treatment groups ( $\mathrm{n}=100 \mathrm{DO} /$ treatment group) were loaded onto the SDS PAGE gel. The same protein band was also observed in granulosa cell lysates $\left(5 \times 10^{5}\right.$ cells $)$ from the $\mathrm{PMSG}+\mathrm{hCG}$ treatment group. However, when the immunoblot detection was repeated using preadsorbed mab37a to test the specificity of these protein bands, the background was too high to determine if the protein bands in question were still present following detection with the preadsorbed antibody. 
Wild-type mouse BMP15

\begin{tabular}{|c|c|c|c|c|c|c|c|c|c|c|c|c|c|c|c|c|c|c|c|}
\hline $\mathrm{M}$ & A & $\mathrm{L}$ & $\mathrm{L}$ & $\mathrm{T}$ & $I$ & $\mathrm{~L}$ & $\mathrm{R}$ & $I$ & $\mathrm{~L}$ & $\mathrm{~L}$ & W & $\mathrm{G}$ & V & V & $\mathrm{L}$ & $\mathrm{F}$ & $\mathrm{M}$ & $E$ & $Q$ \\
\hline $\mathrm{R}$ & V & $Q$ & $\mathrm{M}$ & A & $\mathrm{K}$ & P & G & W & P & S & $\mathrm{T}$ & A & $\mathrm{L}$ & $\mathrm{L}$ & $\mathrm{A}$ & D & D & $\mathrm{P}$ & $\mathrm{T}$ \\
\hline $\mathrm{L}$ & $\mathrm{P}$ & $S$ & $I$ & $\mathrm{~L}$ & $\mathrm{D}$ & $\mathrm{L}$ & $A$ & $\mathrm{~K}$ & $\mathrm{E}$ & $\bar{A}$ & $\mathrm{P}$ & $\mathrm{G}$ & K & $\mathrm{E}$ & $\mathrm{M}$ & K & $Q$ & W & $\mathrm{P}$ \\
\hline$Q$ & G & $Y$ & $P$ & $\mathrm{~L}$ & $\mathrm{R}$ & $Y$ & $\mathrm{M}$ & $\mathrm{L}$ & $\mathrm{K}$ & $\mathrm{L}$ & $Y$ & $\mathrm{H}$ & $\mathrm{R}$ & $S$ & A & D & $\mathrm{P}$ & $\mathrm{H}$ & G \\
\hline $\mathrm{H}$ & P & $\mathrm{R}$ & $\mathrm{E}$ & $\mathrm{N}$ & $\mathrm{R}$ & $\mathrm{T}$ & I & G & A & K & $\mathrm{M}$ & V & $\mathrm{R}$ & $\mathrm{L}$ & V & K & P & $S$ & A \\
\hline $\mathrm{N}$ & $\mathrm{T}$ & V & $\mathrm{R}$ & $\mathrm{P}$ & $\mathrm{P}$ & $\mathrm{R}$ & G & S & $W$ & $\mathrm{H}$ & $\mathrm{V}$ & $Q$ & $\mathrm{~T}$ & $\mathrm{~L}$ & D & $\mathrm{F}$ & P & $\mathrm{L}$ & A \\
\hline S & $\mathrm{N}$ & $Q$ & V & A & $Y$ & $\mathrm{E}$ & $\mathrm{L}$ & I & $\mathrm{R}$ & A & $\mathrm{T}$ & V & V & $Y$ & $\mathrm{R}$ & $\mathrm{H}$ & $Q$ & $\mathrm{~L}$ & $\mathrm{H}$ \\
\hline $\mathrm{L}$ & V & $\mathrm{N}$ & $Y$ & $\mathrm{H}$ & $\mathrm{L}$ & $S$ & C & $\mathrm{H}$ & V & $\mathrm{E}$ & $\mathrm{T}$ & $W$ & V & P & K & C & $\mathrm{R}$ & $\mathrm{T}$ & $\mathrm{K}$ \\
\hline $\mathrm{H}$ & $\mathrm{L}$ & $\mathrm{P}$ & $S$ & $S$ & $\mathrm{~K}$ & $S$ & G & $S$ & $S$ & K & $\mathrm{P}$ & $S$ & P & $\mathrm{M}$ & $S$ & K & $A$ & W & $\mathrm{T}$ \\
\hline $\mathrm{E}$ & $I$ & $\mathrm{D}$ & I & $\mathrm{T}$ & $\mathrm{H}$ & $\mathrm{C}$ & $I$ & $Q$ & $Q$ & K & $\mathrm{L}$ & $W$ & $\mathrm{~N}$ & $\mathrm{R}$ & K & G & $\mathrm{R}$ & $S$ & V \\
\hline $\mathrm{L}$ & $\mathrm{R}$ & $\mathrm{L}$ & $\mathrm{R}$ & $\mathrm{F}$ & $\mathrm{M}$ & $\mathrm{C}$ & $Q$ & $Q$ & $Q$ & K & G & $\mathrm{N}$ & $\mathrm{E}$ & $\mathrm{T}$ & $\mathrm{R}$ & $\mathrm{E}$ & $\mathrm{F}$ & $\mathrm{R}$ & $W$ \\
\hline $\mathrm{H}$ & G & $\mathrm{M}$ & $\mathrm{T}$ & $S$ & $\mathrm{~L}$ & D & V & A & $\mathrm{F}$ & $\mathrm{L}$ & $\mathrm{L}$ & $\mathrm{L}$ & Y & $F$ & $\mathrm{~N}$ & D & $\mathrm{T}$ & D & D \\
\hline $\mathrm{R}$ & V & $Q$ & G & K & L & $\mathrm{L}$ & A & $\mathrm{R}$ & G & $Q$ & $E$ & $\mathrm{E}$ & $\mathrm{L}$ & $\mathrm{T}$ & $\mathrm{D}$ & $\mathrm{R}$ & $\mathrm{E}$ & $S$ & $S$ \\
\hline $\mathrm{F}$ & L & $\mathrm{M}$ & $\mathrm{R}$ & $S$ & V & $\mathrm{R}$ & $Q$ & A & $\mathrm{C}$ & $\mathrm{S}$ & I & $\mathrm{E}$ & $\mathrm{S}$ & D & A & $\mathrm{S}$ & $\mathrm{C}$ & P & $S$ \\
\hline$Q$ & $\mathrm{E}$ & $\mathrm{H}$ & D & G & $S$ & $\mathrm{~V}$ & $\mathbb{N}$ & $\mathrm{N}$ & $Q$ & $\mathrm{C}$ & $S$ & L & $\mathrm{H}$ & $\mathrm{P}$ & $Y$ & K & $\mathrm{V}$ & $S$ & $\mathrm{~F}$ \\
\hline $\mathrm{H}$ & $Q$ & $\mathrm{~L}$ & G & W & D & $\mathrm{H}$ & W & $I$ & $I$ & A & $\mathrm{P}$ & $\mathrm{R}$ & $\mathrm{L}$ & $Y$ & $\mathrm{~T}$ & $\mathrm{P}$ & $\mathrm{N}$ & $Y$ & $\mathrm{C}$ \\
\hline $\mathrm{K}$ & $\mathrm{G}$ & $I$ & $\mathrm{C}$ & $\mathrm{T}$ & $\mathrm{R}$ & $\mathrm{V}$ & $\mathrm{L}$ & $\mathrm{P}$ & $Y$ & G & $\mathrm{L}$ & $\mathrm{N}$ & $\mathrm{S}$ & $\mathrm{P}$ & $\mathrm{N}$ & $\mathrm{H}$ & $\mathrm{A}$ & $I$ & I \\
\hline$Q$ & $\mathrm{~S}$ & L & V & $\mathrm{N}$ & $\mathrm{E}$ & L & V & $\mathrm{N}$ & $\mathrm{H}$ & $S$ & V & $\mathrm{P}$ & $Q$ & $\mathrm{P}$ & $\mathrm{S}$ & C & V & $\mathrm{P}$ & $Y$ \\
\hline$\vec{N}$ & $\mathrm{~F}$ & $\mathrm{~L}$ & $\mathrm{P}$ & $\mathrm{M}$ & $S$ & I & L & $\mathrm{L}$ & I & $\mathrm{E}$ & $\mathrm{T}$ & $\mathrm{N}$ & $\mathrm{G}$ & $S$ & I & $\mathrm{L}$ & $Y$ & K & $\mathrm{E}$ \\
\hline$Y$ & $E$ & G & $\mathrm{M}$ & I & A & $Q$ & $S$ & $\mathrm{C}$ & $\mathrm{T}$ & $\mathrm{C}$ & $\mathrm{R}$ & - & & & & & & & \\
\hline
\end{tabular}

Wild-type mouse GDF9

\begin{tabular}{|c|c|c|c|c|c|c|c|c|c|c|c|c|c|c|c|c|c|c|c|}
\hline $\mathrm{T}$ & $\mathrm{E}$ & $\mathrm{V}$ & K & $S$ & V & $\mathrm{F}$ & $\mathrm{H}$ & $\mathrm{T}$ & - & I & L & $F$ & K & D & $\mathrm{H}$ & A & $\mathrm{R}$ & A & $S$ \\
\hline $\mathrm{P}$ & $\mathrm{T}$ & $F$ & $\mathrm{R}$ & K & K & $\mathrm{T}$ & G & $\mathrm{T}$ & $\mathrm{R}$ & $\mathrm{R}$ & C & V & $\mathrm{P}$ & $S$ & - & $\mathrm{F}$ & $S$ & $Q$ & V \\
\hline $\mathrm{M}$ & $\mathrm{A}$ & $\mathrm{L}$ & $\mathrm{P}$ & $S$ & $\mathrm{~N}$ & $\mathrm{~F}$ & $\mathrm{~L}$ & $\mathrm{~L}$ & G & $\mathrm{V}$ & $\mathrm{C}$ & C & $\mathrm{F}$ & A & $W$ & $\mathrm{~L}$ & C & $\mathrm{F}$ & L \\
\hline S & $S$ & $\mathrm{~L}$ & S & $S$ & $Q$ & A & $S$ & $\mathrm{~T}$ & $\mathrm{E}$ & $\mathrm{E}$ & S & $Q$ & $S$ & G & A & S & $E$ & $\mathrm{~N}$ & $\mathrm{~V}$ \\
\hline $\mathrm{E}$ & $S$ & $\mathrm{E}$ & A & D & $\mathrm{P}$ & W & $S$ & L & $\mathrm{L}$ & L & $\mathrm{P}$ & $\mathrm{V}$ & $\mathrm{D}$ & G & $\mathrm{T}$ & $\mathrm{D}$ & $\mathrm{R}$ & $\mathrm{S}$ & $\mathrm{G}$ \\
\hline $\mathrm{L}$ & $\mathrm{L}$ & $\mathrm{P}$ & $\mathrm{P}$ & $\mathrm{L}$ & $F$ & $\mathrm{~K}$ & $\mathrm{~V}$ & $\mathrm{~L}$ & $S$ & D & $\mathrm{R}$ & $R$ & G & $\mathrm{E}$ & $\mathrm{T}$ & $\mathrm{P}$ & $\mathrm{K}$ & $\mathrm{L}$ & $\mathrm{Q}$ \\
\hline $\mathrm{P}$ & $\mathrm{D}$ & $S$ & $\mathrm{R}$ & $\mathrm{A}$ & $\mathrm{L}$ & $Y$ & $Y$ & $\mathrm{M}$ & K & K & $\mathrm{L}$ & $Y$ & K & $\mathrm{T}$ & $Y$ & A & $\mathrm{T}$ & K & $\mathrm{E}$ \\
\hline G & $\mathrm{V}$ & P & K & $\mathrm{P}$ & $S$ & $\mathrm{R}$ & S & $\mathrm{H}$ & $\mathrm{L}$ & $Y$ & $\mathrm{~N}$ & $\mathrm{~T}$ & $\mathrm{~V}$ & $\mathrm{R}$ & $\mathrm{L}$ & $\mathrm{F}$ & $S$ & $\mathrm{P}$ & C \\
\hline A & $Q$ & $Q$ & $E$ & $Q$ & A & P & $S$ & $\mathrm{~N}$ & $Q$ & V & $\mathrm{T}$ & G & $\mathrm{P}$ & $\mathrm{L}$ & $\mathrm{P}$ & $\mathrm{M}$ & V & D & $\mathrm{L}$ \\
\hline $\mathrm{L}$ & $\mathrm{F}$ & $\mathrm{N}$ & $\mathrm{L}$ & D & $\mathrm{R}$ & V & $\mathrm{T}$ & A & $\mathrm{M}$ & $\mathrm{E}$ & $\mathrm{H}$ & L & $\mathrm{L}$ & $\mathrm{K}$ & $S$ & $\mathrm{~V}$ & $\mathrm{~L}$ & $\mathrm{~L}$ & $Y$ \\
\hline $\mathrm{T}$ & L & $\mathrm{N}$ & $\mathrm{N}$ & $S$ & A & $S$ & $S$ & $S$ & $\mathrm{~S}$ & $\mathrm{~T}$ & V & $\mathrm{T}$ & $\mathrm{C}$ & $\mathrm{M}$ & C & D & $\mathrm{L}$ & V & V \\
\hline K & $\mathrm{E}$ & A & $\mathrm{M}$ & $S$ & $S$ & G & $\mathrm{R}$ & A & $\mathrm{P}$ & $\mathrm{P}$ & $\mathrm{R}$ & A & $\mathrm{P}$ & $Y$ & $S$ & $\mathrm{~F}$ & $\mathrm{~T}$ & $\mathrm{~L}$ & K \\
\hline $\mathrm{K}$ & $\mathrm{H}$ & $\mathrm{R}$ & $\mathrm{W}$ & I & $\mathrm{E}$ & I & $\mathrm{D}$ & V & $\mathrm{T}$ & $S$ & $\mathrm{~L}$ & L & Q & P & L & V & $\mathrm{T}$ & $S$ & S \\
\hline $\mathrm{E}$ & $\mathrm{R}$ & $\mathrm{S}$ & I & $\mathrm{H}$ & $\mathrm{L}$ & $S$ & V & $\mathrm{N}$ & $F$ & $\mathrm{~T}$ & $\mathrm{C}$ & $\mathrm{T}$ & K & D & Q & V & P & $E$ & D \\
\hline G & V & $\mathrm{F}$ & S & $\mathrm{M}$ & $\mathrm{P}$ & $\mathrm{L}$ & $S$ & V & $\mathrm{P}$ & P & $S$ & L & I & $\mathrm{L}$ & $Y$ & $\mathrm{~L}$ & $\mathrm{~N}$ & $\mathrm{D}$ & $\mathrm{T}$ \\
\hline S & $\mathrm{T}$ & $Q$ & $\mathrm{~A}$ & $Y$ & $\mathrm{H}$ & $\mathrm{S}$ & W & $Q$ & $\mathrm{~S}$ & L & $Q$ & $S$ & $\mathrm{~T}$ & W & $\mathrm{R}$ & $\mathrm{P}$ & $\mathrm{L}$ & $Q$ & $\mathrm{H}$ \\
\hline $\mathrm{P}$ & $\mathrm{G}$ & Q & A & G & V & A & A & $\mathrm{R}$ & P & V & K & $\mathrm{E}$ & $\mathrm{E}$ & A & I & $\mathrm{E}$ & $\mathrm{V}$ & $E$ & \\
\hline $\mathrm{R}$ & $S$ & $\mathrm{P}$ & $\mathrm{R}$ & $R$ & $\mathrm{R}$ & $\mathrm{R}$ & G & $Q$ & $\mathrm{~K}$ & A & $I$ & $\mathrm{R}$ & $S$ & $E$ & A & K & $\mathrm{G}$ & $\mathrm{P}$ & L \\
\hline $\mathrm{L}$ & $\mathrm{T}$ & $A$ & S & $\mathrm{F}$ & $\mathrm{N}$ & $\mathrm{L}$ & S & $E$ & $Y$ & $F$ & $\mathrm{~K}$ & $Q$ & $F$ & $\mathrm{~L}$ & $F$ & $\mathrm{P}$ & $Q$ & $\mathrm{~N}$ & $E$ \\
\hline C & $E$ & $\mathrm{~L}$ & $\mathrm{H}$ & $\mathrm{D}$ & $\mathrm{F}$ & $\mathrm{R}$ & $\mathrm{L}$ & $S$ & $\mathrm{~F}$ & $S$ & $Q$ & L & $\mathrm{K}$ & $\mathrm{W}$ & D & $\mathrm{N}$ & $\mathrm{W}$ & $I$ & $\mathrm{~V}$ \\
\hline A & $\mathrm{P}$ & $\mathrm{H}$ & $\mathrm{R}$ & $Y$ & $\mathrm{~N}$ & $\mathrm{P}$ & $\mathrm{R}$ & $Y$ & C & K & G & D & C & P & $\mathrm{R}$ & A & $\mathrm{V}$ & $\mathrm{R}$ & $\mathrm{H}$ \\
\hline $\mathrm{R}$ & Y & G & $S$ & $\mathrm{P}$ & V & $\mathrm{H}$ & $\mathrm{T}$ & $\mathrm{M}$ & $\mathrm{V}$ & Q & $\mathrm{N}$ & I & I & $Y$ & $\mathrm{E}$ & K & $\mathrm{L}$ & $\mathrm{D}$ & $\mathrm{P}$ \\
\hline S & $\mathrm{V}$ & $\mathrm{P}$ & $\mathrm{R}$ & $\mathrm{P}$ & $S$ & $\mathrm{C}$ & V & $\mathrm{P}$ & G & K & $Y$ & $S$ & $\mathrm{P}$ & L & $S$ & V & L & $\mathrm{T}$ & I \\
\hline $\mathrm{E}$ & $\mathrm{P}$ & D & $\mathrm{G}$ & $S$ & $I$ & A & $Y$ & K & $\mathrm{E}$ & $Y$ & $\mathrm{E}$ & $\mathrm{D}$ & $\mathrm{M}$ & $I$ & A & $\mathrm{T}$ & $R$ & $\mathrm{C}$ & $\mathrm{T}$ \\
\hline C & $\mathrm{R}$ & - & $\mathrm{H}$ & G & G & $\mathrm{H}$ & $F$ & $\mathrm{~N}$ & $\mathrm{~K}$ & $\mathrm{P}$ & A & W & Q & $\mathrm{S}$ & $\mathrm{N}$ & A & V & G & L \\
\hline $\mathrm{R}$ & V & $\mathrm{P}$ & G & $Q$ & $\mathrm{R}$ & A & $S$ & C & D & $\mathrm{Q}$ & $S$ & L & $\mathrm{R}$ & A & A & $Q$ & C & $\mathrm{T}$ & $\mathrm{L}$ \\
\hline C & $\mathrm{E}$ & $\mathrm{R}$ & $\mathrm{G}$ & $\mathrm{K}$ & $\mathrm{C}$ & V & $\mathrm{C}$ & G & - & A & $\mathrm{H}$ & $\mathrm{R}$ & V & $Q$ & $\mathrm{C}$ & $\mathrm{P}$ & - & $\mathrm{V}$ & - \\
\hline $\mathrm{R}$ & A & $\mathrm{H}$ & S & $\mathrm{L}$ & V & V & A & $I$ & $\mathrm{~N}$ & Q & V & $\mathrm{K}$ & C & $\mathrm{N}$ & $S$ & $\mathrm{~F}$ & G & $E$ & L \\
\hline$F$ & $\mathrm{~L}$ & $\mathrm{P}$ & $\mathrm{T}$ & $S$ & V & $\mathrm{V}$ & $F$ & $S$ & G & Q & $I$ & C & - & $\mathrm{H}$ & K & $S$ & $R$ & V & $\mathrm{E}$ \\
\hline
\end{tabular}

$\operatorname{mab} 47 \mathrm{~b}$

polyclonal mouse antisera $4 \mathrm{e}$

polyclonal mouse antisera $8 \mathrm{f}$

H83 potentially recognize

furin cut site 
Figure 3A: Wild-type mouse BMP15 (accession number: NP_033887.1 and GDF9 (accession number: NP 032136.2) precursor (promature) protein amino acid sequences and the known primary antibody target regions

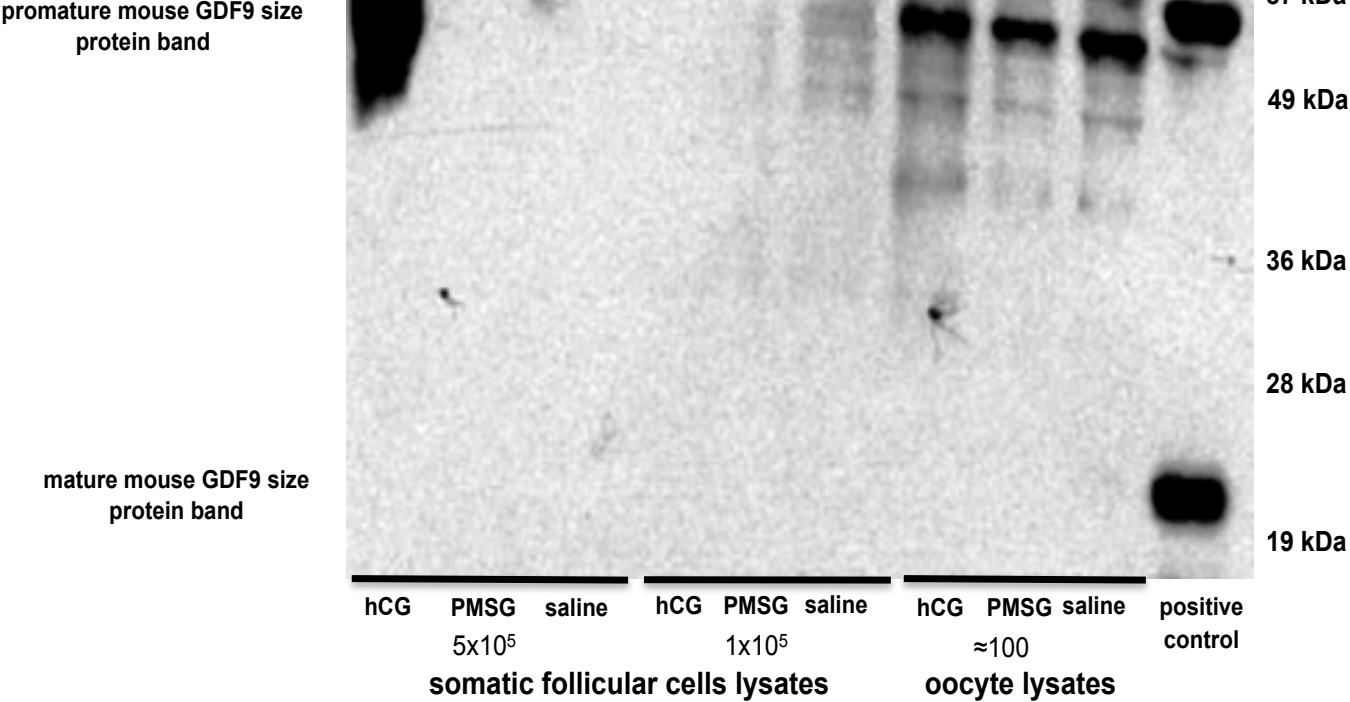

Figure 3B: Characterisation of mab37a. Protein bands detected in saline, PMSG and PMSG+hCG treated mouse ovarian follicular samples by Western blot analysis using mab37a as primary antibody. Protein molecule sizes in $\mathrm{kDa}$ are specified on the right and the protein forms described on the left side of the image. The positive control was HEK 293 cell derived wild-type mouse GDF9 conditioned media. The specificity of the bands could not be determined due to high background when the primary antibody was preadsorbed before immunoblotting.

Mab47b was also successful in recognising the positive control in the preliminary experiments and protein bands corresponding in size to known forms of mouse GDF9 in some of the cell lysate samples (i.e. DO from PMSG+hCG treated mice). Using preadsorbed mab47b antibody also resulted in high background after ECL development, but not to the extent that would make it impossible to recognise if the protein bands in question were still present after using the blocked antibody for immuno-detection (Figure 3C). For this reason, the rest of the Western blot studies were performed using mab47b for the detection of mouse GDF9. 


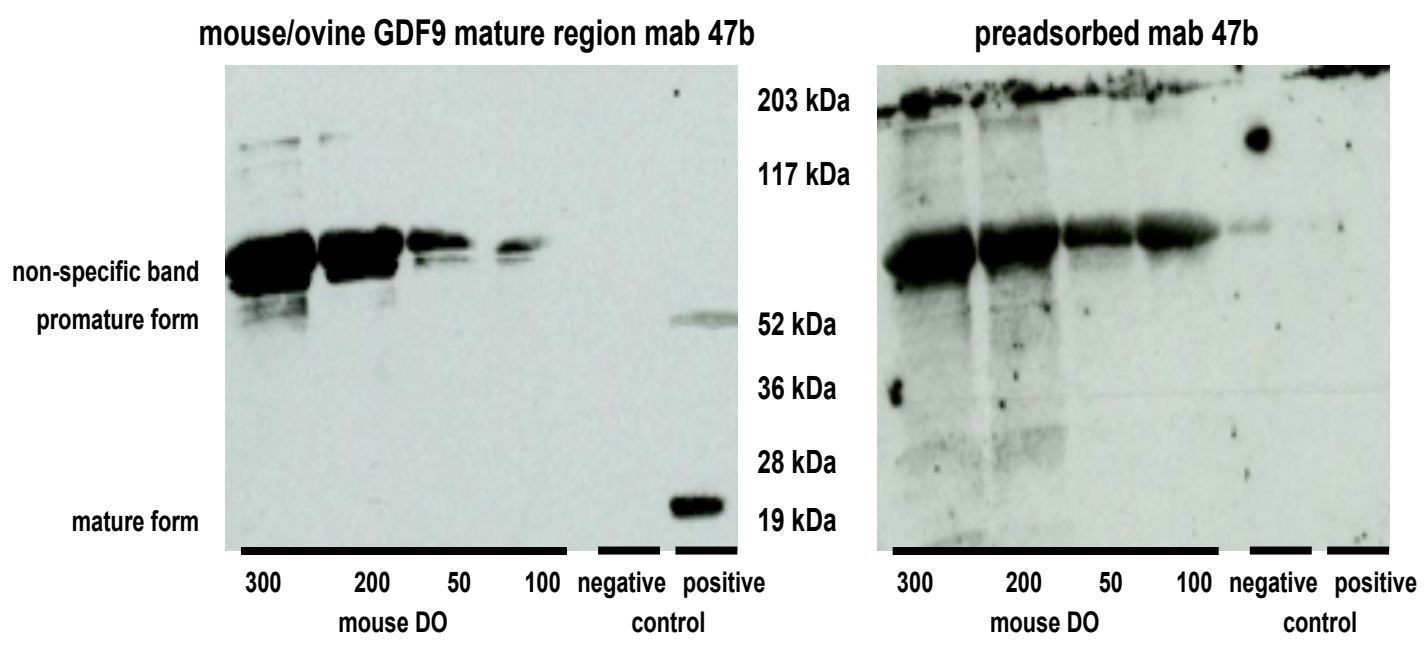

Figure 3C: Characterisation of mab47b. Protein bands detected in 50-300 mouse DO lysate series by Western blot analysis using mab47b as primary antibody. The positive control was HEK 293 cell derived wild-type (wt) mouse GDF9 conditioned media, while the negative control was wt mouse BMP15 conditioned media. Antibody preadsorption, carried out using the peptide that the antibody was raised against, resulted in the mature band in the positive control, and the promature bands in the DO lysate ( $\mathrm{n}=300$ oocytes) being blocked. Molecular sizes in $\mathrm{kDa}$ are specified in the centre with the protein forms described on the left side of the image.

Neither BMP15 antibodies tested (A-20 or H-83) were able to unequivocally recognise the 293 HEK cell derived mature mouse BMP15 protein in conditioned media, therefore a different positive control was required. No suitable positive control was found for H-83, but A-20 recognised the 293 HEK cell expressed human mature and promature BMP15 protein in conditioned media (Figure 3D). Considering that A-20 was raised against the human BMP15 protein, it is likely that it could recognise the human BMP15 protein with greater sensitivity than the mouse protein and that the amount of mouse BMP15 in the conditioned media was insufficient for detection. As the A-20 antibody also came with a blocking peptide, suitable for antibody preadsorption to validate the specificity of any protein bands detected, it was more suitable for use in Western blot experiments. 


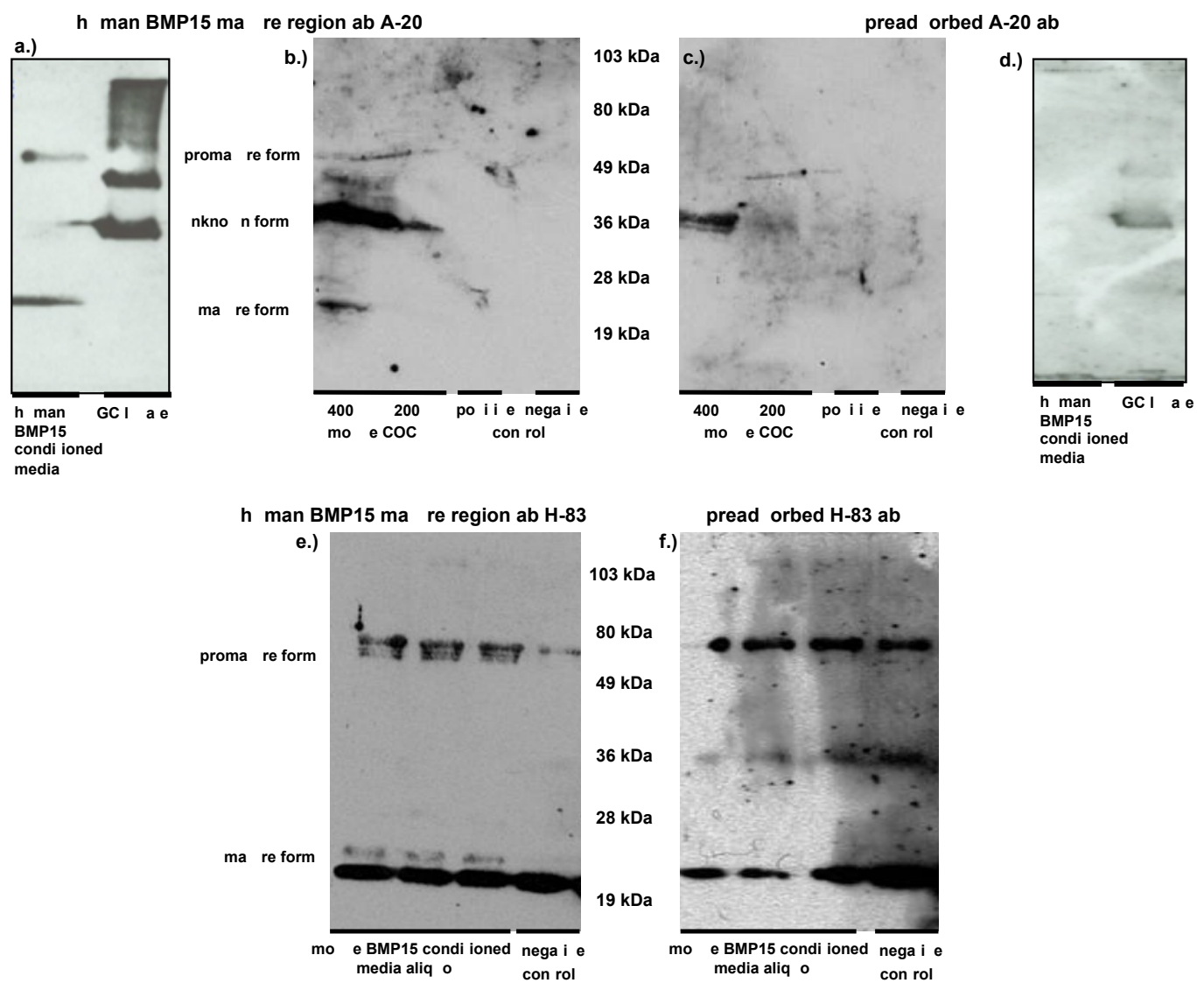

Figure 3D: Characterisation of BMP15 mature region antibodies H-83 and A-20. Protein bands detected in mouse COC lysates and HEK 293 cell expressed wt mouse BMP15 or GDF9 conditioned media aliquots by Western blot analysis using the A-20 (panels a-d) and H-83 (panels c-d) human BMP15 mature region primary antibodies. The positive control was HEK 293 cell derived wild type (wt) mouse or human BMP15 conditioned media (panels a and d), while the negative control was wt mouse GDF9 conditioned media for all immunoblots. A-20 antibody preadsorption (panels $\mathrm{c}$ and $\mathrm{d}$ ) was carried out using the supplied blocking peptide, while $\mathrm{H}-83$ was preadsorbed (panel $\mathrm{f}$ ) with recombinant mouse BMP15 produced in E. coli. A-20 antibody specifically recognised mature and promature size BMP15 bands in human BMP15 conditioned media (panel a), but not in mouse BMP15 conditioned media. However A-20 was able to detect mouse BMP15 mature protein in 400 COC lysates (panel b). Immunoblotting with H-83 antibody resulted in faint mature and promature BMP15 size bands in the wt mouse BMP15 conditioned media, but also a non-specific protein band of similar size to the target proteins (panel e), which were also present when the antibody was preadsorbed with mouse BMP15 peptide (panel f). This made it impossible to determine with any certainty if the bands were specific. Molecular sizes in kDa are specified in the centre, with the protein forms described on the left side of the image.

The A-20 antibody recognised a $37 \mathrm{kDa}$ sized specific BMP15 band, which does not correspond in size to known mouse BMP15 protein forms. It is the size of the 
mature BMP15 dimer, but under reducing conditions, a dimer should not have been detected. Experiments aimed at testing whether the $37 \mathrm{kDa}$ band might be an authentic mature dimer were undertaken by adding additional reducing reagent (an extra $10 \%$ of $\beta$-mercaptoethanol) to the cell lysates during Western blot sample preparation. Under these conditions, the mature BMP15 band became more pronounced in the developed immunoblots. However, as the $37 \mathrm{kDa}$ size bands remained and it was not possible to establish if the signal strength of these bands were reduced, identification of the $37 \mathrm{kDa}$ band as a mature protein dimer could not be confirmed unequivocally.

It was determined during the preliminary stages of this project that mouse antisera $8 \mathrm{f}$ was able to recognise the proregion and promature forms of mouse BMP15 with high sensitivity in both the positive control and cell lysate samples. Therefore $8 \mathrm{f}$ was considered suitable for use in the present protein mapping study (Figure 3E). The mouse GDF9 proregion antisera 4e was excluded from the final antibody panel, due to its lack of sensitivity (results not shown).
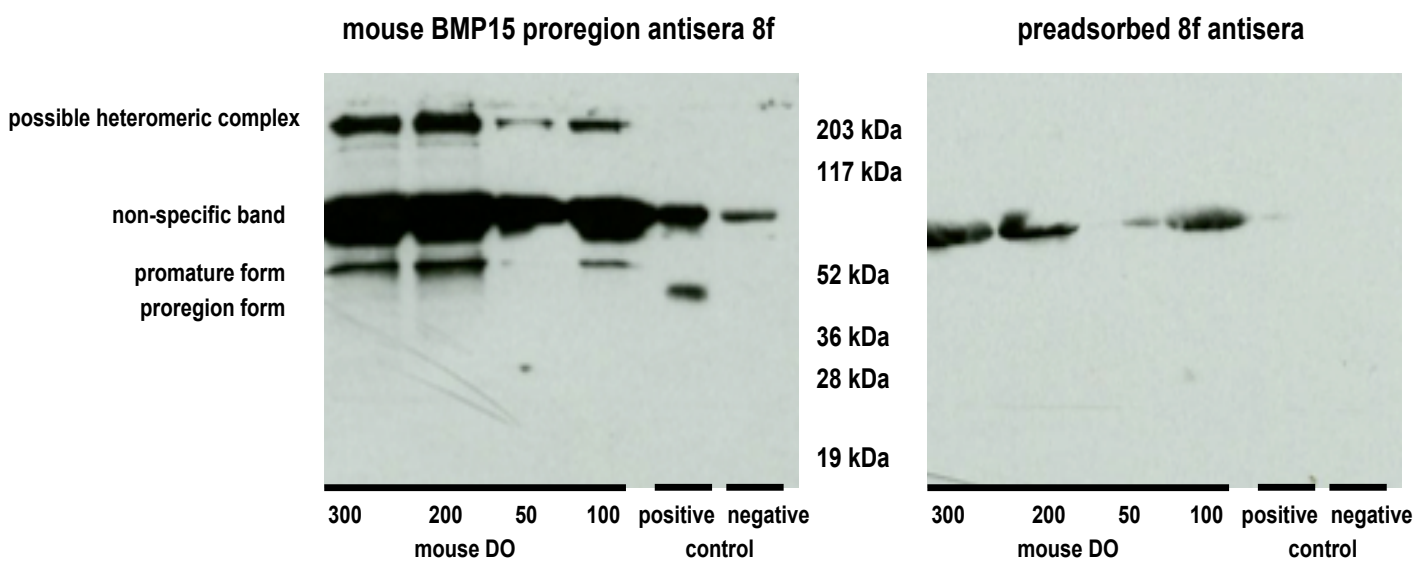

Figure 3E: Characterisation of BMP15 proregion antisera $8 \mathrm{f}$. Protein bands detected in a mouse DO lysate series by Western blot analysis using mouse proregion antisera $8 \mathrm{f}$ as the primary antibody. The positive control was HEK 293 cell derived wild-type (wt) mouse BMP15 conditioned media, while the negative control was wt mouse GDF9 conditioned media. Antibody preadsorption was carried out using the mouse BMP15 proregion peptide: this resulted in the proregion positive control band and promature bands in the 100-300 DO lysate samples being blocked. Molecular sizes in $\mathrm{kDa}$ are specified in the centre, with the protein forms described on the left side of the image. 


\subsubsection{Experimental design}

When planning the Western blot studies, several factors had to be taken into account: these included the limited amount of sample available, the maximum sample volume able to be loaded onto the SDS PAGE gels and the necessity of visualising both the BMP15 and GDF9 protein bands on the same immunoblot after repeated stripping and reanalysing the membranes with the risk of causing potential signal loss.

Furthermore, it was considered important for the sample concentrations to be kept similar from the different treatment groups and for the repeat experiments to be reproducible. After testing the selected antibodies for their sensitivity in recognising the target protein during repeated stripping and reanalysing the same membrane, it was decided that the first immunoblot assay carried out would be for the mature BMP15 protein using the goat polyclonal antibody A-20 (Santa Cruz), followed by stripping and reanalysis of the membrane with the preadsorbed A-20 antibody for validating specificity of the protein bands detected.

After another stripping of the membrane, it was to be reanalysed with the monoclonal GDF9 mature region antibody 47B followed by stripping and blotting with the preadsorbed 47B antibody. The last protein form to be visualised was the proregion and the uncleaved promature form of mouse BMP15, using the mouse polyclonal antisera $8 \mathrm{f}$, followed by stripping the membrane one last time and reanalysing with the preadsorbed $8 \mathrm{f}$ antibody. In this way, the expression pattern of the different forms of both mouse BMP15 and GDF9 could be evaluated in the same samples.

\subsubsection{Sample preparation}

The samples analysed for protein localisation using Western blotting were pooled mouse DO and mixed GC/CC lysates from the three established treatment groups: control, PMSG, PMSG + hCG; representing different stages in follicular development. Two sets of samples of the three established treatments groups were collected. The DO samples had to be pooled within treatment groups at each 
collection because the number of DO collected from individual animals contained protein levels below the sensitivity of the Western blot assay. The number of GC/CC collected from individual animals contained high enough levels of the target proteins in some samples to be detected by Western blotting. Thus, two independent pools of DO and eight independent pools of $\mathrm{GC} / \mathrm{CC}$ cells were generated for each of the three treatment groups. These samples were run in the first set of Western blot experiments as six separate immunoblots. For the DO samples, $\sim 400 \mathrm{DO}$ were pooled per treatment group, but the somatic cell samples, containing both GC and CC, were analysed separately from individual animals after the amount of protein was determined in each sample by BCA protein assay. This experiment was used to collect BMP15 and GDF9 protein localisation data during different stages of follicular development that corresponded to the mouse Bmp15 and Gdf9 mRNA expression results obtained during the ISH and qPCR studies.

In a second set of Western blot experiments ( $\mathrm{n}=2$ independent pools of samples), the expression patterns of mouse BMP15 and GDF9 were compared in COC before and after the oocyte underwent GVBD following the preovulatory LH surge (simulated using hCG treatment). The pooled, expanded CC (from 100 COC) and pooled GVBD DO $(n=100)$ were compared to cell lysates of intact GV $\operatorname{COC}(n=100)$ and intact GVBD COC $(n=100)$. GC collected from follicles 9 hours post hCG treatment were also tested.

\subsection{Results and conclusions}

\subsubsection{Bmp15 and Gdf9 mRNA expression}

As assessed by ISH, Bmp 15 and Gdf9 mRNA expression was restricted to the oocytes of follicles at all developmental stages in all three treatment groups (Table 3A, Figure 3E). The follicular types identified on the hybridised tissue sections ranged from type 3 primary follicles to type 8 preovulatory follicles with expanded cumulus mass occurring immediately before ovulation (Table 3A). With 
the exception of Bmp15 expression in type 3 primary follicles, all other follicular types showed strong silver staining emitting from the oocyte. No staining was observed in any somatic follicular cell types when hybridised with either Bmp15 or Gdf9 antisense probes (Table 3A, Figure 3F). Tissue sections hybridised with either Bmpl5 or Gdf9 sense probes also had no signal above background in any of the three treatment groups, providing evidence that all signals observed on sections labelled with antisense probes were specific for either mouse Bmpl5 or Gdf9 mRNA (Figure 3F). Large illustrative ISH images can be found in Appendix III.

Table 3A: In situ hybridisation summary

\begin{tabular}{|c|c|c|c|c|c|c|}
\hline \multicolumn{7}{|c|}{$\begin{array}{l}\text { Follicular type } \\
5\end{array}$} \\
\hline \multicolumn{7}{|c|}{ Oocytes } \\
\hline Bmp15 & $\mathbf{X}$ & $\sqrt{ }$ & $\sqrt{ }$ & $\sqrt{ }$ & $\sqrt{ }$ & $\sqrt{ }$ \\
\hline Gdfy & $\sqrt{ }$ & $\sqrt{ }$ & $\sqrt{ }$ & $\sqrt{ }$ & $\sqrt{ }$ & $\sqrt{ }$ \\
\hline \multicolumn{7}{|c|}{ Somatic Cells } \\
\hline Bmp15 & $\mathbf{X}$ & $\mathbf{X}$ & $\mathbf{x}$ & $\mathbf{X}$ & $\mathbf{X}$ & $\mathbf{x}$ \\
\hline Gdf 9 & $\mathbf{X}$ & $\mathbf{X}$ & $\mathrm{X}$ & $\mathbf{X}$ & $\mathbf{X}$ & $\mathbf{X}$ \\
\hline
\end{tabular}

' $\sqrt{ }$ ' indicates positive gene expression, while ' $x$ ' indicates no expression 
Bmp15 antisense
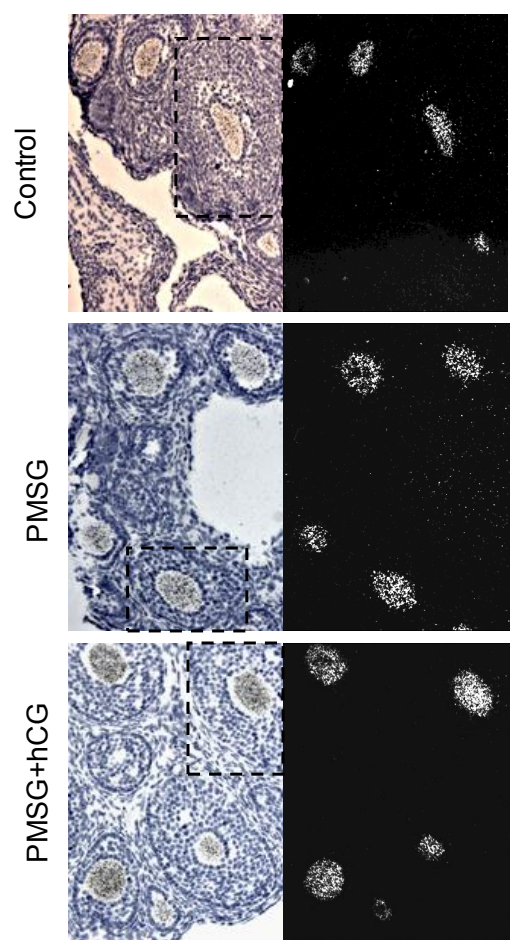

Gdf9 antisense
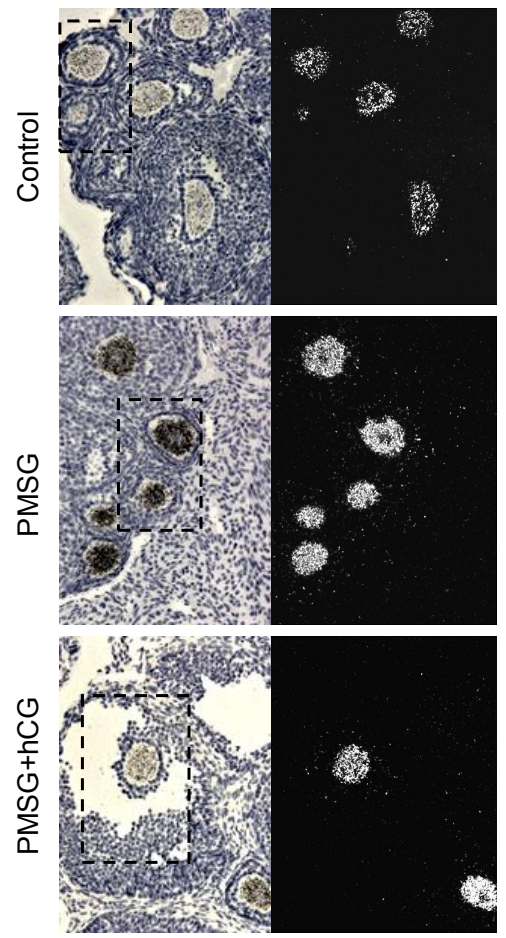

Bmp15 antisense enlarged
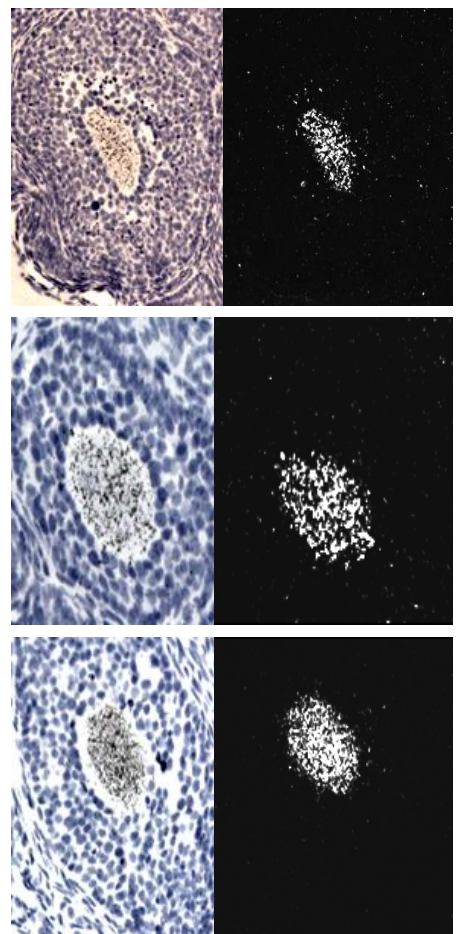

Gdf9 antisense enlarged
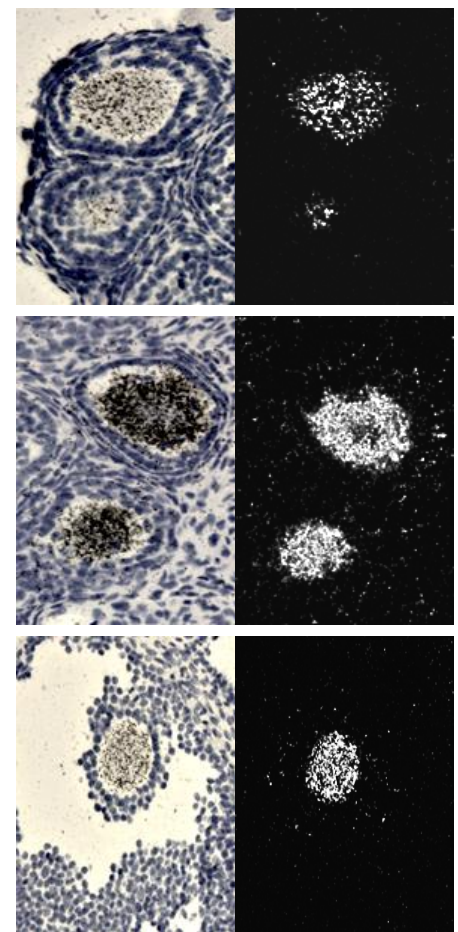

Bmp15 sense
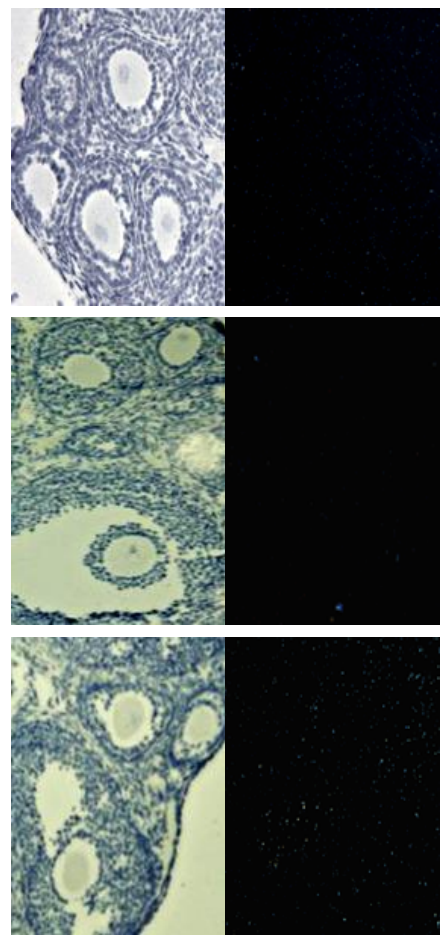

Gdf9 sense
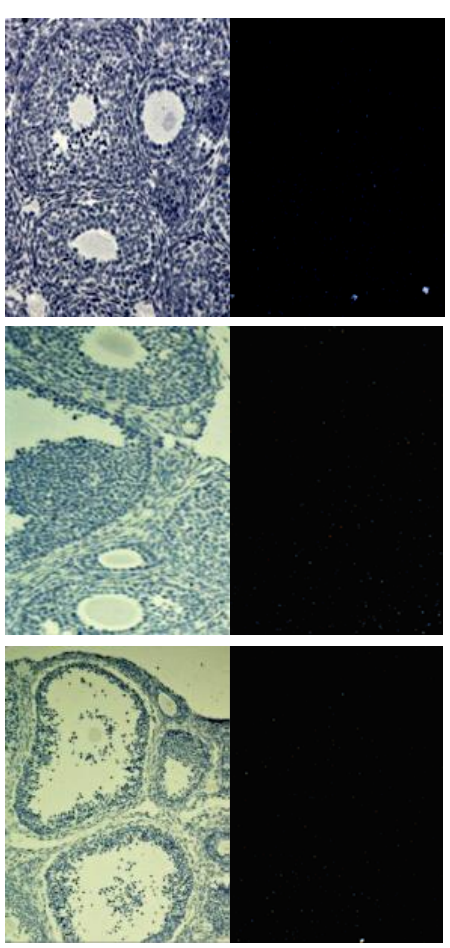

Figure 3F: In situ hybridisation images detecting Bmpl5 and Gdf9 in ovarian sections from mice treated with saline, PMSG and PMSG + hCG. The treatment groups are described on the left side of the images, with the radio-labelled probes specified on top. The enlarged antisense images (second column) represent the areas highlighted on the original antisense images (first column). 
Multiplex qPCR analysis of individual DO $(n=97)$ and corresponding CC also confirmed that mouse Bmp15 and Gdf9 mRNA expression is confined to the oocyte of the developing follicle. No expression of these genes was detected in $\mathrm{CC}$ except when the oocyte was damaged during the denudation process, as evidenced from the photographs taken at that time. Images of COC and DO collected for qPCR analysis from all three treatment groups ( $\mathrm{n}=3$ animals/group) are shown in Figure 3G. All oocytes collected from control (saline treated) and PMSG treated animals had an intact germinal vesicle (GV), while oocytes from PMSG + hCG treated animals often underwent germinal vesicle breakdown (GVBD) by the time of collection. COC with oocytes in GVBD could be identified by the expanded cumulus mass, and required enzymatic digestion, using hyaluronidase solution (described in detail in chapter 2, section 2.1.2.4.), before the oocyte could be denuded without damage.

Examples of images where oocytes were damaged during collection, leading to false positive mRNA expression results, can be seen in Figure $3 \mathrm{H}$.

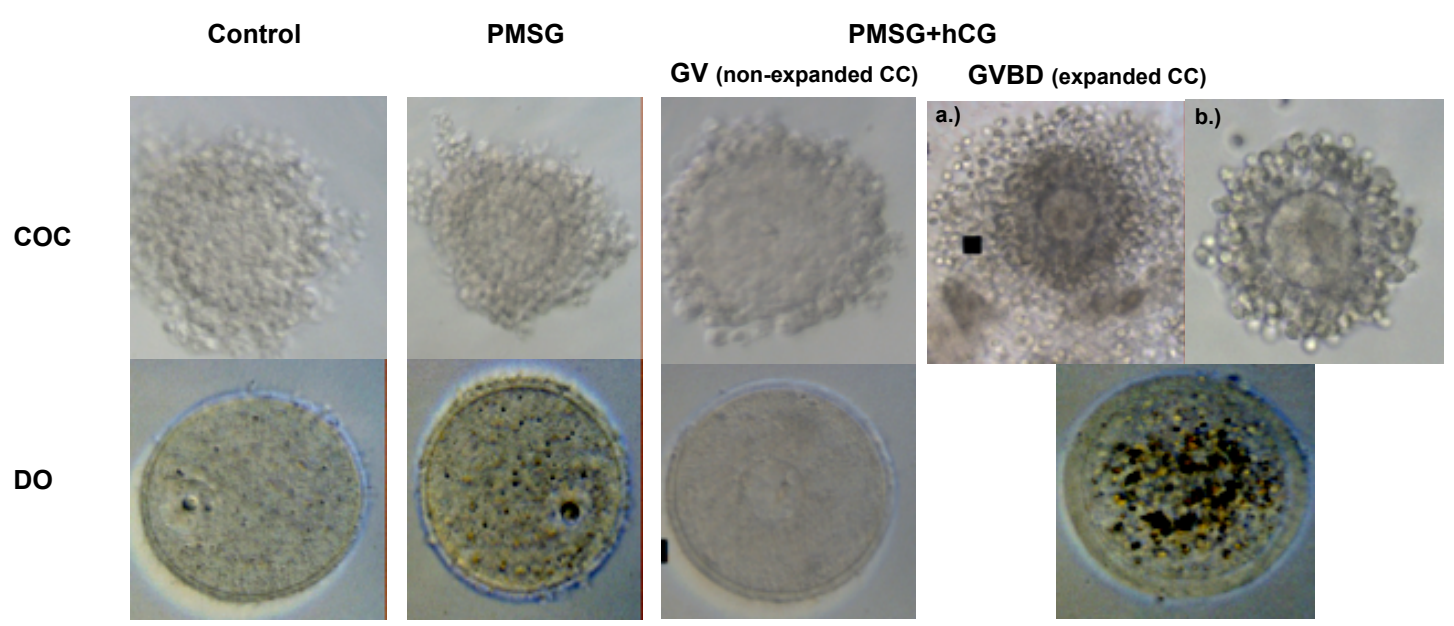

Figure 3G: Images of intact mouse COC and DO samples collected for qPCR. Control (saline treated) and PMSG treated COC were mechanically denuded. Some COC from PMSG+hCG treated animals had undergone germinal vesicle breakdown (GVBD) at the time of collection, recognisable by an expanded cumulus mass. The outer expanded cumulus layers (panel a.) were enzymatically removed first before the inner cumulus layer (i.e. corona radiata; panel b.) was removed mechanically. COC from the PMSG + hCG treated group with intact germinal vesicles $(\mathrm{GV})$ were mechanically denuded without prior enzyme treatment. 


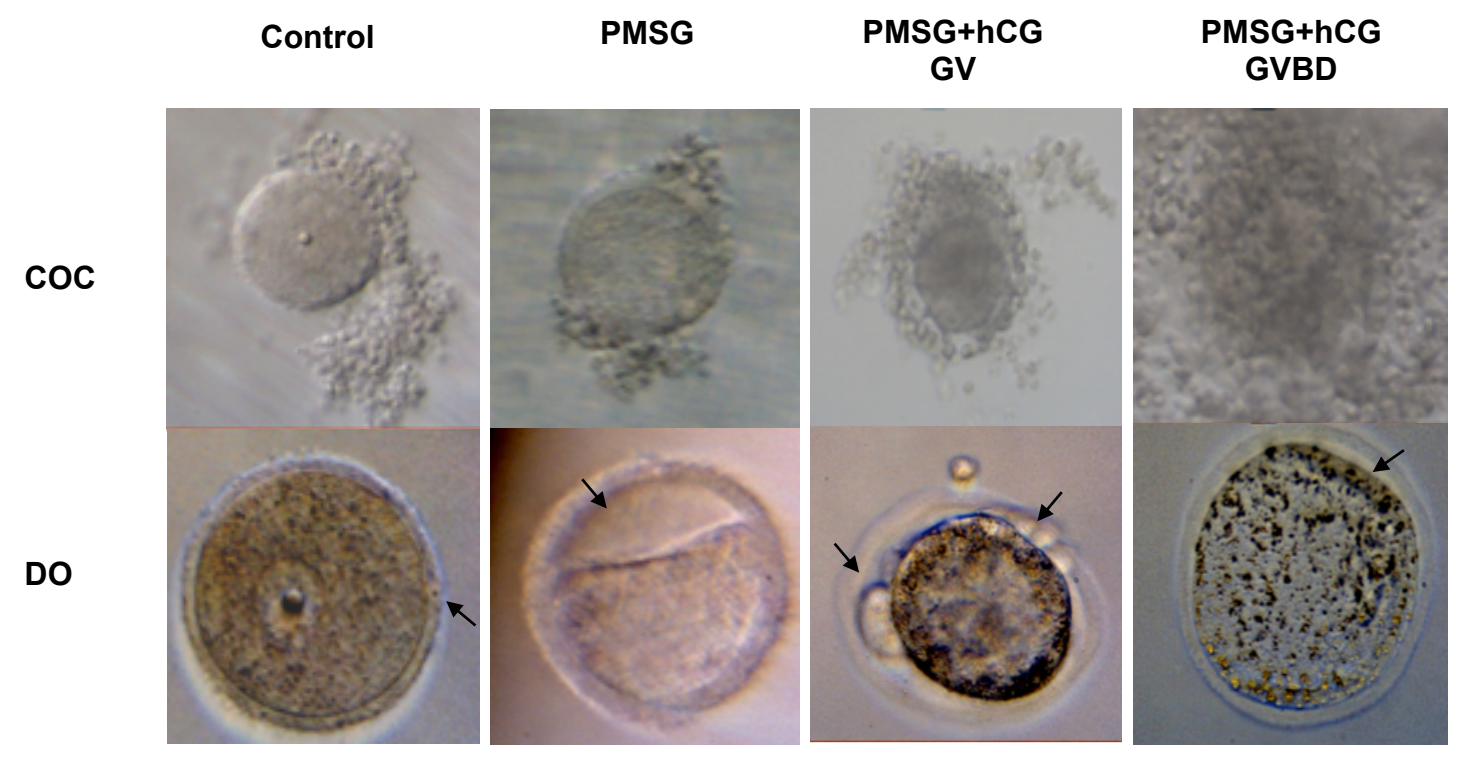

Black arrows point to areas of damage e.g. tear in oocyte zona pellucida, cytoplasm shrinkage etc.

Figure 3H: Examples of mouse DO samples damaged at sample collection from each treatment group. The top panel shows the COC before denuding; the bottom panel shows the damaged oocyte following denuding. The denuding process, which includes vigorous pipetting up and down and also enzymatic digestion for COC with expanded cumulus mass (GVBD stage) often resulted in some level of damage to the zona pellucida, leading to leakage of cytoplasm and contamination of the cumulus cells. Even minor damage to the oocyte caused false positive mRNA expression results in the corresponding cumulus cells.

Expression levels of Bmpl5 and Gdf9 mRNA (Figure 3H, a) remained constant between DO collected from the control $(n=23)$ and PMSG $(n=28)$ treated groups. DO samples from the PMSG+hCG treated group $(\mathrm{n}=46)$ had significantly lower levels of both Bmp15 $(\mathrm{P}<0.001)$ and $G d f 9(\mathrm{P}<0.05)$ mRNA, compared to DO from the control and PMSG treated groups (Figure 3I a). Once the oocyte underwent GVBD $(n=22)$ following the preovulatory LH surge simulated by hCG treatment in the present study (Figure 3I b), Bmp15 and Gdf9 mRNA levels decreased further compared to oocytes with intact GV $(n=24)$. 


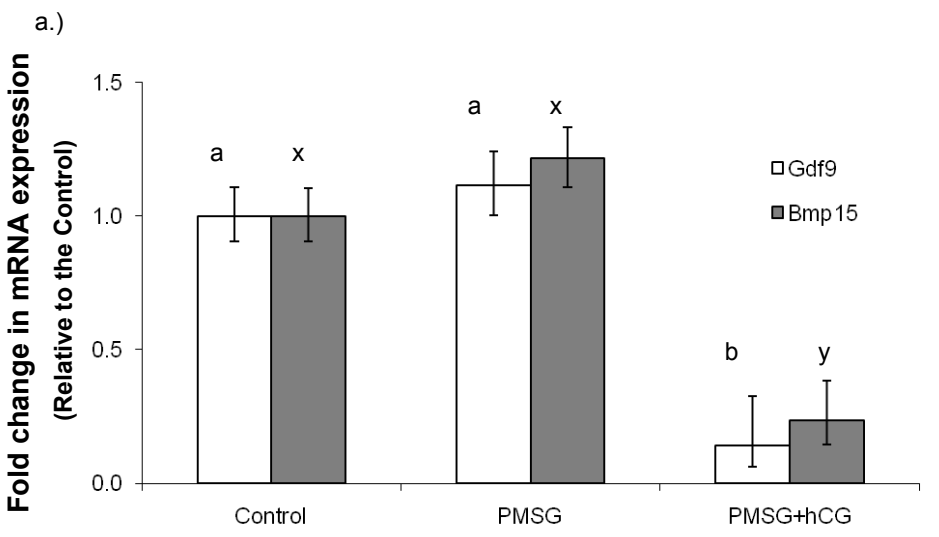

Treatment groups b.)

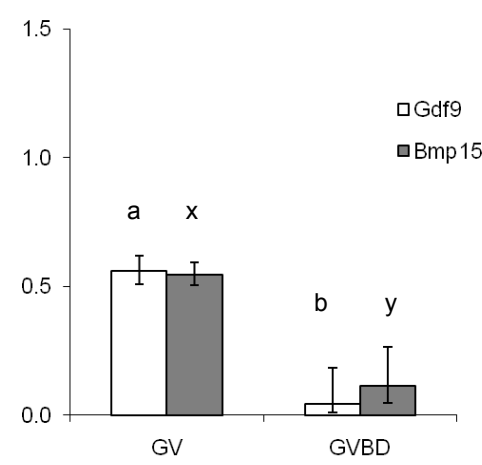

PMSG+hCG treatment

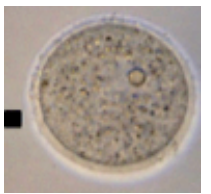

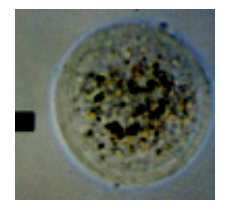

Figure 3I: Mean relative Bmp15 and Gdf9 mRNA expression levels in DO collected from control, PMSG and PMSG + hCG treated mice. Graph a) presents the overall differences in expression levels between the three treatment groups. Graph b) compares the expression levels of PMSG + hCG treated mice, when analyses were grouped based on the presence $(\mathrm{GV})$, or absence (GVBD) of a germinal vesicle. Within each graph, different letters denote significant differences between groups as determined by ANOVA. Y-axis shows the fold change in mRNA expression levels relative to control on both graphs. Note that the black boxes appearing on the oocyte images are part of the fluorescent imaging component of the software used and are not relevant to the images themselves.

When mRNA expression levels in oocytes of $\mathrm{PMSG}+\mathrm{hCG}$ treated mice were corrected against control values, mean expression levels in oocytes that had a GV present were lower than GV stage oocytes in the PMSG-treated group.

The ratio of Bmp15:Gdf9 mRNA (Table 3B) remained constant throughout follicular development, both before and after the LH surge. The tight correlation between Bmp15 and Gdf9 mRNA expression levels reported in other species not treated with gonadotrophins (Crawford and McNatty 2012) was observed here as well, as evidenced by the coefficient of variation $\left(R^{2}\right)$ values given in Table 3B.

The statistical analysis was performed by one-way analysis of variance (ANOVA), using the IBM SPSS statistical package. $\mathrm{P}$ values $<0.05$ were considered to be significant. Each sample was analysed twice to ensure 
repeatability of the qPCR assays. The inter- and intraassay coefficiences for Bmp15, Gdf9 and Rpl19 were calculated form the $\mathrm{C}_{\mathrm{T}}$ values of the calibrator samples included in each qPCR run at the beginning and the end of the runs. The interassay CVs for Bmp15, Gdf9 and Rpl19 were 2.1\%, 4.2\% and $1.8 \%$ respectively. The intra assay CVs were $<1 \%$ for Bmpl5 and Rpl19, and $2.1 \%$ for Gdf9.

Table 3B: Ratio of Bmp15:Gdf9 mRNA levels between treatment groups

Control

$$
\text { Bmp 15: Gdf9 mean ratio } \pm \mathrm{SEM}
$$

PMSG

$$
1: 4.56 \pm 0.43
$$

correlation coeff. $\left(\mathrm{R}^{2}\right)$

PMSG + hCG (total)

$1: 3.81 \pm 0.16$

0.92

0.98

PMSG+hCG (GV)

$1: 4.09 \pm 0.16$

0.97

PMSG+hCG $($ GVBD $) \quad 1: 4.35 \pm 0.22$

0.97

(Bmp 15:Gdf9 mRNA ratios between treatment groups were not significantly different by linear regression and ANOVA of ratio values.)

\subsubsection{BMP15 and GDF9 protein localisation}

Pooled DO lysates and individual follicular somatic cell lysates from each of the 3 treatment groups (control, hCG and/or PMSG treated animals) were analysed for BMP15 and GDF9 protein localisation using Western blot analysis. Protein localisation results were accepted if the appropriate signals for positive and negative controls were observed on the immunoblots with both the primary antibody and preadsorbed primary antibody.

Mature mouse BMP15 protein bands $(17-20 \mathrm{kDa})$ were detected in both the oocyte and somatic cell lysates from all 3 treatment groups, when A-20 polyclonal human BMP15 mature region antibody (Santa Cruz) was used for detection (Figure 3J). A protein band between $28-37 \mathrm{kDa}$ in size (Figure 3J a), which was absent or greatly reduced when analysed with the antigen-preadsorbed 
primary antibody (Figure 3J b), was detected in all of the samples. This did not correspond to the size of known forms of the BMP15 protein. The non-cleaved precursor/promature protein was detected in the positive control (293 HEK cell expressed human BPM15 conditioned media), but not in any of the follicular cell lysates. However, another unknown large protein band between 118-211 kDa was detected in the DO lysates in all three treatment groups, which was also blocked when the membrane was reanalysed with preadsorbed A-20 antibody, using the supplied blocking peptide (Santa Cruz). The proregion of BMP15 (40-42 kDa) was also detected in both the DO and somatic cell lysates in all 3 treatment groups when using the mouse polyclonal antisera $8 \mathrm{f}$ (Figure $3 \mathrm{~J} \mathrm{c}$ ). The non-cleaved promature protein or any larger protein bands could not be visualised using $8 \mathrm{f}$ as primary antibody due to non-specific signals above the $50 \mathrm{kDa}$ mark (Figure 3J d). 


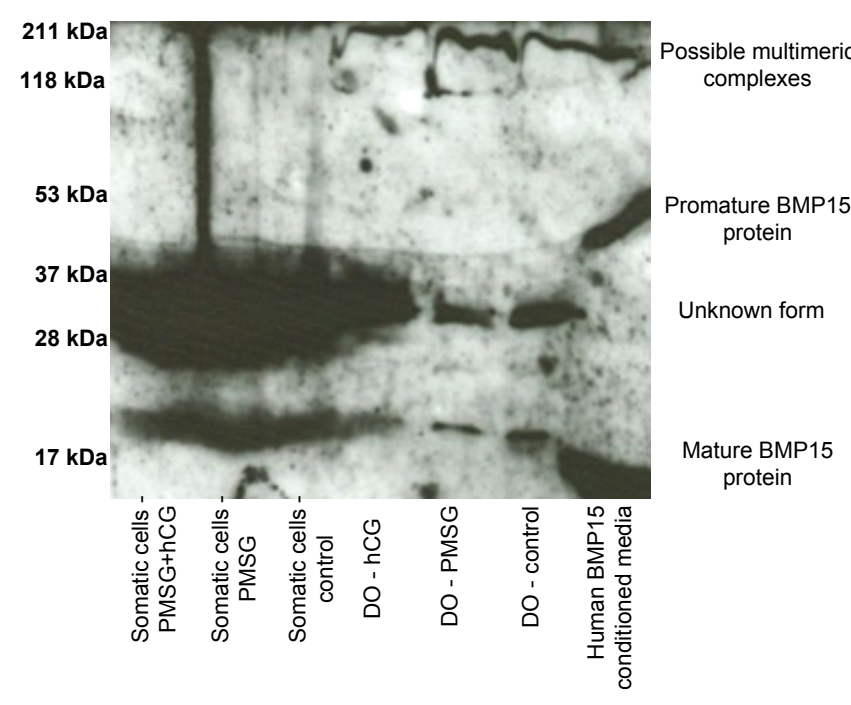

c.) mouse BMP15 protein (8f proregion antisera)

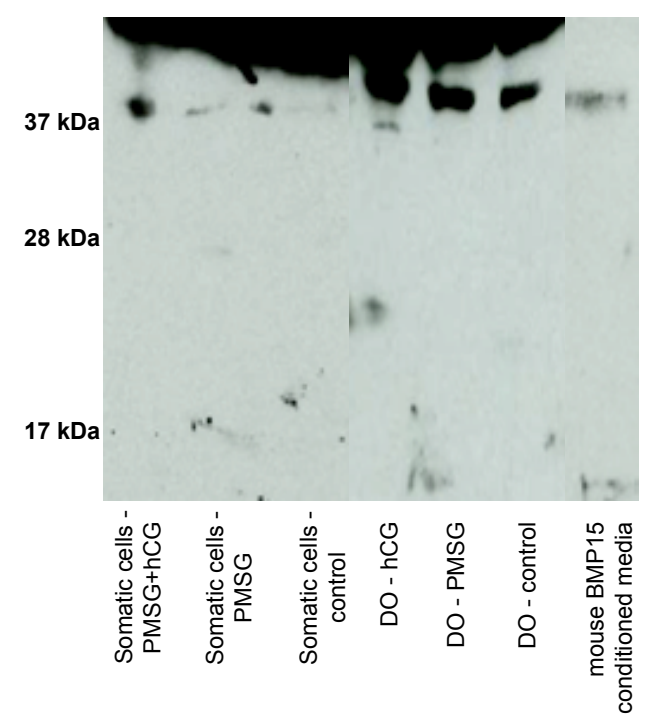

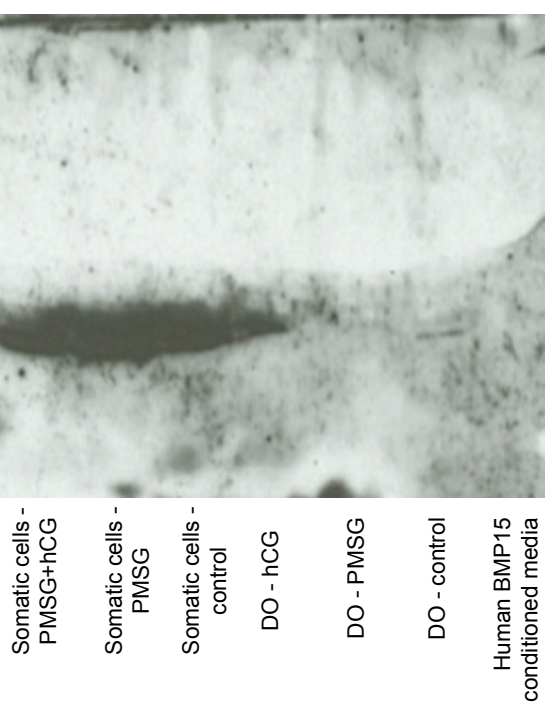

d.) predsorbed primary antibody

BMP15 proregion protein

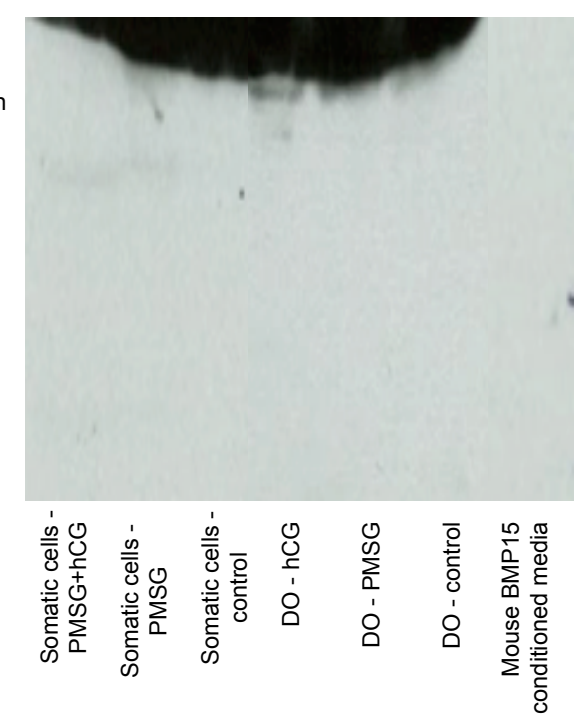

Note: Images c.) and d.) are edited images of two Western blot membranes cut together to show the best representation of both the DO and somatic cell BMP15 proregion expression. The original images can be found in Appendix II.

Figure 3J: BMP15 protein localisation in saline (control), PMSG and PMSG + hCG treated mouse ovarian follicular samples, as detected by Western blot analysis. Somatic follicular cell $(\mathrm{GC} / \mathrm{CC})$ lysates of known protein concentration and oocyte lysates of around 400 denuded oocytes (DO) were analysed from each of the 3 treatment groups to compare the detectable BMP15 protein forms in follicular samples representing different developmental stages. 
The mature form of GDF9 (19-22 kDa) was detected in somatic cell lysates in all 3 treatment groups and these could be blocked, Figure $3 \mathrm{~K} \mathrm{~b}$ ). However, no mature form was found in the DO samples (Figure $3 \mathrm{~K}$ a). No other forms of GDF9 could be visualised in these experiments.

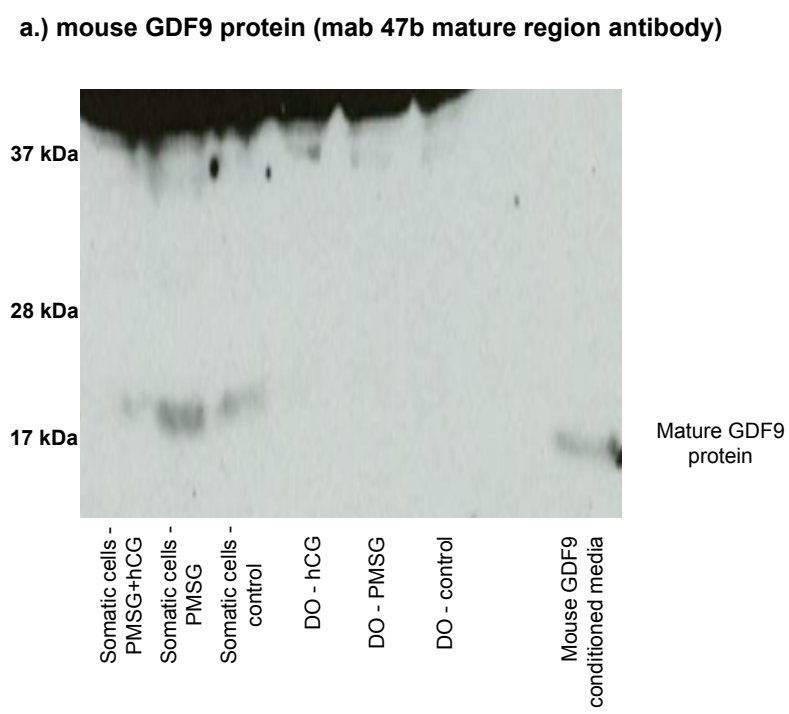

b.) preadsorbed primary antibody

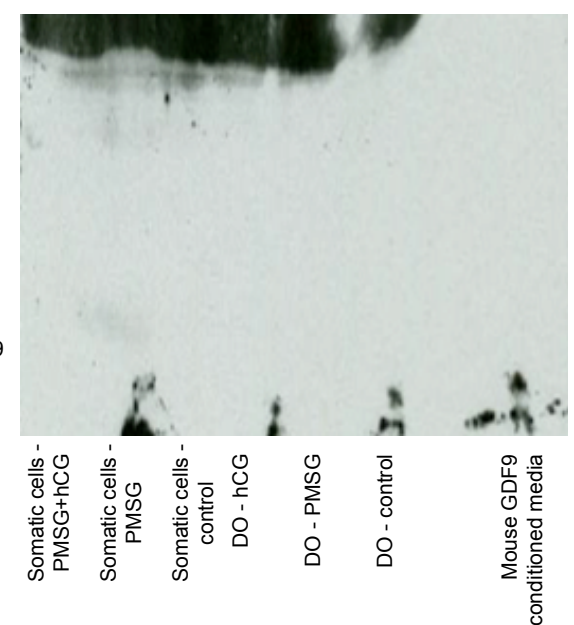

Figure 3K: GDF9 protein expression in saline, $\mathrm{PMSG}$ and $\mathrm{PMSG}+\mathrm{hCG}$ treated mouse ovarian follicular samples, as detected by Western blot analysis. Molecular sizes in $\mathrm{kDa}$ are specified on the left, with the protein forms described in between the images.

To characterise BMP15 and GDF9 protein localisation after the preovulatory LH surge, intact GVBD COC (with expanded cumulus mass and oocytes in GVBD), GV COC and GC samples were collected from mice 9 hours post hCG treatment. They were analysed either as lysates of GC and intact GVBD COC $(n=100)$, or as isolated GVBD DO $(n=100)$ and their corresponding CC $(n=100)$. Protein levels of these fractions were compared to those of GV COC lysates $(n=100)$. 

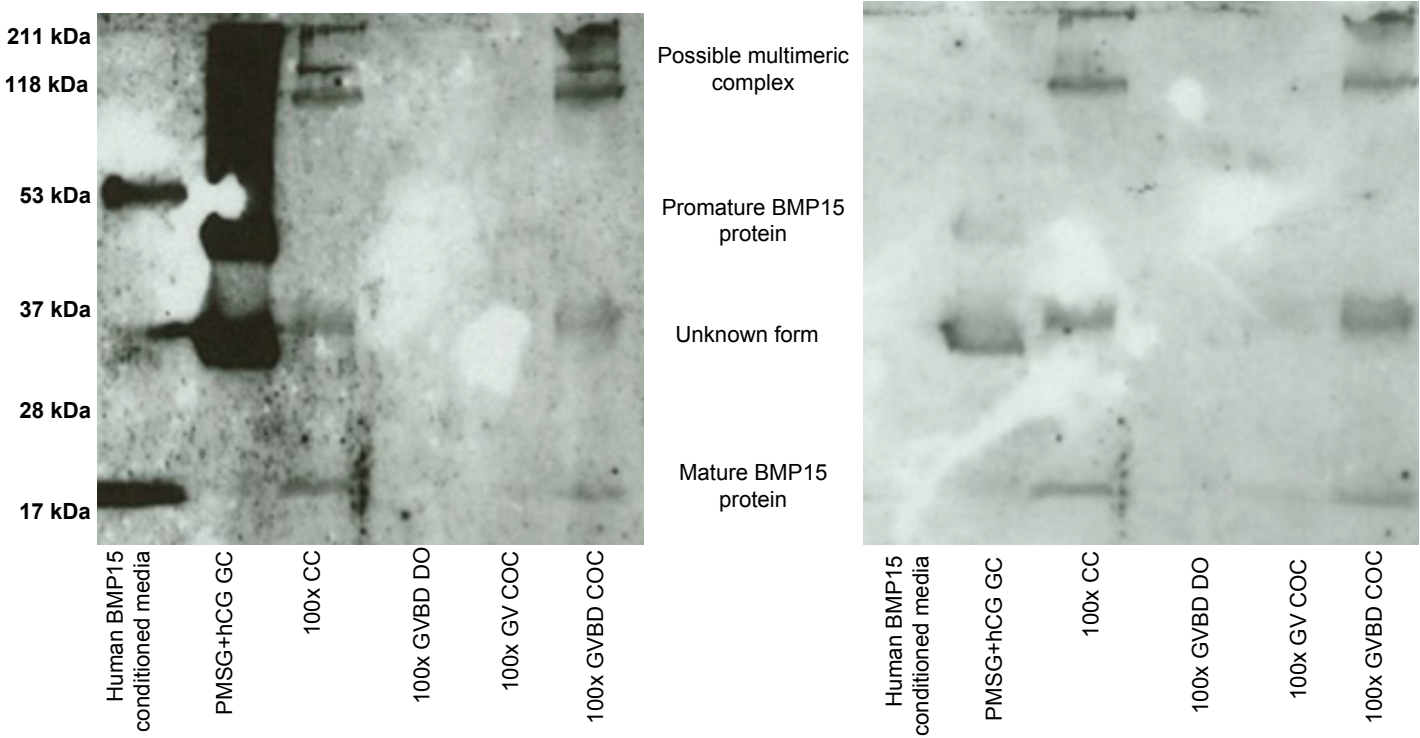

c.) mouse BMP15 protein (8f proregion antisera)

d.) preadsorbed primary antibody
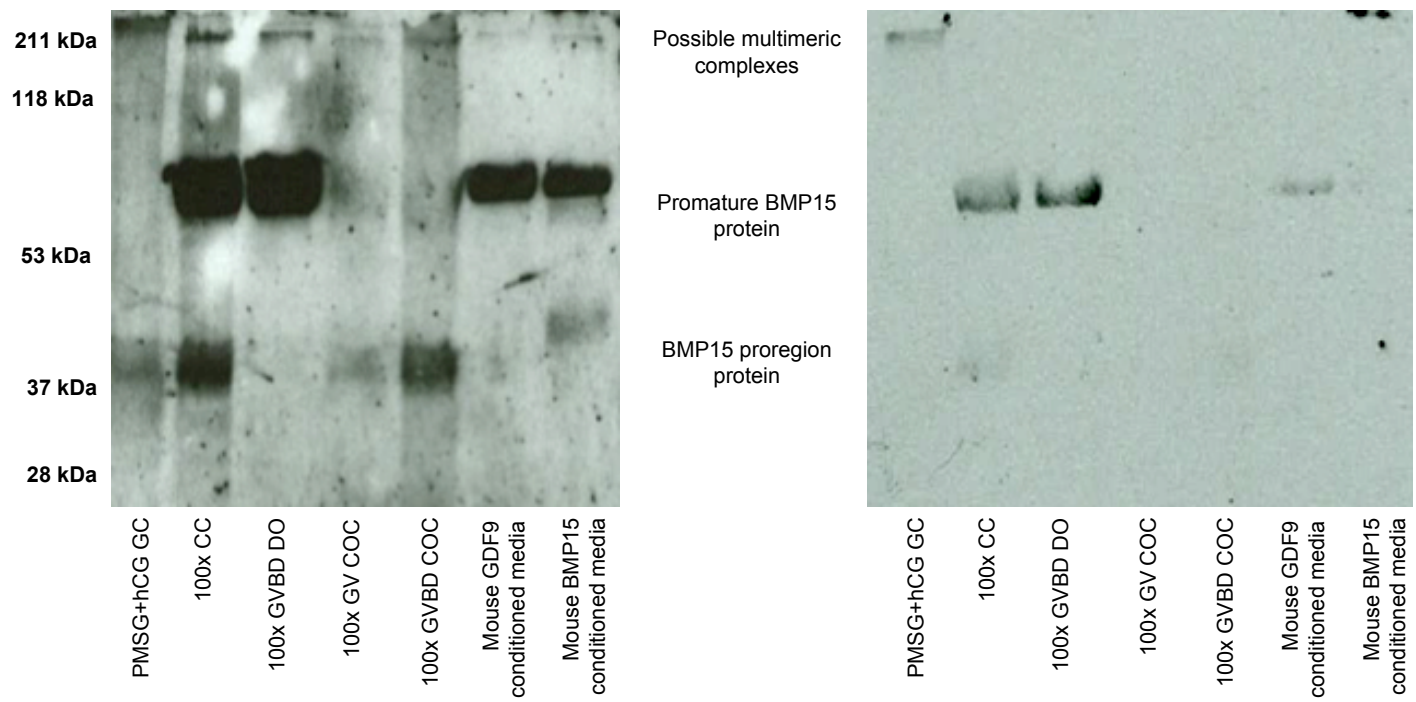

Figure 3L: Mouse BMP15 protein localisation in ovarian follicular samples before and after the preovulatory LH surge. Intact COC ['pre- (GV COC) and post-germinal vesicle breakdown (GVBD COC)], denuded GVBD stage oocytes (GVBD DO), the corresponding cumulus mass (CC), and preovulatory post-LH surge granulosa cells (PMSG + hCG GC) from $\mathrm{PMSG}+\mathrm{hCG}$ treated animals were analysed for the presence of different BMP15 protein forms, using BMP15 mature region (A-20; panels a and b) and proregion (8f; panels $\mathrm{c}$ and $\mathrm{d}$ ) antibodies. Preadsorbed primary antibody detection (right side images) was used to confirm the specificity of the detected protein bands. Molecular sizes are given in $\mathrm{kDa}$ on the right side of the images with the protein forms with confirmed specificity indicated between the original and preadsorbed antibody immunoblot images. 
The mature form of BMP15 could not be detected in any of the COC samples (Figure L a). The unknown form of BMP15 at the 28-37 kDa mark was present in the GC lysates. The uncleaved promature BMP15 form was detected in the positive control and possibly in the GC sample, although this was obscured by some non-specific signal. A large 118-211 kDa band, absent in preadsorbedantibody analysis (Figure 3L b), was visualised in the GVBD COC and the CC lysates.

The proregion of BMP15 was detected in GVBD COC, and the analysis of DO versus CC, both extracted from GVBD COC, showed the location of the protein to be mainly the CC rather than the oocytes (see Figure $3 \mathrm{~L} \mathrm{c}$ ).

GV COC also contained BMP15 proregion protein, as did the GC lysate, but the signals were less intense in these samples compared to GVBD COC or the cumulus lysate extracted from GVBD COC. A specific protein band, absent when analysed with preadsorbed antibody, and corresponding in size to the uncleaved precursor promature BMP15 protein $(45-52 \mathrm{kDa})$, was detected in the GVBD DO and CC samples but not in intact GV or GVBD COC lysates or in GC samples (Figure 3L c, d). This surprising lack of detectable promature BMP15 protein in GVBD COC was possibly due to incomplete reduction of the sample, preventing antibody recognition of this form of BMP15 in the intact COC.

GDF9 mature protein could only be detected in the expanded CC samples, isolated from the GVBD COC (Figure 3M a). A GDF9 precursor protein size band (45-54 kDa), which was not observed when the antibody was blocked (Figure $3 \mathrm{M} \mathrm{b}$ ), was present in both the GVBD COC and the CC samples. 

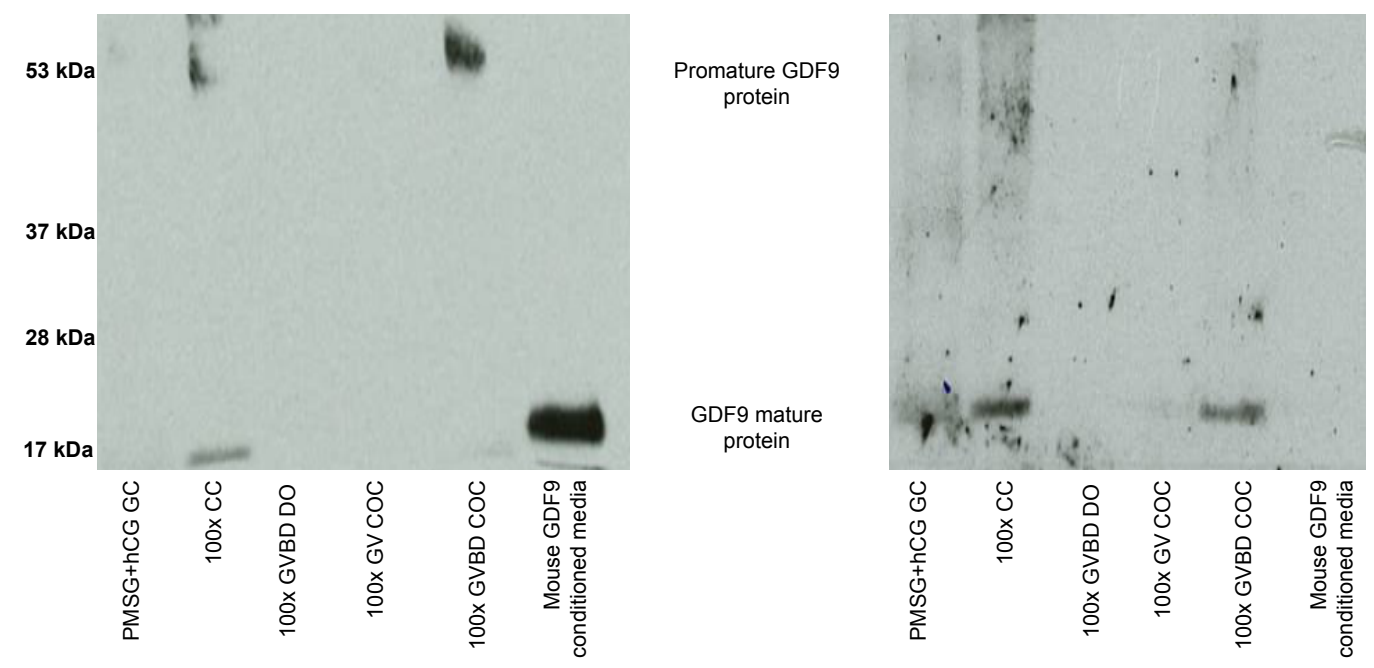

Figure 3M: Mouse GDF9 protein expression in ovarian follicular samples before and after the preovulatory LH surge. Molecular sizes given on the left in $\mathrm{kDa}$, the detected protein forms indicated in the centre of the figure. Size difference in the detected GDF9 mature region protein bands between conditioned media and cell lysates is most likely due to differences in phosphorylation between the different sample types. The preadsorbed antibody immunoblot on the right shows nonspecific protein bands in the GVBD COC and CC samples, which were not present in the original blot. These bands are a slightly different size to the mature protein bands detected in the original blot on the left side.

Table 3C: Summary table of BMP15 protein localisation and mRNA expression in mouse follicular cells

\begin{tabular}{|c|c|c|c|c|c|c|}
\hline \multirow{2}{*}{ mouse BMP15 expression } & \multicolumn{2}{|c|}{ mRNA } & \multicolumn{4}{|c|}{ protein } \\
\hline & DO & CC & $\operatorname{COC}$ & DO & $\mathrm{CC}$ & GC \\
\hline $\begin{array}{c}\text { Control group } \\
\text { (Early follicular development) }\end{array}$ & 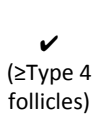 & $\boldsymbol{x}$ & not tested & $\begin{array}{c}\mathrm{m} ; \mathrm{p} ; \\
37 \mathrm{kDa} ; \\
118-211 \mathrm{kDa}\end{array}$ & \multicolumn{2}{|c|}{$\begin{array}{c}\mathrm{m} ; \mathrm{p} ; 37 \mathrm{kDa} \\
\text { (tested as GC/CC lysate) }\end{array}$} \\
\hline $\begin{array}{c}\text { PMSG group } \\
\text { (Late follicular development) }\end{array}$ & $\checkmark$ & $\boldsymbol{x}$ & not tested & $\begin{array}{c}\mathrm{m} ; \mathrm{p} ; \\
37 \mathrm{kDa} ; \\
118-211 \mathrm{kDa}\end{array}$ & \multicolumn{2}{|c|}{$\begin{array}{c}\mathrm{m} ; \mathrm{p} ; 37 \mathrm{kDa} \\
\text { (tested as GC/CC lysate) }\end{array}$} \\
\hline $\begin{array}{c}\text { PMSG+hCG group } \\
{[\text { Post preovulatory LH surge }(\mathrm{GV}+\mathrm{GVBD})]}\end{array}$ & $\checkmark \downarrow$ & $\boldsymbol{x}$ & not tested & $\begin{array}{c}\mathrm{m} ; \mathrm{p} ; \\
37 \mathrm{kDa} \\
118-211 \mathrm{kDa}\end{array}$ & \multicolumn{2}{|c|}{$\begin{array}{c}\mathrm{m} ; \mathrm{p} ; 37 \mathrm{kDa} \\
\text { (tested as } \mathrm{GC} / \mathrm{CC} \text { lysate) }\end{array}$} \\
\hline \multirow[t]{2}{*}{ GV stage } & $\checkmark \downarrow$ & $\boldsymbol{x}$ & $\mathrm{p} ; \mathrm{pm}$ & not tested & not tested & \multirow{2}{*}{$\begin{array}{c}\text { p; pm; } \\
37 \mathrm{kDa} \\
\\
\text { (collected } \\
\text { from } \\
\text { both GV } \\
\text { and } \\
\text { GVBD } \\
\text { follicles) }\end{array}$} \\
\hline & 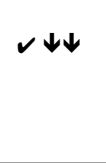 & $\boldsymbol{x}$ & $\begin{array}{c}\mathrm{p} ; \\
118-211 \mathrm{kDa}\end{array}$ & $\mathrm{pm}$ & $\begin{array}{c}\mathrm{p} ; \mathrm{pm} \\
118-211 \mathrm{kDa}\end{array}$ & \\
\hline $\begin{array}{l}\mathrm{COC}=\text { oocyte-cumulus } \mathrm{C} \\
\boldsymbol{V}=\text { expression; } \boldsymbol{\downarrow}=\exp \\
\mathrm{m}=\text { mature protein; } \mathrm{p}=\mathrm{p} \\
\text { unknown protein forms }\end{array}$ & $\begin{array}{l}\text { plex; } \mathrm{DO}= \\
\text { sion down } \\
\text { egion prot }\end{array}$ & $\begin{array}{l}\text { nude } \\
\text { gulat } \\
\text { pm }\end{array}$ & $\begin{array}{l}\text { ocyte; } \mathrm{CC}=\mathrm{c} \\
=\text { no expres } \\
\text { mature prot }\end{array}$ & $\begin{array}{l}\text { nulus mass; } C \\
\text {; } 37 \text { kDa and }\end{array}$ & $\begin{array}{l}=\text { granulosa } \\
18-211 \mathrm{kDa}=\end{array}$ & \\
\hline
\end{tabular}


Table 3D: Summary table of GDF9 protein localisation and mRNA expression in mouse follicular cells.

\begin{tabular}{|c|c|c|c|c|c|c|}
\hline \multirow{2}{*}{ mouse GDF9 expression } & \multicolumn{2}{|c|}{ mRNA } & \multicolumn{4}{|c|}{ protein } \\
\hline & DO & $\mathrm{CC}$ & $\operatorname{coc}$ & DO & $\mathrm{CC}$ & GC \\
\hline $\begin{array}{c}\text { Control group } \\
\text { (Early follicular development) }\end{array}$ & $\checkmark v$ & $x$ & not tested & $\boldsymbol{x}$ & \multicolumn{2}{|c|}{$\frac{\mathrm{m}}{\text { (tested as } \mathrm{GC} / \mathrm{CC} \text { lysate) }}$} \\
\hline $\begin{array}{c}\text { PMSG group } \\
\text { (Late follicular development) }\end{array}$ & $\checkmark v$ & $x$ & not tested & $\boldsymbol{x}$ & \multicolumn{2}{|c|}{$\frac{\mathrm{m}}{\text { (tested as } \mathrm{GC} / \mathrm{CC} \text { lysate) }}$} \\
\hline $\begin{array}{c}\text { PMSG+hCG group } \\
{[\text { Post preovulatory LH surge }(\mathrm{GV}+\mathrm{GVBD})]}\end{array}$ & レレむ & $x$ & not tested & $\boldsymbol{x}$ & \multicolumn{2}{|c|}{$\begin{array}{c}\mathrm{m} \\
\text { (tested GC/CC lysate) }\end{array}$} \\
\hline GV stage & レレむ & $\boldsymbol{x}$ & $\boldsymbol{x}$ & not tested & not tested & \\
\hline GVBD stage & レレむむ & $\boldsymbol{x}$ & $\mathrm{pm}$ & $\boldsymbol{x}$ & $\mathrm{m}, \mathrm{pm}$ & \\
\hline \multicolumn{7}{|c|}{$\begin{array}{l}\mathrm{COC}=\text { oocyte-cumulus complex; } \mathrm{DO}=\text { denuded oocyte; } \mathrm{CC}=\text { cumulus mass; } \mathrm{GC}=\text { granulosa cells } \\
\boldsymbol{V} \boldsymbol{\boldsymbol { V }}=\text { expression quantifiably higher than } \mathrm{BMP} 15 ; \boldsymbol{\downarrow}=\text { expression down-regulated } \boldsymbol{x}=\text { no } \\
\text { expression; } \\
\mathrm{m}=\text { mature protein; } \mathrm{pm}=\text { promature protein } \\
\text { Note: proregion protein was not tested due to lack of specific antibody }\end{array}$} \\
\hline
\end{tabular}

\subsubsection{Conclusions}

This study confirmed other reports that the sole source of BMP15 and GDF9 mRNA expression and protein production within the mouse ovary is the oocyte (McGrath, Esquela et al. 1995; Dong, Albertini et al. 1996; Dube, Wang et al. 1998; Laitinen, Vuojolainen et al. 1998; Crawford and McNatty 2012). Additionally, Bmp15 and Gdf9 mRNA expression was detected exclusively in the oocytes of the growing follicles at all developmental stages, including after the preovulatory LH surge.

Bmp15 mRNA expression was visualised by ISH in oocytes of type 4 to type 8 preovulatory follicles. Other studies also reported Bmp15 to be first expressed in mouse oocytes at the late primary, early secondary stage (type 3btype 4 follicles) (Dube, Wang et al. 1998). The lack of Bmp15 mRNA expression in small type 3 follicles could mean that BMP15 has no role in early primary stages of mouse follicular growth. However, it cannot be ruled out that Bmp15 mRNA expression is too low in early primary stage mouse follicles to be detected 
by ISH. In contrast, Gdf9 mRNA expression was detected throughout all developmental stages in the oocytes of follicles from type 3 to type 8. Even though densitometry analysis was not carried out on the hybridised mouse ovarian sections to quantify gene expression, it appeared evident, from studying the tissue slides, that Gdf9 is expressed at higher levels than Bmp15 in the mouse ovary throughout follicular development. This observation was confirmed by multiplex qPCR results, where $G d f 9$ was on average 4.12 times more abundant than Bmp15 (Bmp15:Gdf9 mRNA expression level ratio 1:4.12 \pm 0.14 ) at all antral stages of follicular growth. The quantitative PCR data points to a tight co-regulation of Bmp15 and Gdf9 expression in antral follicles regardless of developmental level, but the mechanism behind the co-regulation remains to be elucidated. Both genes were expressed at constant levels throughout follicular development until the preovulatory LH surge, after which expression of Bmp15 and Gdf9 mRNA was down-regulated, with a further drop in expression levels once the oocyte underwent GVBD prior to ovulation.

In the present study, oocyte maturation was achieved by hCG treatment, simulating the preovulatory LH surge. In response to the superovulation treatment, at $9 \mathrm{~h}$ post-hCG some oocytes in each animal had undergone GVBD, while others remained at the GV stage. This shows that the microenvironments of follicles are not fully synchronised by the superovulation treatment. Furthermore the decreased expression observed in the GVBD oocytes compared to the GV stage oocytes following hCG treatment suggests that Bmpl5 and Gdf9 mRNA levels continue to decrease as the oocyte progresses through maturation.

The observed Bmp15 and Gdf9 mRNA expression timeline fits into known physiological events taking place in the ovary during follicular development and around the time of ovulation. During follicular growth, BMP15 and GDF9 regulate follicular somatic cell function (Dong, Albertini et al. 1996; Galloway, McNatty et al. 2000; Juengel, Hudson et al. 2002; McNatty, Lawrence et al. 2006) by promoting GC proliferation (Hayashi, McGee et al. 1999; Otsuka, Yao et al. 2000; Vitt, Hayashi et al. 2000; Vitt, McGee et al. 2000; Hreinsson, Scott et al. 2002; Nilsson and Skinner 2002; Di Pasquale, Beck-Peccoz et al. 2004; McNatty, Juengel et al. 2005a; McNatty, Juengel et al. 2005b), preventing premature luteinisation (Otsuka, Yao et al. 2000; Vitt, Hayashi et al. 2000; Yamamoto, 
Christenson et al. 2002) and maintaining CC and GC phenotype (Elvin, Clark et al. 1999; Matzuk 2000; Dragovic, Ritter et al. 2005). Once the follicle reaches the preovulatory stage and the oocyte achieves developmental competence, the antiluteinisation and mitogenic effects of BMP15 and GDF9 are no longer required. Following the preovulatory LH surge, Bmp15 and Gdf9 mRNA expression is down-regulated in the oocyte. At this time the cumulus mass undergoes GDF9facilitated expansion (Elvin, Clark et al. 1999; Matzuk 2000), leading to the termination of the gap junction communication between the oocyte and the somatic follicular cells (Granot and Dekel 1994; Larsen, Chen et al. 1996; Kalma, Granot et al. 2004; Sela-Abramovich, Chorev et al. 2005). Following cumulus cell expansion, the GC switch from oestradiol to progesterone production and the oocyte is ready for ovulation and subsequent fertilisation (Eppig 2001).

In the present study, 400 denuded oocytes and 17-25 $\mu \mathrm{g}$ somatic follicular cell lysate were analysed from each treatment group to achieve the detection of the BMP15 protein, a sample amount based on results obtained from pilot experiments. The detection of both the mature and proregion forms of the BMP15 protein in all three treatment groups indicates that BMP15 was being actively translated and processed throughout follicular development in the mouse follicles. Mature BMP15 expression was detected in somatic follicular cells in small antral follicles and the proregion of BMP15 was also detected in these follicles.

The findings that both the mature and the proregion protein were localised within the oocytes as well as outside in the $\mathrm{GC} / \mathrm{CC}$ lysates indicates that posttranslational processing of BMP15 occurs within the oocyte, but doesn't rule out the possibility of processing also occurring outside the oocyte.

Following the preovulatory LH surge, the loss of oocyte-cumulus communication, with decreased expression levels of Bmp15 and Gdf9 mRNA, is likely to remove the inhibitory effect of BMP15 and GDF9 protein on the luteinisation of somatic follicular cells. However, the presence of the various protein forms of BMP15 and GDF9 observed in GC and CC following the preovulatory LH surge seems to contradict a loss of inhibition by these growth factors, and will be discussed further in Chapter 5. 
A specific $\sim 37 \mathrm{kDa}$ size protein band, detected in all oocyte and somatic cell samples, does not correspond to known forms of mouse BMP15. It is slightly larger than the light chain of mouse $\operatorname{IgG}(25 \mathrm{kDa})$ and thus is unlikely to be a technical artefact related to the presence of $\operatorname{IgG}$ in the samples. A mature dimer of BMP15 would be similar in size to this band but since the experiment was performed under reducing conditions, mature BMP15 dimers should not have been present. It is possible the reduction was incomplete, perhaps due to a large amount of BMP15 dimer protein present. This possibility is supported by improved BMP15 mature protein detection when an extra $10 \%$ of reducing agent (ß-mercaptoethanol) was added to the cell lysates during Western blot sample preparation. Increasing the reducing agent however did not result in observable decrease in the putative dimer. Further experiments with cellular samples subjected to a stronger reduction protocol and compared with native samples, and with samples subjected to chemical cross-linking, would clarify any interactions between the monomers of BMP15, and similarly for GDF9.

Alternatively, it is possible that this BMP15 band is some form of the mature BMP15 protein, strongly bound to other proteins that failed to undergo reduction. The large 118-211 kDa protein band present in all oocyte lysates, which was also absent when using a preadsorbed primary antibody for detection, could also be a form of mouse BMP15, potentially part of a large multimeric complex that was not reduced by sample treatment.

The mature form of GDF9 protein was detected in somatic follicular cells at all stages of follicular development in the mouse ovary. The finding that denuded oocyte samples did not show mature GDF9 protein expression, despite the high levels of Gdf9 mRNA expression in DO throughout follicular growth, is consistent with the hypothesis that the promature form of the GDF9 is rapidly secreted outside of the oocyte and is processed in the cumulus cell matrix. Alternatively, GDF9 within the oocyte might have been associated with proteins or folded in such a way to be resistant to the reducing agents used in sample treatment, and therefore not recognisable by the antibodies used. The protein could also be captured specifically or non-specifically by the extracellular matrix of the somatic follicular cells, preventing the loss during sample preparation. The presence or absence of the non-cleaved precursor protein could not be determined 
due to non-specific signalling above $40 \mathrm{kDa}$ when using mab47b primary antibody for detection. The source of the non-specific signal is most likely the heavy chain of mouse $\operatorname{IgG}$, which is about $55 \mathrm{kDa}$ in size, the same size as the precursor GDF9 promature protein. The available polyclonal mouse proregion antisera was not sensitive enough to detect the GDF9 proregion in the follicular cell lysates.

Analysis of BMP15 and GDF9 localisation post-hCG treatment in GVBD COC lysates, prepared from COC with expanded CC and oocytes in GVBD, helped to determine if there is a difference in protein expression by mouse follicles following the pre-ovulatory LH surge.

GVBD COC showed strong BMP15 proregion localisation, as did the expanded $\mathrm{CC}$ extracted from GVBD COC, but not the corresponding DO GVBD. The precursor promature BMP15 protein however was detected in both the GVBD DO and CC lysates, pointing to enzymatic processing of BMP15 potentially occurring outside of the oocyte following the secretion of the full-length promature protein by the oocyte. The BMP15 proregion protein was also detected in GV COC post hCG treatment with non-expanded cumulus mass and oocytes with intact germinal vesicle, but to a lesser extent then in GVBD COC, which indicates that protein translation and/or the posttranslational processing is up-regulated after the oocyte undergoes germinal vesicle breakdown. Granulosa cells collected following hCG treatment also showed evidence of the BMP15 proregion, but not the precursor protein, which potentially means that even though GC are not capable of producing BMP15, they could be capable of processing precursor BMP15. The lack of detection of the mature form of BMP15 in COC and DO collected from PMSG + hCG treated animals in this set of experiments is most likely due to the lower amounts of samples analysed (lysate of $100 \mathrm{DO}$ or $100 \mathrm{COC}$ ), compared to the previous experiment, where the mature form of BMP15 was detected when analysed the lysate of 400 DO from each of the three treatment groups were analysed.

GVBD COC, and to a lesser extent extracted CC lysates, showed promature mouse GDF9 protein localisation, with the CC samples also showing mature GDF9 localisation. This suggests that GDF9 is produced by the oocyte as 
the promature precursor protein, and is able to be secreted outside the oocyte either with or without processing, potentially to the extracellular matrix of the expanded CC. In the earlier experiments, mature GDF9 protein was detected in somatic follicular cells in all three treatment groups, including following hCG treatment. However, when $\mathrm{CC}$ and GC lysates were analysed separately post hCG treatment in this second set of Western blot experiments, GDF9 was not detected in $\mathrm{GC}$, only in $\mathrm{CC}$, which could mean that the GDF9 protein is primarily associated with CC following the preovulatory LH surge. GDF9 protein was not detected in GV COC post-hCG treatment, which could also be explained by upregulation of protein production and/or processing in the mouse follicle only after GVBD following the preovulatory LH surge.

In summary, tight co-regulation of Bmpl5 and Gdf9 mRNA expression was observed at all antral stages of follicular development with a mean Bmp15:Gdf9 ratio of 1:4.12. Expression was localised to the oocytes of the developing follicle at all stages of follicular growth, with steady expression levels until following the preovulatory LH surge. After the LH surge (simulated by hCG administration), mRNA expression levels of both Bmp15 and Gdf9 decreased, with further reductions observed once the oocyte underwent GVBD directly before ovulation. Thus, continued maturation of the oocyte was associated with continued reduction of Bmpl5 and Gdf9 mRNA. The finding that both cleaved and uncleaved protein forms were detected in somatic follicular cell samples, despite these cells not being capable of producing these growth factors, could mean that following transcription and translation of BMP15 and GDF9 by the oocyte, the posttranslational modification of these proteins might also take place outside the oocyte. However, detection of the target proteins in $\mathrm{CC}$ but not in $\mathrm{DO}$, could also have been made possible by the extracellular matrix of the expanded cumulus mass capturing the rapidly secreted and processed oocyte derived proteins. The presence of the target proteins mostly in GVBD COC points to an up-regulation of BMP15 and GDF9 protein production and/or processing in the mouse follicle after GVBD following the preovulatory LH surge. Alternatively, an up-regulated recruitment of BMP15 and GDF9 to the ECM by other proteins or compounds, or by the proregion of these growth factors, could also result in the apparent increased localisation observed following GVBD. 
It is important to note that further studies are necessary to confirm the timing of production and localisation of BMP15 and GDF9 protein forms in the mouse ovary, since currently the lack of highly sensitive, specific antibodies presents challenges when analysing protein localisation by Western blotting. The presence of non-specific protein bands of similar size to the target proteins on the immunoblots, and the high background signal generated by either the antibodies or their blocking peptides make data interpretation difficult. More sensitive mouse BMP15 and GDF9 antibodies would also aid the visualisation of these proteins by other techniques such as confocal immunohistochemistry. 


\section{Chapter 4: Biological activity of the non-cleaved}

\section{precursor proteins of mouse BMP15 and GDF9}

\subsection{Introduction}

BMP15 and GDF9 belong to a unique subgroup of the TGF- $\beta$ protein superfamily, characterised by having only six of the seven conserved cysteine molecules normally forming the mature region of TGF- $\beta$ proteins. The missing fourth cysteine residue, found in most other TGF- $\beta$ superfamily proteins, is responsible for covalent dimerisation by forming a disulphide bond between two proprotein molecules, before enzymatic processing at the RXXR cutting site releases a biologically active mature dimer (McPherron and Lee 1993; Dube, Wang et al. 1998; Laitinen, Vuojolainen et al. 1998); (reviewed in Juengel and McNatty 2005). Despite BMP15 and GDF9 being unable to form covalently bound dimers, it has been shown that they can form non-covalently bound homo- and heterodimers, or exist as monomers in vitro (Liao, Moore et al. 2003; McIntosh, Lun et al. 2008). As with several other TGF- $\beta$ proteins, there is evidence for noncovalent interactions between the BMP15 proregion and mature region protein after enzymatic processing, and similarly between the GDF9 proregion and mature region protein (McIntosh, Lun et al. 2008). Co-immunoprecipitation experiments using 293 HEK cell expressed mouse BMP15 and GDF9 proteins show that the proregion of mouse BMP15 can also form heteromeric complexes with the mature region of mouse GDF9, as well as with the mature mouse BMP15 dimer or monomer, whilst mouse GDF9 can be detected mostly as a mature homodimer (McIntosh, Lun et al. 2008).

It has also been reported that in some species, such as mice (McIntosh, Lun et al. 2008), sheep (McNatty, Lawrence et al. 2006) and humans (Saito, Yano et al. 2008), BMP15 and GDF9 are secreted in vitro not only as a mature protein but also as cleaved proregion and uncleaved promature proteins. 
The importance of the proregions and precursor proteins in regulating the biological activity of TGF- $ß$ superfamily proteins has been highlighted in several studies. The non-covalent interaction between the cleaved proregion and the mature dimer keeps some TGF- $\beta$ superfamily members inactive, while in others it is necessary to store the protein in the extracellular matrix (ECM) (Annes, Chen et al. 2004; Anderson, Goldberg et al. 2008; Ramirez and Sakai 2010). TGF-ß monomers reportedly are able to form complexes with ECM linked binding proteins, preventing disulphide bridge formation between the TGF- $\beta$ molecules and therefore keeping them inactive (Shi, Zhu et al. 2011). The mitogenic activities of mouse TGF- $\beta 1$, TGF- $\beta 2$ and TGF- $\beta 3$ proteins were inhibited by interaction between the mature region and proregion forms of these proteins both in vitro and in vivo (Bottinger, Factor et al. 1996). The uncleaved precursor forms of TGF- $\beta$ proteins belonging to the nodal family were shown to have different bioactivities and stabilities than the cleaved mature protein forms (Le Good, Joubin et al. 2005). The uncleaved Nodal precursor protein was also reported to maintain proprotein convertase enzyme (furin and PACE4) activity to facilitate its own processing and by promoting Bmp4 expression to activate a positive feedback loop enhancing nodal expression in mouse embryos (Ben-Haim, Lu et al. 2006). Intact proregionmature region interaction has also been shown to enhance the bioactivity of antiMullerian hormone (Wilson, di Clemente et al. 1993).

Each of the proregions of BMP15 and GDF9 has physiological importance within and outside the oocyte of the ovarian follicle. In rat granulosa cell cultures treated with mouse BMP15 and GDF9 together, immunoneutralisation using antibodies raised against the proregion of mouse BMP15 resulted in diminished synergistic bioactivity of BMP15 and GDF9, as measured by reduced proliferation of granulosa cells (McIntosh, Lun et al. 2008). Mutations identified causing amino acid substitutions in the proregions of human BMP15 and GDF9 were linked to hypergonadotrophic ovarian failure (Di Pasquale, Beck-Peccoz et al. 2004; Dixit, Rao et al. 2006). Immunisation against the proregion of BMP15 or GDF9 in mice (McIntosh, Lawrence et al. 2012) resulted in different ovulation rates and reduced litter sizes, emphasising the importance of the GDF9 and BMP15 proregion in vivo in regulating fertility in mammals. However, the biological activity and potential 
role of most other secreted forms of BMP15 and GDF9, including the uncleaved precursor protein, are unknown.

The overall aim of this study was to investigate the potential bioactivity of the uncleaved promature forms of mouse BMP15 and GDF9 by assessing the abilities of these precursor proteins to increase granulosa cell proliferation in vitro. The aim was firstly to design and produce, in 293 HEK mammalian cells, noncleavable mouse BMP15 and GDF9 precursor proteins with the proregion to mature region cleavage sites mutated so that processing of the precursors by furinlike enzymatic activities was prevented. The biological activities of the uncleaved

promature precursor proteins were then to be compared, using the ${ }^{3} \mathrm{H}$-thymidine incorporation bioassays, to the known active mature forms of BMP15 and GDF9, also produced in 293 HEK cells (McNatty, Lawrence et al. 2006; McIntosh, Lun et al. 2008; Saito, Yano et al. 2008). However, due to unexpected cleavage of the GDF9 protein, experiments to test the biological activity of the uncleaved GDF9 were not undertaken.

\subsection{Method Optimisation}

4.2.1 Designing and generating non-cleavable mouse Bmp15 and Gdf9 gene constructs

When designing the altered cleavage site between the proregions and the mature regions of mouse BMP15 and GDF9, both PAM and Blosum amino acid substitution matrices (Dayhoff 1978; Altschul 1991; Henikoff and Henikoff 1993; Johnson and Overington 1993) were consulted to ensure that the chosen mutations would have minimal alteration to protein charge and polarity, and therefore folding of the protein. It was hoped that the altered cleavage site would not be recognised by the proprotein convertase enzymes such as furin, thus preventing proteolytic cleavage so that the biological activity of the intact precursor protein could be assessed. 
Details of the design and generation of the non-cleavable proteins can be found in Chapter 2, section 2.6.

Briefly, constructs to produce non-cleavable Bmp15 and Gdf9 were designed (Chapter 2, Table 2F) and then purchased from GenScript USA Inc. (Piscataway, NJ, USA). The DNA constructs were then subcloned into pEFIRES and transfected into HEK 293 cells for the production of non-cleavable protein.

To check that the cells were producing RNA (and thus protein) with the correct sequences, after collection of the conditioned media, RNA from the transfected HEK 293 cell cultures was extracted using the ArrayPure ${ }^{\mathrm{TM}}$ Nano-scale RNA purification kit from EPICENTRE Biotechnologies. The messenger RNA was reverse transcribed to cDNA using the Superscript ${ }^{\circledR}$ VILO $^{\mathrm{TM}}$ cDNA synthesis kit from Invitrogen, as described in Chapter 2, section 2.5.1. Full-length mouse Bmp15 and Gdf9 were amplified using primers described in Chapter 2, Table 2A. The resulting products were verified to contain the altered furin cleavage site by automated sequence analysis at the Waikato DNA Sequencing Facility (University of Waikato, Hamilton, New Zealand).

Aliquots of the harvested, non-cleavable mouse BMP15 and GDF9 conditioned (serum-free) media were evaluated, and non-cleavable protein content was quantified by Western blot detection and densitometry analysis using Image $\mathrm{J}$ software.

4.2.2 Detection and quantification of the non-cleavable mouse BMP15 and GDF9 protein forms

The Western blot protocol that was used is detailed in Chapter 2, section 2.4. The antibodies used for evaluation of the non-cleavable proteins were mouse BMP15 proregion polyclonal antisera 8f and ovine/mouse mature GDF9 monoclonal antibody $47 \mathrm{~b}$. Both antibodies had been validated to recognise the non-cleaved promature form of the target proteins. The protein separation on SDS-PAGE gel by electrophoresis had to be optimised for the detection of the non-cleavable mouse BMP15. The mouse proregion antisera $8 \mathrm{f}$ has been shown to recognise a 
large non-specific band similar in size to the promature (precursor) BMP15 protein (see Figure 4A).

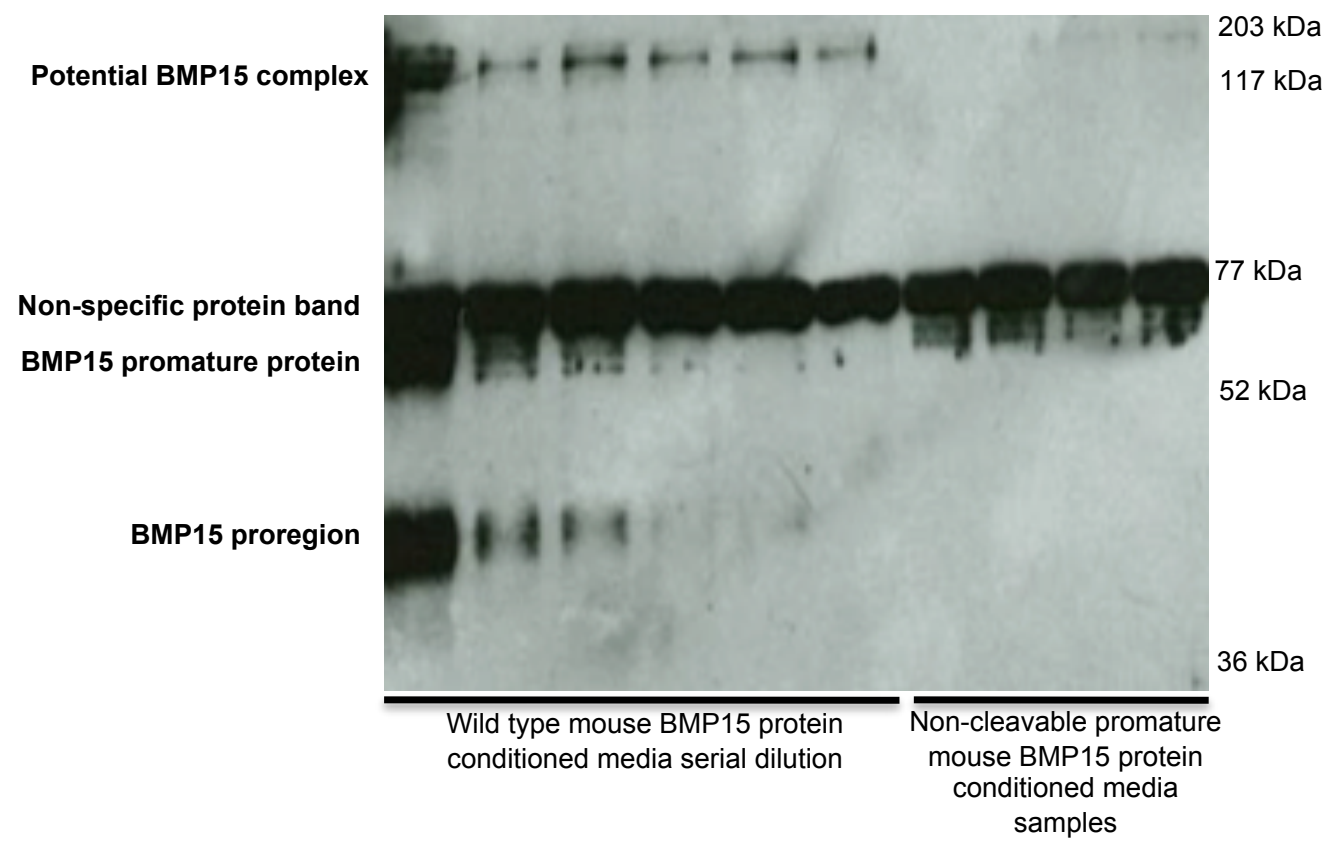

Figure 4A: Serial dilution of wild-type mouse BMP15 (dilution range: 10ng $0.2 \mathrm{ng}$ ) and aliquots of non-cleavable promature mouse BMP15 conditioned media as detected on $13.5 \%$ SDS PAGE gel by immunoblotting with BMP15 proregion antisera $8 \mathrm{f}$.

To be able to separate the promature BMP15 protein band from the non-specific band above it, different SDS PAGE gel concentrations were trialled ranging from $13.5 \%$ to $7.5 \%$. The $10 \%$ and $7.5 \%$ gels (Figures $4 \mathrm{D}-\mathrm{F}$ ) were successful in separating the two proteins to allow quantification of the non-cleaved mouse BMP15 promature protein band using Image J densitometry software, without signal interference from the non-specific protein band above. Three technical repeats (same samples analysed in three different assays) utilizing 7.5\% SDS PAGE gel for Western blot analysis were used for quantification of the noncleavable mouse BMP15 protein.

The reference sample for quantifying the non-cleavable content of the freshly harvested conditioned media was quantified wild-type mouse BMP15 conditioned HEK 293 cell expressed media (McIntosh, Lun et al. 2008). Known concentrations of wild-type mouse protein standards, and respective non-cleavable 
promature protein conditioned media series, were generated by diluting the conditioned media with distilled water, and analysed by electrophoresis on SDS PAGE gels to separate the proteins, followed by Western blotting.

\subsubsection{Methyl- ${ }^{3} \mathrm{H}$-thymidine uptake assay optimisation}

The biological activity of the non-cleavable form of mouse BMP15 in comparison with the wild type protein was evaluated by the ability to promote rat granulosa cell proliferation in methyl- ${ }^{3} \mathrm{H}$-thymidine uptake assays.

The rat granulosa cell (GC) culture system was used since the effects of combinations of GDF9 and BMP15 on rat GC proliferation are well known (McNatty, Juengel et al. 2005b; McIntosh, Lun et al. 2008), and the collection of sufficient numbers of rat GC for all required treatment replicates could be achieved quickly and efficiently.

An established rat GC culture protocol (Lin, Pitman-Crawford et al. 2012) was modified slightly to suit the current study. Rat GC were cultured in serum-free media for $16-18 \mathrm{~h}$ in 96 well flat-bottom plates at 20000 total cells in $55 \mu 1$ M199/1\% PenStrep media per well at $37^{\circ} \mathrm{C}$, 95\% humidity under 5\% $\mathrm{CO}_{2}$. In preliminary experiments, suitable positive controls for the ${ }^{3} \mathrm{H}$-thymidine uptake assays were identified. It was established in dose response studies that a combination of $6 \mathrm{ng} / \mathrm{ml}$ wild-type mouse BMP15 and $60 \mathrm{ng} / \mathrm{ml}$ ovine GDF9 conditioned media increases rat GC proliferation, as reported earlier (McNatty, Juengel et al. 2005b; McIntosh, Lun et al. 2008), while neither growth factor had any effect when administered alone, thereby providing suitable controls when testing the biological activity of the non-cleavable promature protein forms. Mouse GDF9 had shown biological activity on its own in the rat GC culture system; therefore it was deemed unsuitable to test the synergistic biological activity of the various mouse BMP15 and GDF9 protein forms, since the interpretation of the results would have been equivocal (Figure 4B). 


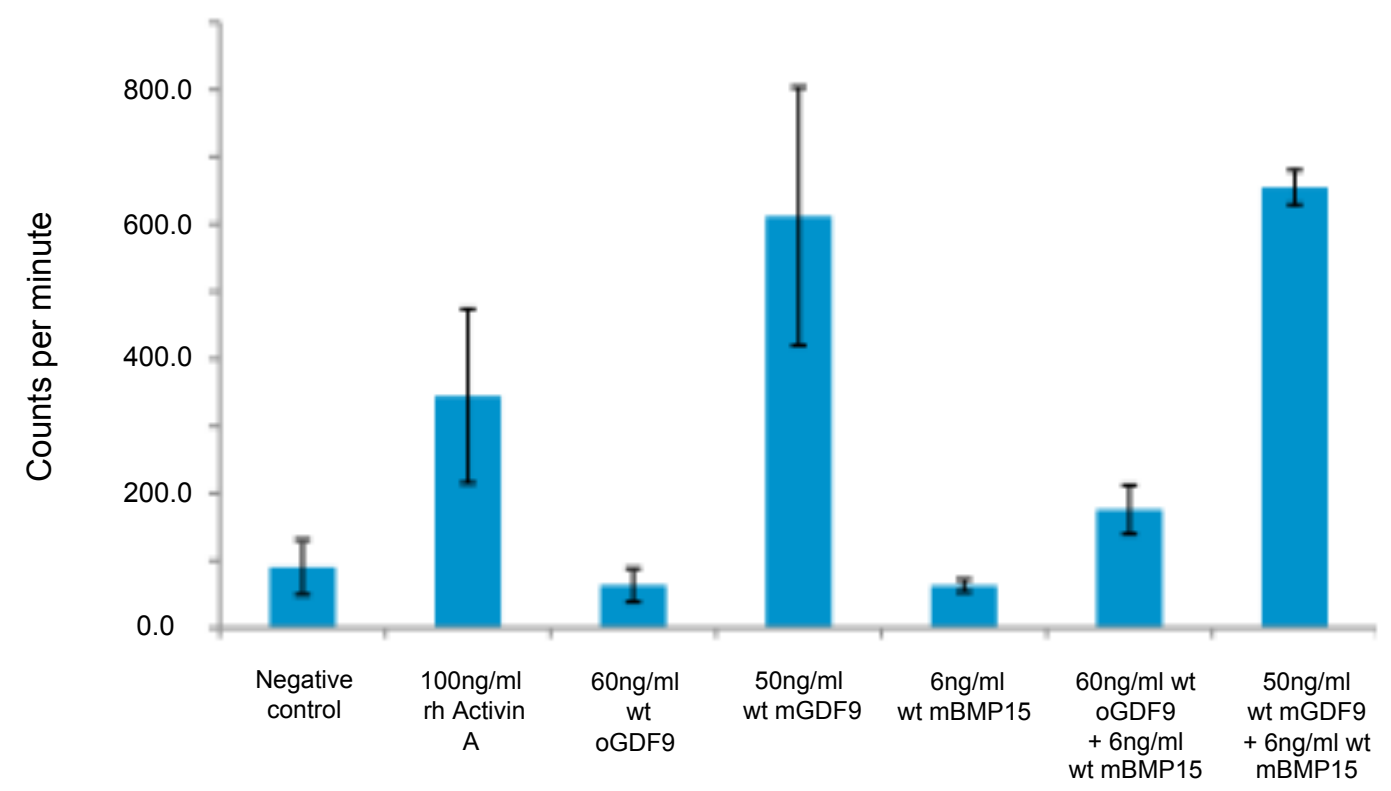

Figure 4B: Example of a validation ${ }^{3} \mathrm{H}$-thymidine uptake assay, testing the biological activity of mouse (m), ovine (o) wild-type (wt) GDF9 and wt mBMP15 alone and in combination to select a suitable positive control for testing the biological activity of the non-cleavable mBMP15 and mGDF9.

Two more assay controls were tested and adopted for the ${ }^{3} \mathrm{H}$-thymidine uptake assays. These included $100 \mathrm{ng} / \mathrm{ml}$ recombinant human activin A and 32 denuded rat oocytes (DO). Assays in which the activin A positive control failed to stimulate ${ }^{3} \mathrm{H}$-thymidine uptake $\geq 1$.5-fold and where the DO failed to stimulate ${ }^{3} \mathrm{H}$ thymidine uptake $\geq 10$-fold were excluded from analysis. It was established previously that components present in the HEK 293 conditioned media interfere with the proliferative activity of granulosa cells, regardless of species of origin (McIntosh, Lun et al. 2008). Therefore, the amount of HEK 293 cell conditioned media was standardised between all treatments and controls at $8 \%$ of the total volume per well. Where the treatment did not amount to $8 \%$, the deficit was made up with HEK 293 conditioned media collected from HEK 293 cells transfected with empty pEFIRES vector.

The ${ }^{3} \mathrm{H}$-thymidine incorporation data were analysed by REML using the GenStat Release 15.1 statistical programme. Counts were log-transformed to stabilise variance. The structure of the model included the technical replicates ( $n=5$ wells/treatment) nested within the biological replicates $(n=5$ independent GC 
pools). The predicted means were compared by two-tailed $t$ test using the approximate average standard error of difference, with $\mathrm{p}<0.05$ considered significant. Tests were limited to pre-planned comparisons. To facilitate interpretation, data are presented as fold changes compared to the negative control.

\subsection{Results}

4.3.1 Generation of non-cleavable mouse promature BMP15 and GDF9

Immunoblot detection carried out on conditioned media harvested from HEK 293 cells transfected with the non-cleavable mouse Gdf9 gene construct showed that, even though non-cleaved promature protein was produced by the transfected HEK 293 cells, most of the proprotein was processed and could be detected as the mature GDF9 protein form (Figure 4C).

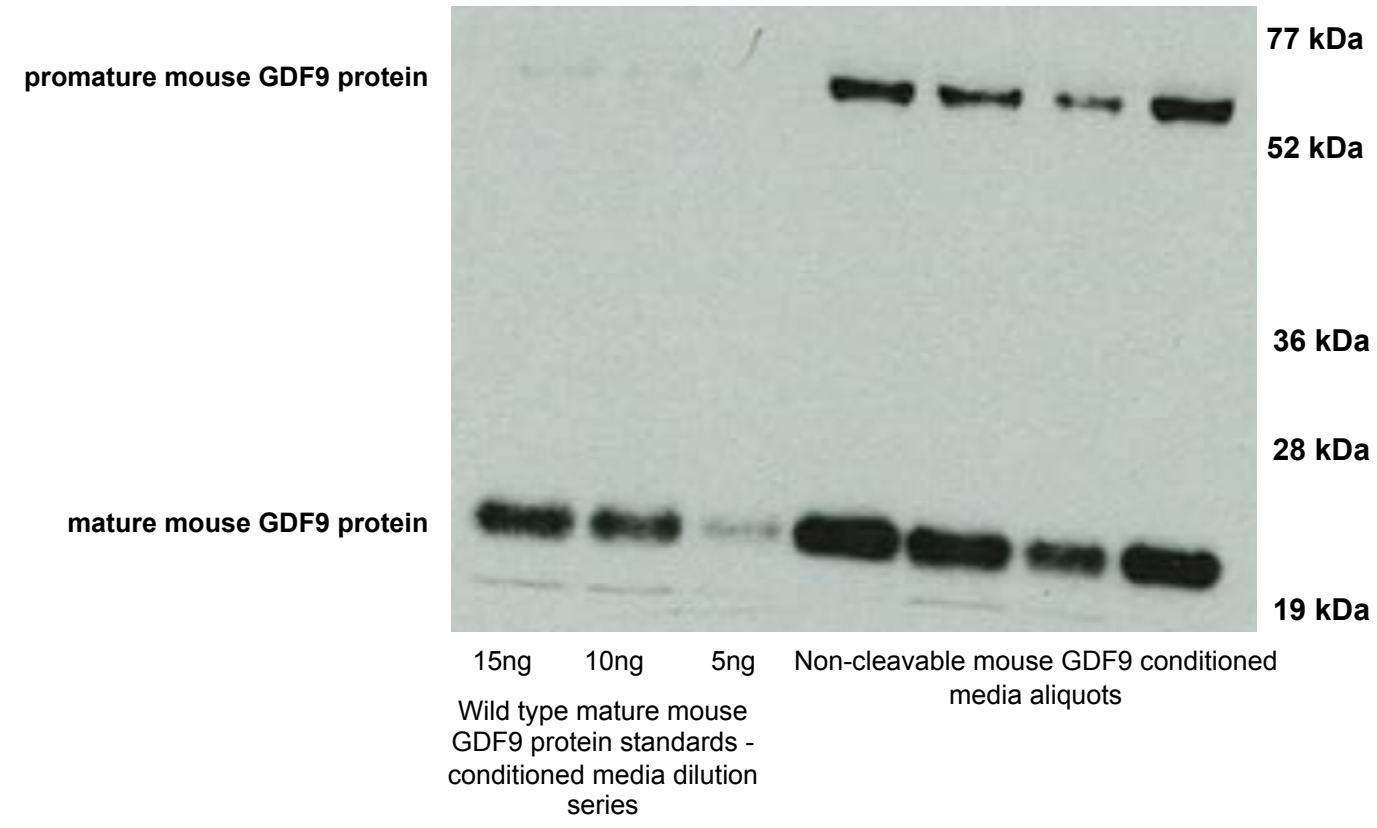

Figure 4C: Non-cleavable mouse GDF9 protein and wild-type mouse GDF9 protein conditioned media Western blot analysis, using mouse/ovine GDF9 mature region mab $47 b$. 
Despite the mutated GDF9 conditioned media containing relatively large amounts of the promature protein form compared to the wild-type (wt) GDF9 conditioned media, it also contained the mature region of the protein in larger quantities. Therefore, further evaluation of this conditioned media, and investigation of mouse GDF9 precursor activity, was not undertaken.

Western blot analysis of the conditioned media collected from HEK 293 cell cultures transfected with the mouse Bmp15 gene construct containing an altered furin cut site, showed that production of the non-cleavable mouse BMP15 promature protein was successful, as shown in Figures 4D and 4E.

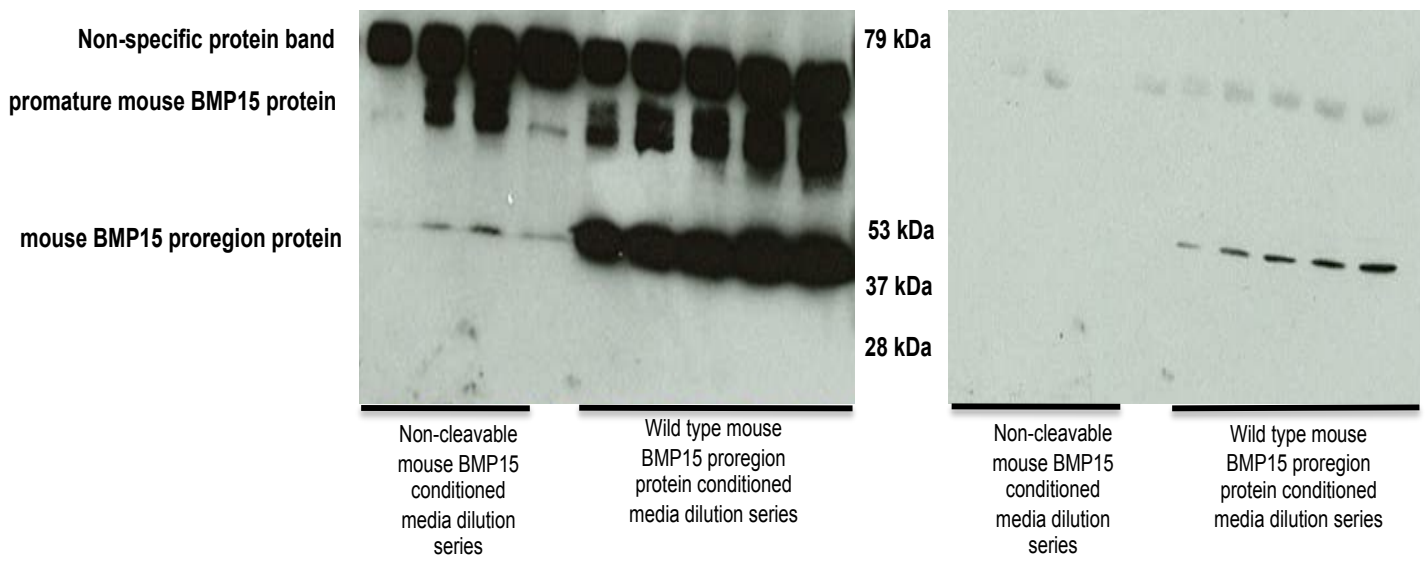

Figure 4D: Mouse BMP15 protein forms in non-cleavable (estimated concentration range: $3 \mathrm{ng}-0.75 \mathrm{ng}$ ) and wild type (dilution range $9.6 \mathrm{ng}-4.8 \mathrm{ng}$ ) mouse BMP15 protein conditioned media, detected on 10\% SDS PAGE gel, using a) mouse proregion antisera $8 \mathrm{f}$ and b) mouse proregion antisera $8 \mathrm{f}$ preadsorbed with the immunisation proregion antigen.

To quantify the non-cleavable mouse BMP15 protein content of the HEK 293 cell expressed conditioned media, the wt mouse BMP15 conditioned media was used as a reference sample. The mature protein content of the wt mouse BMP15 conditioned media was quantified to be $0.8 \mathrm{ng} / \mu \mathrm{l}$ by McIntosh, et al (2008), using E. coli expressed recombinant mouse BMP15 mature protein as a primary reference sample (McIntosh, Lun et al. 2008), but the BMP15 proregion content 
was not quantified due to the lack of recombinant proregion protein as a reference sample.

To estimate the amount of wt mouse BMP15 proregion in the standards, the assumption was made that the proregion protein content of the wt BMP15 conditioned media is 2.17 times of the mature protein content, giving the $\mathrm{wt}$ BMP15 proregion concentration of $1.7 \mathrm{ng} / \mu \mathrm{l}$. This assumption was based on the molecular weights of the different mouse BMP15 protein forms (MW of wt full length form $=44897.8 \mathrm{~g} / \mathrm{mole}$; MW of wt mature region $=13996.9 \mathrm{~g} / \mathrm{mole}$; MW of wt proregion $=30330.26 \mathrm{~g} / \mathrm{mole}$ ), and presuming that for every 1 mature BMP15 protein molecule there is a proregion molecule in the conditioned media, which has $2.17 \mathrm{x}$ the molecular weight of the mature protein. Using this estimated value, the wt mouse BMP15 proregion standard curve was created as shown in Figure 4E. A standard (15.6 ng) was chosen from the linear part of the curve to normalise all non-quantified protein band density values to this density signal value. The unknown BMP15 protein concentrations were estimated by comparing the signal density values of the serial dilutions of the non-cleavable BMP15 conditioned media protein bands to the signal density values of the chosen quantified protein band of the wild type standard. The Western blot analysis was repeated three times and the concentration was calculated as the average of the three technical replicates.

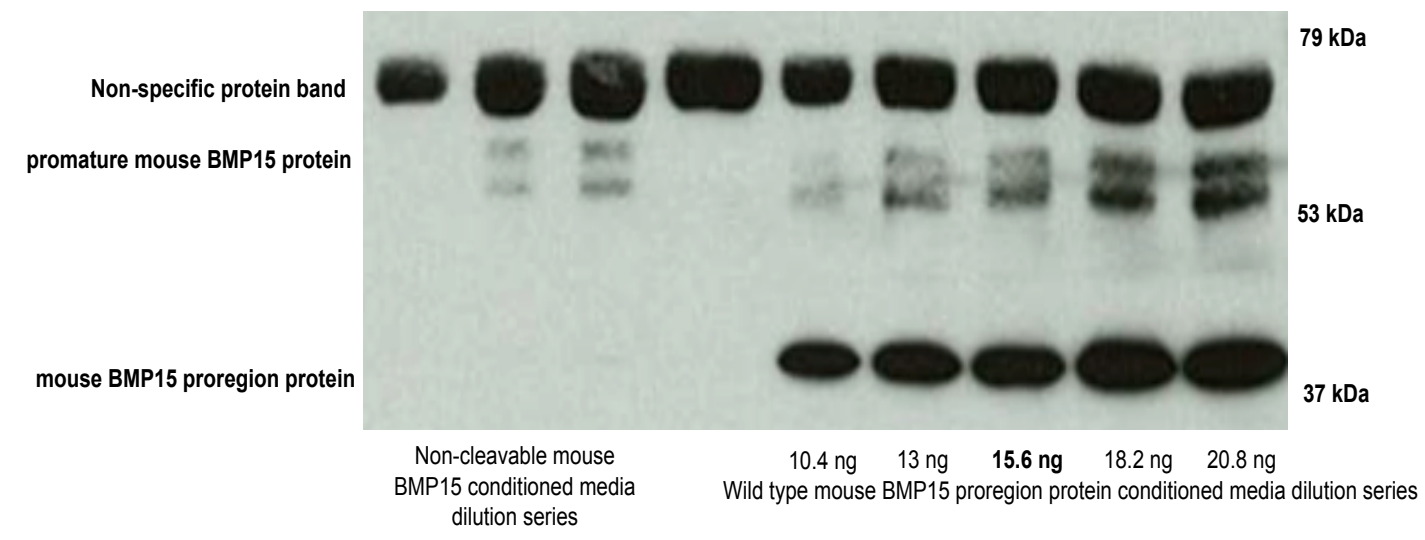

Figure 4E: Quantification of protein forms in non-cleavable mouse BMP15 protein conditioned media, using 7.5\% SDS PAGE gel. Estimated concentration range: $1.5 \mathrm{ng}-3 \mathrm{ng}$, detected by mouse proregion antisera $8 \mathrm{f}$ and compared to a wild type mouse BMP15 conditioned media dilution series (10.4ng - $20.8 \mathrm{ng})$, $\mathrm{n}=3$. The wild-type standard chosen for calculating concentrations based on signal density is highlighted in bold (15.6 ng/well wt BMP15 proregion protein). 
The non-cleavable BMP15 promature protein content in the conditioned media was calculated to be $1.73 \mathrm{ng} / \mu \mathrm{l}$. For comparison, the full-length promature protein concentration of the wt mouse BMP15 conditioned media was $0.85 \mathrm{ng} / \mu 1$. The wt conditioned media also contained $1.74 \mathrm{ng} / \mu \mathrm{l}$ BMP15 proregion protein, while the non-cleavable BMP15 conditioned media had negligible amounts $(<5 \%)$ of proregion protein. The weak band of mouse BMP15 proregion size in the noncleavable mouse BMP15 conditioned media was only detected on overexposed and overloaded immunoblots (Figure 4F). Moreover, when using preadsorbed primary antibody for detection, only partial removal of the wt BMP15 proregion size band was achieved (Figure 4D). This raises the question as to whether this was incomplete preadsorption, or whether there is a non-specific band of the same size as the mouse BMP15 proregion protein $(40 \mathrm{kDa})$ present in the conditioned media samples, which can be detected when large volumes of the non-cleavable BMP15 conditioned media samples are loaded onto the SDS PAGE gels.

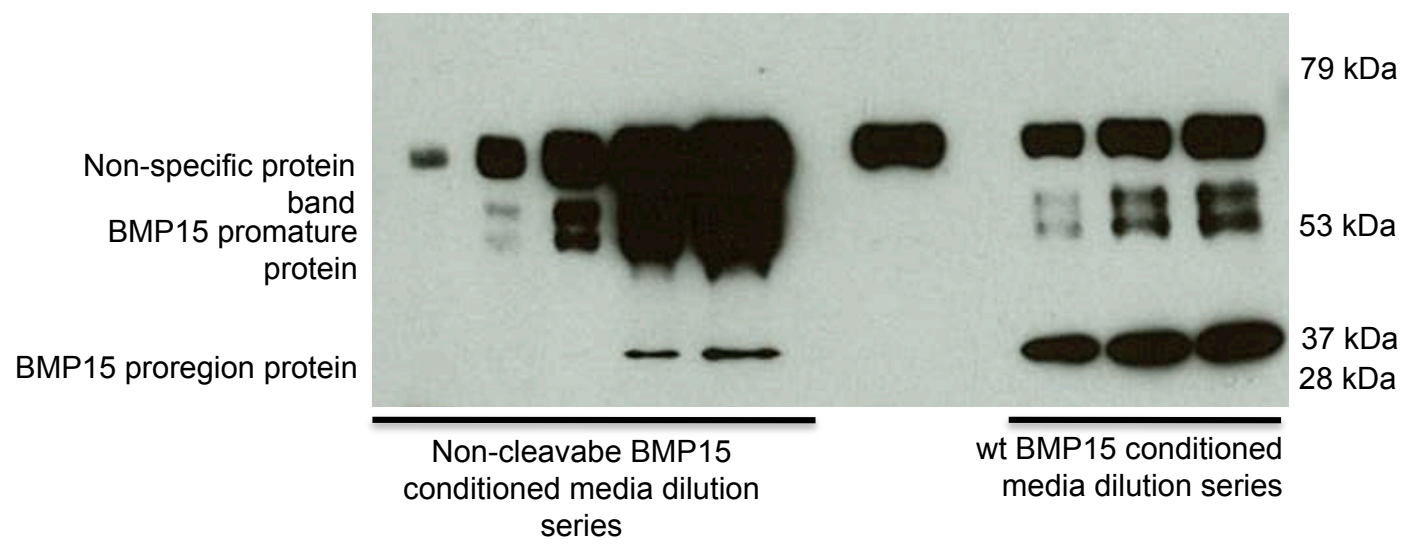

Figure 4F: Overexposed Western immunoblot showing mouse BMP15 proregionsized protein in both wild-type (dilution range $9.6 \mathrm{ng}-4.8 \mathrm{ng}$ ) and mutated (estimated concentration range $12 \mathrm{ng}-0.75 \mathrm{ng}$ ) BMP15 conditioned media on a $7.5 \%$ SDS PAGE gel, detected by the mouse BMP15 proregion antisera $8 \mathrm{f}$.

When the wild-type and the mutated protein standard curves were created by plotting the density of the detected protein bands against the volume of standards, the two standard curves were shown to be approximately parallel to each other 
with high correlation (as assessed by regression analysis in GenStat Release 15.1), providing evidence that the antibody was recognising both the wild-type and the mutated protein forms with the same sensitivity and specificity (Figure 4G).

Fitted and observed relationship

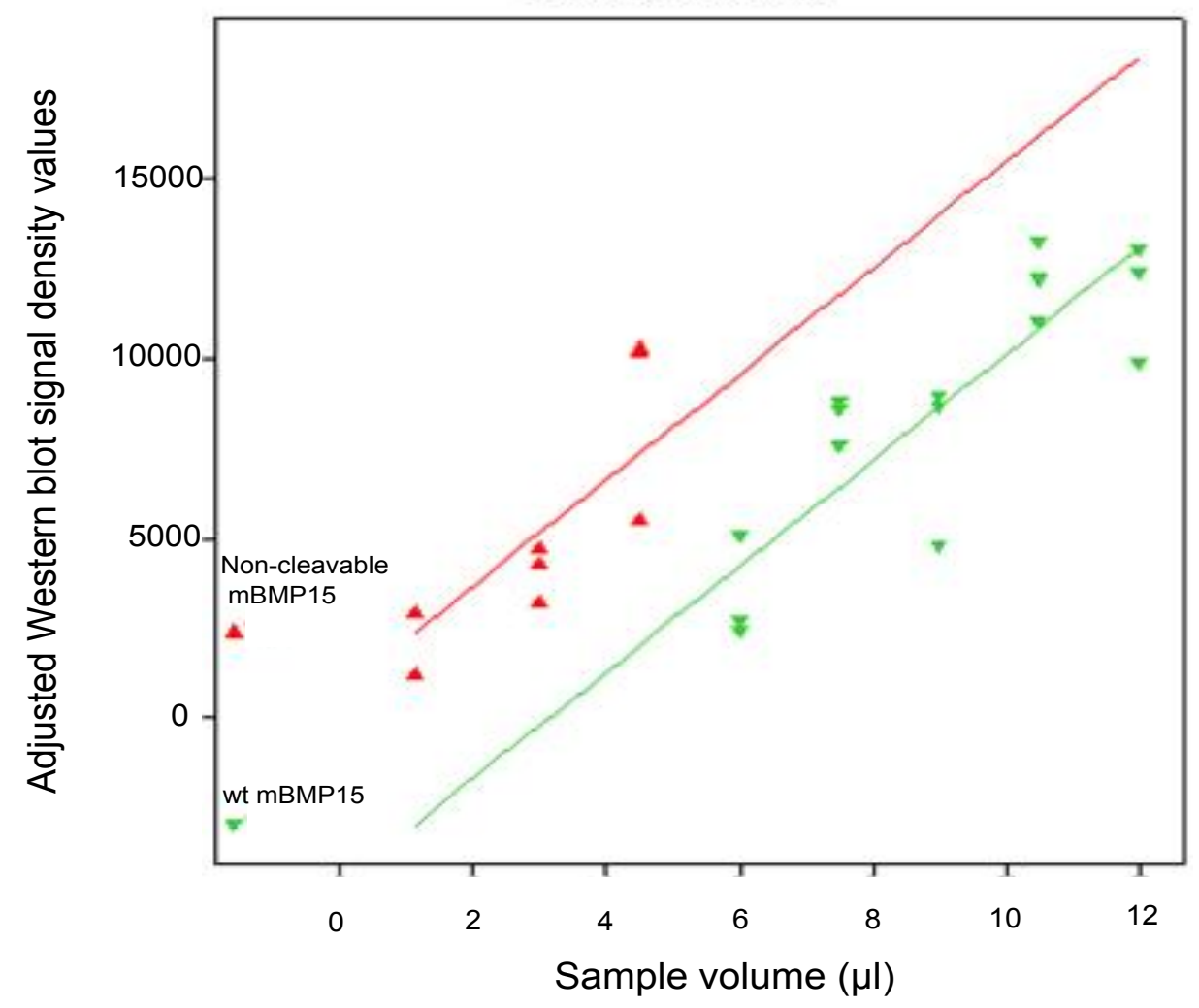

Figure 4G: Parallelism between standard curves of the non-cleavable and wildtype mouse BMP15 promature proteins, when using the mouse proregion antisera $8 \mathrm{f}$. 
4.3.2 Biological activity of the non-cleavable mouse BMP15 promature protein

The biological activity of the non-cleavable promature BMP15 protein was assessed with rat GC methyl- ${ }^{3} \mathrm{H}$-thymidine uptake assays $(\mathrm{n}=5$ independent pools of GC). The activity of the promature protein was compared to the activity of wild-type mature mouse BMP15 and ovine GDF9 protein forms both in combination and individually. Conditioned media containing wt mouse BMP15 and wt ovine GDF9 mature protein were tested at concentrations of $6 \mathrm{ng} / \mathrm{ml}$ and at $60 \mathrm{ng} / \mathrm{ml}$ respectively, either individually or in combination. The above concentrations were chosen as they were shown to have a positive effect on the proliferation of rat GC when combined (McNatty, Lawrence et al. 2006; McIntosh, Lun et al. 2008). At the concentrations examined, neither the wt mouse BMP15 nor the wt ovine GDF9 had any effect on the proliferation of rat GC when administered alone. However, a synergistic effect of the combined treatment was observed with respect to thymidine uptake by rat GC.

In order to compare treatment effects between wt and non-cleavable protein treatments, the amount of mature region protein present in the non-cleavable BMP15 protein treatment was also calculated. The molecular weight of the fulllength promature mouse BMP15 protein is $44897.8 \mathrm{~g} / \mathrm{mole}$. The molecular weight of the wt mouse BMP15 mature region is $13996.9 \mathrm{~g} / \mathrm{mole}$ and the proregion is $30330.26 \mathrm{~g} / \mathrm{mole}$. It follows then that if the concentration of the non-cleavable BMP15 conditioned media is $1.73 \mathrm{ng} / \mu 1$ promature BMP15 protein, than the mature portion of this is $0.54 \mathrm{ng} / \mu 1$. Using this concentration value, the tested noncleavable protein treatments were administered as either 3,6 , or $12 \mathrm{ng} / \mathrm{ml}$ mature BMP15 protein portion of the non-cleavable promature protein, and were used either as individual treatments, or combined with $60 \mathrm{ng} / \mathrm{ml}$ wt ovine GDF9 mature protein. A range of 3, 6 and $12 \mathrm{ng} / \mathrm{ml}$ mature portion of the non-cleavable BMP15 conditioned media was chosen, given the semi-quantitative nature of the estimation of concentration due to the number of assumptions required for the methodology.

Proliferation results are presented as fold changes, normalised to the negative control, which was rat GC treated with $8 \%$ (v/v) 293 cell culture media, harvested 
from HEK 293 cells transfected with pEFIRES plasmid only. The combined wt mouse BMP15 and wt ovine GDF9 treatments showed a mean increase $(p<0.001)$ in rat $\mathrm{GC}{ }^{3} \mathrm{H}$-thymidine uptake by 3 fold (range: 2.2-3.8). In comparison, no significant increase in proliferation was observed when individual wt ovine GDF9 or wt mouse BMP15 treatment was used [1.1 fold (0.9-1.2) and 0.9 fold (0.8-1.2) respectively].

Combining 3, 6 or $12 \mathrm{ng} / \mathrm{ml}$ mature portion of the non-cleavable mouse BMP15 promature protein with $60 \mathrm{ng} / \mathrm{ml}$ wt ovine GDF9 mature protein caused a significant increase $(\mathrm{p}<0.001)$ in rat GC proliferation at $1.3,1.5$ and 1.9 fold, ranging between 1.0-1.6, 1.4-1.9 and 1.7-2.5 respectively. However, the magnitude of the simulation was significantly less $(p<0.001)$ than observed with the wt mouse BMP15 comparing the combined ovine GDF9 and wt mouse BMP15 to any of the combined non-cleavable mouse BMP15 and ovine GDF9 treatments. When administering the non-cleavable mouse BMP15 protein treatments alone, $3 \mathrm{ng} / \mathrm{ml}$ and $6 \mathrm{ng} / \mathrm{ml}$ non-cleavable BMP15 treatments caused a non-significant increase of 1.1 fold (0.9-1.4 and 1.0-1.4 respectively), and the 12 $\mathrm{ng} / \mathrm{ml}$ treatment a significant $(\mathrm{p}<0.05) 1.2$ fold $(1.0-1.3)$ increase in thymidine incorporation in rat GC. Direct comparison of the $6 \mathrm{ng} / \mathrm{ml}$ non-cleavable mouse BMP15 treatment to the $6 \mathrm{ng} / \mathrm{ml}$ wt mouse BMP15 treatment also indicated a significant difference $(p<0.05)$ in mitogenic activity of these two forms (Figure $4 \mathrm{H})$. 


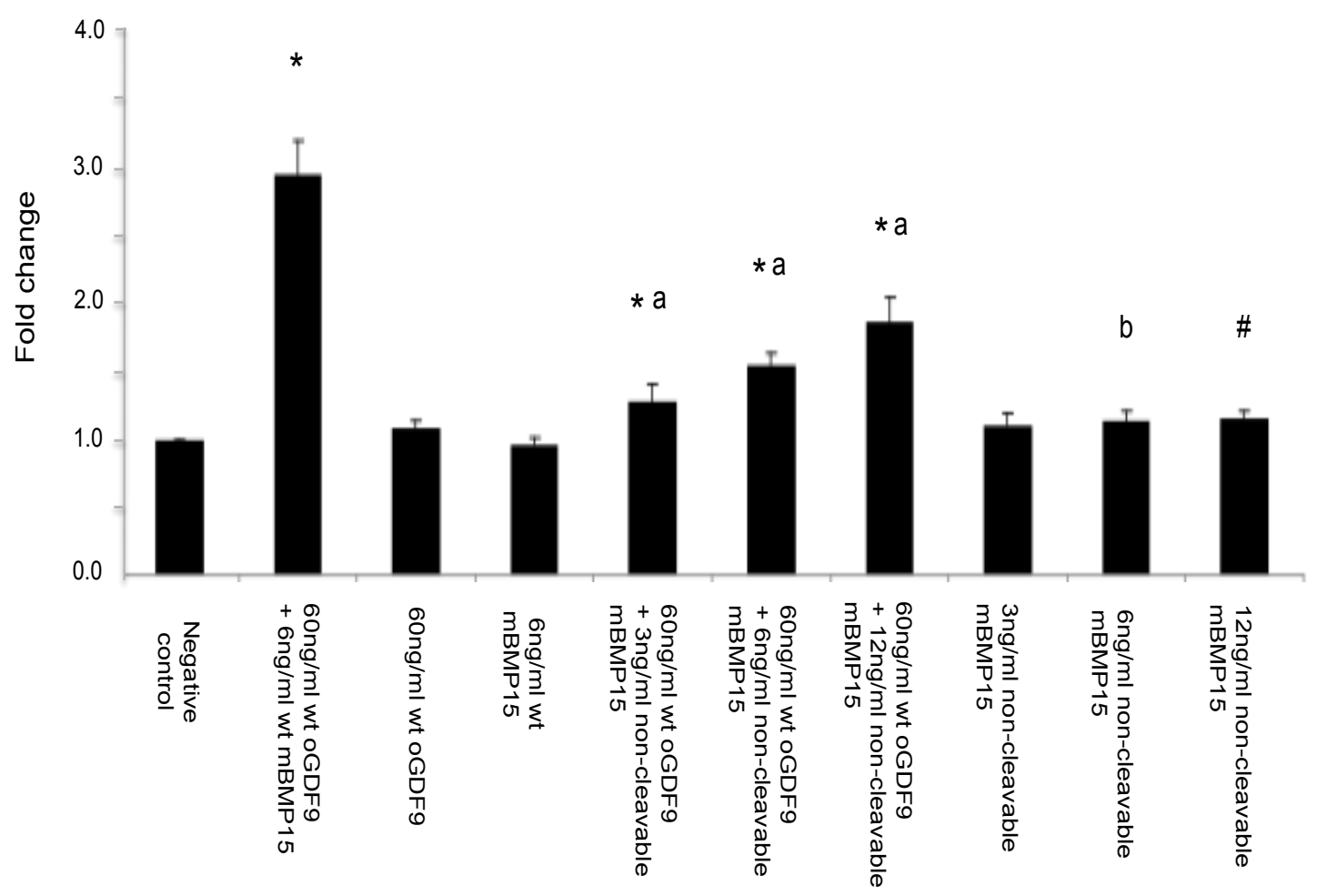

Significant differences compared to negative control are represented by * $(p<0.001)$ and $\#(p<0.05)$. Significant differences compared to $60 \mathrm{ng} / \mathrm{ml}$ wt $0 \mathrm{GDF} 9+6 \mathrm{ng} / \mathrm{ml}$ wt mBMP15 are represented by a $(\mathrm{p}<0.001)$. Significant differences compared to $6 \mathrm{ng} / \mathrm{ml}$ wt mBMP15 are represented by $\mathrm{b}(\mathrm{p}<0.05)$.

Figure 4H: Methyl- ${ }^{3} \mathrm{H}$-thymidine uptake by rat granulosa cells in response to treatment with wt or non-cleavable mBMP15 conditioned media, alone or in combination with wt oGDF9. The error bars represent SEM. Preplanned comparisons included determining if treatments affected ${ }^{3} \mathrm{H}$-thymidine uptake compared to the negative control, and whether the effects of the non-cleavable mBMP15 in combination with wt oGDF9 were similar to the effects of the combined effects of the wt oGDF9 and wt mBMP15. The effect of the $6 \mathrm{ng} / \mathrm{ml} \mathrm{wt}$ mBMP15 was also compared to the individual non-cleavable mBMP15 treatment. Abbreviations: $\mathrm{o}$ - ovine; $\mathrm{m}$ - mouse; $\mathrm{wt}$ - wild-type; $\mathrm{rh}$ - recombinant human

\subsection{Conclusions}

It has been hypothesised that in most species tested so far, the biologically active forms of both BMP15 and GDF9 are the non-covalently bound, cleaved mature dimers, but the biological activities of other protein forms such as the uncleaved full-length mouse BMP15 protein have not been evaluated. Given that 
mouse BMP15 and GDF9 have been detected as both cleaved and uncleaved protein at different stages of follicular development in vivo (Chapter 3), the aim of this study was to identify any potential biological activity of the unprocessed promature form of these proteins.

The finding that, in conditioned media samples collected from the altered Gdf9 transfected HEK 293 cells, posttranslational processing of GDF9 did not completely stop indicates that either there are other enzymes capable of successfully cleaving the human kidney cell derived mouse GDF9 precursor protein at another cleavage site, or that the furin proprotein convertase enzyme is able to recognise an alternative cleavage site to the native RRRR sequence. The general motif established for a possible furin cleavage site is an arginine residue located in position 1 of the cut site and at least two more basic residues at either position 2, 4 or 6 for cleavage by furin to occur (Nakayama 1997). It has been shown that, although the RXXR sequence represents the preferential furin cleavage site, under certain circumstances furin can recognise the RXXXRR sequence as a cut site (Krysan, Rockwell et al. 1999; Thomas 2002).

Such a possible alternative cleavage site (RXXXRR) was introduced by the mutations (RRRR altered to QRRQ) upstream from the native cut site, as shown on Figure 4I. It is likely that this alternative cut site was used in the processing of the mutated GDF9 sequence, preventing the generation of noncleavable mGDF9, and instead producing cleaved protein forms similar in size to those produced by cleavage at the furin cut site. 


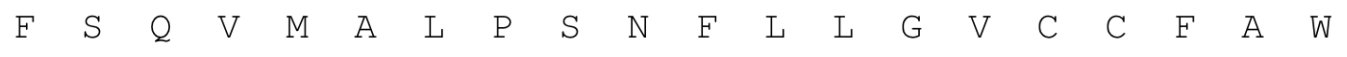

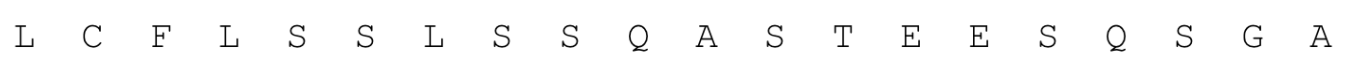

$$
\begin{aligned}
& \begin{array}{llllllllllllllllllllllllllllllll}
S & E & N & V & E & S & E & A & D & P & W & S & L & L & L & P & V & D & G & T
\end{array} \\
& \begin{array}{lllllllllllllllllllllllllllllll}
\mathrm{D} & \mathrm{R} & \mathrm{S} & \mathrm{G} & \mathrm{L} & \mathrm{L} & \mathrm{P} & \mathrm{P} & \mathrm{L} & \mathrm{F} & \mathrm{K} & \mathrm{V} & \mathrm{L} & \mathrm{S} & \mathrm{D} & \mathrm{R} & \mathrm{R} & \mathrm{G} & \mathrm{E} & \mathrm{T}
\end{array} \\
& \begin{array}{lllllllllllllllllllllll}
P & K & L & Q & P & D & S & R & A & L & Y & Y & M & K & K & L & Y & K & T & Y
\end{array} \\
& \begin{array}{llllllllllllllllllllll}
\text { A } & \text { T } & K & \text { E } & G & V & P & K & P & S & R & S & H & L & Y & N & T & V & R & L
\end{array}
\end{aligned}
$$

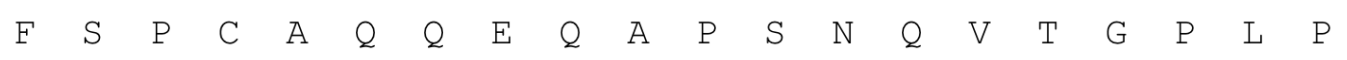

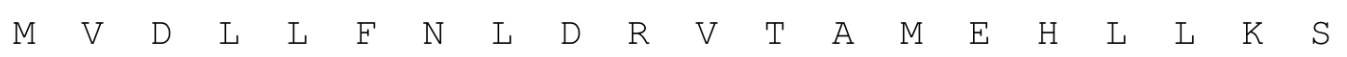

$$
\begin{aligned}
& \begin{array}{lllllllllllllllllllllllllll}
V & \mathrm{~L} & \mathrm{~L} & \mathrm{Y} & \mathrm{T} & \mathrm{L} & \mathrm{N} & \mathrm{N} & \mathrm{S} & \mathrm{A} & \mathrm{S} & \mathrm{S} & \mathrm{S} & \mathrm{S} & \mathrm{T} & \mathrm{V} & \mathrm{T} & \mathrm{C} & \mathrm{M} & \mathrm{C}
\end{array} \\
& \begin{array}{llllllllllllllllllllllllllll}
\mathrm{D} & \mathrm{L} & \mathrm{V} & \mathrm{V} & \mathrm{K} & \mathrm{E} & \mathrm{A} & \mathrm{M} & \mathrm{S} & \mathrm{S} & \mathrm{G} & \mathrm{R} & \mathrm{A} & \mathrm{P} & \mathrm{P} & \mathrm{R} & \mathrm{A} & \mathrm{P} & \mathrm{Y} & \mathrm{S}
\end{array} \\
& \begin{array}{lllllllllllllllllllllllllllllll}
\mathrm{F} & \mathrm{T} & \mathrm{L} & \mathrm{K} & \mathrm{K} & \mathrm{H} & \mathrm{R} & \mathrm{W} & \mathrm{I} & \mathrm{E} & \mathrm{I} & \mathrm{D} & \mathrm{V} & \mathrm{T} & \mathrm{S} & \mathrm{L} & \mathrm{L} & \mathrm{Q} & \mathrm{P} & \mathrm{L}
\end{array} \\
& \begin{array}{lllllllllllllllllllll}
V & \mathrm{~T} & \mathrm{~S} & \mathrm{~S} & \mathrm{E} & \mathrm{R} & \mathrm{S} & \mathrm{I} & \mathrm{H} & \mathrm{L} & \mathrm{S} & \mathrm{V} & \mathrm{N} & \mathrm{F} & \mathrm{T} & \mathrm{C} & \mathrm{T} & \mathrm{K} & \mathrm{D} & \mathrm{Q}
\end{array} \\
& \begin{array}{llllllllllllllllllllllllll}
V & P & E & D & G & V & F & S & M & P & L & S & V & P & P & S & L & I & L & Y
\end{array} \\
& \begin{array}{llllllllllllllllllllllllllllllllll}
\mathrm{L} & \mathrm{N} & \mathrm{D} & \mathrm{T} & \mathrm{S} & \mathrm{T} & \mathrm{Q} & \mathrm{A} & \mathrm{Y} & \mathrm{H} & \mathrm{S} & \mathrm{W} & \mathrm{Q} & \mathrm{S} & \mathrm{L} & \mathrm{Q} & \mathrm{S} & \mathrm{T} & \mathrm{W} & \mathrm{R}
\end{array}
\end{aligned}
$$

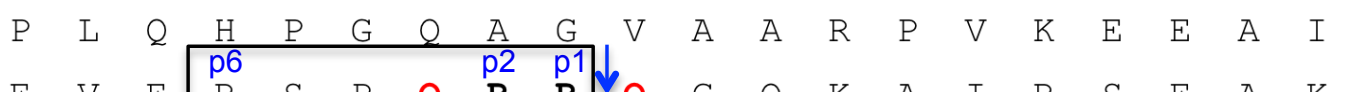

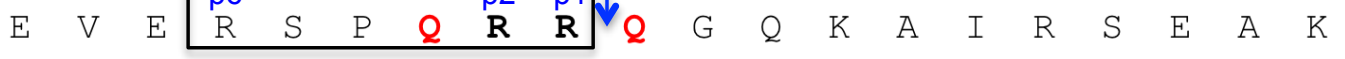

$$
\begin{aligned}
& \begin{array}{llllllllllllllllllllllllll}
G & \mathrm{P} & \mathrm{L} & \mathrm{L} & \mathrm{T} & \mathrm{A} & \mathrm{S} & \mathrm{F} & \mathrm{N} & \mathrm{L} & \mathrm{S} & \mathrm{E} & \mathrm{Y} & \mathrm{F} & \mathrm{K} & \mathrm{Q} & \mathrm{F} & \mathrm{L} & \mathrm{F} & \mathrm{P}
\end{array} \\
& \begin{array}{llllllllllllllllllllll}
2 & N & E & C & E & L & H & D & F & R & L & S & F & S & Q & L & K & W & D & N
\end{array} \\
& \begin{array}{lllllllllllllllllllllllllllll}
W & I & V & A & P & H & R & Y & N & P & R & Y & C & K & G & D & C & P & R & A
\end{array} \\
& \begin{array}{llllllllllllllllllllllll}
\mathrm{V} & \mathrm{R} & \mathrm{H} & \mathrm{R} & \mathrm{Y} & \mathrm{G} & \mathrm{S} & \mathrm{P} & \mathrm{V} & \mathrm{H} & \mathrm{T} & \mathrm{M} & \mathrm{V} & \mathrm{Q} & \mathrm{N} & \mathrm{I} & \mathrm{I} & \mathrm{Y} & \mathrm{E} & \mathrm{K}
\end{array} \\
& \begin{array}{lllllllllllllllllllllllllllll}
L & D & P & S & V & P & R & P & S & C & V & P & G & K & Y & S & P & L & S & V
\end{array} \\
& \begin{array}{lllllllllllllllllllll}
\mathrm{L} & \mathrm{T} & \mathrm{I} & \mathrm{E} & \mathrm{P} & \mathrm{D} & \mathrm{G} & \mathrm{S} & \mathrm{I} & \mathrm{A} & \mathrm{Y} & \mathrm{K} & \mathrm{E} & \mathrm{Y} & \mathrm{E} & \mathrm{D} & \mathrm{M} & \mathrm{I} & \mathrm{A} & \mathrm{T}
\end{array} \\
& \begin{array}{lllll}
R & C & T & C & R
\end{array}
\end{aligned}
$$

Altered furin cleavage site highlighted in bold letters, with the mutations in red. Proposed alternative cutsite boxed. p1; 2 and p6 shows the positions of the necessary basic amino acids in a successful furin cut site, with blue arrow pointing to the cleavage.

Figure 4I: Potential alternative furin cleavage site generated in the altered mouse GDF9 amino acid sequence.

Testing of the non-cleavable BMP15 conditioned media, which was produced by HEK 293 cells transfected with the Bmp15 gene construct containing an altered furin cleavage site, showed that enzymatic processing of the BMP15 precursor protein was successfully halted when the cleavage site was altered from RSVR to QSVQ. In comparison, analysis of the wt BMP15 conditioned media showed unimpaired proteolytic cleavage of the precursor protein with both the 
cleaved and uncleaved protein forms detected. Western blot experiments carried out as part of the present study confirmed that in vitro, as for human and ovine BMP15, mouse BMP15 is secreted both as cleaved and uncleaved proteins (McIntosh, Lun et al. 2008; McMahon, Sharma et al. 2008; Reader, Heath et al. 2011). The wild-type BMP15 conditioned media contained on average less than $20 \%$ of the uncleaved promature protein, while $95 \%$ of the non-cleavable BMP 15 conditioned media was the full-length BMP15 protein, making it suitable as a reference sample to test the biological activity of the promature form of the mouse BMP15 protein. Hashimoto, et al (2005) reported that mouse BMP15 is only secreted as the uncleaved promature form in vitro and proposed that the mature form of the protein is not secreted in mice until just before ovulation (Hashimoto, Moore et al. 2005). In contrast, it has been shown by McIntosh, et al (2008), that mouse BMP15 is indeed processed in vitro and the cleaved mature and proregion forms are present in significant quantities in transfected 293 HEK cell conditioned media.

It is likely that the promature form of mouse BMP15 has a stimulatory activity on rat GC thymidine incorporation, since treating rat GC with 3,6 or 12 $\mathrm{ng} / \mathrm{ml}$ mature portion of non-cleavable mouse BMP15 conditioned media in combination with $60 \mathrm{ng} / \mathrm{ml}$ ovine GDF9 caused a modest, but significant increase in GC proliferation in a dose-dependent manner, which was also observed when administering $12 \mathrm{ng} / \mathrm{ml}$ mature portion of the non-cleavable BMP15 treatments alone.

If, as discussed in section 4.3.1, a small amount $(<5 \%)$ of the BMP15 protein is processed and the cleaved protein forms are secreted together with the noncleavable promature BMP15 into conditioned media, these processed forms could potentially account for some of the bioactivity observed in the ${ }^{3} \mathrm{H}$-thymidine uptake assays. However, it is more likely that it is the non-cleavable form of the mouse promature BMP15 protein which stimulates rat GC thymidine uptake, since when comparing the effects of the same dose $(6 \mathrm{ng} / \mathrm{ml})$ of wt and noncleavable mouse BMP15 individually, the latter stimulated rat GC proliferation significantly $(p<0.05)$ more than wt mBMP15. To assess the bioactivity of the uncleaved promature form of mouse BMP15 further, its affinity for binding to the membrane bound type I and type II BMP receptors would need to be evaluated. 
Interestingly, the wt BMP15 conditioned media contained protein bands of large molecular weight $(117-203 \mathrm{kDa})$, which seem to be recognised by the mouse BMP15 proregion antibody 8f, but were not present in the non-cleavable BMP15 conditioned media (Figure 4B). This could mean that in vitro, the proregion of BMP15 is involved in the formation of large protein complexes, as reported by McIntosh et al, (2008), which does not happen, or not to the same extent, when the proregion is not released from the proprotein by enzymatic cleavage.

In summary, the present study provides evidence that the full-length, uncleaved promature form of mouse BMP15 is biologically active. The proregion of mouse BMP15 may also be important for the formation of large BMP15 protein complexes, as these were not observed when cleavage of the proregion was prevented by mutation of the cut site recognised by members of the proprotein convertase family.

Unimpaired mouse GDF9 protein processing, despite the native RRRR furin cleavage site being altered to QRRQ, indicates that either proprotein convertases or other enzymes with affinity for cut sites other than the furin RXXR site may be capable of processing the GDF9 precursor protein in mice.

Increasing evidence is available to support the hypothesis that it is not just the mature forms of the BMP15 and GDF9 proteins that are biologically active (Di Pasquale, Beck-Peccoz et al. 2004; Dixit, Rao et al. 2005; Dixit, Rao et al. 2006; McIntosh, Lun et al. 2008; McIntosh, Lawrence et al. 2012). The proregions of TGF- $\beta$ protein superfamily members have the potential to play multiple direct and indirect roles (Wilson, di Clemente et al. 1993; Bottinger, Factor et al. 1996; Thies, Chen et al. 2001; Yang, Ratovitski et al. 2001; Annes, Chen et al. 2004; Le Good, Joubin et al. 2005; Ramirez and Sakai 2010; Shi, Zhu et al. 2011) in regulating the biological activity of these growth factors. Similarly, evidence that the uncleaved precursors of several TGF- $\beta$ family proteins play diverse regulatory roles is also increasing (Ben-Haim, Lu et al. 2006; Anderson, Goldberg et al. 2008), including that of the results presented here. 


\section{Chapter 5: General Discussion}

\subsection{The sole source of Bmp15 and Gdf9 is the oocyte in the mouse ovary}

From the results of the ISH and qPCR studies, the location of Bmp15 and Gdf9 mRNA expression was found to be exclusively within oocytes of the mouse ovary. From the three treatment groups of prepubertal female mice primed with PMSG, PMSG + hCG or saline as a control, which were used to represent the developmental stages of follicular growth before and after the preovulatory LH surge, ISH indicated that Bmpl5 was first expressed at the early secondary stage (type 4 follicles) whereas the first $G d f 9$ expression was observed at the primary stage (type 3 follicles). This confirms other reports in regards to the timing of Gdf9 expression in the mouse ovary (McGrath, Esquela et al. 1995), although the timing of Bmp15 expression in the mouse follicle was reported to be slightly earlier at late primary (type 3b) stage (Dube, Wang et al. 1998). This discrepancy between the reported timing of first Bmp15 expression in mouse oocytes could be caused by differences in sensitivity of the different ISH methods used. Both results however suggest that BMP15 has a minimal, if any, role in early primary follicular development in mice.

The results from the qPCR studies were crucial in confirming that the sole source of Bmpl5 and Gdf9 mRNA expression is the oocyte in the mouse ovary. In rats, a similar pattern for Bmp15 mRNA was reported, with expression localised to the oocyte, and increasing during the preantral stages and then constant through to ovulation (Erickson and Shimasaki 2003). GDF9 is also reported to be oocytederived for most species studied (for review, see Mazerbourg and Hsueh 2003). In the present study, the ISH results alone might infer that sensitivity may have been an issue in detecting Bmpl5 and Gdf9 mRNA but it is not an issue when qPCR is used. A number of qPCR sample collection methods were tested to minimise the possibility of cross contamination between the different ovarian cell types. The optimisation of the sample collection highlighted the importance of sample purity and provided a potential cause for the contradicting reports in various species 
(Duffy 2003; Silva, van den Hurk et al. 2005; Paradis, Novak et al. 2009; Celestino, Lima-Verde et al. 2011; Hosoe, Kaneyama et al. 2011) regarding the location of BMP15 and GDF9 mRNA expression.

The tight correlation between mouse Bmpl5 and Gdf9 mRNA expression previously reported (Crawford and McNatty 2012) was confirmed in the present study. Moreover, it has been shown for the first time that this tight correlation between Bmpl5 and Gdf9 remains constant at all stages of antral follicular development in the mouse. This finding is consistent with the hypothesis that BMP15 and GDF9 cooperate to regulate follicular growth and oocyte maturation throughout all stages of antral follicular development (McNatty, Juengel et al. 2005a; McNatty, Juengel et al. 2005b; McNatty, Lawrence et al. 2006).

It was also demonstrated in mice that, throughout all stages of antral follicular development, $G d f 9$ is expressed in greater abundance relative to Bmp15 with the mean Bmp 15:Gdf9 mRNA ratio remaining constant at 1:4.12. In contrast it has been shown in monovular species (e.g. sheep, cow and red deer) that the mean BMP15:GDF9 mRNA ratio is much lower (Crawford and McNatty 2012), suggesting that a low BMP15:GDF9 ratio might be associated with low ovulation quota, while a higher BMP15:GDF9 ratio such as observed in rats (Crawford and McNatty 2012), as well as in mice, is indicative of high ovulation rate. One exception to this notion was found for the polyovular pig where the BMP15:GDF9 ratio was 1:0.5 (Crawford and McNatty 2012). Nevertheless, the species-specific relative mRNA expression levels of Bmp15 and Gdf9, and the tight correlation observed between the expression levels of these genes in all species studied, points to these being important and highly regulated elements in the molecular actions of BMP15 and GDF9.

The results reported in this thesis indicated that while the Bmp15: Gdf9 expression ratio in mouse oocytes remained unchanged throughout follicular growth, the Bmp15 and Gdf9 message levels after the LH surge declined in GV oocytes and decreased still further in those undergoing GVBD. This decrease in gene expression coincides with the breakdown of gap junctions between the oocyte and the surrounding cumulus cells during cumulus expansion (Granot and Dekel 1994; Larsen, Chen et al. 1996; Kalma, Granot et al. 2004; Sela-Abramovich, Chorev et al. 2005) and could be a physiological effect of the breakdown in the bidirectional 
communication between the oocyte and somatic follicular cells. The downregulation of these genes is likely to remove the inhibitory effects of the oocyte on certain somatic cell functions (Otsuka, Yao et al. 2000; Vitt, Hayashi et al. 2000; Yamamoto, Christenson et al. 2002). For example this would remove an inhibitory effect on granulosa cells to undergo luteinisation and increase progesterone production (Eppig 2001).

\subsection{BMP15 and GDF9 protein is localised primarily to cumulus/granulosa cells in the mouse ovary following the preovulatory LH surge}

Western blot analyses of mouse follicular cell samples collected from the three established treatment groups determined that both BMP15 and GDF9 are produced in a number of forms during the different stages of follicular development in mouse follicles. The cleaved mature and proregion forms of mouse BMP15 were detected in both oocyte and somatic cell lysates collected from all three treatment groups. Uncleaved promature (precursor) BMP15 protein as well as large, potentially multimeric complexes, were detected only in the oocytes both before and after hCG treatment, until the oocyte underwent LH induced GVBD, when the large complexes were observed exclusively in the expanded cumulus cell lysate. After GVBD, the only BMP15 protein form detected in the oocyte was the uncleaved promature protein. The detection of the different GDF9 protein forms was hindered by the lack of specific antibodies and non-specific signalling. Therefore, prior to the LH induced GVBD in oocytes, only the cleaved mature region protein was identified and only in somatic follicular cells. Following GVBD, both the cleaved mature and uncleaved promature GDF9 protein was observed in the expanded cumulus mass. The fact that GDF9 was detected in somatic cells only, and only as mature protein, could mean that the protein is secreted rapidly from the oocyte at this time, and processed immediately. However, GDF9 has been observed in mouse oocytes by immunocytochemistry (Elvin, Clark et al. 1999), supporting the notion that the inability to detect GDF9 in mouse oocytes in the present study may have been an assay sensitivity issue. The protein content in oocyte lysates compared to somatic 
cell samples used in the Western blot assays was not standardised, therefore it is possible that there were larger pools of somatic cells analysed compared to oocytes.

The detected BMP15 and GDF9 protein forms at different stages of mouse follicular development are summarized in Figures 5A and 5B. The diagram also includes an additional hypothesis, which proposes a posttranslational processing and secretion profile of BMP15 and GDF9 from the mouse oocyte.

A previous study by Gueripel, et al (2006), also reported BMP15, as well as GDF9, protein expression in mouse oocytes throughout follicular development, and BMP15 expression in the expanded cumulus mass after the preovulatory LH surge and in follicular fluid of atretic follicles. Another report however indicated that BMP15 is only present in the mouse follicle after the preovulatory LH surge, immediately before ovulation (Yoshino, McMahon et al. 2006). This study had the same experimental design and model animal as the present work, but analysed only $6 \mu \mathrm{g}$ of follicular cell lysate (less than half of what was tested in this thesis), and used a different, potentially less sensitive antibody for detection. The findings of this thesis study are contradictory to another report, that in vitro, mouse BMP15 protein is produced by transfected HEK 293 and $\mathrm{CHO}$ cells as the uncleaved promature protein only, suggesting that during posttranslational processing the full-length protein undergoes degradation, rather than enzymatic cleavage and secretion (Hashimoto, Moore et al. 2005).

The results presented here are in agreement with findings by McIntosh, et al (2008), reporting that mouse BMP15 and GDF9 are indeed produced in vitro as both cleaved and uncleaved proteins, as well as in large, potentially multimeric complexes. 


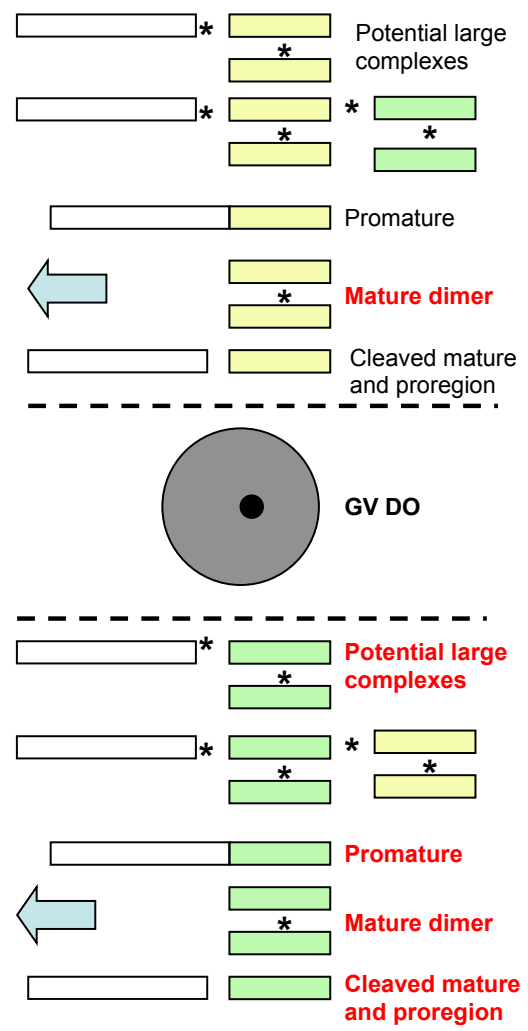

Protein forms detected by Western blot analysis in the present study are labelled with black letters. Protein forms labelled with red letters are forms that are hypothetical. * denotes non-covalent interaction between monomers; yellow boxes represent the BMP15 mature region, green boxes the GDF9 mature region, while clear boxes represent either BMP15 or GDF9 proregion forms.

Figure 5A: BMP15 and GDF9 protein expression in the mouse follicle before the LH surge. Prior to the preovulatory LH surge, which triggers GVBD in the preovulatory oocytes, BMP15 was detected in DO at all stages of follicular development as both the cleaved mature and proregions, uncleaved promature form, and large, potentially multimeric complexes and although there was evidence for a homodimeric form this was not unequivocally proven. This indicates that the oocyte is producing and secreting both processed and unprocessed proteins, as well as assembling large, potentially latent complexes, most likely for storage in the ECM for possible further processing. The cleaved pro- and mature regions and the mature dimer were detected in somatic follicular cells at the same developmental stages. This could either mean that these are the forms capable of binding to the cell membrane-associated receptor complexes, or that the somatic cells, as well as the DO, are also able to process the large complexes and/or the promature form of BMP15.

GDF9 protein expression was not detected in the DO but only in CC as processed mature protein. The lack of available antibodies prevented collection of required data to determine whether GDF9 expression was similar to that of $\mathrm{BMP} 15$, as in the figure, or if it differed. 


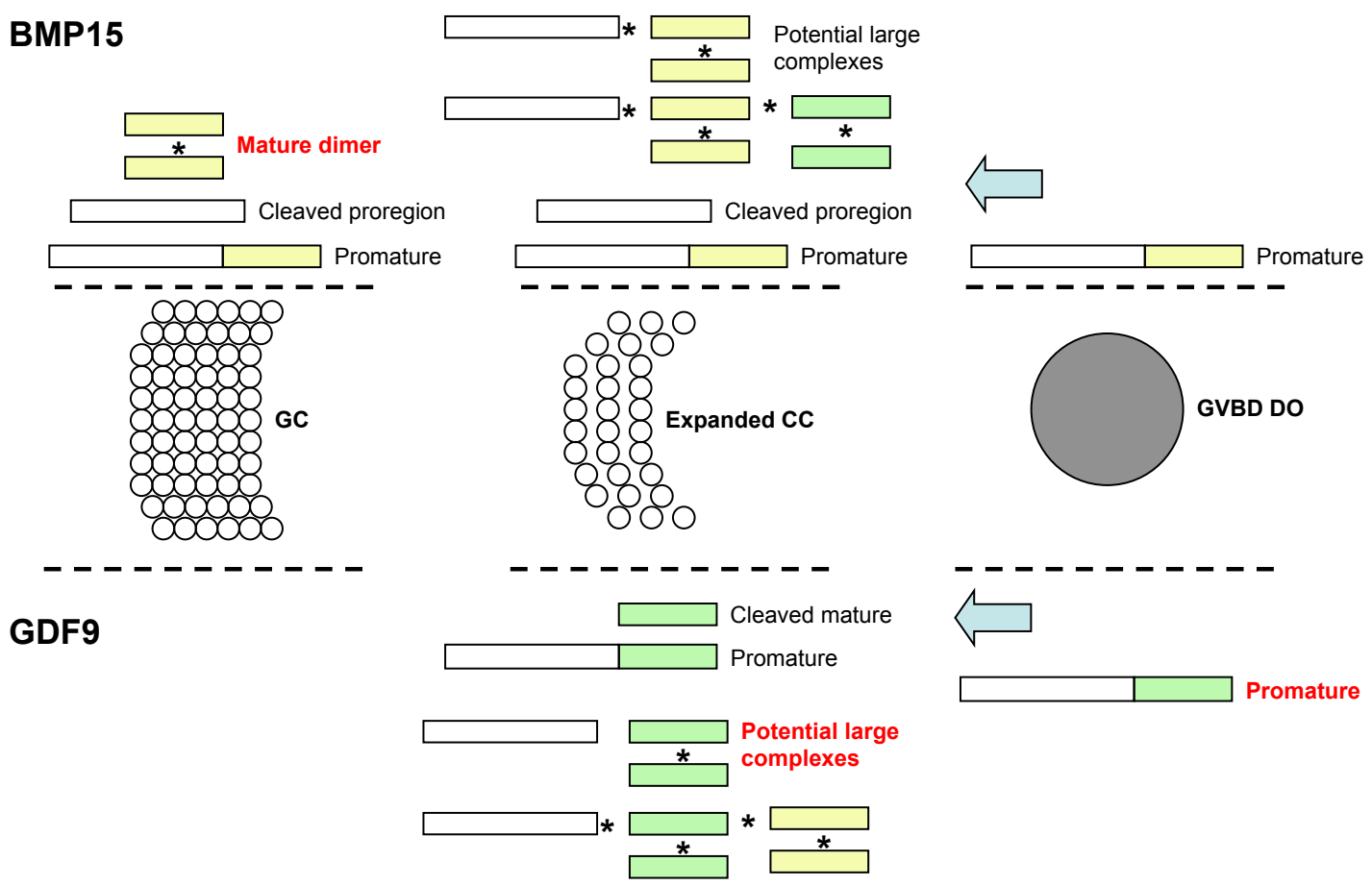

Protein forms detected by Western blot analysis in the present study are labelled with black letters. Protein forms labelled with red letters are forms that are hypothetical. * denotes non-covalent interaction between monomers; yellow boxes represent the BMP15 mature region, green boxes the GDF9 mature region, while clear boxes represent either BMP15 or GDF9 proregion forms.

Figure 5B: BMP15 and GDF9 protein expression in the mouse follicle after the LH surge. Following the preovulatory LH surge, only the uncleaved promature BMP15 protein was detected in the GVBD DO, suggesting that processing of the protein slowed in the DO. The large protein complexes, the promature BMP15 and the cleaved proregion were detected in the expanded cumulus mass, giving further weight to the notion that the large complexes serve as a latent stored form, awaiting further enzymatic and other processing in the ECM. Further out in the granulosa cell compartment of the follicle, cleaved and uncleaved forms of the protein, but not the large complexes, were also detected. This could either mean that the GC is not capable of storing and processing the large complexes, or that the detection of the target proteins in CC but not in DO has been made easier by the extracellular matrix of the expanded cumulus mass capturing the rapidly secreted and processed oocyte-derived proteins.

GDF9 protein expression potentially follows the same pattern as BMP15 with both cleaved and uncleaved GDF9 detected in the CC compartment after the LH surge. This supports the idea that posttranslational processing of the secreted proproteins could take place inside or outside of the oocyte.

However, it is important to note, that proteins in biochemical solutions may differ from those in biological fluids where they are associated proteoglycans and binding proteins (Russell and Robker 2007). The same report by McIntosh et al, 
(2008) also showed that immunoneutralization of the proregion of mouse BMP15 inhibits the synergistic bioactivity of mouse BMP15 and GDF9 in vitro, providing further evidence of the importance of the mouse BMP15 proregion in regulating bioactivity of these proteins. A more recent study reported that immunising mice with BMP15 or GDF9 proregion peptides leads to altered ovulation rates and smaller litter sizes (McIntosh, Lawrence et al. 2012). In co-immunoprecipitation experiments, the proregions of mouse BMP15 and GDF9 individually associated with mouse granulosa cells, providing evidence that the proregion forms of these proteins are able to directly interact with somatic follicular cells in vitro (Mester, et al 2013; submitted manuscript). The presence of the BMP15 proregion throughout follicular development in mice, as detected in the present study, also supports the proregion having important functions in the regulation of follicular development.

The uncleaved promature form of BMP15 was detected in oocytes and somatic cells following GVBD, induced by hCG treatment, but was not observed in less mature follicles in oocytes or in the surrounding somatic follicular cells. One explanation is that with an up-regulation of BMP15 protein expression after the LH surge, the promature BMP15 is at a level that is able to be visualised by Western blot. However, it is also possible that posttranslational processing of BMP15 is down-regulated in the mouse follicles just before ovulation, but does not cease completely since the cleaved proregion of BMP15 was also detected in cumulus cells collected from follicles with GVBD oocytes. Since the proregion was no longer present in GVBD DO, but only in the corresponding cumulus mass and to a lesser extent GC, postranslational processing could potentially be taking place outside of the oocyte as well, as reported in the case of other TGF- $\beta$ superfamily members, such as nodal (Beck, Le Good et al. 2002) and myostatin (Anderson, Goldberg et al. 2008). Another possibility is that the proregion protein could have been secreted from the oocyte throughout follicular development but only sequestered in the expanded cumulus mass by binding proteins, proteoglycan or other molecules whose expression was up-regulated after the LH surge (Russell and Robker 2007). Similar roles and expression patterns are likely to apply for the GDF9 protein forms as indicated in Figures $5 \mathrm{~A}$ and $5 \mathrm{~B}$, but this was not confirmed due to lack of specific antibodies able to recognise the different mouse GDF9 forms. 
Both the DO and the somatic cell lysates also showed the expression of an unidentified $37 \mathrm{kDa}$ protein specifically recognised by the BMP15 mature region antibody. This might be a dimeric form of BMP15 protein or a monomeric form associated with another protein (potentially an ECM binding protein), even though the Western blot was run under reducing conditions. Despite the reducing conditions, evidence that this $37 \mathrm{kDa}$ protein was an authentic non-covalently bound mature BMP15 dimer is indicated from the blocking experiment, where the BMP15 mature region antibody (A-20) was preadsorbed with the blocking peptide supplied by the manufacturer, showing a significant decline in the $37 \mathrm{kDa}$ signal intensity.

The inability to detect a GDF9 mature homodimer in the present Western blot series however raises doubts about the authenticity of the $37 \mathrm{kDa}$ BMP15 band. The possibility of inadequate reduction of Western blot samples was raised earlier, since the addition of an extra $10 \%$ of reducing agent (ß-mercaptoethanol) improved the detection of the BMP15 mature protein in all sample types. Therefore a GDF9 homodimer, if present, should have been detected. A potential mouse GDF9 mature dimer however would be slightly larger than the BMP15 dimer, above the $40 \mathrm{kDa}$ mark, where non-specific signalling was often observed on immunoblots, masking the possible detection of a GDF9 dimer. It is also possible, that in vivo, mouse GDF9 does not form mature homodimers, despite it being one of the protein forms detected previously in vitro (McIntosh, Lun et al. 2008). Under the present experimental conditions no heterodimers of BMP15 and GDF9 were detected either. To confirm the presence or absence of homodimers and/or heterodimers the experiments would have to be repeated using nonreducing and/or cross-linking reagents as described by Edwards et al (2008). A recent report by Peng, et al (2013) described the presence of GDF9 and BMP15 homodimers and heterodimers in rodents and humans although these finding has been disputed (see Mottershead, Harrison et al. 2013).

Another unidentified BMP15 protein form detected was a large 118-211 kDa band in the DO lysates at all developmental stages and also in the cumulus mass collected from GVBD COC following hCG treatment. This band could represent large multimeric complexes, involving both the mature and the proregions of BMP15, since it was recognised by both the proregion (8f) and the mature region 
(A-20) antibodies. Again, these bands could have been the products of incomplete reduction, or an artefact of the conditions of the Western blotting technique. Similar high molecular weight complexes, containing the pro- and mature regions of recombinant mouse BMP15 and GDF9 proteins after chemical cross-linking, have been observed previously (McIntosh, Lun et al. 2008). Other TGF- $\beta$ proteins, such as myostatin (Thies, Chen et al. 2001; Anderson, Goldberg et al. 2008) and TGF- $\beta 1,2$ and 3 are also known to be held in association with latencyassociated peptides (LAP), bound to latent TGF- $\beta$ binding proteins in the ECM, forming large inactive complexes, before the biologically active TGF- $\beta$ ligand is released for signalling (Miyazono, Hellman et al. 1988; Kanzaki, Olofsson et al. 1990; Moren, Olofsson et al. 1994; Saharinen, Taipale et al. 1998; Koli, Saharinen et al. 2001; Rifkin 2005). The BMP15, and potentially the GDF9, mature proteins may also be stored in a similar fashion, bound non-covalently to the proregion and potentially to other binding proteins for transport, recruitment and sequestration before becoming biologically active, as suggested previously (Simpson, Stanton et al. 2012; Watson, Mottershead et al. 2012). Two TGF-ß monomers were shown to create a complex with an ECM- linked binding protein, preventing disulphide bridge formation between the TGF- $\beta$ molecules thereby keeping them inactive, until integrin molecules released and activated the growth factors by applying tactile forces (Shi, Zhu et al. 2011). Similar mechanisms could play a role in the storage and activation of mouse BMP15, and potentially GDF9, involving components of the cumulus cell matrix.

When COC, GC and CC lysates were tested separately following hCG treatment, only the CC contained detectable levels of GDF9 in the form of uncleaved promature protein. This, together with the presence of the uncleaved BMP15 and large potentially latent complexes in $\mathrm{CC}$, supports the hypothesis that together with the down-regulation of Bmpl5 and Gdf9 mRNA expression in the oocytes, proteolytic processing of both BMP15 and GDF9 may also be reduced after the preovulatory LH surge. However, the inability to detect GDF9 in other ovarian cell samples could also have been due to insufficient sample concentrations. Similarly, not being able to detect other forms of the protein could be attributed to the lack of specific antibodies. To overcome these technical difficulties, previous studies characterising BMP15 and/or GDF9 used his- or FLAG taged recombinant 
proteins and employed antibodies raised against the tags for detection of the various forms of BMP15 and GDF9 protein. The generation of more specific monoclonal antibodies for mouse BMP15 and GDF9 mature regions and proregions would be highly valuable, in order to clarify changes in the expression levels, changes in location and changes in protein form occurring during follicular development.

In summary, oocyte-derived mouse BMP15 and GDF9 are produced at all stages of follicular development and possibly enzymatically processed by both the oocyte and within the extracellular matrix surrounding somatic follicular cell compartment. The proregion of BMP15 might be involved in assembling large multimeric complexes, but the function and biological activity of these complexes are unknown, although they could also be a consequence of the in vitro conditions. It could not be determined if similar complexes of GDF9 were present as there was no suitable GDF9 proregion antibody available and the mature region antibody used often produced non-specific signalling above the $40 \mathrm{kDa}$ mark, making it impossible to detect any protein forms larger than the $40 \mathrm{kDa}$ proregion. Following the preovulatory LH surge, the expression of both genes are downregulated in the oocyte and the posttranslational processing of the proteins are reduced, just as the gap-junction communication between the oocyte and the somatic follicular cells is disabled, removing the inhibitory effects of oocyte produced growth factors from the somatic cells, and enabling luteinisation of GC and ovulation of the COC.

\subsection{The uncleaved promature form of mouse BMP15 is biologically active}

The present results showed that the full-length, uncleaved promature forms of mouse BMP15 and GDF9 are present in follicular cell lysates from the mouse ovary. This raises the possibility that the promature proteins have a biological or regulatory activity. To establish whether secreted promature forms of BMP15 and GDF9 have biological activity, molecular constructs were designed in order to produce non-cleavable promature forms of these proteins where the RXXR furin 
cleavage sites between the pro- and mature domains of each of BMP15 and GDF9 proteins were modified to QXXQ.

In the case of mouse GDF9 protein, where the original amino acid motif was RRRR, the modification to QRRQ lead to the creation of a six amino acid long sequence (RSPQRR) that fulfilled the requirement for a potential secondary, less efficient furin cleavage site (Nakayama 1997; Krysan, Rockwell et al. 1999; Thomas 2002) (see Chapter 4, Figure 4H). This secondary cut site could explain why enzymatic processing of the modified mouse GDF9 occurred, yet was incomplete. When compared to the wild-type protein, where close to $100 \%$ of the GDF9 protein was cleaved, processing of the modified GDF9 was less efficient, as evidenced by the presence of a relatively large amount of non-cleaved promature protein in the modified GDF9 conditioned media. Since enzymatic processing of GDF9 was not fully blocked, the biological activity of the fulllength promature mouse GDF9 was not investigated further. Purification of the promature form of GDF9 protein, or repeated transfection of 293 HEK cells with a $G d f 9$ construct containing a different mutation was not attempted due to time constraints.

A promature form of mouse BMP15 was successfully produced by transfected 293 HEK cells and quantified in a series of Western blot experiments. To determine the biological activity of the promature mouse BMP15, a rat GC culture system was established and treated with different concentrations of the modified full-length promature mouse BMP15 either alone, or together with ovine GDF9. As has been shown previously (McNatty, Juengel et al. 2005b; McIntosh, Lun et al. 2008), the combination of wt mouse BMP15 and wt ovine GDF9 had a synergistic effect in up-regulating rat GC thymidine incorporation as a marker for cell proliferation: this stimulatory effect was not observed when administering either growth factor alone. In a series of ${ }^{3} \mathrm{H}$-thymidine uptake assays, it was shown, in this thesis, that the full-length promature mouse BMP15 was biologically active, albeit being less potent then the wild-type protein. A point of caution in interpreting the bioassay results is noted, due to the possibility that the non-cleavable mouse BMP15 conditioned media may have contained a very small amount of cleaved mature region protein. However, while the concentration of the 
mature region present in the final assay was potentially at the threshold of biological activity of BMP15 (McNatty, Juengel et al. 2005b), it seems unlikely that the activity observed could be attributed solely to a mature region contaminant. The bioactivity of the wild-type mouse BMP15 conditioned media, containing mostly the cleaved mature form that was present at significantly higher levels than the non-cleavable form, suggesting that defective posttranslational processing negatively affects both the bioactivity of BMP15 and its ability to interact with GDF9. This interpretation is consistent with previous findings by others (Liao, Moore et al. 2003; Liao, Moore et al. 2004; Hashimoto, Moore et al. 2005). Although the wild-type mouse BMP15 had a positive effect on rat GC proliferation only when administered together with ovine GDF9, the promature form of BMP15 showed some limited stimulatory effect on thymidine incorporation alone but not at the levels observed when present with ovine GDF9.

In conclusion, the present study provides evidence that the unprocessed promature form of BMP15 is bioactive either alone or together with GDF9. However, given that the activity of the promature form of BMP15 is lower than when there is greater abundancy of mature BMP15, it is suggested that the higher molecular weight forms are less able to have significant effects on follicular somatic cell functions. Moreover, the present findings suggest that the proregion of mouse BMP15 may well be involved in contributing to the formation of large multimeric complexes in follicular fluid. This interpretation is based on the fact that in noncleavable mouse BMP15 conditioned media, these multimeric complexes were absent, most likely because the uncleaved BMP15 proregion was unavailable for binding to other moieties.

\subsection{Future Directions}

One question the present study did not address is that concerning the issue of Bmpl5 and Gdf9 mRNA expression levels, and their expression ratios, in oocytes during the preantral stages of follicular development. The sample collection method used for qPCR was only suitable for collecting COC from antral follicles. Collection of COC by laser dissection would be a possible 
approach to collect specific cell samples at the preantral developmental stages. Studying mRNA expression levels and the correlation between the expressions of these genes at these earlier stages of follicular development, as well as the relative expression level of GDF9 before that of BMP15, would enhance our understanding of the molecular actions of $G d f 9$ as well as Bmp15. Moreover, application of the same rigorous sample collection method described in this study for other species such as goats, pigs and primates would help clarify the disparate reports of species differences in ovarian expression patterns of BMP15 and GDF9.

The characterisation of BMP15 and GDF9 protein expression in the mouse ovary was hindered by the lack of specific antibodies to recognise the various forms of mouse BMP15 and GDF9. The non-specific binding of the available antibodies often made it difficult to interpret some of the protein expression data. Generation of highly sensitive and specific monoclonal antibodies, especially to recognise the proregion of mouse GDF9, the mature region of mouse BMP15 and the uncleaved promature form of the proteins, potentially by using peptides incorporating the cleavage site, would provide further information on the location and posttranslational processing of BMP15 and GDF9 within the mouse follicle. Indeed, one of the most pressing rate-limiting steps in elucidating the molecular forms and actions of BMP15 and GDF9 protein is the lack of specific antibodies with well-characterized reference standards. It would have also been informative, if the present Western blot studies were undertaken under non-reducing conditions and further investigations using cross-linking reagents. The current controversies concerning the existence of homodimers and possible heterodimers where modified proteins with pull-down tags were analysed, is testimony to this issue (see Mottershead, Harrison et al. 2013; Peng, Li et al. 2013).

A study on IVF patients reported that in human follicles, a higher GDF9 mature protein concentration in the follicular fluid was associated with higher embryo quality, while there was no correlation between the levels of follicular fluid BMP15 mature protein, or either of the precursor protein concentration and embryo quality (Gode, Gulekli et al. 2011). Another report comparing BMP15 levels in human follicular fluid also obtained from IVF patients showed that high BMP15 concentrations in follicular fluid was associated with better oocyte quality 
(Wu, Tang et al. 2007). The BMP15 precursor protein, as well as the cleaved mature and proregion, were detected in abundance in porcine follicular fluid in follicles both before and after the preovulatory LH surge, suggesting a role for BMP15 around the time of ovulation (Paradis, Novak et al. 2009). However, the results from these studies are questionable as the reports did not include appropriate reference standards (positive ligand or antibody controls, molecular ladders etc.) nor evidence for GDF9 or BMP15 specificity.

In mice, immunohistochemical analysis showed follicular fluid BMP15 expression but only in atretic follicles (Gueripel, Brun et al. 2006). Again questions can be raised about the specificity of antibodies used for these studies. Further analyses of follicular fluid samples from mouse follicles to determine which BMP15 and GDF9 protein forms are present during the periovulatory stage of follicular development, compared to what is known about molecular forms in mono-ovulatory species such as humans, could provide information on how these growth factors affect ovulation quota. However, as discussed earlier, the key issue of quality antibodies and reference standards remains as the key limiting factor.

Subtilisin-like proprotein convertases (SPCs), including furin and PACE4 have been shown to process TGF- $\beta$ superfamily proteins (Dubois, Laprise et al. 1995; Gueripel, Brun et al. 2006), such as Nodal and BMP4 (Constam and Robertson 2000). Furin was also reported to increase the processing of TGF- $\beta 1$ (Dubois, Laprise et al. 1995). The fact that some SPC and BMP protein expression overlaps in mouse embryos also suggests that enzymes belonging to the SPC family are responsible for enzymatic processing of BMP proteins (Constam, Calfon et al. 1996; Constam and Robertson 1999). The specific SPCs capable of processing BMP15 and GDF9 however have not yet been identified. Identification of the enzymes capable of processing BMP15 and GDF9 within the follicle, and whether their activities are regulated by gonadotrophins would provide important information to further our understanding of how the actions of these growth factors are regulated.

The antibodies used for Western blot analysis were also evaluated in these studies using immunohistochemistry with confocal microscopy, aiming to visualise the cellular localisation of BMP15 and GDF9 protein expression within the mouse 
ovary. However, the sensitivity and specificity of these antibodies were unable to distinguish the fluorescent signal of the target proteins from the background signal created by auto-fluorescence of contaminating red blood cells and the fixative used. By using more specific monoclonal mouse antibodies for immunohistochemical and/or Western blotting techniques, enhanced visualisation of the proregion and mature regions of mouse BMP15 and GDF9, and any colocalisation of these different protein forms, is more likely to be achieved. Visualisation of the co-expression of the different protein forms in vivo, together with immunoneutralisation of the different protein forms in bioassays, would also help to determine the role of the proregions and precursor proteins. It was proposed that in vivo, BMP15 and GDF9 might operate as promature complexes, despite the synergistic effects of these growth factors being observed even in the absence of the proregion forms of the proteins in vitro (Mottershead, Ritter et al. 2012). Further characterisation of the potential multimeric complexes by coimmunoprecipitaion with specific antibodies or 2D Western blot analysis, could shed some light to the molecular basis of the synergistic action of BMP15 and GDF9. This would be aided by determining whether the promature forms of BMP15 and GDF9 are able to bind to the type I and type II BMP receptors, or if they could initiate signalling through the Smad pathway and if they would activate the Smad1/5/8 or the Smad 2/3 pathway. A better understanding of the molecular forms and actions of BMP15 and GDF9 will enable future technologies to improve the maturation-rates of oocytes during IVM and IVF in vitro, thereby leading to new and improved fertility treatments for livestock, endangered species and humans. 


\section{Appendix I. Reagents and Solutions}

\section{Histology}

4\% Paraformaldehyde fixative $(250 \mathrm{ml})$

Paraformaldehyde solution:

Dissolve 10 g paraformaldehyde (Sigma Aldrich, Cat. No: P6148-500G) in 125 $\mathrm{ml}$ distilled water with continuous stirring on a hotplate (working in the fumehood). Monitor the temperature of the solution. When the temperature reaches $65^{\circ} \mathrm{C}$, add a few drops of $1 \mathrm{M} \mathrm{NaOH}$, until the solution clears. Let the solution cool down, and then filter through Whatman filter paper No1.

Double strength PBS solution:

Dissolve $2.5 \mathrm{~g}$ of $\mathrm{NaH}_{2} \mathrm{PO}_{4}$ (Sigma Aldrich, Cat No: S3139) and $4 \mathrm{~g}$ of $\mathrm{Na}_{2} \mathrm{HPO}_{4}$ (Sigma Aldrich, Cat No: S3264) in $125 \mathrm{ml}$ distilled water.

Combined the filtered paraformaldehyde solution and the double strength PBS solution in a 1:1 ratio. Adjust $\mathrm{pH}$ to 7.4 , if necessary. Store refrigerated, use for a maximum of 1 week.

\section{Phosphate buffered saline (PBS)}

Dissolve 5 PBS tablets (Sigma-Aldrich, Cat. No: P4417-100TAB) in $1 \mathrm{~L}$ distilled water. Sterilise the solution by autoclaving.

\section{$70 \% ; 80 \%$ or $95 \%$ ethanol solution}

Absolute ethanol (PureScience, Wellington, New Zealand, Cat. No: 2009985.2500) was diluted to the required concentration with distilled water.

\section{Acid alcohol}

Prepare $1 \mathrm{~L}$ of $70 \%$ ethanol as described above and then add $10 \mathrm{ml}$ of concentrated Hydrochloric acid (1\%) (HCl, AR grade, UNIVAR, Seven Hills, Australia, Cat No: 1367-2.5L). 


\section{$\underline{\text { In Situ Hybridisation Solutions }}$}

\section{Diethylpyrocarbonate (DEPC) treated water}

Add 1ml of DEPC (Sigma-Aldrich, Cat. No. 40718) to $1 \mathrm{~L}$ of distilled water. Stir overnight in the fume hood with the lid loose on the bottle. Autoclave the DEPC treated water to break down the chemical to carbon dioxide and water.

\section{0x SSC}

$3 \mathrm{M} \mathrm{NaCl}, 0.3 \mathrm{M} \mathrm{Na}$ citrate $\mathrm{x} 2 \mathrm{H}_{2} \mathrm{O}$

Dissolve $175.3 \mathrm{~g} \mathrm{NaCl}$ (reagent grade, Scharlau, Cat. No: SO02270500) and 88.2 g Na citrate x $2 \mathrm{H}_{2} \mathrm{O}$ (Sigma Aldrich, Cat. No: W302600) in $1 \mathrm{~L}$ of un-autoclaved DEPC water. Adjust the $\mathrm{pH}$ to 7.0 and autoclave. 5x SSC, $2 \mathrm{x}$ SSC and $0.2 \mathrm{x}$ SSC solutions were diluted from the 20x SSC stock solution using either DEPC treated water or distilled water.

\section{2x SSC/50\% Formamide solution}

To get $100 \mathrm{ml}$ of the solution, mix $10 \mathrm{ml} 20 \mathrm{x}$ SSC stock solution, $50 \mathrm{ml}$ formamide (Sigma Aldrich, Cat No: F9037) and $40 \mathrm{ml}$ DEPC treated water or distilled water (as required).

\section{Proteinase K $(10 \mathrm{mg} / \mathrm{ml})$}

Resuspend lyophilized Proteinase K powder to a final concentration of $10 \mathrm{mg} / \mathrm{ml}$ in $50 \mathrm{mM}$ Tris- $\mathrm{HCl} \mathrm{pH} 8.0$ (made in DEPC treated water) on ice. Filter sterilise through $0.22 \mu \mathrm{m}$ filter. Store in aliquots at $-20{ }^{\circ} \mathrm{C}$.

Proteinase K Digestion buffer was prepared by adding $20 \mu \mathrm{l}$ of Proteinase K (10 $\mathrm{mg} / \mathrm{ml}$ ) to a solution of $0.2 \mathrm{M}$ Tris $\mathrm{HCl} \mathrm{pH}: 7.2$ and $50 \mathrm{mM}$ EDTA pH 8.0.

\section{Acetic anhydride}

Purchased from Sigma Aldrich, Cat No: 242845. 


\section{Hybridisation Mix}

For $1 \mathrm{ml}$ Hybridisation Mix combine:

$60 \mu 15 \mathrm{M} \mathrm{NaCl}, 10 \mu 11 \mathrm{M}$ Tris $\mathrm{HCl}$ pH 6.8, $20 \mu 10.5 \mathrm{M} \mathrm{NaP}$ pH 6.8, $10 \mu 10.5 \mathrm{M}$ EDTA pH 8.0, $20 \mu 1$ Denhards solution (50x stock), $50 \mu 11$ M DTT, $100 \mu 1$ tRNA $(10 \mathrm{mg} / \mathrm{ml})$ and $20 \mu \mathrm{l}$ DEPC treated water. Add $200 \mu \mathrm{l}$ dextran sulphate $(50 \%$ (w/v) Pharmica). Vortex well. Add $500 \mu \mathrm{l}$ deionised formamide. Vortex and incubate on ice for 10 minutes. Centrifuge at $13,000 \mathrm{~g}$ for $10 \mathrm{~min}$. Use supernatant to dilute the radiolabeled riboprobe.

\subsection{Ammonium Acetate pH 7.0}

Dissolve $57.81 \mathrm{~g}$ ammonium acetate (Sigma Aldrich, Cat No: A1542) in $100 \mathrm{ml}$ of un-autoclaved DEPC treated water, adjust the $\mathrm{pH}$ to 7.0.

Autoclave the solution to break down the DEPC content to carbon dioxide and water.

\section{M Tris}

Dissolve $60.55 \mathrm{~g}$ Tris (Invitrogen, Cat. No: 15504-020, MW: $121.14 \mathrm{~g} / \mathrm{mol}$ ) in $400 \mathrm{ml}$ autoclaved DEPC treated water; adjust the $\mathrm{pH}$ to $6.8,7.2$ or 7.5 as required. Dilute to $500 \mathrm{ml}$ with autoclaved DEPC treated water. Sterilise solution by autoclaving.

\section{0 mM EDTA pH 8.0}

Dissolve 73.06 g EDTA (ethylenediaminetetraacetic acid, BDH, Poole, England, Cat No: $100935 \mathrm{~V}$ ) in $400 \mathrm{ml}$ of un-autoclaved DEPC water. Adjust the $\mathrm{pH}$ to 8.0 with $5 \mathrm{M} \mathrm{NaOH}$. Make volume up to $500 \mathrm{ml}$ with autoclaved DEPC treated water. Sterilise solution by autoclaving.

\section{M Triethanolamine pH 8.0}

Dissolve $53 \mathrm{ml}$ of triethanolamine (Sigma Aldrich, Cat. No: 90279) in unautoclaved DEPC treated water. Adjust the $\mathrm{pH}$ to 8.0 with concentrated $\mathrm{HCl}$ (37\%), dilute to $200 \mathrm{ml}$ with un-autoclaved DEPC treated water. Wrap bottle in tin foil and autoclave. Store at room temperature. Dilute to the required concentration with DEPC treated water. 


\section{$5 \mathrm{M} \mathrm{NaCl}$}

Dissolve $146.1 \mathrm{~g} \mathrm{NaCl}$ in $500 \mathrm{ml}$ un-autoclaved DEPC water. Autoclave the solution to break down the DEPC content to carbon dioxide and water.

\section{$0.5 \mathrm{M} \mathrm{NaPO}_{4} \mathrm{pH} 6.8$}

Dissolve $7.09 \mathrm{~g} \mathrm{Na}_{2} \mathrm{HPO}_{4}$ in $100 \mathrm{ml}$ of un-autoclaved DEPC water to make $0.5 \mathrm{M}$ $\mathrm{Na}_{2} \mathrm{HPO}_{4}$.

Dissolve $7.8 \mathrm{~g} \mathrm{NaH}_{2} \mathrm{PO} 4 \mathrm{in} 100 \mathrm{ml}$ of un-autoclaved DEPC water and autoclave to make $0.5 \mathrm{M} \mathrm{NaH}_{2} \mathrm{PO}_{4}$. Use $0.5 \mathrm{M} \mathrm{NaH}_{2} \mathrm{PO}_{4}$ to adjust the $\mathrm{pH}$ of $0.5 \mathrm{M} \mathrm{Na}_{2} \mathrm{HPO}_{4}$ to 6.8. Heat to $68^{\circ} \mathrm{C}$ to break down DEPC, then filter sterilise the solution. Note that the finished solution should not be autoclaved as precipitation occurs.

\section{Denhardts 50x}

Dissolve 0.2 g polyvinylpyrrolidone (PVP, Sigma Aldrich), 0.2 g BSA (bovine serum albumin, ICPbio, Cat. No. ABRE-010) and 0.2 g Ficoll 400 (Sigma Aldrich, Cat No: F2637) in $20 \mathrm{ml}$ DEPC treated water. Filter sterilise through 0.22 $\mu \mathrm{m}$ filter. Store in aliquots at $-20^{\circ} \mathrm{C}$.

\subsection{Dithiothreitol (DTT)}

Dissolve $1.54 \mathrm{~g}$ DTT (BDH, Cat. No: 443852A) in $10 \mathrm{ml}$ of autoclaved DEPC water. Filter sterilise through $0.22 \mu \mathrm{m}$ filter. Store in aliquots at $-20^{\circ} \mathrm{C}$.

\section{tRNA (10 mg/ml)}

Make up the vial of tRNA to the required concentration with autoclaved DEPC water. Filter sterilise through $0.22 \mu \mathrm{m}$ filter. Store in aliquots at $-20^{\circ} \mathrm{C}$.

\section{0\% Dextran Sulphate}

Dissolve $10 \mathrm{~g}$ Dextran sulphate (Pharmacia brand) in $20 \mathrm{ml}$ of autoclaved DEPC water. Heat to help dissolve the dextran sulphate (Note that it is a very viscous solution). Filter through $0.22 \mu \mathrm{m}$ filter. Store in aliquots at $-20^{\circ} \mathrm{C}$ 


\section{RNAse A $(20 \mathrm{mg} / \mathrm{ml})$}

Add $5 \mathrm{ml}$ of autoclaved (sterile) DEPC treated water to the vial of unopened Rnase A (100 mg, Sigma Aldrich, Cat. No: R4875). Vortex, filter sterilise through a $0.22 \mu \mathrm{m}$ filter and aliquot. Incubate the aliquots for 2 minutes in boiling water bath. Cool to room temperature, then store at $-20^{\circ} \mathrm{C}$.

\subsection{Ammonium acetate / Ethanol solutions}

$30 \%$ Ethanol solution: Mix $20 \mathrm{ml}$ of $7.5 \mathrm{M}$ ammonium Acetate with $150 \mathrm{ml}$ of ethanol, make up to $500 \mathrm{ml}$ with autoclaved DEPC treated water.

$60 \%$ Ethanol solution: Mix $20 \mathrm{ml}$ of $7.5 \mathrm{M}$ ammonium Acetate with $300 \mathrm{ml}$ of ethanol, make up to $500 \mathrm{ml}$ with autoclaved DEPC treated water.

80\% Ethanol solution: Mix $20 \mathrm{ml}$ of $7.5 \mathrm{M}$ ammonium Acetate with $400 \mathrm{ml}$ of ethanol, make up to $500 \mathrm{ml}$ with autoclaved DEPC treated water.

95\% Ethanol: Mix $20 \mathrm{ml}$ of $7.5 \mathrm{M}$ ammonium Acetate with $475 \mathrm{ml}$ of ethanol, make up to $500 \mathrm{ml}$ with autoclaved DEPC treated water.

\section{$1 \%$ Acetic Acid}

Mix $10 \mathrm{ml}$ of glacial acetic acid (Scharlau, Cat No: AC03522500) with $990 \mathrm{ml}$ of distilled water.

\section{Scott's Tap Water}

Weigh out 2.0 g potassium bicarbonate (potassium hydrogen carbonate) and 20.0 g magnesium sulphate $\left(\mathrm{MgSO}_{4} \times 7 \mathrm{H}_{2} 0\right.$, Sigma-Aldrich, Cat No: M1880). Dissolve

in distilled water and add $1 \mathrm{ml}$ formalin (Scharlau, Cat No: FO00102500) as a preservative. Make up to $1 \mathrm{~L}$ with distilled water.

\section{Ilford Fixer - 5L}

Dissolve contents of Ilford Ilfofix II in $3750 \mathrm{ml}$ un-autoclaved distilled water and stir to mix.

Make up to $5 \mathrm{~L}$. Filter through 2 pieces of Whatman filter paper No 1 into $2 \mathrm{x}$ 2.5 L dark glass bottles. Store at $4^{\circ} \mathrm{C}$. 


\section{$\underline{\text { Western blot solutions }}$}

\section{$1 \mathrm{M}$ Tris buffer $\mathrm{pH} 7.5$}

Disolve $60.7 \mathrm{~g}$ Tris (Invitrogen, Cat. No: 15504-020, MW: $121.14 \mathrm{~g} / \mathrm{mol}$ ) in distilled water, adjust the $\mathrm{pH}$ to 7.5 with concentrated $\mathrm{HCl}$, make up to $500 \mathrm{ml}$ with distilled water.

\subsection{Tris-HCl pH 8.8}

Dissolve $36.34 \mathrm{~g}$ of Tris in $160 \mathrm{ml}$ distilled water and adjust the $\mathrm{pH}$ to 8.8 with concentrated $\mathrm{HCl}$. Make up to $200 \mathrm{ml}$ with distilled water, store at $4{ }^{\circ} \mathrm{C}$.

\subsection{Tris-HCl pH 6.8}

Dissolve $6.06 \mathrm{~g}$ of Tris in $80 \mathrm{ml}$ distilled water and adjust the $\mathrm{pH}$ to 6.8 with concentrated $\mathrm{HCl}$. Make up to $100 \mathrm{ml}$ with distilled water, store at $4^{\circ} \mathrm{C}$.

\section{$10 \%$ (w/v) Sodium Dodecyl Sulphate (SDS)}

Dissolve $20 \mathrm{~g}$ of SDS (BDH, Cat. No: 444464T) in $200 \mathrm{ml}$ distilled water. Store at room temperature.

\section{$10 \%(w / v)$ Ammonium persulphate}

Dissolve $1 \mathrm{~g}$ of ammonium persulphate (Sigma Aldrich, Cat No:215589) in $10 \mathrm{ml}$ distilled water. Store in aliquots at $4{ }^{\circ} \mathrm{C}$.

\section{Bis-acrylamide (30\%)}

Bis-acrylamide (30\%) was purchased from BioRad (Cat. No: 161-0158).

\section{TEMED}

$N, N, N^{\prime}, N^{\prime}$-Tetramethylethylenediamine (TEMED) was purchased from BioRad (Cat. No: 161-0800).

\section{Low salt Tris wash buffer (TBS)}

Dissolve $9 \mathrm{~g} \mathrm{NaCl}$ (Thermo Fisher Scientific NZ, Cat No: AC19409-0010) in 20 $\mathrm{ml} 1 \mathrm{M}$ Tris buffer $\mathrm{pH}$ 7.5. Add $1 \mathrm{ml}$ Tween 20 (MW: $1227.72 \mathrm{~g} / \mathrm{mol}$ ); make up to $1 \mathrm{~L}$ with distilled water. 


\section{$5 \%$ Blotto solution}

Dissolve $5 \mathrm{~g}$ of non-fat milk powder in $100 \mathrm{ml}$ of low salt Tris wash buffer. Let stand for 10 minutes before use.

\section{Enhanced chemi-luminescence (ECL) reagents}

$250 \mathrm{mM}$ luminol (5-amino-2,3-dihydro-1,4-phthalazinedione):

Dissolve $0.44 \mathrm{~g}$ of luminol (Sigma Aldrich, Cat No: 45106182) in $10 \mathrm{ml}$ dimethyl sulphoxide (DMSO, Sigma-Aldrich, Cat No: D2650). Store aliquots at $-20{ }^{\circ} \mathrm{C}$.

90 mM P-coumaric acid:

Dissolve $0.15 \mathrm{~g}$ of P-coumaric (Sigma-Aldrich, Cat No: C9008-5G) acid in $10 \mathrm{ml}$ DMSO. Store aliquots at $-20{ }^{\circ} \mathrm{C}$.

Reagent A: Mix $8.85 \mathrm{ml}$ distilled water, $1 \mathrm{ml} 1 \mathrm{M}$ Tris $\mathrm{pH} 8.5,100 \mu 1250 \mathrm{mM}$ luminol and $44 \mu 190 \mathrm{mM}$ P-coumaric acid.

Reagent B: Mix $9 \mathrm{ml}$ distilled water, $1 \mathrm{ml} 1 \mathrm{M}$ Tris $\mathrm{pH} 8.5$ and $6 \mu$ l hydrogen peroxide (Scharlau, Cat. No: HI0136100). Make reagents A and B just before use and combine them directly before adding to the membrane.

\section{Ponceau stain}

Dissolve $1 \mathrm{~g}$ of Ponceau S (BDH Laboratory Supplies, Cat. No: 440832H) in 200 $\mathrm{ml}$ distilled water, then add $2 \mathrm{ml}$ Acetic acid. Store at room temperature.

\section{0x Tris-glycine transfer buffer}

Dissolve $30.3 \mathrm{~g}$ Tris base and $114 \mathrm{~g}$ Glycine (BDH, Cat. No: 101196X, MW: $75.07 \mathrm{~g} / \mathrm{mol}$ ) in $1 \mathrm{~L}$ of distilled water. Store at room temperature.

- $2 \mathrm{~L}$ of 1x transfer buffer: Mix $200 \mathrm{ml}$ of 10x Tris-glycine transfer buffer, $400 \mathrm{ml}$ of methanol and 1.6 L distilled water.

\section{5x DNA loading dye}

Combine $0.8 \mathrm{ml}$ distilled water (10.81\%), $1 \mathrm{ml} 0.5 \mathrm{M}$ Tris-HCl pH 6.8 (13.51\%), $0.8 \mathrm{ml}$ glycerol (10.81\%), $4.6 \mathrm{ml}$ 10\% SDS (62.16\%), $114 \mathrm{mg} 100 \mathrm{mM}$ DTT $(1.08 \% \mathrm{w} / \mathrm{v})$ and $0.2 \mathrm{ml} \mathrm{1 \%}$ bromophenol blue sodium salt (BPB, Sigma-Aldrich, Cat. No: BE131-5G) (2.7\%). Aliquot and store at $-20^{\circ} \mathrm{C}$. 


\section{5x SDS PAGE running buffer}

Dissolve 72 g glycine (Sigma Aldrich, Cat No: G8898) (7.2\%), 15 g Tris (1.5\%) and $5 \mathrm{~g}$ SDS $(0.5 \%)$ in distilled water. Adjust the $\mathrm{pH}$ to 8.3 . Make up to $1 \mathrm{~L}$ with distilled water and store at room temperature. Before use, dilute $100 \mathrm{ml}$ of 5x SDS PAGE running buffer with $400 \mathrm{ml}$ distilled water

\section{RIPA Lysis buffer}

Dissolve $0.15 \mathrm{~g}$ Tris (25mM), $0.438 \mathrm{~g} \mathrm{NaCl}(150 \mathrm{mM}), 500 \mathrm{mg}$ Sodium deoxycholate (Sigma Aldrich, Cat No: 30970) (1\%), $50 \mathrm{mg}$ SDS (0.1\%) and $500 \mu 1$ Tween 20 (Sigma Aldrich, Cat No: P1379) (1\%) in $30 \mathrm{ml}$ distilled water. Dilute to $48 \mathrm{ml}$ with distilled water. Add $2 \mu$ protease inhibitor (25x stock) just prior to use. $25 \mathrm{x}$ protease inhibitor stock is made up by resuspending 1 tablet (Roche, Cat No: 11697498001) in $2 \mathrm{ml}$ distilled water. Store smaller aliquots of it at $-20^{\circ} \mathrm{C}$.

\section{Stripping buffer}

Dissolve $2 \mathrm{~g}$ of SDS in $100 \mathrm{ml}$ of $62.5 \mathrm{mM}$ Tris $\mathrm{HCl} \mathrm{pH}$ 6.7. Warm the solution in a $50{ }^{\circ} \mathrm{C}$ waterbath. Add $700 \mu 1$ ß-mercaptoethanol (Life Technologies, Cat No: 21985-023) just prior to use.

\section{Other reagents and solutions}

\section{6x DNA loading dye}

Mix $5 \mathrm{ml}$ of autoclaved distilled water, $20 \mathrm{ml} 0.5 \mathrm{M}$ EDTA pH 8.0, 0.025 g BPB, and $5 \mathrm{ml}$ sterile glycerol. Aliquot and store at $-20^{\circ} \mathrm{C}$.

\section{Ampicilin (50 mg/ml)}

Dissolve $500 \mathrm{mg}$ of Ampicillin in $10 \mathrm{ml}$ autoclaved distilled water. Filter through a $0.22 \mu \mathrm{m}$ filter. Aliquot and store at $-20{ }^{\circ} \mathrm{C}$.

\section{0x TAE buffer}

Dissolve $242 \mathrm{~g}$ of Tris in $700 \mathrm{ml}$ distilled water. Add $57.1 \mathrm{ml}$ of glacial acetic acid and $100 \mathrm{ml}$ of $0.5 \mathrm{M}$ EDTA $\mathrm{pH}$ 8.0. Dilute to $1 \mathrm{~L}$ with distilled water. 


\subsection{Ethylenediaminetetraacetic acid (EDTA) pH 8.0}

Dissolve $9.3 \mathrm{~g}$ of EDTA (BDH, Cat. No: 100935V) in DEPC treated water and adjust the $\mathrm{pH}$ to 8.0 with $5 \mathrm{M} \mathrm{NaOH}$. Dilute to $50 \mathrm{ml}$ with DEPC water and store at room temperature.

\section{M Sodium hydroxide $(\mathrm{NaOH})$}

Dissolve $30 \mathrm{~g}$ of $\mathrm{NaOH}$ in $150 \mathrm{ml}$ DEPC water. Store at room temperature.

\section{LB broth}

Dissolve $5 \mathrm{~g} \mathrm{Bacto}^{\mathrm{TM}}$ Yeast Extract (Becton Dickinson, Sparks, MD, Cat No: 212750), 10 g Bacto $^{\mathrm{TM}}$ Tryptone (Becton Dickinson, Sparks, MD, Cat No: $211705)$ and $10 \mathrm{~g} \mathrm{NaCl}$ in $1 \mathrm{~L}$ distilled water. Autoclave.

\section{LB agar}

Dissolve 15 g Bacto $^{\mathrm{TM}}$ Agar (Becton Dickinson, Sparks, MD, Cat No: 214010) in $1 \mathrm{~L} \mathrm{LB}$ broth and autoclave. Add $1 \mathrm{ml}$ of $150 \mathrm{mg} / \mathrm{ml}$ ampicillin before pouring plates.

\section{$2 \% \mathrm{X}$-gal}

Add $10 \mathrm{ml}$ of $\mathrm{N}$, N-dimethyl formamide to a vial of $200 \mathrm{mg}$ X-gal (VWR International, Darmstadt, Germany, Cat No: A49780001). Mix and wrap in tinfoil. Store at $-20^{\circ} \mathrm{C}$. 


\section{Appendix II. Original images for Figure 3I}

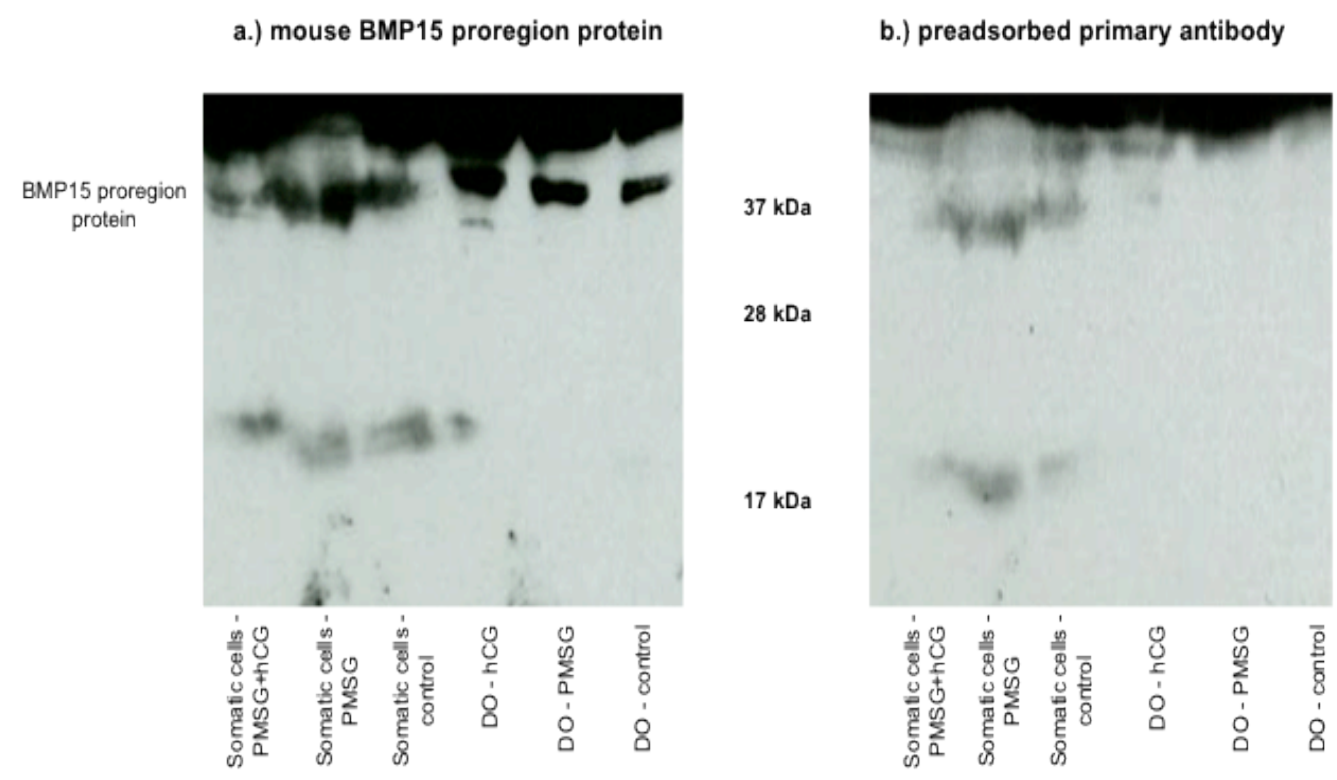

c.) mouse BMP15 proregion protein

d.) preadsorbed primary antibody
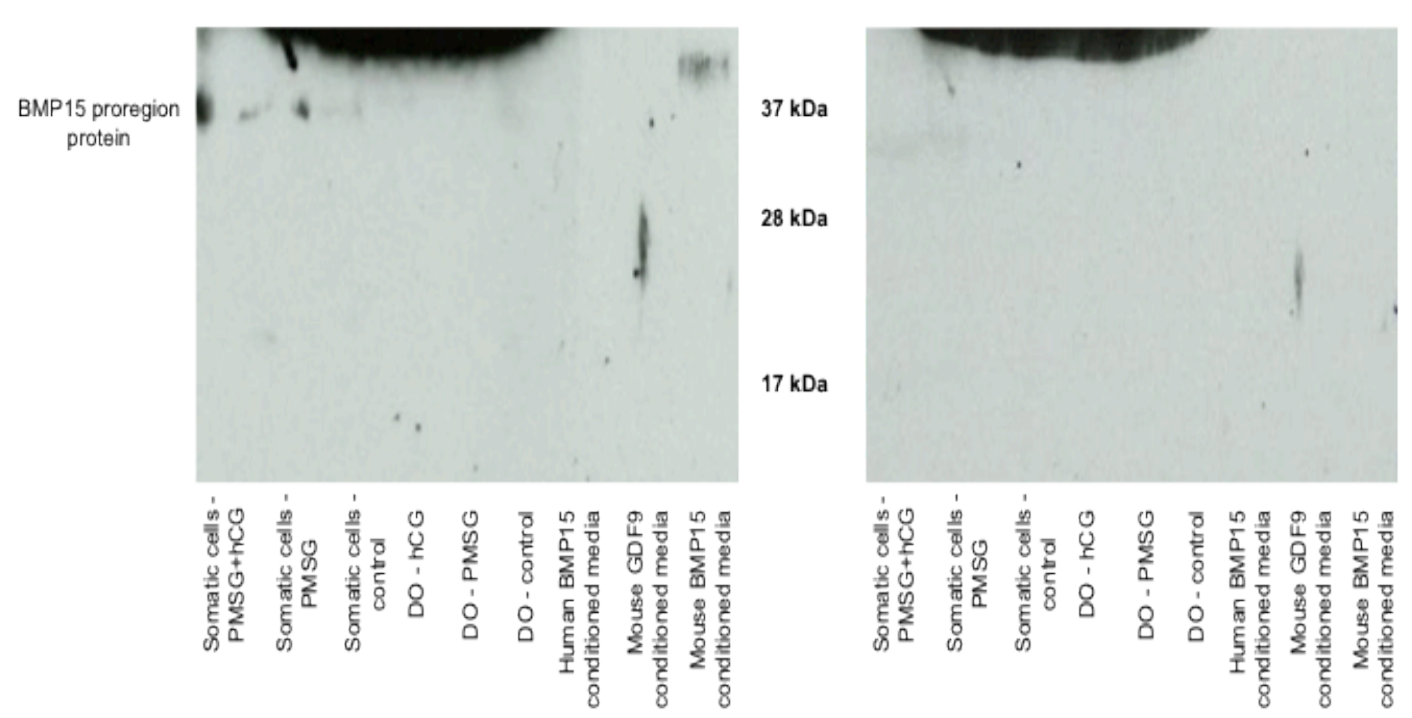

Original Western blot images used in edited images in Chapter 3, Figure 3I, panels c) and d), to show the best representation of BMP15 proregion expression in DO and somatic cell lysates collected from Control, PMSG and PMSG+hCG treated animals.

Note, that the samples analysed and shown in panels a) and c) were collected in two separate experiments. Panel b) and d) show results of antibody preadsorption following stripping membranes a) and c) respectively. 


\section{Appendix III. In situ hybridisation images}
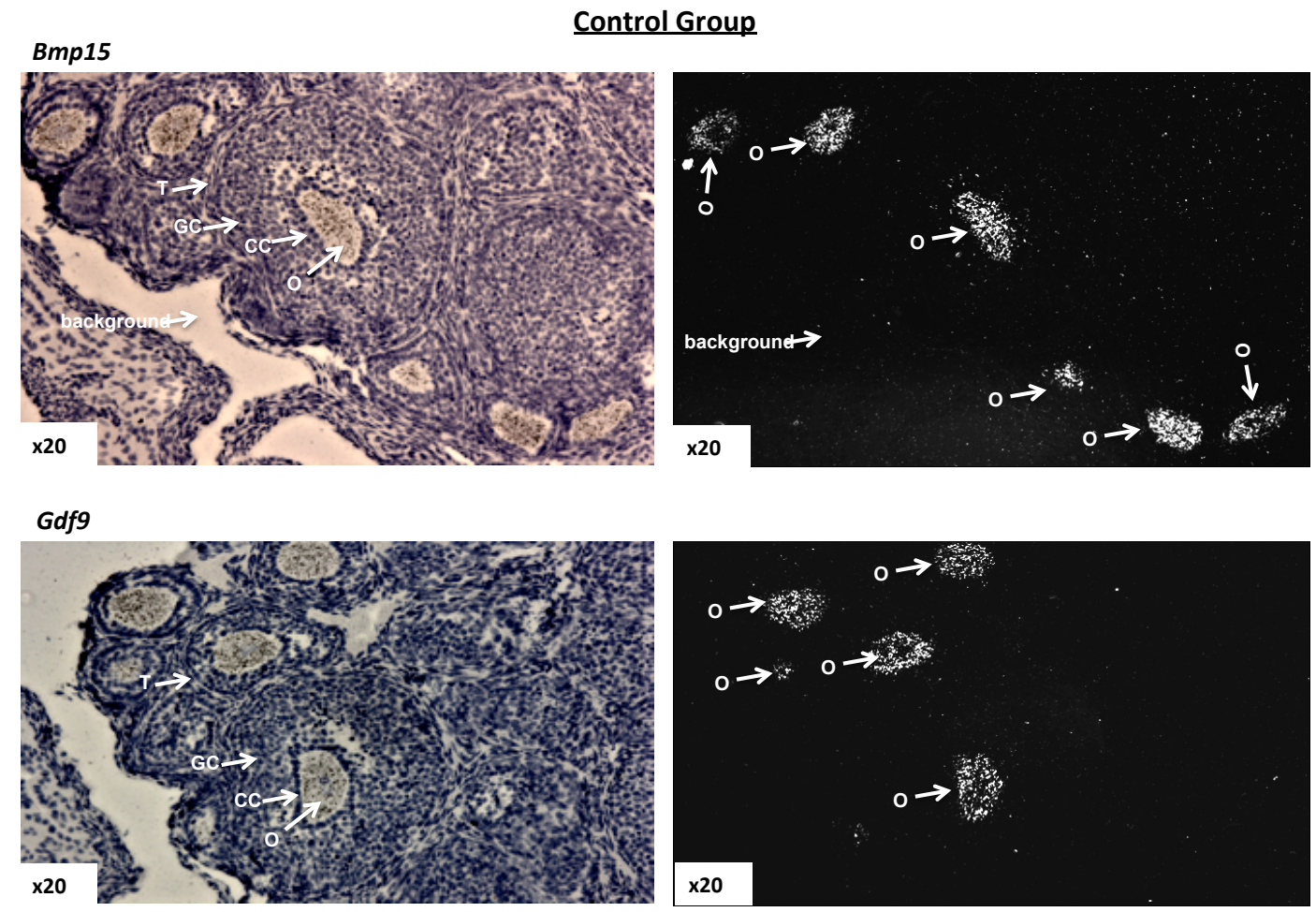

Bmp15

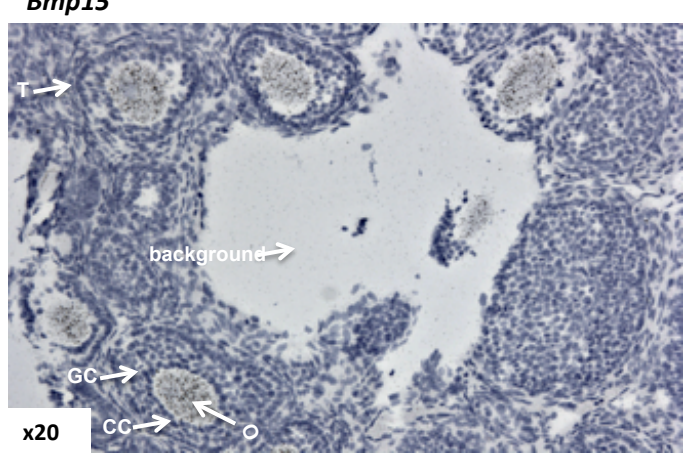

Gdf9

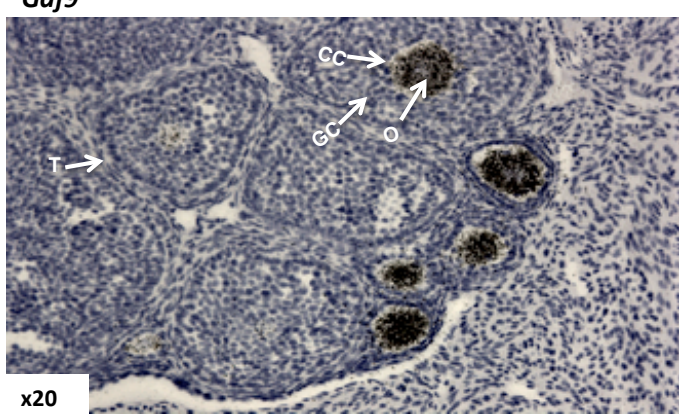

PMSG Group
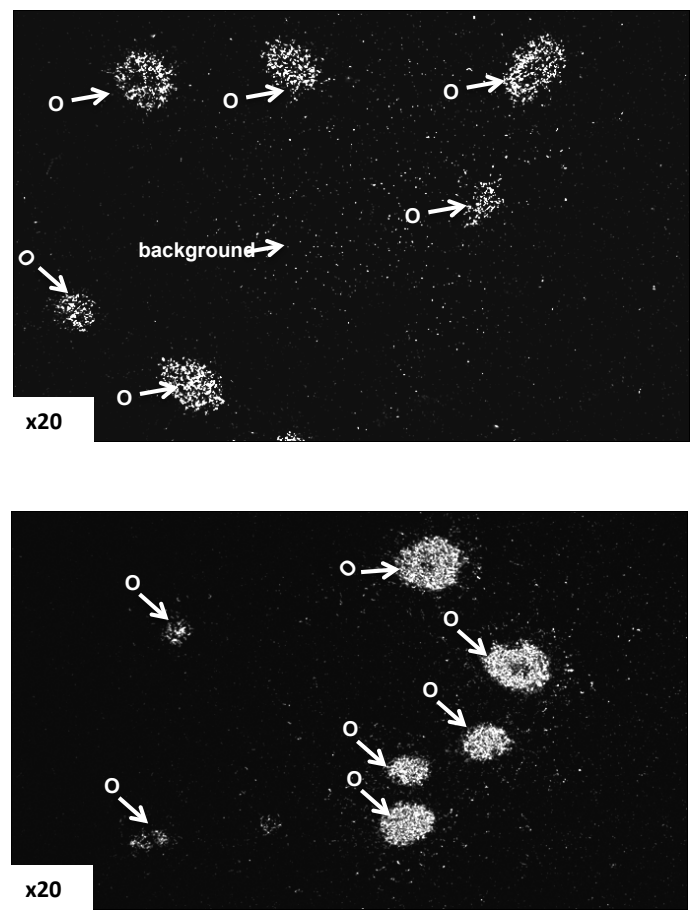

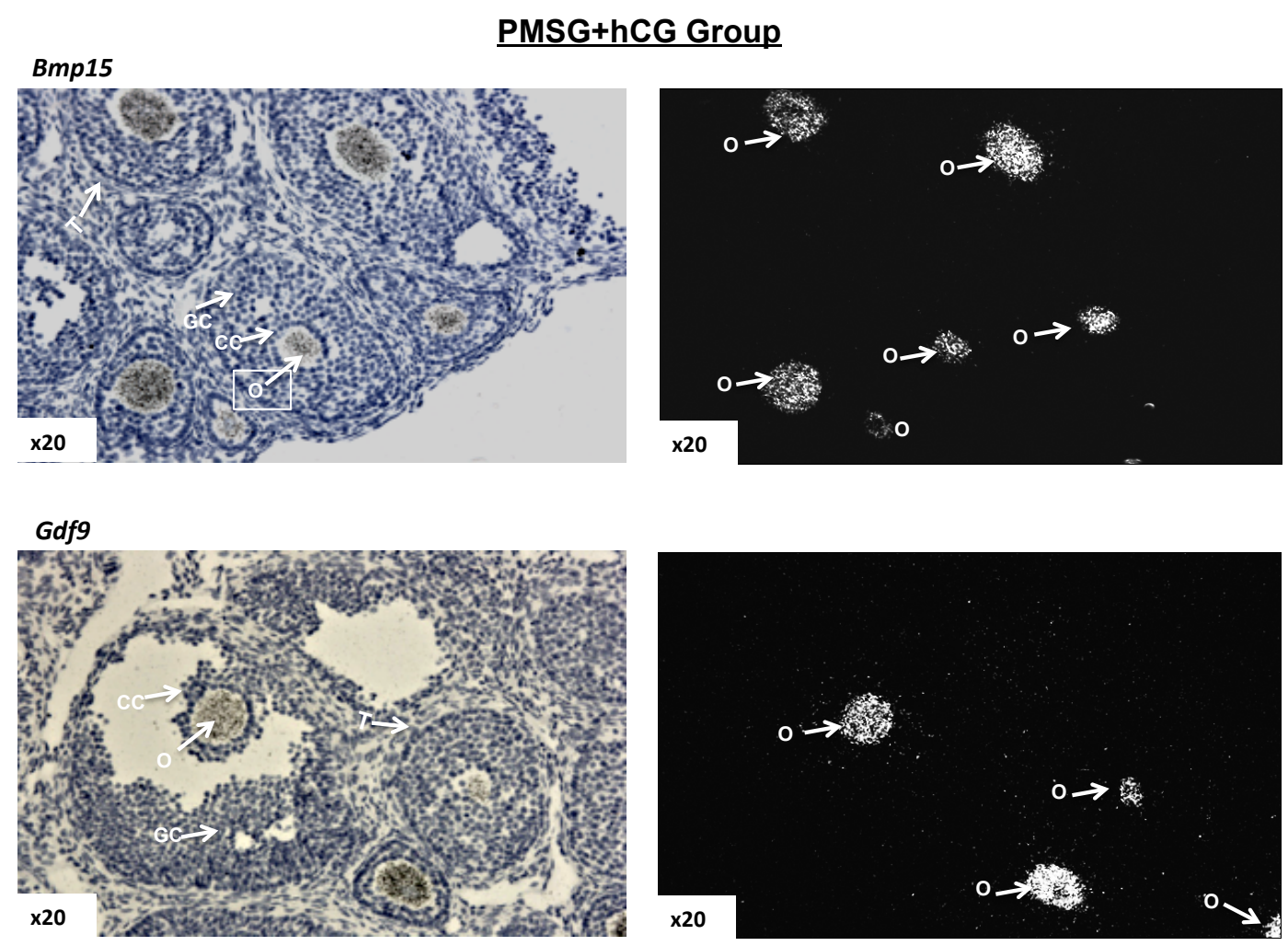

$\mathrm{o}=$ oocyte $; \mathrm{GC}=$ granulosa cells $; \mathrm{CC}=$ cumulus cells; $\mathrm{T}=$ theca cells

Lightfield and darkfield images of mouse ovarian cross sections, showing silver grain localisation exclusively in the oocytes, denoting Bmpl5 or Gdf9 mRNA expression following in situ hybridisation. 


\section{References}

Aaltonen, J., M. P. Laitinen, K. Vuojolainen, R. Jaatinen, N. HorelliKuitunen, L. Seppa, H. Louhio, T. Tuuri, J. Sjoberg, R. Butzow, O. Hovata, L. Dale and O. Ritvos (1999). "Human growth differentiation factor 9 (GDF-9) and its novel homolog GDF-9B are expressed in oocytes during early folliculogenesis." The Journal of Clinical Endocrinology and Metabolism 84(8): 2744-2750.

Abbott, D. H., D. A. Dumesic and S. Franks (2002). "Developmental origin of polycystic ovary syndrome - a hypothesis." The Journal of Endocrinology 174(1): 1-5.

Abel, M. H., A. N. Wootton, V. Wilkins, I. Huhtaniemi, P. G. Knight and H. M. Charlton (2000). "The effect of a null mutation in the follicle-stimulating hormone receptor gene on mouse reproduction." Endocrinology 141(5): 17951803.

Adashi, E. Y., C. E. Resnick, E. R. Hernandez, J. V. May, A. F. Purchio and D. R. Twardzik (1989). "Ovarian transforming growth factor-beta (TGF beta): cellular site(s), and mechanism(s) of action." Molecular and Cellular Endocrinology 61(2): 247-256.

Aittomaki, K., J. L. Lucena, P. Pakarinen, P. Sistonen, J. Tapanainen, J. Gromoll, R. Kaskikari, E. M. Sankila, H. Lehvaslaiho, A. R. Engel, E. Nieschlag, I. Huhtaniemi and A. de la Chapelle (1995). "Mutation in the follicle-stimulating hormone receptor gene causes hereditary hypergonadotropic ovarian failure." Cell 82(6): 959-968.

Alam, H., E. T. Maizels, Y. Park, S. Ghaey, Z. J. Feiger, N. S. Chandel and M. Hunzicker-Dunn (2004). "Follicle-stimulating hormone activation of hypoxia-inducible factor-1 by the phosphatidylinositol 3-kinase/AKT/Ras 
homolog enriched in brain (Rheb)/mammalian target of rapamycin (mTOR) pathway is necessary for induction of select protein markers of follicular differentiation." The Journal of Biological Chemistry 279(19): 19431-19440.

Altschul, S. F. (1991). "Amino acid substitution matrices from an information theoretic perspective." Journal of Molecular Biology 219(3): 555-565.

Anderson, S. B., A. L. Goldberg and M. Whitman (2008). "Identification of a novel pool of extracellular pro-myostatin in skeletal muscle." The Journal of Biological Chemistry 283(11): 7027-7035.

Annes, J. P., Y. Chen, J. S. Munger and D. B. Rifkin (2004). "Integrin alphaVbeta6-mediated activation of latent TGF-beta requires the latent TGF-beta binding protein-1." The Journal of Cell Biology 165(5): 723-734.

Backstrom, C. T., A. S. McNeilly, R. M. Leask and D. T. Baird (1982). "Pulsatile secretion of LH, FSH, prolactin, oestradiol and progesterone during the human menstrual cycle." Clinical Endocrinology 17(1): 29-42.

Baird, D. T., I. A. Swanston and A. S. McNeilly (1981). "Relationship between LH, FSH, and prolactin concentration and the secretion of androgens and estrogens by the preovulatory follicle in the ewe." Biology of Reproduction 24(5): 1013-1025.

Baker, T. G. (1963). "A Quantitative and Cytological Study of Germ Cells in Human Ovaries." Proceedings of the Royal Society of London. Series B, Containing papers of a Biological character. Royal Society 158: 417-433.

Beck, S., J. A. Le Good, M. Guzman, N. Ben Haim, K. Roy, F. Beermann and D. B. Constam (2002). "Extraembryonic proteases regulate Nodal signalling during gastrulation." Nature Cell Biology 4(12): 981-985. 
Ben-Haim, N., C. Lu, M. Guzman-Ayala, L. Pescatore, D. Mesnard, M. Bischofberger, F. Naef, E. J. Robertson and D. B. Constam (2006). "The nodal precursor acting via activin receptors induces mesoderm by maintaining a source of its convertases and BMP4." Developmental Cell 11(3): 313-323.

Bilezikjian, L. M., A. L. Blount, C. J. Donaldson and W. W. Vale (2006). "Pituitary actions of ligands of the TGF-beta family: activins and inhibins." Reproduction 132(2): 207-215.

Billig, H., I. Furuta and A. J. Hsueh (1993). "Estrogens inhibit and androgens enhance ovarian granulosa cell apoptosis." Endocrinology 133(5): 2204-2212.

Bodensteiner, K. J., C. M. Clay, C. L. Moeller and H. R. Sawyer (1999). "Molecular cloning of the ovine Growth/Differentiation factor-9 gene and expression of growth/differentiation factor-9 in ovine and bovine ovaries." Biology of Reproduction 60(2): 381-386.

Bodin, L., E. Di Pasquale, S. Fabre, M. Bontoux, P. Monget, L. Persani and P. Mulsant (2007). "A novel mutation in the bone morphogenetic protein 15 gene causing defective protein secretion is associated with both increased ovulation rate and sterility in Lacaune sheep." Endocrinology 148(1): 393-400.

Bornslaeger, E. A., P. Mattei and R. M. Schultz (1986). "Involvement of cAMP-dependent protein kinase and protein phosphorylation in regulation of mouse oocyte maturation." Developmental Biology 114(2): 453-462.

Bottinger, E. P., V. M. Factor, M. L. Tsang, J. A. Weatherbee, J. B. Kopp, S. W. Qian, L. M. Wakefield, A. B. Roberts, S. S. Thorgeirsson and M. B. Sporn (1996). "The recombinant proregion of transforming growth factor betal (latencyassociated peptide) inhibits active transforming growth factor betal in transgenic 
mice." Proceedings of the National Academy of Sciences of the United States of America 93(12): 5877-5882.

Bristol, S. K. and T. K. Woodruff (2004). "Follicle-restricted compartmentalization of transforming growth factor beta superfamily ligands in the feline ovary." Biology of Reproduction 70(3): 846-859.

Britt, K. L., A. E. Drummond, V. A. Cox, M. Dyson, N. G. Wreford, M. E. Jones, E. R. Simpson and J. K. Findlay (2000). "An age-related ovarian phenotype in mice with targeted disruption of the Cyp 19 (aromatase) gene." Endocrinology 141(7): 2614-2623.

Britt, K. L., A. E. Drummond, M. Dyson, N. G. Wreford, M. E. Jones, E. R. Simpson and J. K. Findlay (2001). "The ovarian phenotype of the aromatase knockout (ArKO) mouse." The Journal of Steroid Biochemistry and Molecular Biology 79(1-5): 181-185.

Britt, K. L., P. K. Saunders, S. J. McPherson, M. L. Misso, E. R. Simpson and J. K. Findlay (2004). "Estrogen actions on follicle formation and early follicle development." Biology of Reproduction 71(5): 1712-1723.

Britt, K. L., P. G. Stanton, M. Misso, E. R. Simpson and J. K. Findlay (2004). "The effects of estrogen on the expression of genes underlying the differentiation of somatic cells in the murine gonad." Endocrinology 145(8): 3950-3960.

Brown, M. A., Q. Zhao, K. A. Baker, C. Naik, C. Chen, L. Pukac, M. Singh, T. Tsareva, Y. Parice, A. Mahoney, V. Roschke, I. Sanyal and S. Choe (2005). "Crystal structure of BMP-9 and functional interactions with pro-region and receptors." The Journal of Biological Chemistry 280(26): 25111-25118. 
Buccione, R., B. C. Vanderhyden, P. J. Caron and J. J. Eppig (1990). "FSH-induced expansion of the mouse cumulus oophorus in vitro is dependent upon a specific factor(s) secreted by the oocyte." Developmental Biology 138(1): 16-25.

Burns, K. H., C. Yan, T. R. Kumar and M. M. Matzuk (2001). "Analysis of ovarian gene expression in follicle-stimulating hormone beta knockout mice." Endocrinology 142(7): 2742-2751.

Bustin, S. A., V. Benes, J. A. Garson, J. Hellemans, J. Huggett, M. Kubista, R. Mueller, T. Nolan, M. W. Pfaffl, G. L. Shipley, J. Vandesompele and C. T. Wittwer (2009). "The MIQE guidelines: minimum information for publication of quantitative real-time PCR experiments." Clinical Chemistry 55(4): 611-622.

Byers, M., G. G. Kuiper, J. A. Gustafsson and O. K. Park-Sarge (1997). "Estrogen receptor-beta mRNA expression in rat ovary: down-regulation by gonadotropins." Molecular Endocrinology 11(2): 172-182.

Byskov, A. G. (1978). Follicular atresia.In 'The Vertebrate Ovary'. (Ed. Richard E. Jones) Ch.15, Plenum Press: New York.

Cardenas, H., K. A. Burke, R. M. Bigsby, W. F. Pope and K. P. Nephew (2001). "Estrogen receptor beta in the sheep ovary during the estrous cycle and early pregnancy." Biology of Reproduction 65(1): 128-134.

Carmel, P. W., S. Araki and M. Ferin (1976). "Pituitary stalk portal blood collection in rhesus monkeys: evidence for pulsatile release of gonadotropinreleasing hormone (GnRH)." Endocrinology 99(1): 243-248. 
Cattanach, B. M., C. A. Iddon, H. M. Charlton, S. A. Chiappa and G. Fink (1977). "Gonadotrophin-releasing hormone deficiency in a mutant mouse with hypogonadism." Nature 269(5626): 338-340.

Celestino, J. J., I. B. Lima-Verde, J. B. Bruno, M. H. Matos, R. N. Chaves, M. V. Saraiva, C. M. Silva, L. R. Faustino, R. Rossetto, C. A. Lopes, M. A. Donato, C. A. Peixoto, C. C. Campello, J. R. Silva and J. R. Figueiredo (2011). "Steady-state level of bone morphogenetic protein-15 in goat ovaries and its influence on in vitro development and survival of preantral follicles." Molecular and Cellular Endocrinology 338(1-2): 1-9.

Chang, H., C. W. Brown and M. M. Matzuk (2002). "Genetic analysis of the mammalian transforming growth factor-beta superfamily." Endocrine Reviews 23(6): 787-823.

Chegini, N. and K. C. Flanders (1992). "Presence of transforming growth factor-beta and their selective cellular localization in human ovarian tissue of various reproductive stages." Endocrinology 130(3): 1707-1715.

Chen, L., P. T. Russell and W. J. Larsen (1993). "Functional significance of cumulus expansion in the mouse: roles for the preovulatory synthesis of hyaluronic acid within the cumulus mass." Molecular Reproduction and Development 34(1): 87-93.

Cheng, G., Z. Weihua, S. Makinen, S. Makela, S. Saji, M. Warner, J. A. Gustafsson and O. Hovatta (2002). "A role for the androgen receptor in follicular atresia of estrogen receptor beta knockout mouse ovary." Biology of Reproduction 66(1): 77-84.

Chiquoine, A. D. (1954). "The identification, origin, and migration of the primordial germ cells in the mouse embryo." The Anatomical Record 118(2): 135146. 
Chun, S. Y., K. M. Eisenhauer, S. Minami, H. Billig, E. Perlas and A. J. Hsueh (1996). "Hormonal regulation of apoptosis in early antral follicles: folliclestimulating hormone as a major survival factor." Endocrinology 137(4): 14471456.

Clark, J. M. and E. M. Eddy (1975). "Fine structural observations on the origin and associations of primordial germ cells of the mouse." Developmental Biology 47(1): 136-155.

Cohen, B. D., C. A. Nechamen and J. A. Dias (2004). "Human follitropin receptor (FSHR) interacts with the adapter protein 14-3-3tau." Molecular and Cellular Endocrinology 220(1-2): 1-7.

Conneely, O. M., B. Mulac-Jericevic, F. DeMayo, J. P. Lydon and B. W. O'Malley (2002). "Reproductive functions of progesterone receptors." Progress in Hormone Research 57: 339-355.

Conneely, O. M., B. Mulac-Jericevic and J. P. Lydon (2003). "Progesterone-dependent regulation of female reproductive activity by two distinct progesterone receptor isoforms." Steroids 68(10-13): 771-778.

Constam, D. B., M. Calfon and E. J. Robertson (1996). "SPC4, SPC6, and the novel protease SPC7 are coexpressed with bone morphogenetic proteins at distinct sites during embryogenesis." The Journal of Cell Biology 134(1): 181191.

Constam, D. B. and E. J. Robertson (1999). "Regulation of bone morphogenetic protein activity by pro domains and proprotein convertases." The Journal of Cell Biology 144(1): 139-149. 
Constam, D. B. and E. J. Robertson (2000). "SPC4/PACE4 regulates a TGFbeta signaling network during axis formation." Genes \& Development 14(9): 1146-1155.

Couse, J. F., S. C. Hewitt, D. O. Bunch, M. Sar, V. R. Walker, B. J. Davis and K. S. Korach (1999). "Postnatal sex reversal of the ovaries in mice lacking estrogen receptors alpha and beta." Science 286(5448): 2328-2331.

Crawford, J. L. and K. P. McNatty (2012). "The ratio of growth differentiation factor 9: bone morphogenetic protein 15 mRNA expression is tightly co-regulated and differs between species over a wide range of ovulation rates." Molecular and Cellular Endocrinology 348(1): 339-343.

Dayhoff, M. O., Schwartz, R.M., Orcutt, B.C (1978). "A model of evolutionary change in proteins." Atlas of Protein Sequence and Structure. National Biomedical Research Foundation, Washington: 345 - 352.

de Caestecker, M. (2004). "The transforming growth factor-beta superfamily of receptors." Cytokine \& Growth Factor Reviews 15(1): 1-11.

Dekel, N., T. S. Lawrence, N. B. Gilula and W. H. Beers (1981). "Modulation of cell-to-cell communication in the cumulus-oocyte complex and the regulation of oocyte maturation by LH." Developmental Biology 86(2): 356362.

Derynck, R. and Y. E. Zhang (2003). "Smad-dependent and Smadindependent pathways in TGF-beta family signalling." Nature 425(6958): 577584.

di Clemente, N., C. Wilson, E. Faure, L. Boussin, P. Carmillo, R. Tizard, J. Y. Picard, B. Vigier, N. Josso and R. Cate (1994). "Cloning, expression, and 
alternative splicing of the receptor for anti-Mullerian hormone." Molecular Endocrinology 8(8): 1006-1020.

Di Pasquale, E., P. Beck-Peccoz and L. Persani (2004). "Hypergonadotropic ovarian failure associated with an inherited mutation of human bone morphogenetic protein-15 (BMP15) gene." Am J Hum Genet 75(1): 106-111.

Di Pasquale, E. and A. H. Brivanlou (2009). "Bone morphogenetic protein 15 (BMP15) acts as a BMP and Wnt inhibitor during early embryogenesis." J Biol Chem 284(38): 26127-26136.

Di Pasquale, E., R. Rossetti, A. Marozzi, B. Bodega, S. Borgato, L. Cavallo, S. Einaudi, G. Radetti, G. Russo, M. Sacco, M. Wasniewska, T. Cole, P. Beck-Peccoz, L. M. Nelson and L. Persani (2006). "Identification of new variants of human BMP15 gene in a large cohort of women with premature ovarian failure." The Journal of Clinical Endocrinology and Metabolism 91(5): 19761979.

Dierich, A., M. R. Sairam, L. Monaco, G. M. Fimia, A. Gansmuller, M. LeMeur and P. Sassone-Corsi (1998). "Impairing follicle-stimulating hormone (FSH) signaling in vivo: targeted disruption of the FSH receptor leads to aberrant gametogenesis and hormonal imbalance." Proceedings of the National Academy of Sciences of the United States of America 95(23): 13612-13617.

Dixit, H., L. K. Rao, V. Padmalatha, M. Kanakavalli, M. Deenadayal, N. Gupta, B. Chakravarty and L. Singh (2005). "Mutational screening of the coding region of growth differentiation factor 9 gene in Indian women with ovarian failure." Menopause 12(6): 749-754. 
Dixit, H., L. K. Rao, V. V. Padmalatha, M. Kanakavalli, M. Deenadayal, N. Gupta, B. Chakrabarty and L. Singh (2006). "Missense mutations in the BMP15 gene are associated with ovarian failure." Hum Genet 119(4): 408-415.

Docke, F. and G. Dorner (1965). "The mechanism of the induction of ovulation by oestrogens." The Journal of Endocrinology 33(3): 491-499.

Dodson, W. C. and D. W. Schomberg (1987). "The effect of transforming growth factor-beta on follicle-stimulating hormone-induced differentiation of cultured rat granulosa cells." Endocrinology 120(2): 512-516.

Dong, J., D. F. Albertini, K. Nishimori, T. R. Kumar, N. Lu and M. M. Matzuk (1996). "Growth differentiation factor-9 is required during early ovarian folliculogenesis." Nature 383(6600): 531-535.

Dorrington, J., A. V. Chuma and J. J. Bendell (1988). "Transforming growth factor beta and follicle-stimulating hormone promote rat granulosa cell proliferation." Endocrinology 123(1): 353-359.

Dorrington, J. H., Y. S. Moon and D. T. Armstrong (1975). "Estradiol17beta biosynthesis in cultured granulosa cells from hypophysectomized immature rats; stimulation by follicle-stimulating hormone." Endocrinology 97(5): $1328-1331$.

Dragovic, R. A., L. J. Ritter, S. J. Schulz, F. Amato, D. T. Armstrong and R. B. Gilchrist (2005). "Role of oocyte-secreted growth differentiation factor 9 in the regulation of mouse cumulus expansion." Endocrinology 146(6): 2798-2806.

Drummond, A. E. (2005). "TGFbeta signalling in the development of ovarian function." Cell and Tissue Research 322(1): 107-115. 
Drummond, A. E. (2006). "The role of steroids in follicular growth." Reproductive Biology and Endocrinology : RB\&E 4: 16.

Drummond, A. E., K. L. Britt, M. Dyson, M. E. Jones, J. B. Kerr, L. O'Donnell, E. R. Simpson and J. K. Findlay (2002). "Ovarian steroid receptors and their role in ovarian function." Molecular and Cellular Endocrinology 191(1): 27-33.

Dube, J. L., P. Wang, J. Elvin, K. M. Lyons, A. J. Celeste and M. M. Matzuk (1998). "The bone morphogenetic protein 15 gene is X-linked and expressed in oocytes." Molecular Endocrinology 12(12): 1809-1817.

Dubois, C. M., M. H. Laprise, F. Blanchette, L. E. Gentry and R. Leduc (1995). "Processing of transforming growth factor beta 1 precursor by human furin convertase." The Journal of Biological Chemistry 270(18): 10618-10624.

Duffy, D. M. (2003). "Growth differentiation factor-9 is expressed by the primate follicle throughout the periovulatory interval." Biology of Reproduction 69(2): $725-732$.

Dupont, S., A. Krust, A. Gansmuller, A. Dierich, P. Chambon and M. Mark (2000). "Effect of single and compound knockouts of estrogen receptors alpha (ERalpha) and beta (ERbeta) on mouse reproductive phenotypes." Development 127(19): 4277-4291.

Durlinger, A. L., M. J. Gruijters, P. Kramer, B. Karels, T. R. Kumar, M. M. Matzuk, U. M. Rose, F. H. de Jong, J. T. Uilenbroek, J. A. Grootegoed and A. P. Themmen (2001). "Anti-Mullerian hormone attenuates the effects of FSH on follicle development in the mouse ovary." Endocrinology 142(11): 4891-4899.

Durlinger, A. L., P. Kramer, B. Karels, F. H. de Jong, J. T. Uilenbroek, J. A. Grootegoed and A. P. Themmen (1999). "Control of primordial follicle 
recruitment by anti-Mullerian hormone in the mouse ovary." Endocrinology 140(12): 5789-5796.

Eckery, D. C., L. J. Whale, S. B. Lawrence, K. A. Wylde, K. P. McNatty and J. L. Juengel (2002). "Expression of mRNA encoding growth differentiation factor 9 and bone morphogenetic protein 15 during follicular formation and growth in a marsupial, the brushtail possum (Trichosurus vulpecula)." Molecular and Cellular Endocrinology 192(1-2): 115-126.

Edson, M. A., A. K. Nagaraja and M. M. Matzuk (2009). "The mammalian ovary from genesis to revelation." Endocr Rev 30(6): 624-712.

Edwards, S. J., K. L. Reader, S. Lun, A. Western, S. Lawrence, K. P. McNatty and J. L. Juengel (2008). "The cooperative effect of growth and differentiation factor-9 and bone morphogenetic protein (BMP)-15 on granulosa cell function is modulated primarily through BMP receptor II." Endocrinology 149(3): 1026-1030.

Ekart, J., K. McNatty, J. Hutton and J. Pitman (2013). "Ranking and selection of MII oocytes in human ICSI cycles using gene expression levels from associated cumulus cells." Human reproduction 28(11): 2930-2942.

el-Fouly, M. A., B. Cook, M. Nekola and A. V. Nalbandov (1970). "Role of the ovum in follicular luteinization." Endocrinology 87(2): 286-293.

Elvin, J. A., A. T. Clark, P. Wang, N. M. Wolfman and M. M. Matzuk (1999). "Paracrine actions of growth differentiation factor-9 in the mammalian ovary." Mol Endocrinol 13(6): 1035-1048.

Elvin, J. A. and M. M. Matzuk (1998). "Mouse models of ovarian failure." Reviews of Reproduction 3(3): 183-195. 
Elvin, J. A., C. Yan and M. M. Matzuk (2000). "Oocyte-expressed TGFbeta superfamily members in female fertility." Molecular and Cellular Endocrinology 159(1-2): 1-5.

Elvin, J. A., C. Yan, P. Wang, K. Nishimori and M. M. Matzuk (1999). "Molecular characterization of the follicle defects in the growth differentiation factor 9-deficient ovary." Molecular Endocrinology 13(6): 1018-1034.

Emmen, J. M., J. F. Couse, S. A. Elmore, M. M. Yates, G. E. Kissling and K. S. Korach (2005). "In vitro growth and ovulation of follicles from ovaries of estrogen receptor (ER)\{alpha\} and ER \{beta\} null mice indicate a role for ER $\{$ beta $\}$ in follicular maturation." Endocrinology 146(6): 2817-2826.

Eppig, J. (2005). "Mouse oocytes control metabolic co-operativity between oocytes and cumulus cells." Reproduction, Fertility, and Development 17(1-2): 1-2.

Eppig, J. J. (1979a). "FSH stimulates hyaluronic acid synthesis by oocytecumulus cell complexes from mouse preovulatory follicles." Nature 281(5731): 483-484.

Eppig, J. J. (1979b). "Gonadotropin stimulation of the expansion of cumulus oophori isolated from mice: general conditions for expansion in vitro." The Journal of Experimental Zoology 208(1): 111-120.

Eppig, J. J. (2001). "Oocyte control of ovarian follicular development and function in mammals." Reproduction 122(6): 829-838.

Eppig, J. J., F. L. Pendola, K. Wigglesworth and J. K. Pendola (2005). "Mouse oocytes regulate metabolic cooperativity between granulosa cells and oocytes: amino acid transport." Biol Reprod 73(2): 351-357. 
Eppig, J. J., P. F. Ward-Bailey and D. L. Coleman (1985). "Hypoxanthine and adenosine in murine ovarian follicular fluid: concentrations and activity in maintaining oocyte meiotic arrest." Biology of Reproduction 33(5): 1041-1049.

Eppig, J. J., K. Wigglesworth and F. Chesnel (1993). "Secretion of cumulus expansion enabling factor by mouse oocytes: relationship to oocyte growth and competence to resume meiosis." Developmental Biology 158(2): 400409.

Eppig, J. J., K. Wigglesworth and F. L. Pendola (2002). "The mammalian oocyte orchestrates the rate of ovarian follicular development." Proceedings of the National Academy of Sciences of the United States of America 99(5): 2890-2894.

Erickson, G. F. and S. Shimasaki (2003). "The spatiotemporal expression pattern of the bone morphogenetic protein family in rat ovary cell types during the estrous cycle." Reproductive Biology and Endocrinology : RB\&E 1: 9.

Fabre, S., A. Pierre, C. Pisselet, P. Mulsant, F. Lecerf, J. Pohl, P. Monget and D. Monniaux (2003). "The Booroola mutation in sheep is associated with an alteration of the bone morphogenetic protein receptor-IB functionality." The Journal of Endocrinology 177(3): 435-444.

Fair, T. (2003). "Follicular oocyte growth and acquisition of developmental competence." Animal Reproduction Science 78(3-4): 203-216.

Fauser, B. C. and A. M. Van Heusden (1997). "Manipulation of human ovarian function: physiological concepts and clinical consequences." Endocrine Reviews 18(1): 71-106.

Fenwick, M. A., J. M. Mora, Y. T. Mansour, C. Baithun, S. Franks and K. Hardy (2013). "Investigations of transforming growth factor beta (TGF-beta) 
signalling in preantral follicles of female mice reveal differential roles for bone morphogenetic protein 15 (BMP15)." Endocrinology.

Findlay, J. K., K. Britt, J. B. Kerr, L. O'Donnell, M. E. Jones, A. E. Drummond and E. R. Simpson (2001). "The road to ovulation: the role of oestrogens." Reproduction, Fertility, and Development 13(7-8): 543-547.

Fischer, A. H., K. A. Jacobson, J. Rose and R. Zeller (2008). "Hematoxylin and eosin staining of tissue and cell sections." CSH Protocols 2008: pdb prot4986.

Fisher, C. R., K. H. Graves, A. F. Parlow and E. R. Simpson (1998). "Characterization of mice deficient in aromatase (ArKO) because of targeted disruption of the cyp19 gene." Proceedings of the National Academy of Sciences of the United States of America 95(12): 6965-6970.

Fitzpatrick, S. L., D. M. Sindoni, P. J. Shughrue, M. V. Lane, I. J. Merchenthaler and D. E. Frail (1998). "Expression of growth differentiation factor-9 messenger ribonucleic acid in ovarian and nonovarian rodent and human tissues." Endocrinology 139(5): 2571-2578.

Fortune, J. E. and S. E. Vincent (1983). "Progesterone inhibits the induction of aromatase activity in rat granulosa cells in vitro." Biology of Reproduction 28(5): 1078-1089.

Fraser, H. M., N. P. Groome and A. S. McNeilly (1999). "Folliclestimulating hormone-inhibin B interactions during the follicular phase of the primate menstrual cycle revealed by gonadotropin-releasing hormone antagonist and antiestrogen treatment." The Journal of Clinical Endocrinology and Metabolism 84(4): 1365-1369. 
Fukuda, M., K. Katayama and S. Tojo (1980). "Inhibitory effect of progesterone on follicular growth and induced superovulation in the rat." $\underline{\text { Archives }}$ of Gynecology 230(1): 77-87.

Galloway, S. M., K. P. McNatty, L. M. Cambridge, M. P. Laitinen, J. L. Juengel, T. S. Jokiranta, R. J. McLaren, K. Luiro, K. G. Dodds, G. W. Montgomery, A. E. Beattie, G. H. Davis and O. Ritvos (2000). "Mutations in an oocyte-derived growth factor gene (BMP15) cause increased ovulation rate and infertility in a dosage-sensitive manner." Nature Genetics 25(3): 279-283.

Gangrade, B. K. and J. V. May (1990). "The production of transforming growth factor-beta in the porcine ovary and its secretion in vitro." Endocrinology 127(5): 2372-2380.

Gates, A. H. (1956). "Viability and developmental capacity of eggs from immature mice treated with gonadotrophins." Nature 177(4512): 754-755.

Gilchrist, R. B., M. Lane and J. G. Thompson (2008). "Oocyte-secreted factors: regulators of cumulus cell function and oocyte quality." Human Reproduction Update 14(2): 159-177.

Gilchrist, R. B., M. P. Morrissey, L. J. Ritter and D. T. Armstrong (2003). "Comparison of oocyte factors and transforming growth factor-beta in the regulation of DNA synthesis in bovine granulosa cells." Molecular and Cellular Endocrinology 201(1-2): 87-95.

Gilchrist, R. B., L. J. Ritter and D. T. Armstrong (2004). "Oocyte-somatic cell interactions during follicle development in mammals." Animal Reproduction Science 82-83: 431-446.

Gilchrist, R. B., L. J. Ritter, M. Cranfield, L. A. Jeffery, F. Amato, S. J. Scott, S. Myllymaa, N. Kaivo-Oja, H. Lankinen, D. G. Mottershead, N. P. 
Groome and O. Ritvos (2004). "Immunoneutralization of growth differentiation factor 9 reveals it partially accounts for mouse oocyte mitogenic activity." Biology of Reproduction 71(3): 732-739.

Gill, A., M. Jamnongjit and S. R. Hammes (2004). "Androgens promote maturation and signaling in mouse oocytes independent of transcription: a release of inhibition model for mammalian oocyte meiosis." Molecular Endocrinology 18(1): 97-104.

Gill, G. W. (2010). "Gill hematoxylins: first person account." Biotechnic \& Histochemistry : Official Publication of the Biological Stain Commission 85(1): 7-18.

Gilling-Smith, C., D. S. Willis, R. W. Beard and S. Franks (1994). "Hypersecretion of androstenedione by isolated thecal cells from polycystic ovaries." The Journal of Clinical Endocrinology and Metabolism 79(4): 11581165.

Ginsburg, M., M. H. Snow and A. McLaren (1990). "Primordial germ cells in the mouse embryo during gastrulation." Development 110(2): 521-528.

Gode, F., B. Gulekli, E. Dogan, P. Korhan, S. Dogan, O. Bige, D. Cimrin and N. Atabey (2011). "Influence of follicular fluid GDF9 and BMP15 on embryo quality." Fertility and Sterility 95(7): 2274-2278.

Gonzalez-Robayna, I. J., A. E. Falender, S. Ochsner, G. L. Firestone and J. S. Richards (2000). "Follicle-Stimulating hormone (FSH) stimulates phosphorylation and activation of protein kinase $\mathrm{B}(\mathrm{PKB} / \mathrm{Akt})$ and serum and glucocorticoid-lnduced kinase (Sgk): evidence for A kinase-independent signaling by FSH in granulosa cells." Molecular Endocrinology 14(8): 1283-1300. 
Graham, J. D. and C. L. Clarke (1997). "Physiological action of progesterone in target tissues." Endocrine Reviews 18(4): 502-519.

Granot, I. and N. Dekel (1994). "Phosphorylation and expression of connexin-43 ovarian gap junction protein are regulated by luteinizing hormone." The Journal of Biological Chemistry 269(48): 30502-30509.

Gruijters, M. J., J. A. Visser, A. L. Durlinger and A. P. Themmen (2003). "Anti-Mullerian hormone and its role in ovarian function." Molecular and Cellular Endocrinology 211(1-2): 85-90.

Gueripel, X., V. Brun and A. Gougeon (2006). "Oocyte bone morphogenetic protein 15 , but not growth differentiation factor 9, is increased during gonadotropin-induced follicular development in the immature mouse and is associated with cumulus oophorus expansion." Biology of Reproduction 75(6): 836-843.

Gui, L. M. and I. M. Joyce (2005). "RNA interference evidence that growth differentiation factor-9 mediates oocyte regulation of cumulus expansion in mice." Biology of Reproduction 72(1): 195-199.

Hafez, E. S., T. Sugie and I. Gordon (1963). "Superovulation and related phenomena in the beef cow. I. Superovulatory responses following PMS and HCG injections." Journal of Reproduction and Fertility 5: 359-379.

Hahn, J. (1992). "Attempts to explain and reduce variability of superovulation." Theriogenology 38(2): 269-275.

Halpin, D. M., A. Jones, G. Fink and H. M. Charlton (1986). "Postnatal ovarian follicle development in hypogonadal (hpg) and normal mice and associated changes in the hypothalamic-pituitary ovarian axis." Journal of Reproduction and Fertility 77(1): 287-296. 
Handel, M. A. and J. J. Eppig (1998). "Sexual dimorphism in the regulation of mammalian meiosis." Current Topics in Developmental Biology 37: 333-358.

Hanrahan, J. P., S. M. Gregan, P. Mulsant, M. Mullen, G. H. Davis, R. Powell and S. M. Galloway (2004). "Mutations in the genes for oocyte-derived growth factors GDF9 and BMP15 are associated with both increased ovulation rate and sterility in Cambridge and Belclare sheep (Ovis aries)." Biology of Reproduction 70(4): 900-909.

Hashimoto, O., R. K. Moore and S. Shimasaki (2005). "Posttranslational processing of mouse and human BMP-15: potential implication in the determination of ovulation quota." Proceedings of the National Academy of Sciences of the United States of America 102(15): 5426-5431.

Hayashi, M., E. A. McGee, G. Min, C. Klein, U. M. Rose, M. van Duin and A. J. Hsueh (1999). "Recombinant growth differentiation factor-9 (GDF-9) enhances growth and differentiation of cultured early ovarian follicles." Endocrinology 140(3): 1236-1244.

Henikoff, S. and J. G. Henikoff (1993). "Performance evaluation of amino acid substitution matrices." Proteins 17(1): 49-61.

Hild-Petito, S., R. L. Stouffer and R. M. Brenner (1988). "Immunocytochemical localization of estradiol and progesterone receptors in the monkey ovary throughout the menstrual cycle." Endocrinology 123(6): 28962905.

Hillier, S. G. (1994). "Current concepts of the roles of follicle stimulating hormone and luteinizing hormone in folliculogenesis." Human Reproduction 9(2): 188-191. 
Hillier, S. G. (2000). "The Parkes lecture: controlled ovarian stimulation in women." Journal of Reproduction and Fertility 120(2): 201-210.

Hillier, S. G. and F. A. De Zwart (1981). "Evidence that granulosa cell aromatase induction/activation by follicle-stimulating hormone is an androgen receptor-regulated process in-vitro." Endocrinology 109(4): 1303-1305.

Hillier, S. G., R. A. Knazek and G. T. Ross (1977). "Androgenic stimulation of progesterone production by granulosa cells from preantral ovarian follicles: further in vitro studies using replicate cell cultures." Endocrinology 100(6): 1539-1549.

Hirai, M., S. Hirata, T. Osada, K. Hagihara and J. Kato (1994). "Androgen receptor mRNA in the rat ovary and uterus." The Journal of Steroid Biochemistry and Molecular Biology 49(1): 1-7.

Hirshfield, A. N. (1985). "Comparison of granulosa cell proliferation in small follicles of hypophysectomized, prepubertal, and mature rats." Biology of Reproduction 32(4): 979-987.

Hirshfield, A. N. (1991). "Development of follicles in the mammalian ovary." International Review of Cytology 124: 43-101.

Horie, K., K. Takakura, H. Fujiwara, H. Suginami, S. Liao and T. Mori (1992). "Immunohistochemical localization of androgen receptor in the human ovary throughout the menstrual cycle in relation to oestrogen and progesterone receptor expression." Human Reproduction 7(2): 184-190.

Hosoe, M., K. Kaneyama, K. Ushizawa, K. G. Hayashi and T. Takahashi (2011). "Quantitative analysis of bone morphogenetic protein 15 (BMP15) and 
growth differentiation factor 9 (GDF9) gene expression in calf and adult bovine ovaries." Reproductive Biology and Endocrinology : RB\&E 9: 33.

Hreinsson, J. G., J. E. Scott, C. Rasmussen, M. L. Swahn, A. J. Hsueh and O. Hovatta (2002). "Growth differentiation factor-9 promotes the growth, development, and survival of human ovarian follicles in organ culture." The Journal of Clinical Endocrinology and Metabolism 87(1): 316-321.

Hsueh, A. J., E. Y. Adashi, P. B. Jones and T. H. Welsh, Jr. (1984). "Hormonal regulation of the differentiation of cultured ovarian granulosa cells." Endocrine Reviews 5(1): 76-127.

Hu, Y. C., P. H. Wang, S. Yeh, R. S. Wang, C. Xie, Q. Xu, X. Zhou, H. T. Chao, M. Y. Tsai and C. Chang (2004). "Subfertility and defective folliculogenesis in female mice lacking androgen receptor." Proceedings of the National Academy of Sciences of the United States of America 101(31): 1120911214

Hussein, T. S., D. A. Froiland, F. Amato, J. G. Thompson and R. B. Gilchrist (2005). "Oocytes prevent cumulus cell apoptosis by maintaining a morphogenic paracrine gradient of bone morphogenetic proteins." Journal of Cell Science 118(Pt 22): 5257-5268.

Hussein, T. S., J. G. Thompson and R. B. Gilchrist (2006). "Oocytesecreted factors enhance oocyte developmental competence." Developmental Biology 296(2): 514-521.

Hutchinson, L. A., J. K. Findlay, F. L. de Vos and D. M. Robertson (1987). "Effects of bovine inhibin, transforming growth factor-beta and bovine Activin-A on granulosa cell differentiation." Biochemical and Biophysical Research Communications 146(3): 1405-1412. 
Hutt, K. J., E. A. McLaughlin and M. K. Holland (2006). "Kit ligand and c-Kit have diverse roles during mammalian oogenesis and folliculogenesis." Molecular Human Reproduction 12(2): 61-69.

Inagaki, K. and S. Shimasaki (2010). "Impaired PRODUCTION of BMP15 and GDF-9 MATURE PROTEINS DERIVED FROM proproteins WITH mutations in the proregion." Mol Cell Endocrinol.

Iwai, M., K. Yasuda, M. Fukuoka, T. Iwai, K. Takakura, S. Taii, S. Nakanishi and T. Mori (1991). "Luteinizing hormone induces progesterone receptor gene expression in cultured porcine granulosa cells." Endocrinology 129(3): 1621-1627.

Iwai, T., S. Fujii, Y. Nanbu, H. Nonogaki, I. Konishi, T. Mori and H. Okamura (1991). "Effect of human chorionic gonadotropin on the expression of progesterone receptors and estrogen receptors in rabbit ovarian granulosa cells and the uterus." Endocrinology 129(4): 1840-1848.

Jansen, H. T., C. West, M. N. Lehman and V. Padmanabhan (2001). "Ovarian estrogen receptor-beta (ERbeta) regulation: I. Changes in ERbeta messenger RNA expression prior to ovulation in the ewe." Biology of Reproduction 65(3): 866-872.

Jiang, M. S., L. F. Liang, S. Wang, T. Ratovitski, J. Holmstrom, C. Barker and R. Stotish (2004). "Characterization and identification of the inhibitory domain of GDF-8 propeptide." Biochemical and Biophysical Research Communications 315(3): 525-531.

Johnson, M. S. and J. P. Overington (1993). "A structural basis for sequence comparisons. An evaluation of scoring methodologies." Journal of Molecular Biology 233(4): 716-738. 
Jonard, S. and D. Dewailly (2004). "The follicular excess in polycystic ovaries, due to intra-ovarian hyperandrogenism, may be the main culprit for the follicular arrest." Human Reproduction Update 10(2): 107-117.

Juengel, J. L., A. H. Bibby, K. L. Reader, S. Lun, L. D. Quirke, L. J. Haydon and K. P. McNatty (2004). "The role of transforming growth factor-beta (TGF-beta) during ovarian follicular development in sheep." Reproductive Biology and Endocrinology : RB\&E 2: 78.

Juengel, J. L., K. J. Bodensteiner, D. A. Heath, N. L. Hudson, C. L. Moeller, P. Smith, S. M. Galloway, G. H. Davis, H. R. Sawyer and K. P. McNatty (2004). "Physiology of GDF9 and BMP15 signalling molecules." Animal Reproduction Science 82-83: 447-460.

Juengel, J. L., D. A. Heath, L. D. Quirke and K. P. McNatty (2006). "Oestrogen receptor alpha and beta, androgen receptor and progesterone receptor mRNA and protein localisation within the developing ovary and in small growing follicles of sheep." Reproduction 131(1): 81-92.

Juengel, J. L., N. L. Hudson, D. A. Heath, P. Smith, K. L. Reader, S. B. Lawrence, A. R. O'Connell, M. P. Laitinen, M. Cranfield, N. P. Groome, O. Ritvos and K. P. McNatty (2002). "Growth differentiation factor 9 and bone morphogenetic protein 15 are essential for ovarian follicular development in sheep." Biology of Reproduction 67(6): 1777-1789.

Juengel, J. L. and K. P. McNatty (2005). "The role of proteins of the transforming growth factor-beta superfamily in the intraovarian regulation of follicular development." Hum Reprod Update 11(2): 143-160.

Juneja, S. C., N. Chegini, R. S. Williams and G. A. Ksander (1996). "Ovarian intrabursal administration of transforming growth factor beta 1 inhibits 
follicle rupture in gonadotropin-primed mice." Biology of Reproduction 55(6): 1444-1451.

Kaivo-Oja, N., J. Bondestam, M. Kamarainen, J. Koskimies, U. Vitt, M. Cranfield, K. Vuojolainen, J. P. Kallio, V. M. Olkkonen, M. Hayashi, A. Moustakas, N. P. Groome, P. ten Dijke, A. J. Hsueh and O. Ritvos (2003). "Growth differentiation factor-9 induces Smad2 activation and inhibin B production in cultured human granulosa-luteal cells." The Journal of Clinical Endocrinology and Metabolism 88(2): 755-762.

Kaivo-Oja, N., D. G. Mottershead, S. Mazerbourg, S. Myllymaa, S. Duprat, R. B. Gilchrist, N. P. Groome, A. J. Hsueh and O. Ritvos (2005). "Adenoviral gene transfer allows Smad-responsive gene promoter analyses and delineation of type I receptor usage of transforming growth factor-beta family ligands in cultured human granulosa luteal cells." The Journal of Clinical Endocrinology and Metabolism 90(1): 271-278.

Kalma, Y., I. Granot, D. Galiani, A. Barash and N. Dekel (2004). "Luteinizing hormone-induced connexin 43 down-regulation: inhibition of translation." Endocrinology 145(4): 1617-1624.

Kanzaki, T., A. Olofsson, A. Moren, C. Wernstedt, U. Hellman, K. Miyazono, L. Claesson-Welsh and C. H. Heldin (1990). "TGF-beta 1 binding protein: a component of the large latent complex of TGF-beta 1 with multiple repeat sequences." Cell 61(6): 1051-1061.

Kastner, P., A. Krust, B. Turcotte, U. Stropp, L. Tora, H. Gronemeyer and P. Chambon (1990). "Two distinct estrogen-regulated promoters generate transcripts encoding the two functionally different human progesterone receptor forms A and B." The EMBO Journal 9(5): 1603-1614. 
Kezele, P. and M. K. Skinner (2003). "Regulation of ovarian primordial follicle assembly and development by estrogen and progesterone: endocrine model of follicle assembly." Endocrinology 144(8): 3329-3337.

Kingsley, D. M. (1994). "The TGF-beta superfamily: new members, new receptors, and new genetic tests of function in different organisms." Genes \& Development 8(2): 133-146.

Knecht, M., P. Feng and K. Catt (1987). "Bifunctional role of transforming growth factor-beta during granulosa cell development." Endocrinology 120(4): 1243-1249.

Knight, P. G. (1996). "Roles of inhibins, activins, and follistatin in the female reproductive system." Frontiers in Neuroendocrinology 17(4): 476-509.

Knight, P. G. and C. Glister (2001). "Potential local regulatory functions of inhibins, activins and follistatin in the ovary." Reproduction 121(4): 503-512.

Knight, P. G. and C. Glister (2006). "TGF-beta superfamily members and ovarian follicle development." Reproduction 132(2): 191-206.

Knobil, E. (1974). "On the control of gonadotropin secretion in the rhesus monkey." Recent Progress in Hormone Research 30(0): 1-46.

Knobil, E., Ed. (1994). The Physiology of Reproduction. Embriology of Mammalian Gonads and Ducts. New York, Raven Press Ltd.

Koli, K., J. Saharinen, M. Hyytiainen, C. Penttinen and J. Keski-Oja (2001). "Latency, activation, and binding proteins of TGF-beta." Microscopy Research and Technique 52(4): 354-362. 
Krege, J. H., J. B. Hodgin, J. F. Couse, E. Enmark, M. Warner, J. F. Mahler, M. Sar, K. S. Korach, J. A. Gustafsson and O. Smithies (1998). "Generation and reproductive phenotypes of mice lacking estrogen receptor beta." Proceedings of the National Academy of Sciences of the United States of America 95(26): 15677-15682.

Krysan, D. J., N. C. Rockwell and R. S. Fuller (1999). "Quantitative characterization of furin specificity. Energetics of substrate discrimination using an internally consistent set of hexapeptidyl methylcoumarinamides." The Journal of Biological Chemistry 274(33): 23229-23234.

Kubota, T., S. Kamada, M. Taguchi and T. Aso (1994). "Autocrine/paracrine function of transforming growth factor-beta 1 in porcine granulosa cells." Human Reproduction 9(11): 2118-2122.

Kumar, T. R., Y. Wang, N. Lu and M. M. Matzuk (1997). "Follicle stimulating hormone is required for ovarian follicle maturation but not male fertility." Nature Genetics 15(2): 201-204.

Laissue, P., S. Christin-Maitre, P. Touraine, F. Kuttenn, O. Ritvos, K. Aittomaki, N. Bourcigaux, L. Jacquesson, P. Bouchard, R. Frydman, D. Dewailly, A. C. Reyss, L. Jeffery, A. Bachelot, N. Massin, M. Fellous and R. A. Veitia (2006). "Mutations and sequence variants in GDF9 and BMP15 in patients with premature ovarian failure." European Journal of Endocrinology / European Federation of Endocrine Societies 154(5): 739-744.

Laitinen, M., K. Vuojolainen, R. Jaatinen, I. Ketola, J. Aaltonen, E. Lehtonen, M. Heikinheimo and O. Ritvos (1998). "A novel growth differentiation factor-9 (GDF-9) related factor is co-expressed with GDF-9 in mouse oocytes during folliculogenesis." Mechanisms of Development 78(1-2): 135-140. 
Larsen, W. J., L. Chen, R. Powers, H. Zhang, P. T. Russell, C. Chambers, K. Hess and R. Flick (1996). "Cumulus expansion initiates physical and developmental autonomy of the oocyte." Zygote 4(4): 335-341.

Le Good, J. A., K. Joubin, A. J. Giraldez, N. Ben-Haim, S. Beck, Y. Chen, A. F. Schier and D. B. Constam (2005). "Nodal stability determines signaling range." Current Biology : CB 15(1): 31-36.

Liao, W. X., R. K. Moore, F. Otsuka and S. Shimasaki (2003). "Effect of intracellular interactions on the processing and secretion of bone morphogenetic protein-15 (BMP-15) and growth and differentiation factor-9. Implication of the aberrant ovarian phenotype of BMP-15 mutant sheep." The Journal of Biological Chemistry 278(6): 3713-3719.

Liao, W. X., R. K. Moore and S. Shimasaki (2004). "Functional and molecular characterization of naturally occurring mutations in the oocyte-secreted factors bone morphogenetic protein-15 and growth and differentiation factor-9." The Journal of Biological Chemistry 279(17): 17391-17396.

Lin, J. Y., J. L. Pitman-Crawford, A. H. Bibby, N. L. Hudson, C. J. McIntosh, J. L. Juengel and K. P. McNatty (2012). "Effects of species differences on oocyte regulation of granulosa cell function." Reproduction 144(5): 557-567.

Livak, K. J. and T. D. Schmittgen (2001). "Analysis of relative gene expression data using real-time quantitative PCR and the 2(-Delta Delta $\mathrm{C}(\mathrm{T})$ ) Method." Methods 25(4): 402-408.

Lubahn, D. B., J. S. Moyer, T. S. Golding, J. F. Couse, K. S. Korach and O. Smithies (1993). "Alteration of reproductive function but not prenatal sexual development after insertional disruption of the mouse estrogen receptor gene." Proceedings of the National Academy of Sciences of the United States of America 90(23): 11162-11166. 
Luciano, A. M. and J. J. Peluso (1995). "Effect of in vivo gonadotropin treatment on the ability of progesterone, estrogen, and cyclic adenosine 5'monophosphate to inhibit insulin-dependent granulosa cell mitosis in vitro." Biology of Reproduction 53(3): 664-669.

Lundy, T., P. Smith, A. O'Connell, N. L. Hudson and K. P. McNatty (1999). "Populations of granulosa cells in small follicles of the sheep ovary." Journal of Reproduction and Fertility 115(2): 251-262.

Luo, C., J. Zuniga, E. Edison, S. Palla, W. Dong and J. Parker-Thornburg (2011). "Superovulation strategies for 6 commonly used mouse strains." Journal of the American Association for Laboratory Animal Science : JAALAS 50(4): 471-478.

Lydon, J. P., F. J. DeMayo, C. R. Funk, S. K. Mani, A. R. Hughes, C. A. Montgomery, Jr., G. Shyamala, O. M. Conneely and B. W. O'Malley (1995). "Mice lacking progesterone receptor exhibit pleiotropic reproductive abnormalities." Genes \& Development 9(18): 2266-2278.

Lyon, M. F. and P. H. Glenister (1980). "Reduced reproductive performance in androgen-resistant $\mathrm{Tfm} / \mathrm{Tfm}$ female mice." Proceedings of the Royal Society of London. Series B, Containing papers of a Biological character. Royal Society 208(1170): 1-12.

Martinez-Royo, A., E. Dervishi, J. L. Alabart, J. J. Jurado, J. Folch and J. H. Calvo (2009). "Freemartinism and FecXR allele determination in replacement ewes of the Rasa Aragonesa sheep breed by duplex PCR." Theriogenology 72(8): 1148-1152.

Massague, J. (1990). "The transforming growth factor-beta family." Annual Review of Cell Biology 6: 597-641. 
Matzuk, M. M. (2000). "Revelations of ovarian follicle biology from gene knockout mice." Molecular and Cellular Endocrinology 163(1-2): 61-66.

May, J. V., J. P. Frost and D. W. Schomberg (1988). "Differential effects of epidermal growth factor, somatomedin-C/insulin-like growth factor I, and transforming growth factor-beta on porcine granulosa cell deoxyribonucleic acid synthesis and cell proliferation." Endocrinology 123(1): 168-179.

Mazerbourg, S. and A. J. Hsueh (2003). "Growth differentiation factor-9 signaling in the ovary." Molecular and Cellular Endocrinology 202(1-2): 31-36.

Mazerbourg, S., C. Klein, J. Roh, N. Kaivo-Oja, D. G. Mottershead, O. Korchynskyi, O. Ritvos and A. J. Hsueh (2004). "Growth differentiation factor-9 signaling is mediated by the type I receptor, activin receptor-like kinase 5." Molecular Endocrinology 18(3): 653-665.

McAllister, J. M., W. Byrd and E. R. Simpson (1994). "The effects of growth factors and phorbol esters on steroid biosynthesis in isolated human theca interna and granulosa-lutein cells in long term culture." The Journal of Clinical Endocrinology and Metabolism 79(1): 106-112.

McGee, E. A. and A. J. Hsueh (2000). "Initial and cyclic recruitment of ovarian follicles." Endocrine Reviews 21(2): 200-214.

McGrath, S. A., A. F. Esquela and S. J. Lee (1995). "Oocyte-specific expression of growth/differentiation factor-9." Molecular Endocrinology 9(1): 131-136.

McIntosh, C. J., S. Lawrence, P. Smith, J. L. Juengel and K. P. McNatty (2012). "Active immunization against the proregions of GDF9 or BMP15 alters ovulation rate and litter size in mice." Reproduction 143(2): 195-201. 
McIntosh, C. J., S. Lun, S. Lawrence, A. H. Western, K. P. McNatty and J. L. Juengel (2008). "The proregion of mouse BMP15 regulates the cooperative interactions of BMP15 and GDF9." Biology of Reproduction 79(5): 889-896.

McMahon, G. A., J. D. Dignam and L. E. Gentry (1996). "Structural characterization of the latent complex between transforming growth factor beta 1 and beta 1-latency-associated peptide." The Biochemical Journal 313 ( Pt 1): 343351.

McMahon, H. E., S. Sharma and S. Shimasaki (2008). "Phosphorylation of bone morphogenetic protein-15 and growth and differentiation factor-9 plays a critical role in determining agonistic or antagonistic functions." Endocrinology 149(2): 812-817.

McNatty, K. P. (1978). "Cyclic changes in antral fluid hormone concentrations in humans." Clinics in Endocrinology and Metabolism 7(3): 577600 .

McNatty, K. P. and D. T. Baird (1978). "Relationship between folliclestimulating hormone, androstenedione and oestradiol in human follicular fluid." The Journal of Endocrinology 76(3): 527-531.

McNatty, K. P., M. Gibb, C. Dobson, D. C. Thurley and J. K. Findlay (1981). "Changes in the concentration of gonadotropic and steroidal hormones in the antral fluid of ovarian follicle throughout the oestrous cycle of the sheep." Australian Journal of Biological Sciences 34(1): 67-80.

McNatty, K. P., D. A. Heath, K. M. Henderson, S. Lun, P. R. Hurst, L. M. Ellis, G. W. Montgomery, L. Morrison and D. C. Thurley (1984). "Some aspects of thecal and granulosa cell function during follicular development in the bovine ovary." Journal of Reproduction and Fertility 72(1): 39-53. 
McNatty, K. P., D. A. Heath, N. Hudson and I. J. Clarke (1990). "Effect of long-term hypophysectomy on ovarian follicle populations and gonadotrophininduced adenosine cyclic 3',5'-monophosphate output by follicles from Booroola ewes with or without the F gene." Journal of Reproduction and Fertility 90(2): $515-522$.

McNatty, K. P., D. A. Heath, N. L. Hudson, S. Lun, J. L. Juengel and L. G. Moore (2009). "Gonadotrophin-responsiveness of granulosa cells from bone morphogenetic protein 15 heterozygous mutant sheep." Reproduction 138(3): $545-551$.

McNatty, K. P., D. A. Heath, N. L. Hudson, K. L. Reader, L. Quirke, S. Lun and J. L. Juengel (2010). "The conflict between hierarchical ovarian follicular development and superovulation treatment." Reproduction 140(2): 287-294.

McNatty, K. P., D. A. Heath, T. Lundy, A. E. Fidler, L. Quirke, A. O'Connell, P. Smith, N. Groome and D. J. Tisdall (1999). "Control of early ovarian follicular development." Journal of Reproduction and Fertility. Supplement 54: 3-16.

McNatty, K. P., N. L. Hudson, L. Whiting, K. L. Reader, S. Lun, A. Western, D. A. Heath, P. Smith, L. G. Moore and J. L. Juengel (2007). "The effects of immunizing sheep with different BMP15 or GDF9 peptide sequences on ovarian follicular activity and ovulation rate." Biology of Reproduction 76(4): $552-560$.

McNatty, K. P., J. L. Juengel, K. L. Reader, S. Lun, S. Myllymaa, S. B. Lawrence, A. Western, M. F. Meerasahib, D. G. Mottershead, N. P. Groome, O. Ritvos and M. P. Laitinen (2005a). "Bone morphogenetic protein 15 and growth differentiation factor 9 co-operate to regulate granulosa cell function in ruminants." Reproduction 129(4): 481-487. 
McNatty, K. P., J. L. Juengel, K. L. Reader, S. Lun, S. Myllymaa, S. B. Lawrence, A. Western, M. F. Meerasahib, D. G. Mottershead, N. P. Groome, O. Ritvos and M. P. Laitinen (2005b). "Bone morphogenetic protein 15 and growth differentiation factor 9 co-operate to regulate granulosa cell function." Reproduction 129(4): 473-480.

McNatty, K. P., J. L. Juengel, T. Wilson, S. M. Galloway, G. H. Davis, N. L. Hudson, C. L. Moeller, M. Cranfield, K. L. Reader, M. P. Laitinen, N. P. Groome, H. R. Sawyer and O. Ritvos (2003). "Oocyte-derived growth factors and ovulation rate in sheep." Reproduction 61: 339-351.

McNatty, K. P., S. Lawrence, N. P. Groome, M. F. Meerasahib, N. L. Hudson, L. Whiting, D. A. Heath and J. L. Juengel (2006). "Meat and Livestock Association Plenary Lecture 2005. Oocyte signalling molecules and their effects on reproduction in ruminants." Reproduction, Fertility, and Development 18(4): 403-412.

McNatty, K. P., A. Makris, C. DeGrazia, R. Osathanondh and K. J. Ryan (1979). "The production of progesterone, androgens, and estrogens by granulosa cells, thecal tissue, and stromal tissue from human ovaries in vitro." The Journal of Clinical Endocrinology and Metabolism 49(5): 687-699.

McPherron, A. C. and S. J. Lee (1993). "GDF-3 and GDF-9: two new members of the transforming growth factor-beta superfamily containing a novel pattern of cysteines." J Biol Chem 268(5): 3444-3449.

Messinis, I. E., C. I. Messini and K. Dafopoulos (2010). "The role of gonadotropins in the follicular phase." Annals of the New York Academy of Sciences 1205: 5-11. 
Miro, F. and S. G. Hillier (1996). "Modulation of granulosa cell deoxyribonucleic acid synthesis and differentiation by activin." Endocrinology 137(2): 464-468.

Miyazawa, K., M. Shinozaki, T. Hara, T. Furuya and K. Miyazono (2002). "Two major Smad pathways in TGF-beta superfamily signalling." Genes to Cells : Devoted to Molecular \& Cellular Mechanisms 7(12): 1191-1204.

Miyazono, K., U. Hellman, C. Wernstedt and C. H. Heldin (1988). "Latent high molecular weight complex of transforming growth factor beta 1. Purification from human platelets and structural characterization." The Journal of Biological Chemistry 263(13): 6407-6415.

Miyoshi, T., F. Otsuka, E. Nakamura, K. Inagaki, K. Ogura-Ochi, N. Tsukamoto, M. Takeda and H. Makino (2012). "Regulatory role of kit ligand-c-kit interaction and oocyte factors in steroidogenesis by rat granulosa cells." Molecular and Cellular Endocrinology 358(1): 18-26.

Moenter, S. M., A. Caraty and F. J. Karsch (1990). "The estradiol-induced surge of gonadotropin-releasing hormone in the ewe." Endocrinology 127(3): $1375-1384$.

Moenter, S. M., A. Caraty, A. Locatelli and F. J. Karsch (1991). "Pattern of gonadotropin-releasing hormone $(\mathrm{GnRH})$ secretion leading up to ovulation in the ewe: existence of a preovulatory GnRH surge." Endocrinology 129(3): 11751182.

Mondschein, J. S., S. F. Canning and J. M. Hammond (1988). "Effects of transforming growth factor-beta on the production of immunoreactive insulin-like growth factor I and progesterone and on $[3 \mathrm{H}]$ thymidine incorporation in porcine granulosa cell cultures." Endocrinology 123(4): 1970-1976. 
Monteagudo, L. V., R. Ponz, M. T. Tejedor, A. Lavina and I. Sierra (2009). "A 17 bp deletion in the Bone Morphogenetic Protein 15 (BMP15) gene is associated to increased prolificacy in the Rasa Aragonesa sheep breed." Animal Reproduction Science 110(1-2): 139-146.

Moor, R. M., Y. Dai, C. Lee and J. Fulka, Jr. (1998). "Oocyte maturation and embryonic failure." Human Reproduction Update 4(3): 223-236.

Moore, R. K., G. F. Erickson and S. Shimasaki (2004). "Are BMP-15 and GDF-9 primary determinants of ovulation quota in mammals?" Trends in Endocrinology and Metabolism: TEM 15(8): 356-361.

Moore, R. K., F. Otsuka and S. Shimasaki (2003). "Molecular basis of bone morphogenetic protein-15 signaling in granulosa cells." The Journal of Biological Chemistry 278(1): 304-310.

Moren, A., A. Olofsson, G. Stenman, P. Sahlin, T. Kanzaki, L. ClaessonWelsh, P. ten Dijke, K. Miyazono and C. H. Heldin (1994). "Identification and characterization of LTBP-2, a novel latent transforming growth factor-betabinding protein." The Journal of Biological Chemistry 269(51): 32469-32478.

Mork, L., D. M. Maatouk, J. A. McMahon, J. J. Guo, P. Zhang, A. P. McMahon and B. Capel (2012). "Temporal differences in granulosa cell specification in the ovary reflect distinct follicle fates in mice." Biology of Reproduction 86(2): 37.

Mottershead, D. G., C. A. Harrison, T. D. Mueller, P. G. Stanton, R. B. Gilchrist and K. P. McNatty (2013). "Growth differentiation factor 9:bone morphogenetic protein 15 (GDF9:BMP15) synergism and protein heterodimerization." Proceedings of the National Academy of Sciences of the United States of America 110(25): E2257. 
Mottershead, D. G., M. M. Pulkki, P. Muggalla, A. Pasternack, M. Tolonen, S. Myllymaa, O. Korchynskyi, Y. Nishi, T. Yanase, S. Lun, J. L. Juengel, M. Laitinen and O. Ritvos (2008). "Characterization of recombinant human growth differentiation factor-9 signaling in ovarian granulosa cells." Molecular and Cellular Endocrinology 283(1-2): 58-67.

Mottershead, D. G., L. J. Ritter and R. B. Gilchrist (2012). "Signalling pathways mediating specific synergistic interactions between GDF9 and BMP15." Molecular Human Reproduction 18(3): 121-128.

Mulsant, P., F. Lecerf, S. Fabre, L. Schibler, P. Monget, I. Lanneluc, C. Pisselet, J. Riquet, D. Monniaux, I. Callebaut, E. Cribiu, J. Thimonier, J. Teyssier, L. Bodin, Y. Cognie, N. Chitour and J. M. Elsen (2001). "Mutation in bone morphogenetic protein receptor-IB is associated with increased ovulation rate in Booroola Merino ewes." Proceedings of the National Academy of Sciences of the United States of America 98(9): 5104-5109.

Nahum, R., Y. Beyth, S. Y. Chun, A. J. Hsueh and A. Tsafriri (1996). "Early onset of deoxyribonucleic acid fragmentation during atresia of preovulatory ovarian follicles in rats." Biology of Reproduction 55(5): 1075-1080.

Nakai, Y., T. M. Plant, D. L. Hess, E. J. Keogh and E. Knobil (1978). "On the sites of the negative and positive feedback actions of estradiol in the control of gonadotropin secretion in the rhesus monkey." Endocrinology 102(4): 1008-1014.

Nakamura, M., T. Minegishi, Y. Hasegawa, K. Nakamura, S. Igarashi, I. Ito, H. Shinozaki, K. Miyamoto, Y. Eto and Y. Ibuki (1993). "Effect of an activin A on follicle-stimulating hormone (FSH) receptor messenger ribonucleic acid levels and FSH receptor expressions in cultured rat granulosa cells." Endocrinology 133(2): 538-544. 
Nakayama, K. (1997). "Furin: a mammalian subtilisin/Kex2p-like endoprotease involved in processing of a wide variety of precursor proteins." The Biochemical Journal 327 ( Pt 3): 625-635.

Natraj, U. and J. S. Richards (1993). "Hormonal regulation, localization, and functional activity of the progesterone receptor in granulosa cells of rat preovulatory follicles." Endocrinology 133(2): 761-769.

Nekola, M. V. and A. V. Nalbandov (1971). "Morphological changes of rat follicular cells as influenced by oocytes." Biology of Reproduction 4(2): 154160.

Nicol, L., S. C. Bishop, R. Pong-Wong, C. Bendixen, L. E. Holm, S. M. Rhind and A. S. McNeilly (2009). "Homozygosity for a single base-pair mutation in the oocyte-specific GDF9 gene results in sterility in Thoka sheep." Reproduction 138(6): 921-933.

Nilsson, E. E., V. Doraiswamy and M. K. Skinner (2003). "Transforming growth factor-beta isoform expression during bovine ovarian antral follicle development." Molecular Reproduction and Development 66(3): 237-246.

Nilsson, E. E. and M. K. Skinner (2002). "Growth and differentiation factor-9 stimulates progression of early primary but not primordial rat ovarian follicle development." Biology of Reproduction 67(3): 1018-1024.

Nimrod, A. (1977). "Studies on the synergistic effect of androgen on the stimulation of progestin secretion by FSH in cultured rat granulosa cells: progesterone metabolism and the effect of androgens." Molecular and Cellular Endocrinology 8(3): 189-199. 
Nimrod, A., G. F. Erickson and K. J. Ryan (1976). "A specific FSH receptor in rat granulosa cells: properties of binding in vitro." Endocrinology 98(1): 56-64.

Odor, D. L. (1960). "Electron microscopic studies on ovarian oocytes and unfertilized tubal ova in the rat." The Journal of Biophysical and Biochemical Cytology 7: 567-574.

Otsuka, F. and S. Shimasaki (2002). "A negative feedback system between oocyte bone morphogenetic protein 15 and granulosa cell kit ligand: its role in regulating granulosa cell mitosis." Proceedings of the National Academy of Sciences of the United States of America 99(12): 8060-8065.

Otsuka, F. and S. Shimasaki (2002). "A novel function of bone morphogenetic protein-15 in the pituitary: selective synthesis and secretion of FSH by gonadotropes." Endocrinology 143(12): 4938-4941.

Otsuka, F., S. Yamamoto, G. F. Erickson and S. Shimasaki (2001). "Bone morphogenetic protein-15 inhibits follicle-stimulating hormone (FSH) action by suppressing FSH receptor expression." J Biol Chem 276(14): 11387-11392.

Otsuka, F., Z. Yao, T. Lee, S. Yamamoto, G. F. Erickson and S. Shimasaki (2000). "Bone morphogenetic protein-15. Identification of target cells and biological functions." The Journal of Biological Chemistry 275(50): 39523-39528.

Palmer, J. S., Z. Z. Zhao, C. Hoekstra, N. K. Hayward, P. M. Webb, D. C. Whiteman, N. G. Martin, D. I. Boomsma, D. L. Duffy and G. W. Montgomery (2006). "Novel variants in growth differentiation factor 9 in mothers of dizygotic twins." The Journal of Clinical Endocrinology and Metabolism 91(11): 47134716. 
Paradis, F., S. Novak, G. K. Murdoch, M. K. Dyck, W. T. Dixon and G. R. Foxcroft (2009). "Temporal regulation of BMP2, BMP6, BMP15, GDF9, BMPR1A, BMPR1B, BMPR2 and TGFBR1 mRNA expression in the oocyte, granulosa and theca cells of developing preovulatory follicles in the pig." Reproduction 138(1): 115-129.

Park, O. K. and K. E. Mayo (1991). "Transient expression of progesterone receptor messenger RNA in ovarian granulosa cells after the preovulatory luteinizing hormone surge." Molecular Endocrinology 5(7): 967-978.

Patrizio, P. and D. Sakkas (2009). "From oocyte to baby: a clinical evaluation of the biological efficiency of in vitro fertilization." Fertility and Sterility 91(4): 1061-1066.

Pedersen, T. and H. Peters (1968). "Proposal for a classification of oocytes and follicles in the mouse ovary." Journal of Reproduction and Fertility 17(3): $555-557$.

Peluso, J. J. (2003). "Progesterone as a regulator of granulosa cell viability." The Journal of Steroid Biochemistry and Molecular Biology 85(2-5): 167-173.

Peluso, J. J., A. M. Luciano, A. Pappalardo and B. A. White (1995). "Cellular and molecular mechanisms that mediate insulin-dependent rat granulosa cell mitosis." Biology of Reproduction 52(1): 124-130.

Peluso, J. J. and A. Pappalardo (1994). "Progesterone and cell-cell adhesion interact to regulate rat granulosa cell apoptosis." Biochemistry and Cell Biology $=$ Biochimie et Biologie Cellulaire 72(11-12): 547-551.

Peng, J., Q. Li, K. Wigglesworth, A. Rangarajan, C. Kattamuri, R. T. Peterson, J. J. Eppig, T. B. Thompson and M. M. Matzuk (2013). "Growth 
differentiation factor 9:bone morphogenetic protein 15 heterodimers are potent regulators of ovarian functions." Proceedings of the National Academy of Sciences of the United States of America 110(8): E776-785.

Peng, X. R., A. J. Hsueh, P. S. LaPolt, L. Bjersing and T. Ny (1991). "Localization of luteinizing hormone receptor messenger ribonucleic acid expression in ovarian cell types during follicle development and ovulation." Endocrinology 129(6): 3200-3207.

Peters, H., A. G. Byskov, R. Himelstein-Braw and M. Faber (1975). "Follicular growth: the basic event in the mouse and human ovary." J Reprod Fertil 45(3): 559-566.

Peters, H. and K. P. McNatty (1980). The Ovary: A correlation of Structure and Function in Mammals, Granada Publishing.

Plant, T. M., Y. Nakai, P. Belchetz, E. Keogh and E. Knobil (1978). "The sites of action of estradiol and phentolamine in the inhibition of the pulsatile, circhoral discharges of LH in the rhesus monkey (Macaca mulatta)." Endocrinology 102(4): 1015-1018.

Presl, J., J. Pospisil, V. Figarova and Z. Krabec (1974). "Stage-dependent changes in binding of iodinated FSH during ovarian follicle maturation in rats." Endocrinologia Experimentalis 8(4): 291-298.

Prochazka, R., L. Nemcova, E. Nagyova and J. Kanka (2004). "Expression of growth differentiation factor 9 messenger RNA in porcine growing and preovulatory ovarian follicles." Biology of Reproduction 71(4): 1290-1295.

Qu, J., P. A. Godin, M. Nisolle and J. Donnez (2000). "Expression of receptors for insulin-like growth factor-I and transforming growth factor-beta in human follicles." Molecular Human Reproduction 6(2): 137-145. 
Rabinovici, J. and R. B. Jaffe (1990). "Development and regulation of growth and differentiated function in human and subhuman primate fetal gonads." Endocr Rev 11(4): 532-557.

Ramirez, F. and L. Y. Sakai (2010). "Biogenesis and function of fibrillin assemblies." Cell and Tissue research 339(1): 71-82.

Rao, M. C., A. R. Midgley, Jr. and J. S. Richards (1978). "Hormonal regulation of ovarian cellular proliferation." Cell 14(1): 71-78.

Reader, K. L., D. A. Heath, S. Lun, C. J. McIntosh, A. H. Western, R. P. Littlejohn, K. P. McNatty and J. L. Juengel (2011). "Signalling pathways involved in the cooperative effects of ovine and murine GDF9+BMP15-stimulated thymidine uptake by rat granulosa cells." Reproduction 142(1): 123-131.

Reynolds, S. R. M. (1973). Blood and lymph vascular systems of the ovary. Handbook of Physiology: a Critical, Comprehensive Presentation of Physiological Knowledge and Concepts. Washington D. C., R. O. Greep, American Physiological Society. II: 261-316.

Richards, J. S. (1994). "Hormonal control of gene expression in the ovary." Endocrine Reviews 15(6): 725-751.

Richardson, S. J., V. Senikas and J. F. Nelson (1987). "Follicular depletion during the menopausal transition: evidence for accelerated loss and ultimate exhaustion." The Journal of Clinical Endocrinology and Metabolism 65(6): 12311237

Rifkin, D. B. (2005). "Latent transforming growth factor-beta (TGF-beta) binding proteins: orchestrators of TGF-beta availability." The Journal of Biological Chemistry 280(9): 7409-7412. 
Robker, R. L., D. L. Russell, L. L. Espey, J. P. Lydon, B. W. O'Malley and J. S. Richards (2000). "Progesterone-regulated genes in the ovulation process: ADAMTS-1 and cathepsin L proteases." Proceedings of the National Academy of Sciences of the United States of America 97(9): 4689-4694.

Rockwell, N. C. and J. W. Thorner (2004). "The kindest cuts of all: crystal structures of Kex 2 and furin reveal secrets of precursor processing." Trends in Biochemical Sciences 29(2): 80-87.

Roh, J. S., J. Bondestam, S. Mazerbourg, N. Kaivo-Oja, N. Groome, O. Ritvos and A. J. Hsueh (2003). "Growth differentiation factor-9 stimulates inhibin production and activates Smad2 in cultured rat granulosa cells." Endocrinology 144(1): 172-178.

Rossetti, R., E. Di Pasquale, A. Marozzi, S. Bione, D. Toniolo, P. Grammatico, L. M. Nelson, P. Beck-Peccoz and L. Persani (2009). "BMP15 mutations associated with primary ovarian insufficiency cause a defective production of bioactive protein." Hum Mutat 30(5): 804-810.

Roy, S. K. (1993). "Epidermal growth factor and transforming growth factor-beta modulation of follicle-stimulating hormone-induced deoxyribonucleic acid synthesis in hamster preantral and early antral follicles." Biology of Reproduction 48(3): 552-557.

Roy, S. K. and A. R. Kole (1998). "Ovarian transforming growth factorbeta (TGF-beta) receptors: in-vitro effects of follicle stimulating hormone, epidermal growth factor and TGF-beta on receptor expression in human preantral follicles." Molecular Human Reproduction 4(3): 207-214. 
Russell, D. L. and R. L. Robker (2007). "Molecular mechanisms of ovulation: co-ordination through the cumulus complex." Human Reproduction Update 13(3): 289-312.

Saharinen, J., J. Taipale, O. Monni and J. Keski-Oja (1998). "Identification and characterization of a new latent transforming growth factor-beta-binding protein, LTBP-4." The Journal of Biological Chemistry 273(29): 18459-18469.

Saito, S., K. Yano, S. Sharma, H. E. McMahon and S. Shimasaki (2008). "Characterization of the post-translational modification of recombinant human BMP-15 mature protein." Protein Sci 17(2): 362-370.

Salustri, A., S. Ulisse, M. Yanagishita and V. C. Hascall (1990). "Hyaluronic acid synthesis by mural granulosa cells and cumulus cells in vitro is selectively stimulated by a factor produced by oocytes and by transforming growth factor-beta." The Journal of Biological Chemistry 265(32): 19517-19523.

Salustri, A., M. Yanagishita and V. C. Hascall (1989). "Synthesis and accumulation of hyaluronic acid and proteoglycans in the mouse cumulus celloocyte complex during follicle-stimulating hormone-induced mucification." The Journal of Biological Chemistry 264(23): 13840-13847.

Salustri, A., M. Yanagishita and V. C. Hascall (1990). "Mouse oocytes regulate hyaluronic acid synthesis and mucification by FSH-stimulated cumulus cells." Developmental Biology 138(1): 26-32.

Saragueta, P. E., G. M. Lanuza and J. L. Baranao (2002). "Autocrine role of transforming growth factor betal on rat granulosa cell proliferation." Biology of Reproduction 66(6): 1862-1868. 
Sawyer, H. R., P. Smith, D. A. Heath, J. L. Juengel, S. J. Wakefield and K. P. McNatty (2002). "Formation of ovarian follicles during fetal development in sheep." Biol Reprod 66(4): 1134-1150.

Scaramuzzi, R. J., N. R. Adams, D. T. Baird, B. K. Campbell, J. A. Downing, J. K. Findlay, K. M. Henderson, G. B. Martin, K. P. McNatty, A. S. McNeilly and et al. (1993). "A model for follicle selection and the determination of ovulation rate in the ewe." Reproduction, Fertility, and Development 5(5): 459478.

Scaramuzzi, R. J., D. T. Baird, B. K. Campbell, M. A. Driancourt, J. Dupont, J. E. Fortune, R. B. Gilchrist, G. B. Martin, K. P. McNatty, A. S. McNeilly, P. Monget, D. Monniaux, C. Vinoles and R. Webb (2011). "Regulation of folliculogenesis and the determination of ovulation rate in ruminants." Reproduction, Fertility, and Development 23(3): 444-467.

Schmid, P., D. Cox, H. van der Putten, G. K. McMaster and G. Bilbe (1994). "Expression of TGF-beta s and TGF-beta type II receptor mRNAs in mouse folliculogenesis: stored maternal TGF-beta 2 message in oocytes." Biochemical and Biophysical Research Communications 201(2): 649-656.

Schreiber, J. R., K. Nakamura and G. F. Erickson (1980). "Progestins inhibit FSH-stimulated steroidogenesis in cultured rat granulosa cells." Molecular and Cellular Endocrinology 19(2): 165-173.

Schreiber, J. R., K. Nakamura and G. F. Erickson (1981). "Progestins inhibit FSH-stimulated granulosa estrogen production at a post-cAMP site." Molecular and Cellular Endocrinology 21(2): 161-170.

Schreiber, J. R. and G. T. Ross (1976). "Further characterization of a rat ovarian testosterone receptor with evidence for nuclear translocation." Endocrinology 99(2): 590-596. 
Schultz, R. M., R. R. Montgomery and J. R. Belanoff (1983). "Regulation of mouse oocyte meiotic maturation: implication of a decrease in oocyte cAMP and protein dephosphorylation in commitment to resume meiosis." Developmental Biology 97(2): 264-273.

Sela-Abramovich, S., E. Chorev, D. Galiani and N. Dekel (2005). "Mitogen-activated protein kinase mediates luteinizing hormone-induced breakdown of communication and oocyte maturation in rat ovarian follicles." Endocrinology 146(3): 1236-1244.

Senbon, S., Y. Hirao and T. Miyano (2003). "Interactions between the oocyte and surrounding somatic cells in follicular development: lessons from in vitro culture." The Journal of Reproduction and Development 49(4): 259-269.

Shi, M., J. Zhu, R. Wang, X. Chen, L. Mi, T. Walz and T. A. Springer (2011). "Latent TGF-beta structure and activation." Nature 474(7351): 343-349.

Shimasaki, S., R. K. Moore, F. Otsuka and G. F. Erickson (2004). "The bone morphogenetic protein system in mammalian reproduction." Endocrine Reviews 25(1): 72-101.

Shuttleworth, G. (2000). Porcine Ovarian Follicle Development and the Renin-Angiotensin System, The University of Nottingham. PhD.

Sicinski, P., J. L. Donaher, Y. Geng, S. B. Parker, H. Gardner, M. Y. Park, R. L. Robker, J. S. Richards, L. K. McGinnis, J. D. Biggers, J. J. Eppig, R. T. Bronson, S. J. Elledge and R. A. Weinberg (1996). "Cyclin D2 is an FSHresponsive gene involved in gonadal cell proliferation and oncogenesis." Nature 384(6608): 470-474. 
Sidis, Y., T. Fujiwara, L. Leykin, K. Isaacson, T. Toth and A. L. Schneyer (1998). "Characterization of inhibin/activin subunit, activin receptor, and follistatin messenger ribonucleic acid in human and mouse oocytes: evidence for activin's paracrine signaling from granulosa cells to oocytes." Biology of Reproduction 59(4): 807-812.

Sidis, Y., A. L. Schneyer, P. M. Sluss, L. N. Johnson and H. T. Keutmann (2001). "Follistatin: essential role for the N-terminal domain in activin binding and neutralization." The Journal of Biological Chemistry 276(21): 17718-17726.

Silva, B. D., E. A. Castro, C. J. Souza, S. R. Paiva, R. Sartori, M. M. Franco, H. C. Azevedo, T. A. Silva, A. M. Vieira, J. P. Neves and E. O. Melo (2011). "A new polymorphism in the Growth and Differentiation Factor 9 (GDF9) gene is associated with increased ovulation rate and prolificacy in homozygous sheep." Animal Genetics 42(1): 89-92.

Silva, J. R., R. van den Hurk, H. T. van Tol, B. A. Roelen and J. R. Figueiredo (2005). "Expression of growth differentiation factor 9 (GDF9), bone morphogenetic protein 15 (BMP15), and BMP receptors in the ovaries of goats." Molecular Reproduction and Development 70(1): 11-19.

Simon, A. M., D. A. Goodenough, E. Li and D. L. Paul (1997). "Female infertility in mice lacking connexin 37." Nature 385(6616): 525-529.

Simpson, C. M., P. G. Stanton, K. L. Walton, K. L. Chan, L. J. Ritter, R. B. Gilchrist and C. A. Harrison (2012). "Activation of latent human GDF9 by a single residue change (Gly 391 Arg) in the mature domain." Endocrinology 153(3): 1301-1310.

Singh, B., X. Zhang and D. T. Armstrong (1993). "Porcine oocytes release cumulus expansion-enabling activity even though porcine cumulus expansion in vitro is independent of the oocyte." Endocrinology 132(4): 1860-1862. 
Sinowatz, F., W. Amselgruber, E. Topfer-Petersen, I. Totzauer, J. Calvete and J. Plendl (1995). "Immunocytochemical characterization of porcine zona pellucida during follicular development." Anatomy and Embryology 191(1): 4146.

Skinner, M. K., J. Keski-Oja, K. G. Osteen and H. L. Moses (1987). "Ovarian thecal cells produce transforming growth factor-beta which can regulate granulosa cell growth." Endocrinology 121(2): 786-792.

Smith, P., W. S. O, K. A. Corrigan, T. Smith, T. Lundy, G. H. Davis and K. P. McNatty (1997). "Ovarian morphology and endocrine characteristics of female sheep fetuses that are heterozygous or homozygous for the inverdale prolificacy gene (fecX1)." Biology of Reproduction 57(5): 1183-1192.

Souza, C. J., B. K. Campbell and D. T. Baird (1996). "Follicular dynamics and ovarian steroid secretion in sheep during anoestrus." Journal of Reproduction and Fertility 108(1): 101-106.

Souza, C. J., B. K. Campbell, A. S. McNeilly and D. T. Baird (2002). "Effect of bone morphogenetic protein 2 (BMP2) on oestradiol and inhibin A production by sheep granulosa cells, and localization of BMP receptors in the ovary by immunohistochemistry." Reproduction 123(3): 363-369.

Souza, C. J., C. MacDougall, B. K. Campbell, A. S. McNeilly and D. T. Baird (2001). "The Booroola (FecB) phenotype is associated with a mutation in the bone morphogenetic receptor type 1 B (BMPR1B) gene." The Journal of Endocrinology 169(2): R1-6.

Spicer, L. J., P. Y. Aad, D. T. Allen, S. Mazerbourg, A. H. Payne and A. J. Hsueh (2008). "Growth differentiation factor 9 (GDF9) stimulates proliferation 
and inhibits steroidogenesis by bovine theca cells: influence of follicle size on responses to GDF9." Biology of Reproduction 78(2): 243-253.

Spiegelman, M. and D. Bennett (1973). "A light- and electron-microscopic study of primordial germ cells in the early mouse embryo." Journal of Embryology and Experimental Morphology 30(1): 97-118.

Su, Y. Q., K. Sugiura, K. Wigglesworth, M. J. O'Brien, J. P. Affourtit, S. A. Pangas, M. M. Matzuk and J. J. Eppig (2008). "Oocyte regulation of metabolic cooperativity between mouse cumulus cells and oocytes: BMP15 and GDF9 control cholesterol biosynthesis in cumulus cells." Development 135(1): 111-121.

Su, Y. Q., X. Wu, M. J. O'Brien, F. L. Pendola, J. N. Denegre, M. M. Matzuk and J. J. Eppig (2004). "Synergistic roles of BMP15 and GDF9 in the development and function of the oocyte-cumulus cell complex in mice: genetic evidence for an oocyte-granulosa cell regulatory loop." Developmental Biology 276(1): 64-73.

Sugiura, K. and J. J. Eppig (2005). "Society for Reproductive Biology Founders' Lecture 2005. Control of metabolic cooperativity between oocytes and their companion granulosa cells by mouse oocytes." Reprod Fertil Dev 17(7): 667-674.

Sugiura, K., Y. Q. Su, F. J. Diaz, S. A. Pangas, S. Sharma, K. Wigglesworth, M. J. O'Brien, M. M. Matzuk, S. Shimasaki and J. J. Eppig (2007). "Oocyte-derived BMP15 and FGFs cooperate to promote glycolysis in cumulus cells." Development 134(14): 2593-2603.

Szoltys, M. and M. Slomczynska (2000). "Changes in distribution of androgen receptor during maturation of rat ovarian follicles." Experimental and Clinical Endocrinology \& Diabetes : Official Journal, German Society of Endocrinology [and] German Diabetes Association 108(3): 228-234. 
Taylor, N. A., W. J. Van De Ven and J. W. Creemers (2003). "Curbing activation: proprotein convertases in homeostasis and pathology." FASEB Journal : Official Publication of the Federation of American Societies for Experimental Biology 17(10): 1215-1227.

Teerds, K. J. and J. H. Dorrington (1992). "Immunohistochemical localization of transforming growth factor-beta 1 and -beta 2 during follicular development in the adult rat ovary." Molecular and Cellular Endocrinology 84(12): R7-13.

ten Dijke, P. and C. S. Hill (2004). "New insights into TGF-beta-Smad signalling." Trends in Biochemical Sciences 29(5): 265-273.

ten Dijke, P., O. Korchynskyi, G. Valdimarsdottir and M. J. Goumans (2003). "Controlling cell fate by bone morphogenetic protein receptors." Molecular and Cellular Endocrinology 211(1-2): 105-113.

Tetsuka, M., P. F. Whitelaw, W. J. Bremner, M. R. Millar, C. D. Smyth and S. G. Hillier (1995). "Developmental regulation of androgen receptor in rat ovary." The Journal of Endocrinology 145(3): 535-543.

Thies, R. S., T. Chen, M. V. Davies, K. N. Tomkinson, A. A. Pearson, Q. A. Shakey and N. M. Wolfman (2001). "GDF-8 propeptide binds to GDF-8 and antagonizes biological activity by inhibiting GDF-8 receptor binding." Growth Factors 18(4): 251-259.

Thomas, G. (2002). "Furin at the cutting edge: from protein traffic to embryogenesis and disease." Nature Reviews. Molecular Cell Biology 3(10): 753766. 
Tibaldi, E., G. Arrigoni, H. M. Martinez, K. Inagaki, S. Shimasaki and L. A. Pinna (2010). "Golgi apparatus casein kinase phosphorylates bioactive Ser-6 of bone morphogenetic protein 15 and growth and differentiation factor 9." FEBS Lett 584(4): 801-805.

Tisdall, D. J., N. Hudson, P. Smith and K. P. McNatty (1994). "Localization of ovine follistatin and alpha and beta A inhibin mRNA in the sheep ovary during the oestrous cycle." Journal of Molecular Endocrinology 12(2): 181193.

Tung, L., M. K. Mohamed, J. P. Hoeffler, G. S. Takimoto and K. B. Horwitz (1993). "Antagonist-occupied human progesterone B-receptors activate transcription without binding to progesterone response elements and are dominantly inhibited by A-receptors." Molecular Endocrinology 7(10): 12561265.

Vanderhyden, B. C., P. J. Caron, R. Buccione and J. J. Eppig (1990). "Developmental pattern of the secretion of cumulus expansion-enabling factor by mouse oocytes and the role of oocytes in promoting granulosa cell differentiation." Developmental Biology 140(2): 307-317.

Vanderhyden, B. C. and E. A. Macdonald (1998). "Mouse oocytes regulate granulosa cell steroidogenesis throughout follicular development." Biology of Reproduction 59(6): 1296-1301.

Vanderhyden, B. C. and A. M. Tonary (1995). "Differential regulation of progesterone and estradiol production by mouse cumulus and mural granulosa cells by A factor(s) secreted by the oocyte." Biology of Reproduction 53(6): 12431250.

Vegeto, E., M. M. Shahbaz, D. X. Wen, M. E. Goldman, B. W. O'Malley and D. P. McDonnell (1993). "Human progesterone receptor A form is a cell- and 
promoter-specific repressor of human progesterone receptor B function." Molecular Endocrinology 7(10): 1244-1255.

Vitt, U. A., M. Hayashi, C. Klein and A. J. Hsueh (2000). "Growth differentiation factor-9 stimulates proliferation but suppresses the folliclestimulating hormone-induced differentiation of cultured granulosa cells from small antral and preovulatory rat follicles." Biology of Reproduction 62(2): 370377.

Vitt, U. A., S. Mazerbourg, C. Klein and A. J. Hsueh (2002). "Bone morphogenetic protein receptor type II is a receptor for growth differentiation factor-9." Biology of Reproduction 67(2): 473-480.

Vitt, U. A., E. A. McGee, M. Hayashi and A. J. Hsueh (2000). "In vivo treatment with GDF-9 stimulates primordial and primary follicle progression and theca cell marker CYP17 in ovaries of immature rats." Endocrinology 141(10): 3814-3820.

Wang, H., K. Andoh, H. Hagiwara, L. Xiaowei, N. Kikuchi, Y. Abe, K. Yamada, R. Fatima and H. Mizunuma (2001). "Effect of adrenal and ovarian androgens on type 4 follicles unresponsive to FSH in immature mice." Endocrinology 142(11): 4930-4936.

Wang, J. and S. K. Roy (2004). "Growth differentiation factor-9 and stem cell factor promote primordial follicle formation in the hamster: modulation by follicle-stimulating hormone." Biology of Reproduction 70(3): 577-585.

Wassarman, P. M. and W. J. Josefowicz (1978). "Oocyte development in the mouse: an ultrastructural comparison of oocytes isolated at various stages of growth and meiotic competence." Journal of Morphology 156(2): 209-235. 
Watson, L. N., D. G. Mottershead, K. R. Dunning, R. L. Robker, R. B. Gilchrist and D. L. Russell (2012). "Heparan sulfate proteoglycans regulate responses to oocyte paracrine signals in ovarian follicle morphogenesis." Endocrinology 153(9): 4544-4555.

Webb, R., G. Baxter, D. McBride, M. Ritchie and A. J. Springbett (1992). "Mechanism controlling ovulation rate in ewes in relation to seasonal anoestrus." Journal of Reproduction and Fertility 94(1): 143-151.

Webb, R. and B. G. England (1982). "Identification of the ovulatory follicle in the ewe: associated changes in follicular size, thecal and granulosa cell luteinizing hormone receptors, antral fluid steroids, and circulating hormones during the preovulatory period." Endocrinology 110(3): 873-881.

Webb, R. and B. G. England (1982). "Relationship between LH receptor concentrations in thecal and granulosa cells and in-vivo and in-vitro steroid secretion by ovine follicles during the preovulatory period." Journal of Reproduction and Fertility 66(1): 169-180.

Webb, R. J., F. Marshall, K. Swann and J. Carroll (2002). "Folliclestimulating hormone induces a gap junction-dependent dynamic change in [cAMP] and protein kinase a in mammalian oocytes." Developmental Biology 246(2): 441-454.

Weil, S. J., K. Vendola, J. Zhou, O. O. Adesanya, J. Wang, J. Okafor and C. A. Bondy (1998). "Androgen receptor gene expression in the primate ovary: cellular localization, regulation, and functional correlations." The Journal of Clinical Endocrinology and Metabolism 83(7): 2479-2485.

Welt, C., Y. Sidis, H. Keutmann and A. Schneyer (2002). "Activins, inhibins, and follistatins: from endocrinology to signaling. A paradigm for the new millennium." Experimental Biology and Medicine 227(9): 724-752. 
Wilson, C. A., N. di Clemente, C. Ehrenfels, R. B. Pepinsky, N. Josso, B. Vigier and R. L. Cate (1993). "Mullerian inhibiting substance requires its Nterminal domain for maintenance of biological activity, a novel finding within the transforming growth factor-beta superfamily." Molecular Endocrinology 7(2): 247-257.

Wilson, T., X. Y. Wu, J. L. Juengel, I. K. Ross, J. M. Lumsden, E. A. Lord, K. G. Dodds, G. A. Walling, J. C. McEwan, A. R. O'Connell, K. P. McNatty and G. W. Montgomery (2001). "Highly prolific Booroola sheep have a mutation in the intracellular kinase domain of bone morphogenetic protein IB receptor (ALK-6) that is expressed in both oocytes and granulosa cells." Biology of Reproduction 64(4): 1225-1235.

Wolfman, N. M., A. C. McPherron, W. N. Pappano, M. V. Davies, K. Song, K. N. Tomkinson, J. F. Wright, L. Zhao, S. M. Sebald, D. S. Greenspan and S. J. Lee (2003). "Activation of latent myostatin by the BMP-1/tolloid family of metalloproteinases." Proceedings of the National Academy of Sciences of the United States of America 100(26): 15842-15846.

Wu, Y. T., L. Tang, J. Cai, X. E. Lu, J. Xu, X. M. Zhu, Q. Luo and H. F. Huang (2007). "High bone morphogenetic protein-15 level in follicular fluid is associated with high quality oocyte and subsequent embryonic development." Human Reproduction 22(6): 1526-1531.

Xiao, S., D. M. Robertson and J. K. Findlay (1992). "Effects of activin and follicle-stimulating hormone (FSH)-suppressing protein/follistatin on FSH receptors and differentiation of cultured rat granulosa cells." Endocrinology 131(3): 1009-1016.

Yamamoto, N., L. K. Christenson, J. M. McAllister and J. F. Strauss, 3rd (2002). "Growth differentiation factor-9 inhibits 3'5'-adenosine monophosphate- 
stimulated steroidogenesis in human granulosa and theca cells." The Journal of Clinical Endocrinology and Metabolism 87(6): 2849-2856.

Yan, C., P. Wang, J. DeMayo, F. J. DeMayo, J. A. Elvin, C. Carino, S. V. Prasad, S. S. Skinner, B. S. Dunbar, J. L. Dube, A. J. Celeste and M. M. Matzuk (2001). "Synergistic roles of bone morphogenetic protein 15 and growth differentiation factor 9 in ovarian function." Mol Endocrinol 15(6): 854-866.

Yang, J., T. Ratovitski, J. P. Brady, M. B. Solomon, K. D. Wells and R. J. Wall (2001). "Expression of myostatin pro domain results in muscular transgenic mice." Molecular Reproduction and Development 60(3): 351-361.

Yen, S. S., B. L. Lasley, C. F. Wang, H. Leblanc and T. M. Siler (1975). "The operating characteristics of the hypothalamic-pituitary system during the menstrual cycle and observations of biological action of somatostatin." Recent Progress in Hormone Research 31: 321-363.

Yeo, C. X., R. B. Gilchrist, J. G. Thompson and M. Lane (2008). "Exogenous growth differentiation factor 9 in oocyte maturation media enhances subsequent embryo development and fetal viability in mice." Human Reproduction 23(1): 67-73.

Yoshino, O., H. E. McMahon, S. Sharma and S. Shimasaki (2006). "A unique preovulatory expression pattern plays a key role in the physiological functions of BMP-15 in the mouse." Proc Natl Acad Sci U S A 103(28): 1067810683.

Zachow, R. J., S. R. Weitsman and D. A. Magoffin (1999). "Leptin impairs the synergistic stimulation by transforming growth factor-beta of folliclestimulating hormone-dependent aromatase activity and messenger ribonucleic acid expression in rat ovarian granulosa cells." Biology of Reproduction 61(4): 1104-1109. 
Zamboni, L. (1974). "Fine morphology of the follicle wall and follicle cell-oocyte association." Biology of Reproduction 10(2): 125-149.

Zeleznik, A. J., D. Saxena and L. Little-Ihrig (2003). "Protein kinase B is obligatory for follicle-stimulating hormone-induced granulosa cell differentiation." Endocrinology 144(9): 3985-3994.

Zhao, H., Y. Qin, E. Kovanci, J. L. Simpson, Z. J. Chen and A. Rajkovic (2007). "Analyses of GDF9 mutation in 100 Chinese women with premature ovarian failure." Fertil Steril 88(5): 1474-1476.

Zhao, Z. Z., J. N. Painter, J. S. Palmer, P. M. Webb, N. K. Hayward, D. C. Whiteman, D. I. Boomsma, N. G. Martin, D. L. Duffy and G. W. Montgomery (2008). "Variation in bone morphogenetic protein 15 is not associated with spontaneous human dizygotic twinning." Hum Reprod 23(10): 2372-2379. 